ANL-78-82

D. 1976

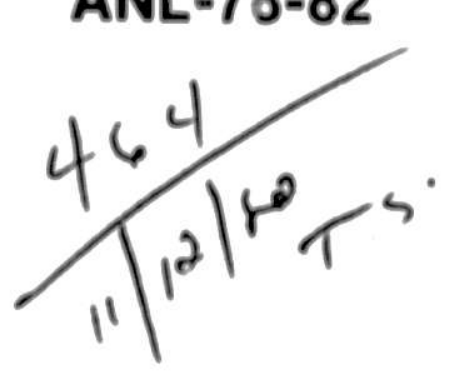

ANL-78-82

\title{
THEORETICAL EVALUATION OF THERMAL IMAGING FOR DETECTION OF EROSIVE WEAR OF INTERNALLY REFRACTORY-LINED TRANSFER LINES
}

by

C. K. Hsieh, W. A. Ellingson, and K. C. Su

ARGONNE NATIONAL LABORATORY, ARGONNE, ILLINOIS

Prepared for the U. S. DEPARTMENT OF ENERGY

under Contract W-31-109-Eng-38 


\section{ARGONNE NATIONAL LABORATORY \\ 9700 South Cass Avenue \\ Argonne, Illinois 60439}

\section{THEORETICAL EVALUATION OF THERMAL IMAGING FOR DETECTION OF EROSIVE WEAR OF INTERNALLY REFRACTORY-LINED TRANSFER LINES}

by

C. K. Hsieh,* W. A. Ellingson, and $\mathrm{K}, \mathrm{C} . \mathrm{Su} * *$

Materials Science Division

May 1980

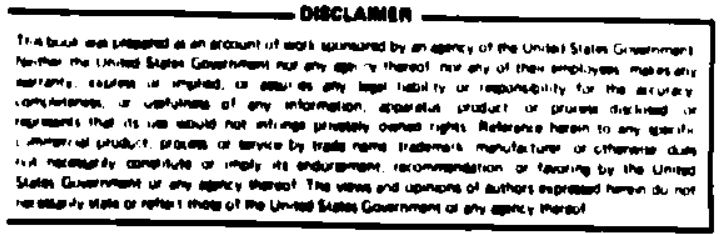


TABLE OF CONTENTS

Page

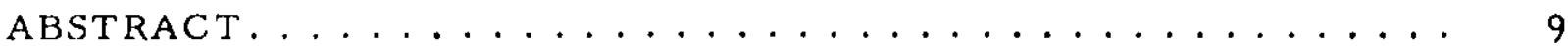

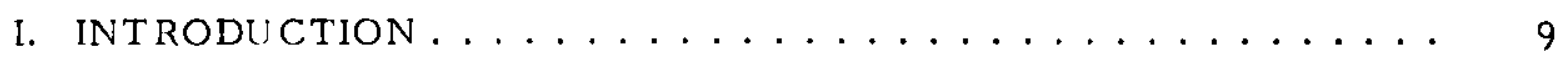

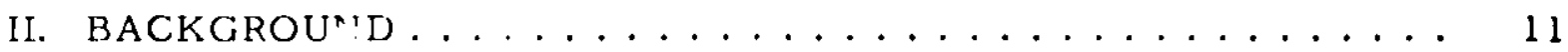

A. Parameters Related to Infrared Scanning Instrument ..... 11

B. Parameters Related to Transmission Path between Scanner

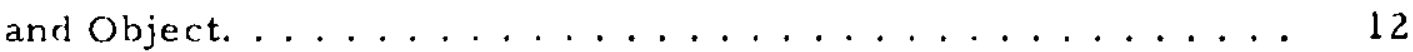

C. Parameter 3 Related to Test Object............. 12

III. GENERAL STATEMENT OF PROBLEM ............ 13

A. Scope of Project. .................... 13

B. Mathematical Formulation................. 13

C. Justification for Boundary Conditions Imposed. . . . . . . 15

IV. DEVELOPMENT OF BASIC HEAT - TRANSFER MODELS . . . . 18

A. Finite-difference Formulation ............... 18

B. Development of Basic Two-dimensional Model. . . . . . . . 20

C. Development of Basic Three-dimensional Model ....... 22

D. Modeling of Thermal Contact Resistance ........... 23

E. Modeling of Surface-emissivity Effects ............ 25

V. TEST OF COMPUTER PROGRAMS USING LIMITING CASES. . . 31

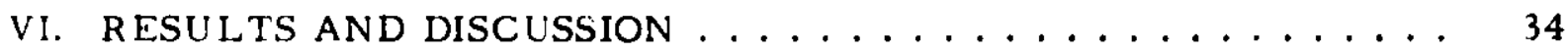

A. Prediction of Surface Temperatures for a Two-dimensional

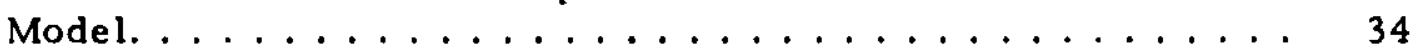

B. Prediction of Surface Temperatures for a Two-dimensional Model Fitted with a Telltale Rib............... 37

C. Prediction of Surface Temperatures for a Three-dimensional

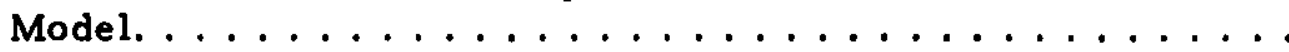

D. Prediction of Surface Temperatures for a Three-dimensional Model with a Dual-component Wall Lining............ 


\section{TABLE OF CONTENTS}

$\underline{\text { Page }}$

E. Prediction of Surface Temperatures for a Three-dimensional Model with Contact Resistances ............... 51

F. Study of Distortions of Infrared Images . . . . . . . . . 53

VII. CONCLUSIONS AND RECOMMENDATIONS ............ 57

\section{APPENDIXES}

A. Computer Program for a Two-dimensional System . . . . . 58

B. Computer Program for a Three-dimensional System...... 64

C. Computer Program for Evaluating Emissivity Effects . . . . . 80

D. Derivation of Equations for Estimating Limiting Temperatures. .................... 83

E. Computer Program for a Two-dimensional System Fitted with a Telltale Rib. ................... 84

F. Computer Program for a Three-dimensional System with a Double-layered Refractory Lining ..............

G. Computer Program for a Three-dimensional Systenı with Interfacial Contact Resistance............. 102

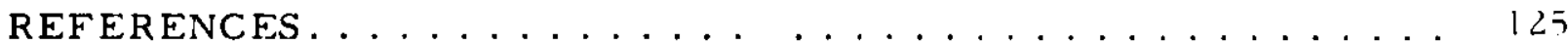




\section{LIST OF FIGURES}

No

$\underline{\text { Title }}$

Page

1. Sectional View of Refractory-lined Transfer Line Used for

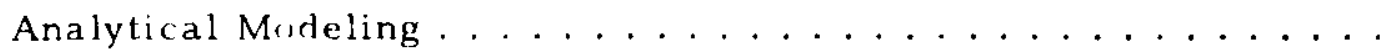

2. Cylindrical Coordinates Used in Formulation of Mathematical

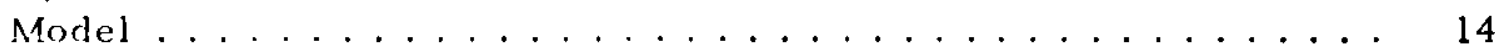

3. Fvaluation of Convective Contribution for $\epsilon=0.2, \mathrm{~T}_{\infty}=50^{\circ} \mathrm{F}$

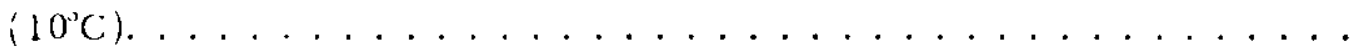

4. Fvaluation of Convective Contribution for $\epsilon=0.2, T_{\infty}=80^{\prime} \mathrm{F}$

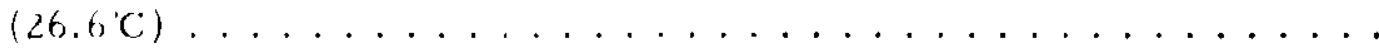

5. Evaluation of Convective Contribution for $\epsilon=0.8, \mathrm{~T}_{\infty}=80^{\circ} \mathrm{F}$

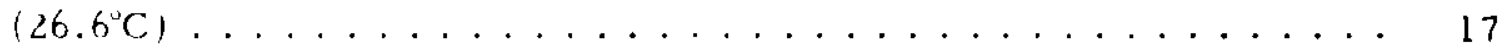

6. Volume Flement in Cylindrical Coordinates .......... 19

7. 'xhematic Diagram Showing Locations of Nine Classes of Nodes 'sed in Differenc" Formulation ................ 21

x. Schematic Diagram Showing Notation lised to Relate Polar ( $)$. Fmission ( $\alpha$ ), and View (f) Angles............. 26

9. Polar-to View-angle Conversion Chart............ 27

19. Polar-to Finission-andle Conversion Chart.......... 27

11. Emission-to View-angle Conversion Chart .......... 27

. Dirertional Emissivity Curve for Metal surface . . . . . . . . 29

13. Directional Emissivity Curve for Nonmetal Surface......... 29

14. Fmissivity Correction Curve for Data in Figs. 9 and $12 \ldots 29$

15. Emissivity Correction Curve for Data in Figs. 9 and 13 .... 29

16. Comparison between Correlated Eq. 46 and Test Dat: ...... 36

17. A Two-dimensional System Modified by Installation of a Telltale

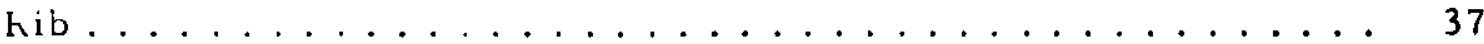

18. A Three-dimensional Surface-temperature Plot Using Data in Table VII ........................

19. A Three-dimensional Plot of the Cavity Configuration Reconstructed from the Temperature Data in Fig. 18.......... 40

20. A Surface Isotherm Map for Data in Table VII. . . . . . . . . . 40

21. Plot of Areas Enclosed inside Isotherm Loops (Table VIII) vs Temperature........................ 41

22. Integrated Energy Equivalents from Table VIII vs Temperature. . 41

23. Eff $t C^{\circ}$ of Cavity Depth on Temperature . . . . . . . . . . . 43

24. Effect of Cavity Width on Temperature . . . . . . . . . . . . 44 


\section{LIST OF FIGURES}

No

$\underline{\text { Title }}$

Page

25. Feature Curves for Cases in Fig. $23 \ldots \ldots . \ldots 45$

26. Feature Curves for Cases in Fig. $24 \ldots \ldots . \ldots . \ldots . \ldots 46$

27. Chart for Predicting Cavity Configurations . . . . . . . . . 47

28. Schematic Diagram Showing Construction of a Transfer Line with Double-layered Refractory Lining............. 48

29. Feature Data for Case in Table X .............. 49

30. Feature Data for Case in Table XI.............. 50

31. Comparison of Three-dimensional Surface-temperature Plots Obtained with Indicated Values of Uniform Interfacial Contact Resistance. . . . . . . . . . . . . . . . . 52

32. Comparison of Three-dimensional Surface-temperature Plots Obtained with Variuus Nonuriform Interfacial Contact

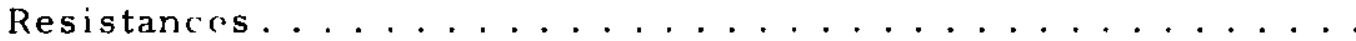

33. Three-dimensional Plots of Variable Interfacial Resistances lised to Gunerate Temperature Plots Presented in Fig. 32.... 55

34. Distortion of Infrared Images ............... 56

A. l. Computer Program for Fvaluating Surface Temperature in a Two-dimensional System ..................

A.2. Schematic Diagram Showing Nodal Locations in a Twodimensional System. . . . . . . . . . . . . . .

B.1. Computer Program for Evaluating Surface Temperaturr in a Three-dimensional System ..................

B.2. Schematic Diagram Showing Nodal Locations in the Axial Direction in a Three-dimensional System ............. 76

C.1. Computer Program for Correction of Emissivity Effects.....

E.1. Computer Program for Evaluating Surface Temperature in a Modified Two-dimensional System Containing a "Telltale Rib". .

F.1. Computer Program for Evaluating Surface Temperature in a Three-dimensional System Constructed with a Double-layered Refractory Lining. . ....................

F.2. Schematic Diagram Showing Nodal Locations in Radial Direction in a Modified Three-dimensional System. .............

G. 1. Computer Program for Evaluating Surface Temperature in a Three-dimensional System with Constant Contact Resistance...

G.2. Computer Program for Evaluating Surface Temperature in a Three-dimensional System with Variable Contact Resistance... 


\section{LIST OF TABLES}

No.

Title

Page

I. Expressions Used to Derive Nodal Equations by Means of Physical Formulation ................... 20

II. Comparison between Numerical and Analytical Data....... 32

III. Test Conditions for Studies of Two-dimensional Model . . . . . 34

IV. Computer Data for a Sample Two-dimensional System . . . . . 35

V. Computer Data for a Two-dimensional System Fitted with a

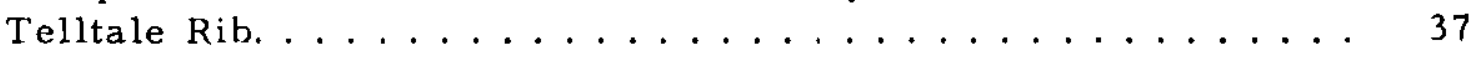

VI. Test Conditions for Studies of Three-dirnensional Model . . . . 38

VII. Sample Output of Surface-temperature Distribution for Study of a Three-dimensional Model ................ 39

VIII. Features Defined by Data in Table VII .............. 39

1X. Computer Data Used for Prediction of Cavity Configuration... . 47

X. Surface-temperature Data for System Shown in Fig. 28 with a 0.5 -in. $(12.7-\mathrm{mm})$-deep Cavity .............. 48

XI. Surface-temperature Data for System Shown in Fig. 28 with a 1.5-in. (38.1-mm)-deep Cavity ................ 51

XII. Test Conditions for Data Presented in Fig. 31 ........ 53

XIII. Test Conditions for Data Presented in Fig. 32 . . . . . . 56

A.1. Definitions of Input Variables for Program in Fig. A.1 . . . . . 62

B.l. Definitions of Additional Input Variables for Program in Fig. B.1.......................... 76 


\title{
THEORETICAL EVALUATION OF THERMAL IMAGING FOR DETECTION OF EROSIVE WEAR OF \\ INTERNALLY REFRACTORY-LINED TRANSFER LINES
}

by

C. K. Hsieh, W. A. Ellingson, and K. C. Su

\begin{abstract}
Infrared scanning has potential use in detecting erosive wear (thickness change) of the refractory surface of largediameter steel pipes internally lined with refractory concrete, which are typical of those used in coal-conversion processes. An analytical study was conducted to determine the viability of this method. Heat-transfer models were developed to predict surface-temperature distributions on the outer metal surface for various erosive-wear conditions on the inner surface, as suming uniform inner-surface temperature. Variables investigated included the rmal conductivity of the refractory concrete, thermal contact resistance between the steel shell and the refractory, outer-surface convective coefficient, cuter-surface radiative properties, and refractory-lining thickness and composition.
\end{abstract}

The study used two - and three-dimensional heat-transfer models and various well-defined rectangular cavities on the inner surface. Temperature resolution, and thus calculation of cavitysizes from surface-temperature profiles, is better when the convective coefficient is small and the interfacial contact resistance is uniformly low. The presence of dual refractoryconcrete liners using a laye $r$ of insulating concrete between the hot-face lining and the steel shell, together with thick steel $(t>25 \mathrm{~mm}$ ), tends to smear temperature patterns and reduce the temperature gradient so that calculation of cavity shapes becomes impractical.

\section{INT RODUCTION}

One of the many tasks in the development of the nation's coal-conversion program is to improve the reliability of plant operation through the use of nondestructive-evaluation (NDE) methods. NDE methods will be increasingly important for characterizing material performance in situ as secondgeneration coal-conversion processes push materials of construction close to their operating limits. One area of particular concern in coal-conversion 
processes is the need to transfer highly erosive media (e.g., coal, ash, and char) under elevated temperatures $\left(\mathrm{T} \sim 500-1000^{\circ} \mathrm{C}\right)$ and pressures $[\mathrm{p} \sim$ 60-70 a.tm (0.6-0.7 Mpa)]. Under these conditions, solid-particle impact erosion (which causes locally thin walls) becomes a serious materialdegradation problem. This is particularly true in transfer lines and in regions in which the erosive media flow must change direction. Continuous monitoring of material conditions in critical areas is important to ensure long-term safe operation of coal-conversion processes and to prevent unnecessary plant shutdowns.

Several methods are being developed to detect potential materialfailure conditions. Ultrasonic techniques ${ }^{1,2}$ can be used to detect erosive wear of metallic transfer lines. Gamma-radiography methods ${ }^{3,4}$ promise to be useful in detecting erosive wear and refractory degradation in refractorylined transfer lines. However, the strong radiation sources $\left(\sim 3.7 \times 10^{12} \mathrm{~Bq}\right)$ required for gamma radiography are potentially hazardous to human beings. Furthermore, gamma-radiography methods require experienced and skilled technicians to produce high-quality images. The infrared scanning technique (thermography) is fast and inexpensive, and yields full-field images. With proper development, this technique could be made part of a routins inspection operation and thus enhance plant safety.

The use of the rmography in the inspection of industrial plants has received much attention in recent years. Because they can measure the temperature of a body without making physical contact with it, the rmographic devices permit a remote sensing capability that is lacking with most other nondestructive testing methods. Equipped with a mechanical scanner, a commercially available state-of-the-art infrared camera can scan a large field of view and present real-time infrared images of scanned objects in a few tenths of milliseconds. The method is thus more powerful than most other nondestructive methods, which rely heavily on sophisticated instrumentation and are handicapped because of their limitation to localized inspections. These advantages have placed infrared scarning in a favorable position for use in plant inspections, as evidenced by the various applications reported in the literature. Thermography techniques have been used to monitor the condition of refractory linings in blast furnaces, stoves, furnace offtakes, and hot-blast mains in the stecl industry. ${ }^{5}$ In power plants, thermographic techniques have been applied to check boiler furnaces and stack walls. ${ }^{6}$ In the utility industries, thermographic techniques are easily implemented to locate hot spots in power transmission lines. ${ }^{7-10}$ Probably most important of all is the application of thermography in chemical-processing-plant reaction vessels and material transfer lines, which must be constantly monitored as part of routine plant operation to locate component malfunctions. ${ }^{7-10}$ 


\section{BACKGROUND}

The capabilities of the rmographic techniques in nondestructive testing have been widely recognized. However, proper data-analysis methods have often been overlooked. The data collected by an infrared scanning system is a function of many parameters, which can be grouped into three categories:

1. Parameters related to the infrared scanning instrument.

2. Parameters related to the transmission path between the scanner and the object.

3. Parameters related to the test object.

These parameters are discussed separately in the following three sections.

\section{A. Parameters Related to Infrared Scanning Instrument}

The infrared cameras presently available from commercial sources are equipped with mechanical scanners. The spatial resolution of the temperature gradient that can be detected is a function of the distance between the camera and the object. A larger camera-to-object distance permits a broader field of observation, but at a lower temperature (spatial) resolution.

Infrared scanning cameras differ from other temperature sensors in the method of data presentation. The infrared camera consists of a scanning camera and an electronic display unit. The scanning optics are synchronized with the oscilloscope in the electronic display so that each point in the optical field of view is transformed into a corresponding point on the oscilloscope screen; the intensity of the modulated beam in the oscilloscope tube is a function of the infrared radiation received. The data output from the infrared camera is thus presented in a two-dimensional array, with the light intensity at each point corresponding to the input energy levels. The oscilloscope screen plays much the same role as a conventional $\mathrm{TV}$ screen. In its normal black-and-white mode of operation, bright spots represent high temperatures and dark spots represent lower temperatures. This method of data presentation causes a problem that is not experienced in more conventional analog or digital data displays. The problem arises when the temperature selectivity and picture black-level controls on the camera* are not properly adjusted to cover the full range of the input intensities. The result is usually a saturation of the picture gray level. Unfortunately, the human eye is only moderately able to differentiate various shades of gray and, as such, this saturation (brightness) phenomenon could evade detection in operation.

Note that a change of the temperature-sensitivity setting to a larger temperature span could resolve the saturation problem. However, a large temperature range also reduces the temperature resolution of the system.

\footnotetext{
*These controls, or controls with similar functions, can be found on nearly all commercial infrared cameras.
} 
The best way to alleviate this problem appears to be the use of a second oscilloscope to present the analog data along with the infrared images. The saturation problem can then be deiected and corrected in the operation.

B. Parameters Related to Transmission Path between Scanner and Object

Since the infrared camera is sensing the radiation emitted from a distant object, the net radiation received by the camera is a function of the ambient conditions between the object and the detector. Among other factors, atmospheric attenuation affects the energy detected. The water vapor and carbon dioxide in the atmosphere have absorption bands located at $\lambda=1.9$, $2.7,4.3$, and $6 \mu \mathrm{m}$, which fall within the sensitivity range of most commercial infrared cameras using indium-antimony ( InSb) detectors. The absorption is a function of the partial pressure of water vapor, the total pressure, and the dry-bulb temperature of the atmosphere, as well as the optical-path length. Only for short paths in a dry and nonfoggy atmosphere can the attenuation be neglected.

\section{Parameters Related to Test Object}

Wind velocity and direction at the test site also affect the temperature distribution on the test object. An increase in the wind velocity or a shift of wind direction toward the test surface tends to increase the convective heattransfer coefficient, thus diminishing the surface temperature. An analysis of the infrared picture without reference to existing wind conditions could result in an erroneous picture interpretation.

The energy actually received by an infrared camera is the surface radiosity, defined as the total radiation leaving a surface. For an opaque surface, this total energy consists of emitted and reflected energy. Since the emitted part is a function of the surface emissivity, among other factors, the emitted energy is a function of the surface conditions. The emissivity is high for most dull surfaces. Additionally, a rough surface emits more energy than a smooth one. It is also known that long-time exposure of a metallic surface to air tends to oxidize the surface and therefore changes the surface emissivity behavior. Emissivity also is directionally dependent. Thus, a round surface emits differently from a flat surface. All these conditions add complexity to the problem and must be accounted for in the analysis of infrared pictures.

The surface reflectivity is a function of the same parameters that govern the surface emissivity. In addition, radiators placed in the vicinity of the test object contribute part of their energy through reflections from the test surfact. A method commonly used to rectify the surface-reflection problem is to paint the test surface black. ${ }^{11}$ 


\section{GENERAL STATEMENT OF PROBLEM}

A. Scope of Project

The problem under investigation in the present project is the development of appropriate heat-transfer models for a refractory-lined duct such that, given a surface-temperature distribution (obtained by a full-field imaging system such as an infrared camera), the cavity size and shape at the interior surface can be predicted. Because refractory thinning reduces thermal protection of the steel pressure boundary, prediction of cavity depth is of primary iportance. The purpose of this investigation is twofcld.

1. To develop heat-transfer models which can be used to make parametric studies that include realistic effects of material status changes on the temperature distributions, in order to establish the limits of the technique. Typical parameters to be studied include thermal conductivity, variation of wall construction, thermal-contact resistance, and outer-surface conditions, including the effect of the convective heat-transfer coefficient. In addition, the erosion-prediction capabilities of the new "telltale rib" model will be investigated.

2. To examine various surface-temperature distributions and predict the sizes and shapes of cavities on the inner surface of the refractory linings, on the basis of the above heat-transfer models.

\section{B. Mathematical Formulation}

The transfer-line configuration studied in this investigation (see Fig. 1) can be readily fitted to a cylindrical coordinate system as shown in Fig. 2 .

The general heat-conduction equation can be written for this cylindrical system as

$$
\frac{\partial T}{\partial t}=\alpha\left(\frac{\partial^{2} \mathrm{~T}}{\partial \mathbf{r}^{2}}+\frac{1}{\mathrm{r}} \frac{\partial \mathrm{T}}{\partial \mathrm{r}}+\frac{1}{\mathrm{r}^{2}} \frac{\partial^{2} \mathrm{~T}}{\partial \theta^{2}}+\frac{\partial^{2} \mathrm{~T}}{\partial \mathbf{z}^{2}}\right)+\frac{\mathrm{Q}^{\prime}}{\partial \mathrm{C}},
$$

where $\alpha$ is the thermal diffusivity, $Q^{\prime}$ is the internal heat generation, $\rho$ is the density, and $c$ is the specific heat of the merium. Under steady-state conditions without heat generation, the governing equation becomes

$$
\frac{\partial^{2} \mathrm{~T}}{\partial \mathbf{r}^{2}}+\frac{1}{\mathbf{r}} \frac{\partial \mathrm{T}}{\partial \mathbf{r}}+\frac{1}{\mathbf{r}^{2}} \frac{\partial^{2} \mathrm{~T}}{\partial \theta^{2}}+\frac{\partial^{2} \mathrm{~T}}{\partial \mathbf{z}^{2}}=0
$$



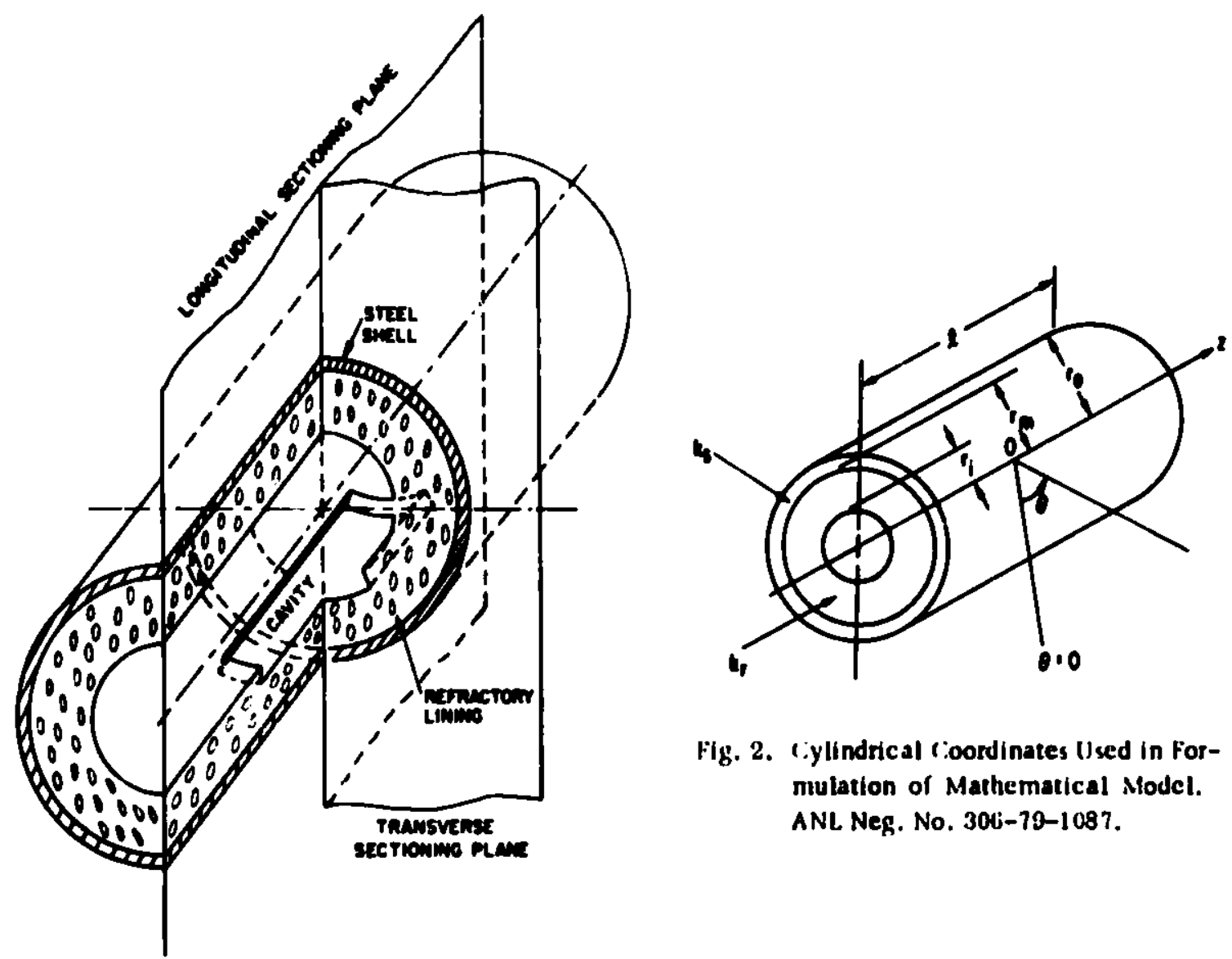

Fig. 2. Cylindrical coordinates Used in Formulation of Mathematical Model. ANL Neg. No. 306-79-1087.

Hig. 1. Sectional View ol Re.fractory-lined Transfer Line Ueed for Analytical Modeling. ANL Neg. No. 306-78-524.

The boundary conditions applicable to the system include a prescribed surface temperature on the inner (hot) refractory surface and a convective boundary on the outer steel surface. In the angular $(\theta)$ direction, the boundary conditionis selected are based on the necessity that the temperature must be ingle valued for an angular increment of $2 \pi$. In the axial ( $z$ ) direction, the boundaries are free from edge effects due to either the cavity wall or axial heat transfer remote from the syotem. Hence, the actual length of the system must be sufficient to ensure that an adiabatic condition prevails at both ends. These boundary conditions can be formulated as follows:

$$
\begin{aligned}
& T\left(r_{i}, \theta, z\right)=T_{i}, \\
& k \frac{\partial T\left(r_{0}, \theta, z\right)}{\partial r}+h\left[T\left(r_{0}, \theta, z\right)-T_{\infty}\right]=0, \\
& \frac{\partial T(r, \theta, z)}{\partial \theta}=\frac{\partial T(r, \theta+2 \pi, z)}{\partial \theta},
\end{aligned}
$$




$$
\begin{aligned}
& T(r, \theta, z)=T(r, \theta+2 \pi, z), \\
& \frac{\partial T(r, \theta,-\ell / 2)}{\partial z}=0,
\end{aligned}
$$

and

$$
\frac{\partial T(r, \theta, \ell / 2)}{\partial z}=0 \text {, }
$$

where $h$ in Eq. 4 represents the convective heat-transfer coefficient.

In practice, the transfer-line wall is composed of a refractoryconcrete lining cast inside a steel shell. In the presence of such a composite structure, two sets of governing equations and boundary conditions are needed to describe the system. A formulation suited to this composite system can be derived by reusing the previous equations, with subscripts added to $T$ to differentiate temperatures in different parts of the medium. In addition, if the contact resistance at the interface is ignored, two new boundary conditions are required at the interface:

$$
k_{r} \frac{\partial T_{r}\left(r_{m}, \theta, z\right)}{\partial r}=k_{8} \frac{\partial T_{g}\left(r_{m}, \theta, z\right)}{\partial r}
$$

and

$$
T_{r}\left(r_{m}, A, z\right)=T_{8}\left(r_{m}, \theta, z\right) .
$$

Here, subscripts $r, m$, and $s$ have been added to designate the refractory concrete, the interface, and the steel shell, respectively.

C. Justification for Boundary Conditions Imposed

The boundary conditions given above are strictly valid only in the angular $(\theta)$ and axial $(z)$ directions. In the radial direction, a certain degree of arbitrariness is necessary. The problem lies in the fact that, strictly speaking, the inner refractory unface is not subjected to a prescribed temperature. In coal-conversion processes, the refractory inside the transfer line is exposed to both convection and radiation from two-phase (solid-gas) mixtures. Cavity recesses in the wall can induce secondary vortices which are not amenable to such simple analysis. In fact, the effective heat-transfer coefficient cannot be estimated for such complicated flow conditions using present atate-of-the-art methods such as finite elements. The assumption of a prescribed surface temperature is thus made in order to aimplify the problem and allow a solution. 
The assumption of a convective boundary at the outer surface, however, is a valid one. A point of caution is that, if the heat is dissipated from a highly emissive surface at elevated temperatures, the radiative component must also be considered. An analysis showing the fraction of the convective contribution to the total heat dissipation can be made by separately considering the convective component as

$$
q_{c}=h T_{\infty}\left(\frac{T_{o}}{T_{\infty}}-1\right)
$$

and the radiative component as

$$
q_{r}=\operatorname{coT}_{\infty}^{4}\left[\left(\frac{T_{0}}{T_{\infty}}\right)^{4}-1\right],
$$

where $c$ is the surface emissivity, $\sigma$ is the Stefan-Boltzmann constant, $T_{0}$ is the outer-surface temperature, and $T_{\infty}$ is the ambient temperature. The fraction of the convective contribution to the total heat dissipation $\left[q_{c} /\left(q_{c}+q_{r}\right)\right]$ can be evaluated and plotted as a function of the temperature ratio $\left(\mathrm{T}_{0} / \mathrm{T}_{\infty}\right)$, as shown in Fig. 3. The following observations can be made from this figure: For the emissivity and temperature values chosen for this plot $(\varepsilon=0.2$, $T_{\infty}=10^{\circ} \mathrm{C}$ ), an increase in the temperature ratio (i.e., $T_{0}$ ) decreases the fraction of the convective contribution. Note that the parameter used in the family of curves shown is the convective coefficient, $h$. The trends of the curves appear to indicate that the fraction of the convective contribution increases more rapidly for small values of $h$ at low temperature ratios. Such a tren $d$ is, nevertheless, reversed when the $h$ values are increased.

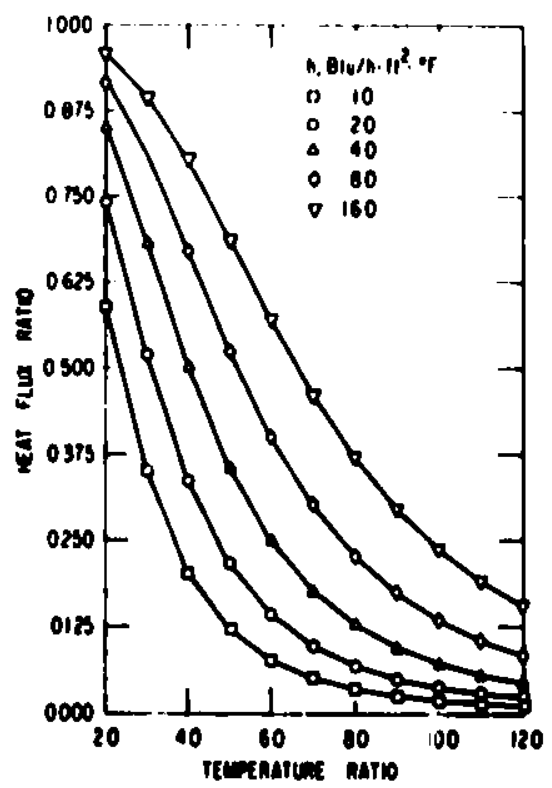

Fig. 3

Evaluation of Convective (intribution for $C=0.2 . T_{\infty}=50^{\circ} \mathrm{F}\left(10^{\circ} \mathrm{C}\right)$. Conversion factor: $1 \mathrm{Btu} / \mathrm{h} \cdot \mathrm{ft}^{2} \cdot{ }^{\circ} \mathrm{F}=5.68 \times 10^{-6} \mathrm{~W} / \mathrm{mm}^{2} .^{\circ} \mathrm{C}$. ANL Neg. No. 306-80-148.

When the emisoivity is kept constant, but $T_{\infty}$ is increased from $10^{\circ} \mathrm{C}$ $\left(50^{\circ} \mathrm{F}\right)$ to $26.6^{\circ} \mathrm{C}\left(80^{\circ} \mathrm{F}\right)$, only a slight upward hift of the curves is noted, as shown in Fig. 4. On the other hand, if the ambient temperature remains 
constant while the emissivity is raised from 0.2 to 0.8 , a downward shift of the curves results (see Fig. 5). This effect is more pronounced at low convection rates under which the fraction of the convective contribution is almost halved over broad temperature ratios.

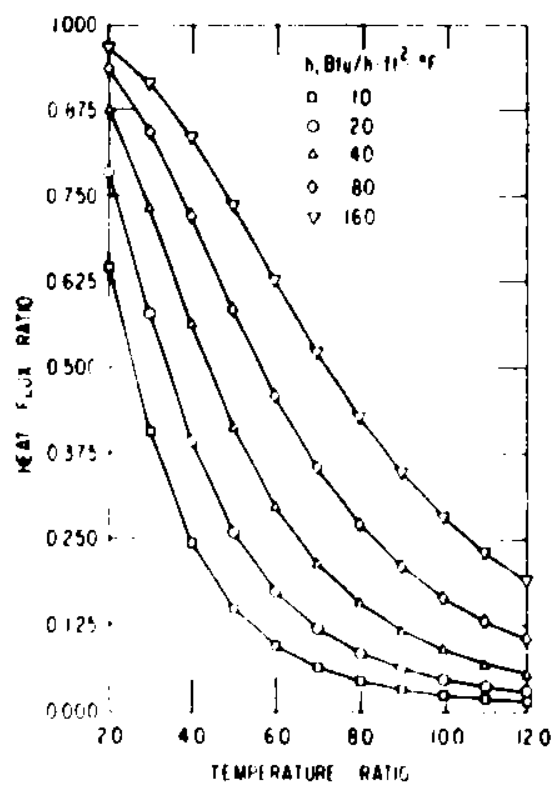

lig. 4

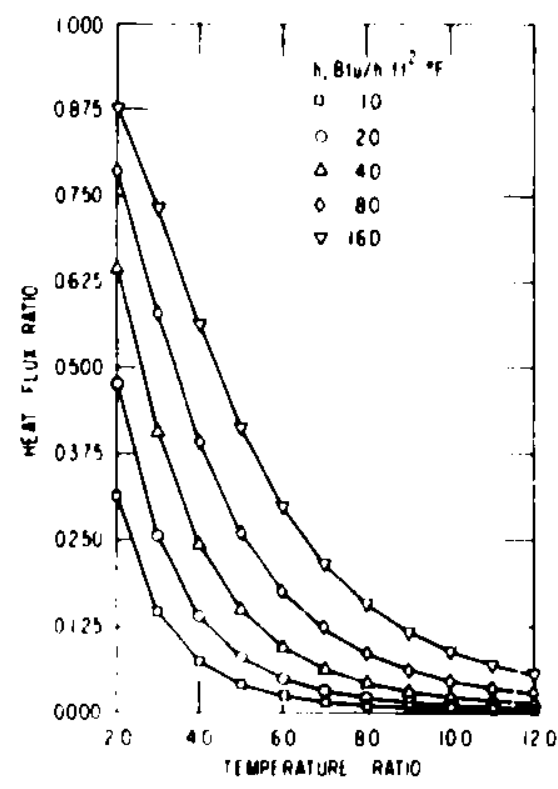

Fig. is
Evaluation of Convective Contribution for $\varepsilon=$ $0.2 . \mathrm{T}_{\alpha}=80^{\circ} \mathrm{F}$ (26.t) (Conversion factor: $1 \mathrm{Btu} / \mathrm{h} \cdot \mathrm{ft}^{2} \cdot \mathrm{F}=5.68 \times 10^{-6} \mathrm{~W} / \mathrm{mm}^{2} \cdot \mathrm{c}$ : ANL Neg. No. $306-80-144$.
Fvaluation of convective contribution for $\varepsilon=$ $0.8, \mathrm{~T}_{\infty}=80 \mathrm{~F}(26,6)(\mathrm{c})$. Conversion factor

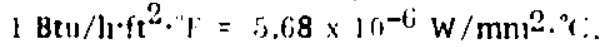
ANL. Neg. No. 306-80-1533.

Note that, for small temperature differences $\left(T_{0}-T_{\infty}\right)$, the following approximation holds :

$$
\left(T_{0}^{2}+T_{\infty}^{2}\right)\left(T_{0}+T_{\infty}\right)=4\left(\frac{T_{0}+T_{\infty}}{2}\right)^{3}
$$

Thus, if the quantity in parentheses on the right of Eq. 13 is denoted as the mean temperature $\mathrm{T}_{\mathrm{m}}$. Eq. 12 can be recast as

$$
\mathrm{q}_{r}=46 \sigma \mathrm{T}_{\mathrm{m}}^{3} \mathrm{~T}_{\infty}\left(\frac{\mathrm{T}_{0}}{\mathrm{~T}_{\infty}}-1\right)
$$

If the coefficient $4 \in \sigma \mathrm{T}_{\mathrm{m}}^{3}$ in Eq. 14 is denoted as $\mathrm{h}_{\mathrm{r}}$, the radiative contribution to heat dissipation can be combined with tice convective component as

$$
q_{c}+q_{r}=\left(h+h_{r}\right) T_{\infty}\left(\frac{T_{0}}{T_{\infty}}-1\right)
$$

Hence, by choosing a suitable value of $h$, we can account for the radiative contribution in the analysis; a separate consideration of the radiative transfer is thus unnecessary. 


\section{DEVELOPMENT OF BASIC HEAT - TRANSFER MODELS}

A. Finite-difference Formulation

The formulation given in the preceding section has been idealized in the sense that the transfer line has not been eroded. In the presence of a cavity defect in the wall (erosion), the structural system takes on a more complicated configuration (see Fig. 1). Under this condition, the exact solution becomes difficult and numerical methods must be relied on ir. $r$ solution. The numerical solution can be effected by a reformulation of the problem into finite difference as follows:

According to Taylor's expansion, one can replace the second derivative $\partial^{2} \mathrm{~T} / \partial \mathrm{r}^{2}$ in Eq. $L$ by a second central-difference quotient:

$$
\frac{\partial^{2} T}{\partial r^{2}}=\frac{T_{i+1, j}-2 T_{i, j}+T_{i-1, j}}{(\Delta r)^{2}}
$$

The truncation error involved in this substitution can be expressed as

$$
E_{T}=-\frac{(\Delta r)^{2}}{12}\left[D_{r}^{4}+\frac{(\Delta r)^{2}}{30} D_{r}^{6}+\ldots\right] T_{i, j},
$$

where the operator $D_{r}$ is defined as

$$
D_{r}=\frac{\partial}{\partial r}
$$

Similarly, the first derivatives that appear in the boundary conditions can be replaced by either a forward-or a backward-difference quotient given, respectively, as

$$
\frac{\partial T}{\partial r}=\frac{T_{i+1, j}-T_{i, j}}{\Delta r}
$$

and

$$
\frac{\partial T}{\partial r}=\frac{T_{i, j}-T_{i-1, j}}{\Delta r}
$$

Again, these truncation errors can be expressed in terms of operators as

$$
E_{T}=-\frac{\Delta r}{2}\left[D_{r}^{2}+\frac{(\Delta r)}{3} D_{r}^{3}+\ldots\right] T_{i, j},
$$

which is valid for a forward difference. For a backward difference, the negative sign on the right of Eq. 21 must be changed to a positive sign. 
The truncation errors given in Eqs. 17 and 21 obviously have different orders of magnitude. Unless an average difference quotient is used for the first partial differential, the error involved in replacing the first partial differential by either a forward- or a backward-difference quotient is of order $\Delta r$, while that for the second differential is $(\Delta r)^{2}$. To rectify this inconsistency, one has to use a refined mesh size at the boundary in order to ensure a uniform truncation error throughout the system. This points to the fact that a simple replacement of differentials by differences might result in a magnitudenonhomogeneous system that is inherent in this method of formulation.

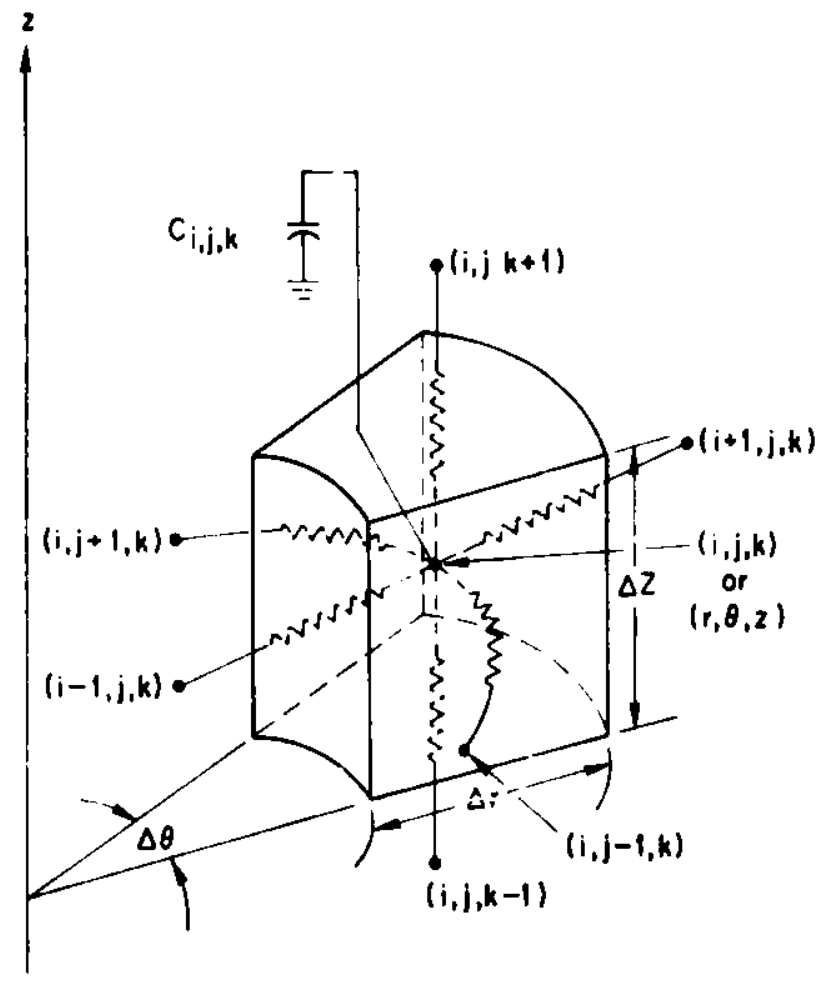

Fig. 6. Volume Element in Cylindrical coordinates. $\triangle N L$ Neg. No. 306-78-520.
A second, and actually better, method to derive a difference formulation is to use a physical analysis. This method is based on the as sumption that an energy balance exists at each nodal point in the system. For the cylindrical system under consideration, the entire region is modularized into volume elements as shown in Fig. 6. Ohm's law can be used to derive heat flow to each node (i,j, k) from each neighboring point. Kirchhoff's law can next be used to sum all heat flow to the nodal point and the sum equated to zero to relate a steady-state condition. This process is repeated for each node in the system such that a complete set of finite-difference equations can be derived. To facilitate the formulation, all nodal-resistance expressions are listed in Table I. The thermalconductivity terms, $k$, in the expres sions have been identified with

subscripts that refer to the temperature level at which the se conductivities are evaluated. Hence, for example, $k_{i}\left(l_{2}\right)$ refers to a conductivity evaluated at $\left(T_{i-1, j, k}+T_{i, j, k}\right) / 2$. The temperature dependency in the thermal conduc- tivity can be accounted for in the analysis. Note that the difference formulation derived here on the basis of the physical analysis will result in a magnitudehomogeneous system. ${ }^{12}$ For this reason, the physical-analys is approach is used exclusively in the present work to derive all the finite-difference formulations. 
IABLE I. Expressions lised to Derive Nodal

Equations by Means of thysical Formulation

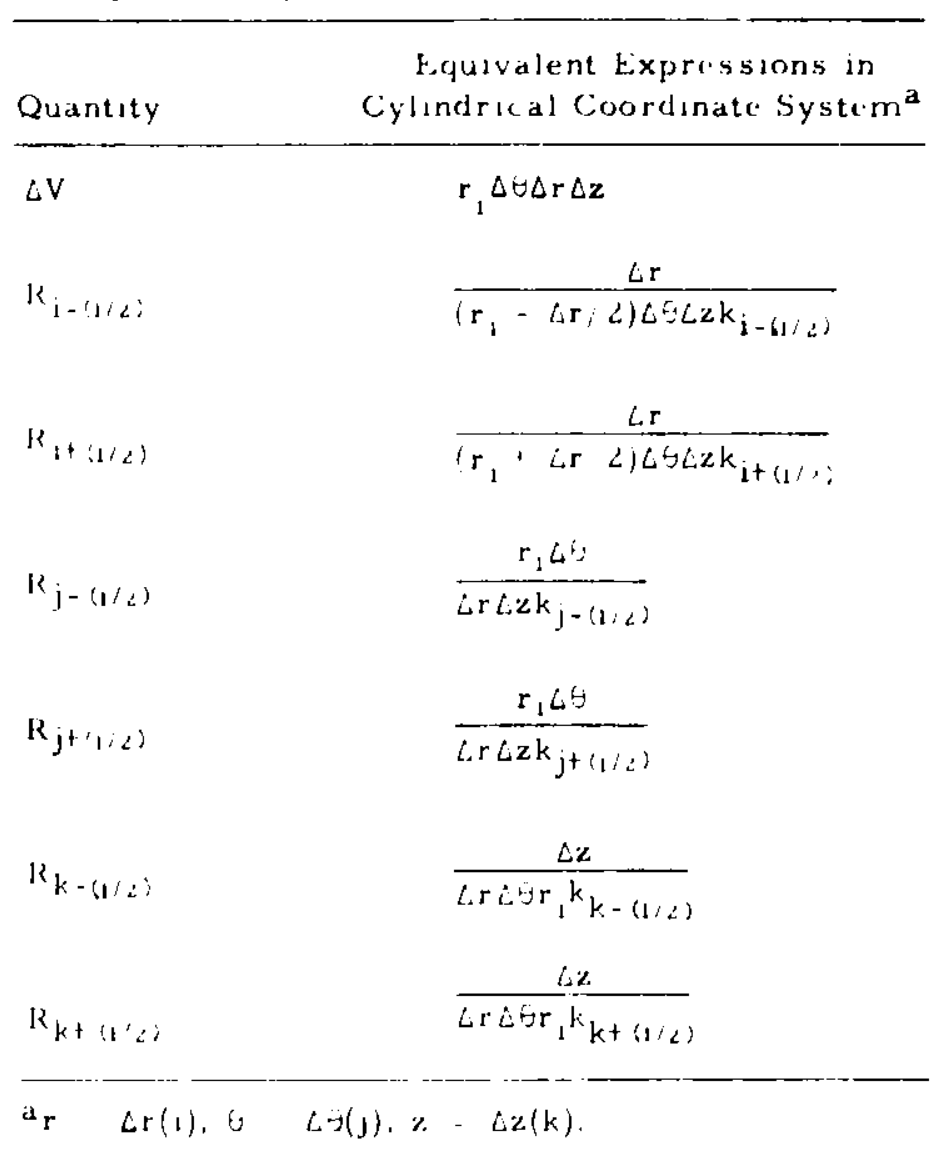

B. Development of Basic Two-dimensional Model

In the two-dimensional model, the temperature is free of $\mathbf{z}$-axis dependency. Hence, the cavity is of infinite length. Finite-difference equations can be derived for this two-dimensional system and summarized as follows:

For interior nodes in the refractory or the steel shell, the temperature can be determined from

$$
\begin{aligned}
T_{i, j}= & \left\{\frac{1}{(\Delta r)^{2}}\left[\left(r_{i}-\frac{\Delta r}{2}\right) T_{i-1, j}+\left(r_{i}+\frac{\Delta r}{2}\right) T_{i+1, j}\right]+\frac{1}{r_{i}(\Delta \theta)^{2}}\left(T_{i, j-1}+T_{i, j+1}\right)\right\} \\
& \cdot\left\{2\left[\frac{r_{i}}{(\Delta r)^{2}}+\frac{1}{r_{i}(\Delta \theta)^{2}}\right]\right\}^{-1}
\end{aligned}
$$

For nodes at the interface between the refractory lining and the steel shell, the temperature can be determined from 


$$
\begin{aligned}
\mathrm{T}_{i, j}= & \left\{\frac{1}{(\Delta \mathrm{r})^{2}}\left[\mathrm{k}_{1}\left(\mathrm{r}_{\mathrm{i}}-\frac{\Delta \mathrm{r}}{2}\right) \mathrm{T}_{\mathrm{i}-1, j}+\mathrm{k}_{2}\left(\mathrm{r}_{\mathrm{i}}+\frac{\Delta \mathrm{r}}{2}\right) \mathrm{T}_{\mathrm{i}+1, j}\right]+\frac{\mathrm{k}_{1}+\mathrm{k}_{2}}{2 \mathrm{r}_{\mathrm{i}}(\Delta \theta)^{2}}\left(\mathrm{~T}_{\mathrm{i}, \mathrm{j}-1}+\mathrm{T}_{\mathrm{i}, \mathrm{j}+1}\right)\right\} \\
& \cdot\left\{\frac{\mathrm{i}}{(\Delta \mathrm{r})},\left[\mathrm{k}_{1}\left(\mathrm{r}_{\mathrm{i}}-\frac{\Delta \mathrm{r}}{2}\right)+\mathrm{k}_{2}\left(\mathrm{r}_{\mathrm{i}}+\frac{\Delta \mathrm{r}}{2}\right)\right]+\frac{\mathrm{k}_{1}+\mathrm{k}_{2}}{\mathrm{r}_{\mathrm{i}}(\Delta \theta)^{2}}\right\}^{-1}
\end{aligned}
$$

where $k_{1}$ and $k_{2}$ are thermal conductivities for the refractory and the steel shell, respectively.

For nodes at the outer surface of the steel shell, the temperature can be determined from

$$
\begin{aligned}
& T_{i, j}=\left[\frac{k_{L}}{(L r)^{2}}\left(r_{i}-\frac{\Delta r}{2}\right) T_{i-1, j}+\frac{h r_{i}}{\Delta r} T_{\infty}+\frac{k_{2}}{2 r_{i}(\Delta \theta)^{2}}\left(T_{i, j-1}+T_{i, j+1}\right)\right] \\
& {\left[\frac{k_{2}}{(\Delta r)^{2}}\left(r_{i}-\frac{\Delta r}{2}\right)+\frac{h r_{1}}{\Delta r}+\frac{k_{2}}{r_{j}(\Delta \theta)^{2}}\right]^{-1}}
\end{aligned}
$$

In applying these equations to nodes at various locations in the system, one should be aware that the temperature distribution is symmetrical with respect to the cavity location in the system. Hence, if the cavity center is set at $\theta=0$ (see Fig. 7), only the region from $\theta=0$ to $180^{\circ}$ need be considered to reduce the computation cost.

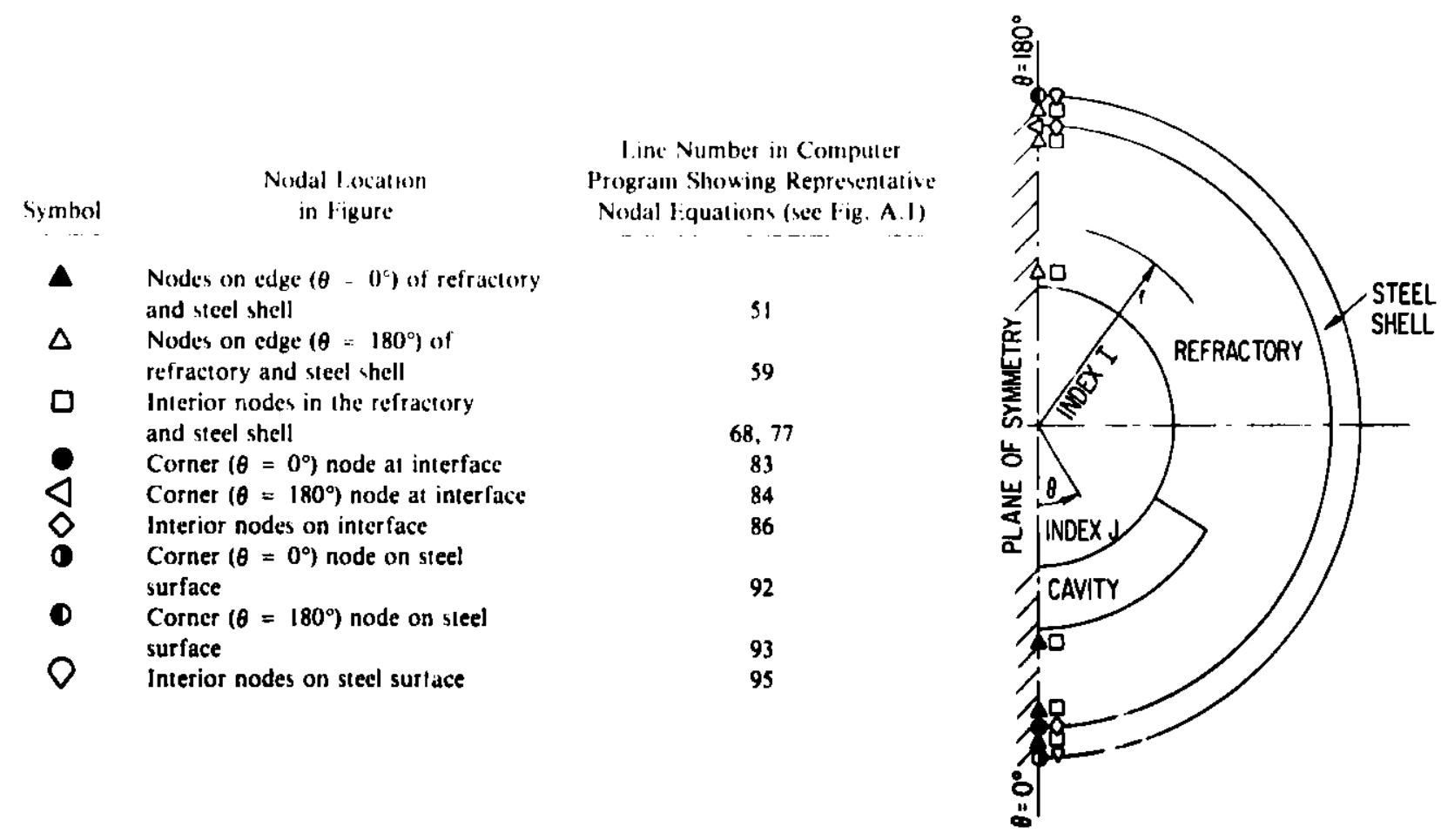

Fig. 7. Schematic Diagram Showing Locations of Nine Classes of Nodes Used in Difference Formulation. ANL Neg. No. 306-80-132. 
For nodes located on the plane of symmetry, the nodal equations can be further simplified. Since the temperature gradient vanishes at the plane of symmetry, one can introduce a fictitious node outside the region of investigation. This fictitious node is related to the interior node by

$$
T_{i, j+1}=T_{i, j-1}
$$

This equation can be used to further simplify the difference formulation for boundary nodes.

For a two-dimensional system as considered here, nine types of nodal equations appear in the solution. Each of these represent a distinct nodal location that requires a general nodal equation for temperature calculations using DO loops. Figure 7 is a schematic diagram showing these nine locations. The total number of equations to be solved simultaneously in the problem, of course, equals the total number of nodes in the system. These nodal equations written in FORTRAN are compiled in the compute $r$ program included as Appendix $A$ to this report.

C. Development of Basic Three-dimensional Model

For the three-dimensional model, the cavity is of finite length. General equations can be derived for this three-dimensional system, again using a physical formulation. For interior nodes in the refractory and the steel shell, the difference equation is developed as

$$
\begin{aligned}
T_{i, j, k}= & \left\{\frac{1}{(\Delta r)^{2}}\left[\left(1-\frac{\Delta r}{2 r_{i}}\right) T_{i-1, j, k}+\left(1+\frac{\Delta r}{2 r_{i}}\right) T_{i+1, j, k}\right]\right. \\
& \left.+\frac{1}{r_{i}^{2}(\Delta \theta)^{2}}\left(T_{i, j-1, k}+T_{i, j+1, k}\right)+\frac{1}{(\Delta z)^{2}}\left(T_{i, j, k-1}+T_{i, j, k+1}\right)\right\} \\
& \cdot\left\{2\left[\frac{1}{(\Delta r)^{2}}+\frac{1}{r_{i}^{2}(\Delta \theta)^{2}}+\frac{1}{(\Delta z)^{2}}\right]\right\}^{-1} .
\end{aligned}
$$

For nodes at the interface between the refractory lining and the steel shell, the difference equation is developed as

$$
\begin{aligned}
T_{i, j, k}= & \left\{-\frac{1}{(\Delta r)^{2}}\left[k_{1}\left(1-\frac{\Delta r}{2 r_{i}}\right) T_{i-1, j, k}+k_{i}\left(1+\frac{\Delta r}{2 r_{i}}\right) T_{i+1, j, k}\right]\right. \\
& \left.+\frac{k_{1}+k_{i}}{2 r_{i}^{2}(\Delta \theta)^{2}}\left(T_{i, j-1, k}+T_{i, j+1, k}\right)+\frac{k_{1}+k_{2}}{2(\Delta z)^{2}}\left(T_{i, j, k-1}+T_{i, j, k+1}\right)\right\} \\
& \cdot\left\{\frac{1}{(\Delta r)^{2}}\left[k_{i}\left(1-\frac{\Delta r}{2 r_{i}}\right)+k_{2}\left(1+\frac{\Delta r}{2 r_{i}}\right)\right]+\frac{k_{1}+k_{2}}{r_{i}^{2}(\Delta \theta)^{2}}+\frac{k_{1}+k_{2}}{(\Delta z)^{2}}\right\}^{-1} .
\end{aligned}
$$


For nodes at the outer surface of the steel shell, the difference equation is given as

$$
\begin{aligned}
T_{i, j, k}= & {\left[\frac{k_{2}}{(\Delta r)^{2}}\left(1-\frac{\Delta r}{2 r_{i}}\right) T_{i-1, j, k}+\frac{h}{\Delta r} T_{\infty}+\frac{k_{2}}{2 r_{i}^{2}(\Delta \theta)^{2}}\left(T_{i, j-1, k}+T_{i, j+1, k}\right)\right.} \\
& \left.+\frac{k_{2}}{2(\Delta z)^{2}}\left(T_{i, j, k-1}+T_{i, j, k+1}\right)\right] \\
& \cdot\left[\frac{k_{2}}{(\Delta r)^{2}}\left(1-\frac{\Delta r}{2 r_{i}}\right)+\frac{h}{\Delta r}+\frac{k_{2}}{r_{i}^{2}(\Delta \theta)^{2}}+\frac{k_{2}}{(\Delta z)^{2}}\right]^{-1}
\end{aligned}
$$

Again, planes of symmetry can be used to economize the solution. This time, in addition to the plane located at $\theta=0$, new planes are placed at $\mathrm{z}=0$ and $\ell / 2$. The coordinates of the system are also fitted such that the origin lies radially along the center of the cavity $(r, 0,0)$. This arrangement permits a reduction of the system to one quadrant of the original volume.

For a three-dimensional system, 27 types of nodal equations appear. Since a graphical presentation of these nodal locations is difficult, a verbal accounting is given as follows: Consider that the system under investigation occupies a space of $\pi \geq \theta \geq 0$ and $\ell / 2 \geq z \geq 0$, where the $z$ axis is one that penetrates normally into the plane of Fig. 7. In this way, the nine classes of nodes that have previously been shown in the two-dimensional system are still valid. Since these nodes can be located at either the front $(z=0)$ or the rear end $(z=\ell / 2)$ of the system, they give a combination of 18 nodal locations that require 18 general equations for temperature calculations using DO loops.

In addition, because of the presence of the axial direction as the third dimension, the re are nodal points located at $(1)\left(r, 0^{\circ}, z\right)$ and $\left(r, 180^{\circ}, z\right)$, where $r_{m}>r>r_{i}$ and $l / 2>z>0 ;(2)\left(r_{m}, 0^{\circ}, z\right)$ and $\left(r_{m}, 180^{\circ}, z\right)$, where $l / 2>z>0$; (3) $\left(r_{0}, 0^{\circ}, z\right)$ and $\left(r_{0}, 180^{\circ}, z\right)$, where $\ell / 2>z>0$; (4) interior nodes inside the refractory, i.e., $(r, \theta, z$,$) , where r_{m}>r>r_{i}, 180^{\circ}>\theta>0, l / 2>z>0$; (5) interior nodes on the refractory/steel interface, i.e., $\left(r_{m}, \theta, z\right)$ with the ranges of $\theta$ and $z$ unchanged from before; and finally, (6) interior nodes on the outer surface of the steel shell, i.e., $\left(r_{0}, \theta, z\right)$. All together, these represent nine additional nodal locations that require nine additional equations in the formulation. A computer program developed for the three-dimensional model is included as Appendix B to this report.

\section{Modeling of Thermal Contact Resistance}

The thermal resistance at the refractory/steel interface has a marked effect on the heat transfer to the steel shell. Unfortunately, modeling this resistance is difficult because of the lack of data available in the literature. 
Most of the data available today have been for metal-to-metal contacts. ${ }^{13-16}$ These data cannot be used to predict a metal-to-ceramic contact, as is necessary for the present study. Experience has shown that, because of the complexity of the contact mechanism present at the interface, analysis using resistance data for metal-to-ceramic contact* may be inaccurate if the data given are not for the same materials. To alleviate this difficulty, the modeling of contact resistance in the present study follows a different approach. The method consists of reorganizing the contact-resistance equation using a dimensionless paramete $r$ that is to be incorporated into the neighboring re sistances. The method is derived from an effective-resistance concept, which owes its origin to the contact-resistance equation given as ${ }^{16}$

$$
R_{c}=\frac{1}{2 \operatorname{nakA}}
$$

where $\mathrm{n}$ is the number of contact spots per unit area, a is the mean radius of the contact spots, $\mathrm{k}$ is the thermal conductivity, and $\mathrm{A}$ is the apparent area in contact. Since it is a resistance, $R_{c}$ can now be incorporated into the resistanc 2 network.

For the problem at hand, the lumping of the contact resistance to the refraccory side of the network appears to be more appropriate, because the magnitude of the contact resistance is comparable to that of the refractory material. As a result, the new resistance at the refractory side takes the form

$$
\frac{\Delta r}{k_{1} A}+\frac{1}{2 \operatorname{nak}_{1} A}=\frac{\Delta r}{k_{1} A}\left[1+\frac{1}{2 n a(\Delta r)}\right]
$$

The bracketed quantity on the right of Eq. 30 plays the role of a modified re sistance factor that offer $s$ the same resistance to heat flow as an interfacial contact resistance. The second term in the brackets is a dimensionless quantity that is always positive in magnitude. The entire bracketed term can thus be designated as $\mathrm{f}$,

$$
f=1+\frac{1}{2 \operatorname{na}(\Delta r)}
$$

in which $f \geq 1 ; f=1$ when the interfacial resistance is zero. This $f$ factor can be used to model a wide range of interfacial conditions and to analyze the resistance effects. Two conditions are studied below for illustration.

When a uniform resistance occurs at the interface, the contact resistance can be modeled by using a constant $f$ value to modify all the resistances

*Only two references 17.18 in the literature report data on metal-to-ceramic contacts. 
at the refractory side of the network. The solution to this case is straightforward, and no further discussion is necessary.

A slightly more involved case is one in which the contact resistance is a variable. In this case, the temperature distribution becomes strongly dependent on how the $f$ function is chosen in the analysis. In the absence of actual resistance data for wodeling, the $f$ function chosen in the present study was dictated by the consideration that the purpose of the selected $f$ function would give rise to a limiting case so that the surface temperature would be upset because of the resistance. With this in mind, the $f$ function was chosen as

$$
\left(\frac{j-J}{J}\right)^{2}+\left(\frac{k-K}{J}\right)^{2}=\frac{v-f}{v-l}
$$

where the coordinates have been expressed using indices ( $j$ for $\theta, k$ for $z$ ). The selected $f$ function has a paraboloid variation, with the peak point located at $(\mathrm{J}, \mathrm{K})$, of value $\mathrm{v}$. Since the center of the cavity is also located at $(\mathrm{J}, \mathrm{K})$ in the analysis, the large contact resistance occurs where the highest heat flow takes place. Thus, the proposed contact resistance will impede the heat flow and also suppress the temperature of the hot spot appearing on the surface. Adjusting the $\mathrm{v}$ value enables a limiting case to be found.

It should be added that the $f$ function developed above (Eq. 31 ) is indeed of general utility. In the future, when the contact-resistance data become available, one can readily convert them to $f$ values and use them in model studies. The equation to be used in this conversion is

$$
f=1+\frac{R_{c} k A}{\Delta r}
$$

which is derived by combining Eqs. 29 and 31.

E. Modeling of Surface-emissivity Effects

Unless a surface is black or is coated with a material of known emissivity, the surface emissivity must be carefully examined before an infrared picture can be analyzed.

The effect of surface emissivity on infrared images was qualitatively discussed in Sec. III.C. In this section, a quantitative prediction of the emissivity will be given to show how the surface-emissivity effect can be incorporated in the model study. Some qualitative data will also be examined in passing in order to support discussions. To facilitate analysis, the surface being investigated is assumed to have a homogeneous structure. That is to say, the surface has neither a peeling-paint appearance, nor nonuniformities of either a physical or chemical nature such as localized smooth or rough 
spots, chins, abrasions, dents, etchings, or rust spots. These nonhomogeneities ca. normally be detected from an infrared image as abnormally hot or cold spots in an otherwise uniform background. Since they can be corrected in the experiment and their appearance is by no means related to the true temperature distributions, an inclusion of these artifacts in the study is meaningless. In the followirg, the modeling of the emissivity effect will start with a development of the relation between emission and view angles. The surfaceemissivity relation will be examined and used to show how the emitted energy will vary in the view field because of the dependence of the emissivity on direction.

The discussion can be facilitated by reference to the schematic shown in Fig. 8, where the infrared camera is at a distance $D$ from the center of

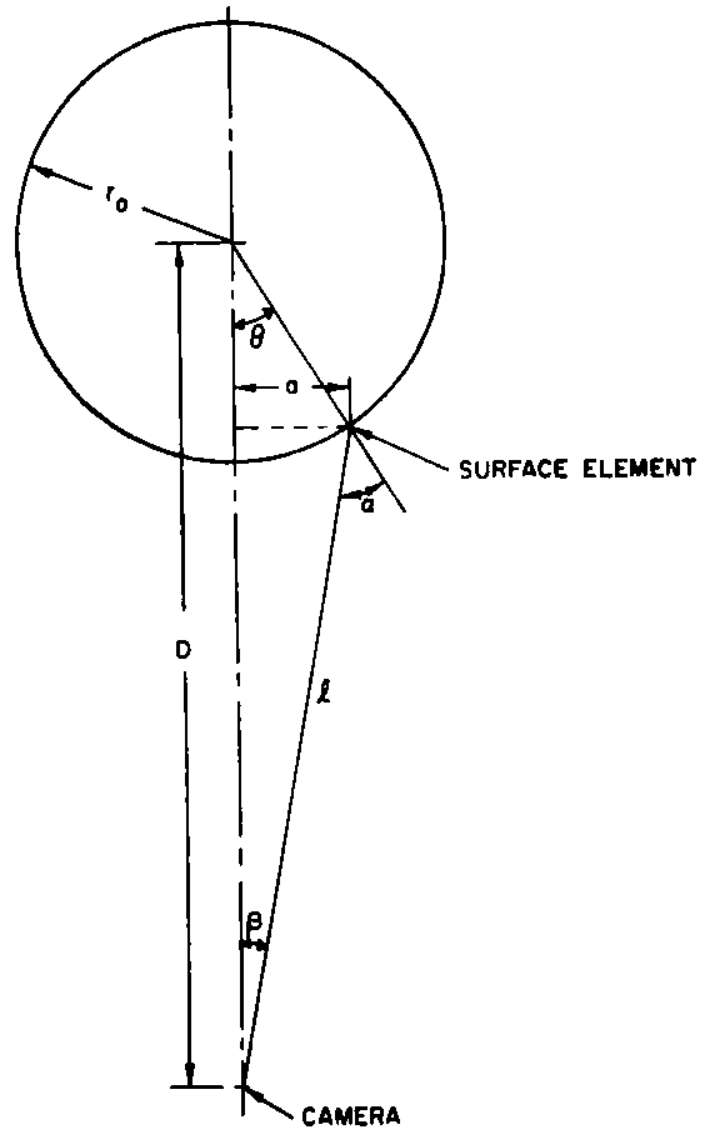

Fig. 8. Schematic Diagram Showing Nutation Used to Relate Polar $(\theta)$. Fimission $(\alpha)$, and View (B) Angles. ANL Neg. No. 306-78-527. the pipe. For a surface element located at a polar angle $\theta$ on the pipe, the emis sion angle from the element is $\alpha$, while the view angle at the camera is $\beta$. The energy reaching the camera from the center of the view field $(\beta=0)$ is due to surface emission normal to the pipe surface and parallel to the lens axis. Unless the viewed surface is diffuse, the emissivity varies strongly with the emission angle. Hence, a relation between emission and view angles must be developed before a correction can be made for emissivity. The law of cosines can be used to relate $\theta$ and $\beta$ as

$D^{2}+r_{0}^{2}-2 D r_{0} \cos \theta=\frac{r_{0}^{2} \sin ^{2} \theta}{\sin ^{2} \beta}$.

For a given test setup, both $D$ and $r_{0}$ are known and the polar and view angles can be found. The emission angle can also be calculated from $\theta$ and $\beta$, using

$$
\alpha=\theta+\beta .
$$

The nonlinearity of Eq. 34 yields a relation between $\theta$ and $\beta$ that is difficult to visualize. A computer program was developed to evaluate these angles. (A computer program evaluating the relations among the angles $\alpha, \beta$, and $\theta$ and the surface emissivity of both metallic and nonmetallic substances is given in Appendix C.) In a test run using $D=1.524 \mathrm{~m}\left(60\right.$ in.) and $r_{0}=0.1333 \mathrm{~m}$ (5.25 in.) as inputs, the angular relations were calculated and plotted. This 
is shown in Figs. 9 and 10. Figure 9 shows that the relation between the view angle and the polar angle (both expressed in radians) is nonlinear. The nonlinearity is quite pronounced toward large angles. Similarly, the relation between the emission angle and the polar angle is also nonlinear, primarily toward large polar angles (see Fig. 10). On the basis of these data, a third figure can be constructed that relates the emission and the view angles; (see Fig. 11). Again, a nonlinear relation is found in the figure.

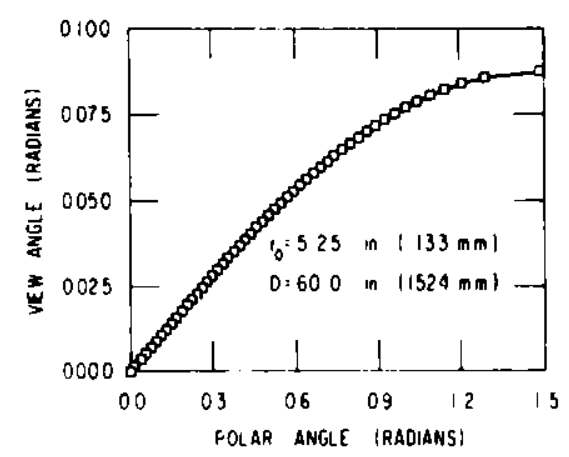

Fig. 9. Polar- to View-angle Conversion Chart. ANL'Neg. Nu. 306-80-146.

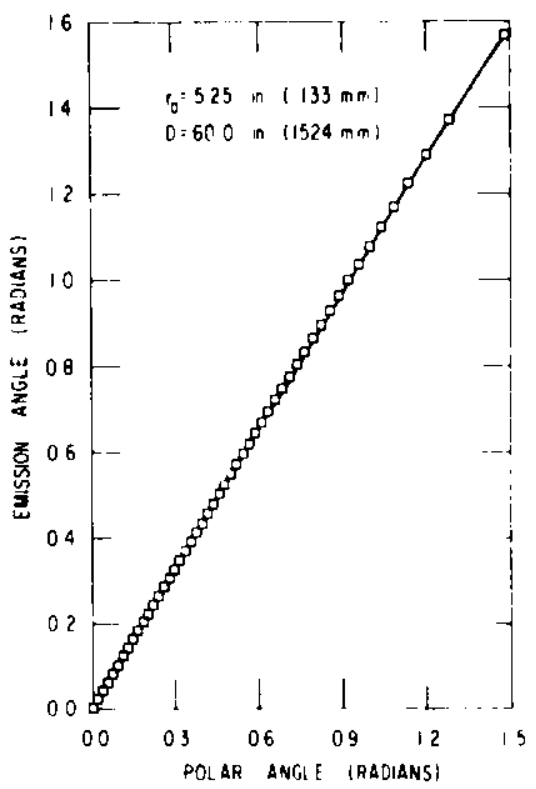

Fig. 10. Polar- to l:mission-angle Conversion Chart. ANL Neg. No. 306-80-142.

Fig. 11

Emission- to View-angle Conversion Chart. ANL Neg. No. 306-80-131. 
The angular relations presented above have significance in studying the distortion of infrared images. As one may recall in the previous modeling using finite differences, the surface-temperature data were evaluated at equal increments of the polar angle $(\theta)$, while the instantaneous fields scanned by the infrared camera and presented on the oscilloscope screen were made in equal increments of the view angle $(\beta)$. In Fig. 9 these two angles are shown to be nonlinear. Hence, a predicted temperature map using the heat-transfer model developed he re might not exactly be the one found on the oscilloscope screen, even if the model were perfect. A distortion of the image in the trans verse direction is inherent in the method, since the two temperature maps cio not share identical angular coordinates.

The problem is further complicated by the fact that the surface emissivity is also a function of the emission angles. In order to evaluate this emissivity effect, the emissivity equations must also be examined. The emis sivity can bc predicted using electromagnetic theory. If the complex refrastive index $\mathrm{N}$ is expressed as

$$
N=n-i k,
$$

where $n$ (index of refraction) and $k$ (extinction coefficient) are known optical constants, the directional spectral emissivity can be calculated using ${ }^{19}$

$$
\varepsilon_{\lambda}^{\prime}=\frac{1}{2} \varepsilon_{1}(\alpha)\left[1+\frac{a^{2}+b^{2}+\sin ^{2} \alpha}{\cos ^{2} \alpha\left(a^{2}+b^{2}+2 a \sin \alpha \tan \alpha+\sin ^{2} \alpha \tan ^{2} \alpha\right)}\right]
$$

where

$$
e_{\perp}(\alpha)=\frac{4 a \cos \alpha}{a^{2}+b^{2}+2 a \cos \alpha+\cos ^{2} \alpha}
$$

The parameters $a$ and $b$ in the above equations can be evaluated using the equations

$$
2 a^{2}=\sqrt{\left(n^{2}-k^{2}-\sin ^{2} \alpha\right)^{2}+4 n^{2} k^{2}}+\left(n^{2}-k^{2}-\sin ^{2} \alpha\right)
$$

and

$$
2 b^{2}=\sqrt{\left(n^{2}-k^{2}-\sin ^{2} \alpha\right)^{2}+4 n^{2} k^{2}}-\left(n^{2}-k^{2}-\sin ^{2} \alpha\right) .
$$

To illustrate how the emissivity varies with angle, two test runs were made. The first used the optical constants $n=4$ and $k=10$, which are representative of metals ( $k \neq 0$ ); hence, the resultant emissivity curve character izes metal behavior. As shown in Fig. 12, the emissivity increases wi+" polar angle and drops rapidly to zero at $90^{\circ}$. Nonmetal behavior $(n=4, k=v$ ) is illustrated in Fig. 13; here, the emissivity is high and holds constant ove $r$ a wide range of polar angles, then again drops down to zero toward $90^{\circ}$. Because 
of the spectral dependency of the optical constants, the emissivity curves given above are strictly valid for a certain wavelength condition. However, because of the spectral insensitivity of most engineering materials in the far infrared, the total emissivity is expected to behave in a like manner.

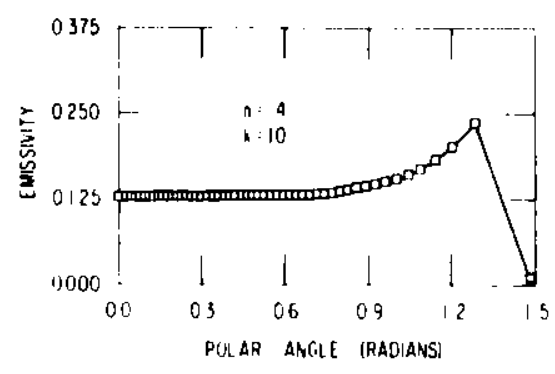

Fig. 12. Directional Emissivity Curve for Metal Surface

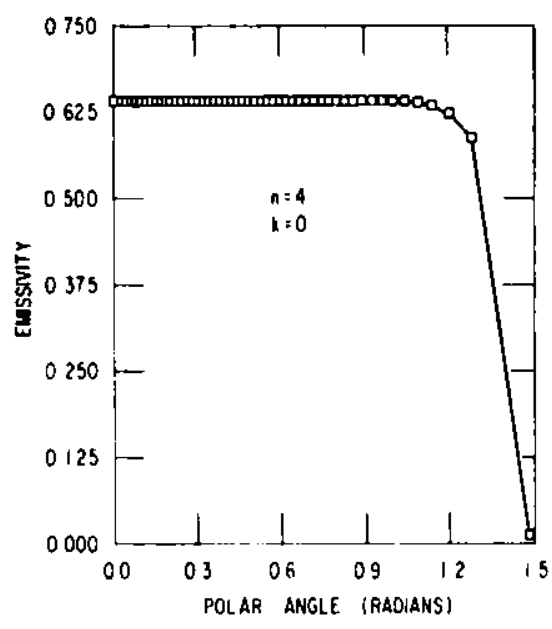

Fig. 13. Directional Emissivity Curve for Nonmetal Surface.

ANL Neg. No. 306-80-150.

The emissivity curves given can be regarded as total emissivities and their values replotted against view angles, as shown in Figs. 14 and 15 . These curves can now be used to study the distortion of infrared images due to emissivity effects. Let the transfer line have a cavity at $\theta=0$ (refer to Fig. 8). Because of the emissivity variation, the anticipated hot spot at the center of the infrared image will not appear as hot as expected if the transfer line has a metallic surface. On the other hand, if the transfer line has a nonmetallic surface, the hot spot tends to cool off rapidly toward the edges.

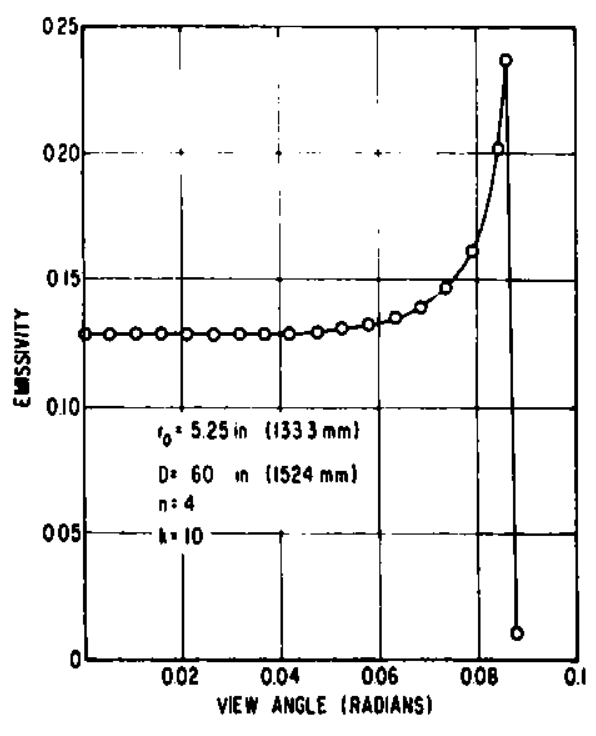

Fig. 14. Emissivity Correction Curve for Data in Figs. 9 and 12. ANL Neg. No. 306-80-149.

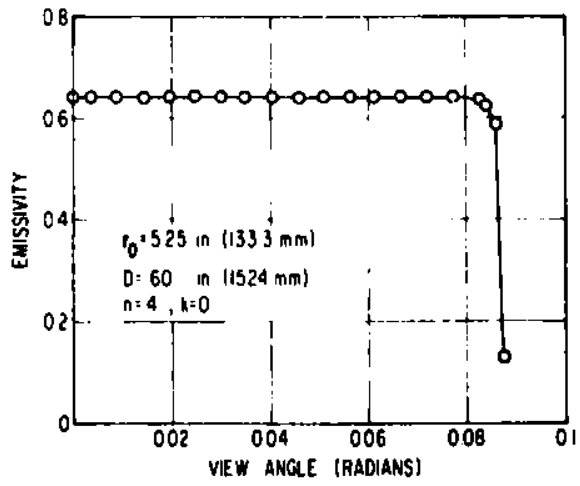

Fig. 15. Emissivity Correction Curve for Data in Figs. 9 and 13. ANL Neg. No. 306-80-155. 
In conclusion, it is important to note that the analysis given above has concentrated on the surface emissivity effects. For a nonblack surface, the reflectivity also plays a role in the total energy detected. Unfortunately, to include the reflected energy in the analysis is difficult, because the reflected energy is also dependent on the radiosity coming from the surroundings. Because of the infinite variations that can occur in the surroundings, a general analysis cannot be made without going into radiative transfer theory in great depth. For this reason, the reflection studies have been omitted; the interested reader is referred to Refs. 20-23. Here, it suffices to say that the reflection problem can be alleviated by using cooled radiation shields. A method of correcting this reflection effect is proposed in Ref. 24. 


\section{TEST OF COMPUTER PROGRAMS USING LIMITING CASES}

The computer programs developed in the present work invoke an iterative solution. (Because of the large number of nodal equations to be solved in this work, the iterative solution appears to be more economical. However, the method is not without drawbacks, as discussed in Ref. 12.) Instead of solving the nodal equations simultaneously using orthodox techniques such as Gaussian elimination or matrix inversions, the program initializes the temperature at each nodal point. An improved temperature is then calculated and repeatedly corrected until the difference between successive computations converges to a prescribed limit. According to this method, the convergence of the solution and the accuracy of temperatures depend heavily on the mesh size chosen as well as the convergence level selected in the computation. For this reason, the computer program must be pretested to determine these parameters.

The method used :or tests consists of comparing the numerical results with analytical solution . Since the total system cannot be solved exactly because of its configutdion and boundary conditions, some limiting cases are used for comna:ison. For the system under investigation, the surface temperature at the center of the cavity should approach that of a cylindrical shell of the same thickness and inner radius if the cavity has a large cross section. Similarly, the temperature farthest away from the cavity should approach that of the same shell if the cavity width is small. In both cases, the temperature on the cylindrical shell can be predicted analytically using (see Appendix D for derivation)

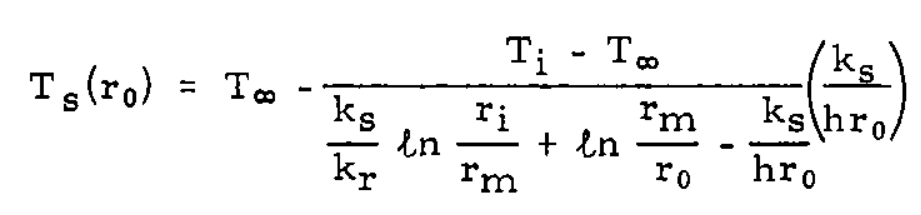

where $T_{\infty}$ is the ambient temperature and $h$ is the convective coefficient at the steel surface; other notations are defined in Fig. 2.

The parameters were tested using the following as inputs:

$$
\begin{aligned}
\mathrm{T}_{\mathrm{i}} & =815^{\circ} \mathrm{C}\left(1500^{\circ} \mathrm{F}\right), \\
\mathrm{T}_{\infty} & =26.6{ }^{\circ} \mathrm{C}\left(80^{\circ} \mathrm{F}\right), \\
\mathrm{k}_{\mathrm{s}} & =4.67 \times 10^{-2} \mathrm{~W} / \mathrm{mm} \cdot{ }^{\circ} \mathrm{C}\left(324 \mathrm{Btu} / \mathrm{h} \cdot \mathrm{ft}^{2} \cdot{ }^{\circ} \mathrm{F} / \mathrm{in} .\right), \\
\mathrm{k}_{\mathrm{r}} & =6.63 \times 10^{-4} \mathrm{~W} / \mathrm{mm} \cdot{ }^{\circ} \mathrm{C}\left(4.6 \mathrm{Btu} / \mathrm{h} \cdot \mathrm{ft}^{2} \cdot{ }^{\circ} \mathrm{F} / \mathrm{in} .\right) \\
\mathrm{r}_{\mathrm{i}} & =50.8 \mathrm{~mm}(2 \mathrm{in} .) \text { and } 63.5 \mathrm{~mm}(2.5 \mathrm{in} .), \\
r_{m} & =127 \mathrm{~mm}(5 \text { in. }),
\end{aligned}
$$




$$
r_{0}=133.3 \mathrm{~mm}(5.25 \text { in. })
$$

and

$$
\begin{aligned}
\mathrm{h}= & 5.68 \times 10^{-5} \mathrm{~W} / \mathrm{mm}^{2} \cdot{ }^{\circ} \mathrm{C}\left(10 \mathrm{Btu} / \mathrm{h} \cdot \mathrm{ft}^{2} \cdot{ }^{\circ} \mathrm{F}\right) \text { and } \\
& 1.13 \times 10^{-4} \mathrm{~W} / \mathrm{mm}^{2} \cdot{ }^{\circ} \mathrm{C}\left(20 \mathrm{Btu} / \mathrm{h} \cdot \mathrm{ft}^{2} \cdot{ }^{\circ} \mathrm{F}\right) .
\end{aligned}
$$

In the computer program, the mesh size was chosen as follows:

$$
\Delta \mathbf{r}=6.35 \mathrm{~mm}(0.25 \text { in.) }
$$

and

$$
\Delta \theta=15^{\circ}
$$

Both the computer program and the analytical equation (Eq. 41) were used to test a cavity size of

$$
\text { depth }=127 \mathrm{~mm}(0.5 \mathrm{in.})
$$

and

$$
\text { angular } \operatorname{span}=120^{\circ} \text {. }
$$

The results, listed in Table II, lead to the following conclusions:

First, the number of iterations needed for solution increases markedly when the cnnvergence criterion (EPS) is reduced. The increase in CPU time is indicative of this inclease. Second, the number of iterations decreases as the value of the convective coefficient increases. A reduction of about $35 \%$ of the CPU time is seen for all EPS values tested. Physically, a large increase in the convective coefficient tends to change a convective boundary to that of a prescribed surface temperature, which is often favorable from the iteration point of view. Third, the agrement between the numerical data and the ana-

\begin{tabular}{|c|c|c|c|c|c|c|c|c|c|c|c|c|}
\hline \multirow{2}{*}{\multicolumn{2}{|c|}{$\begin{array}{c}\text { Convetive } \\
\text { CoeflicienI, } \\
\end{array}$}} & \multirow{2}{*}{\multicolumn{2}{|c|}{$\begin{array}{c}\text { Convergence } \\
\text { Criterion it PSI }\end{array}$}} & \multicolumn{4}{|c|}{ Numerical Dala } & \multicolumn{4}{|c|}{ Analylical Data } & \multirow{3}{*}{$\begin{array}{l}\text { CPU } \\
\text { Iime. }\end{array}$} \\
\hline & & & & \multicolumn{2}{|c|}{ INEWINII. II } & \multicolumn{2}{|c|}{ INTWINII, NII } & \multicolumn{2}{|c|}{$\mathrm{r}_{\mathrm{i}} \quad 2.5 \mathrm{in} .163 .5 \mathrm{mmr}$} & \multicolumn{2}{|c|}{$\mathrm{ci}_{1} 2 \mathrm{in} .150 .8 \mathrm{mml}$} & \\
\hline Btu/h.112.0F & $w / \mathrm{mm}^{2.0 \mathrm{C}}$ & of & ${ }^{\circ} \mathrm{C}$ & 听 & ${ }^{\circ} \mathrm{C}$ & of & ${ }^{\circ} \mathrm{C}$ & of & ${ }^{\circ} \mathrm{C}$ & of & ${ }^{\circ} \mathrm{C}$ & \\
\hline \multirow[t]{3}{*}{10} & $5.68 \times 10^{-5}$ & 0.1 & 0.2 & 251.24 & 124.13 & 230.63 & 110,35 & 239.21 & $\lfloor 15.1\rfloor$ & 203.85 & 95.47 & 51 \\
\hline & & 0.05 & 0.1 & 245,97 & 118.87 & 218.18 & 103.43 & & & & & 60 \\
\hline & & 0.01 & 0.02 & 237.08 & 113,93 & 208.24 & 97.91 & & & & & $\mathbf{M}$ \\
\hline \multirow[t]{3}{*}{20} & $1.13 \times 10^{-4}$ & 0.1 & 0.2 & 174.75 & 79.30 & 158,22 & 10.12 & 164.33 & 73.51 & 144.75 & $\underline{02,63}$ & 33 \\
\hline & & 0.05 & 0.1 & 168.81 & 76.00 & 151.72 & 66.51 & & & & & 39 \\
\hline & & 0.01 & 0.02 & 14.14 & $73.4 !$ & 146.52 & 63.62 & & & & & 53 \\
\hline
\end{tabular}
lytical data is satisfactory. This can be seen from the case in which $h=1.13 \mathbf{x}$ $10^{-4} \mathrm{~W} / \mathrm{mm}^{2} \cdot{ }^{\circ} \mathrm{C}\left(20 \mathrm{Btu} / \mathrm{h} \cdot \mathrm{ft}^{2} \cdot{ }^{\circ} \mathrm{F}\right)$. The iterative surface temperature at the center of the cavity using EPS $=0.00556^{\circ} \mathrm{C}\left(0.01^{\circ} \mathrm{F}\right)$ is $73.41^{\circ} \mathrm{C}$, while that of the analytical solution [for $r_{i}=63.5 \mathrm{~mm}(2.5 \mathrm{in}$.$) ] is 73.51^{\circ} \mathrm{C}$. The corresponding iterative value farthest away from the cavity is $63.62^{\circ} \mathrm{C}$, while the analytical value there [for $r_{i}=50.8 \mathrm{~mm}$ ( 2 in.) ] is $62.63^{\circ} \mathrm{C}$. 
From the above analysis, the selected mesh size appears to be satisfactory for EPS $=0.005566^{\circ} \mathrm{C}\left(0.01^{\circ} \mathrm{F}\right)$. Because of the given boundary conditions, the accuracy of the temperature cannot be further improved for the iterative solution if the mesh size is unconditionally reduced. ${ }^{12}$ In fact, a repeated calculation using $\mathrm{h}=1.13 \times 10^{-4} \mathrm{~W} / \mathrm{mm}^{2} \cdot{ }^{\circ} \mathrm{C}\left(20 \mathrm{Btu} / \mathrm{h} \cdot \mathrm{ft}^{2} \cdot{ }^{\circ} \mathrm{F}\right)$, with $\Delta \mathbf{r}=3.17 \mathrm{~mm}(0.125 \mathrm{in}$.$) and \Delta \theta=5^{\circ}$, results in $\mathrm{TNEW}(\mathrm{NII}, 1)=75.33^{\circ} \mathrm{C}$ $\left(167.61^{\circ} \mathrm{F}\right)$, i.e., about $2^{\circ} \mathrm{C}$ higher, while TNEW(NII, NJ) is $65.86^{\circ} \mathrm{C}\left(150.55^{\circ} \mathrm{F}\right)$ or over $3^{\circ} \mathrm{C}$ higher than required. Also, the cost of running the program is increased by about $20 \%$. Hence, the selection of a very small mesh size is certainly unnecessary.

A reduction of the convergence to EPS $=0.001$, while improving the temperature prediction at all nodal points, makes the cost of running the program prohibitively high. In view of the large amount of data to be computed, a further refinement beyond what is presently used [EPS $=0.01, \Delta \mathbf{r}=6.35 \mathrm{~mm}$ (0.25 in.) and $\Delta \theta=15^{\circ}$ ] would be too costly. For this reason, these parameters are used to compute all the data given in the present work. 


\section{RESULTS AND DISCUSSION}

\section{A. Prediction of Surface Temperatures for a Two-dimensional Model}

Thirty-six cases were tested for the two-dimensional model, using the computer program given in Appendix $A$. The input data to the program are summarized in Table III. This sample run included the following additional inputs:

$$
\begin{aligned}
& \mathrm{h}=5.68 \times 10^{-5} \mathrm{~W} / \mathrm{mm}^{2} \cdot{ }^{\circ} \mathrm{C}\left(10 \mathrm{Btu} / \mathrm{h} \cdot \mathrm{ft}^{2} \cdot{ }^{\circ} \mathrm{F}\right), \\
& \text { cavity depth }=12.7 \mathrm{~mm}(0.5 \mathrm{in} .),
\end{aligned}
$$

and

cavity angular span (width) $=120^{\circ}$.

TABLE III. Test Conditions for Studies of Two-dimensional Model

System Dimensions

$\mathrm{ID}=101.6 \mathrm{~mm}$ (4 in.)

$O D=266.7 \mathrm{~mm}(10.5 \mathrm{in}$.

Refractory thickness $=76.2 \mathrm{~mm}$ (3 in.)

Parameters Related to Boundary Conditions

$\mathrm{T}_{\mathrm{i}}=815^{\circ} \mathrm{C}\left(1500^{\circ} \mathrm{F}\right)$

$1_{\infty}=26.6^{\circ} \mathrm{C}\left(80^{\circ} \mathrm{F}\right)$

h $\quad 5.68 \times 10^{-5} \mathrm{~W} / \mathrm{mm}^{2} \cdot{ }^{\circ} \mathrm{C}\left(10 \mathrm{Btu} / \mathrm{h} \cdot \mathrm{ft}^{2} \cdot{ }^{\circ} \mathrm{F}\right)$

$$
1.13 \times 10^{-4} \mathrm{~W} / \mathrm{mm}^{2} \cdot{ }^{\circ} \mathrm{C}\left(20 \mathrm{Btu} / \mathrm{h} \cdot \mathrm{ft}^{2} \cdot{ }^{\circ} \mathrm{F}\right)
$$

Parameters Related to Material Properties

$$
\begin{aligned}
& \mathrm{k}_{1}=6.63 \times 10^{-4} \mathrm{~W} / \mathrm{mm} \cdot{ }^{\circ} \mathrm{C}\left(4.6 \mathrm{Btu} / \mathrm{h} \cdot \mathrm{ft}^{2} \cdot{ }^{\circ} \mathrm{F} / \mathrm{in} .\right) \\
& \mathrm{k}_{2}=4.67 \times 10^{-2} \mathrm{~W} / \mathrm{mm} \cdot{ }^{\circ} \mathrm{C}\left(324 \mathrm{Btu} / \mathrm{h} \cdot \mathrm{ft}^{2} \cdot{ }^{\circ} \mathrm{F} / \mathrm{in} .\right)
\end{aligned}
$$

Cavity Sizes Tested

Depth $=1.27 \mathrm{~mm}$ (0.5 in.). $19.0 \mathrm{~mm}$ (0.75 in.) $25.4 \mathrm{~mm}$ (1.0 in.), $31.7 \mathrm{~mm}$ (1.25 in.) $38.1 \mathrm{~mm}$ (1.5 in.), $44.4 \mathrm{~mm}$ (1.75 in.)

$$
\begin{aligned}
\text { Angular span }= & 120^{\circ} \\
& 180^{\circ} \\
& 240^{\circ}
\end{aligned}
$$

Mesh Size Used

$$
\begin{aligned}
& \dot{\Delta r}=6.3 \mathrm{~mm}(0.25 \mathrm{in.}) \\
& \Delta \theta=15^{\circ}
\end{aligned}
$$

Convergence $\mathrm{C}$ riterion Used $E P S=0.00556^{\circ} \mathrm{C}\left(0.01^{\circ} \mathrm{F}\right)$ 
The data output, a sample of which appears in Table IV, follows the computer instruction

TNEW(NII, J), J = I, NJ.

As expected, the hot-spot temperature, which is reported as the first data entry in the output array, appears at the center of the surface.

TABIEIV. Computer Data for a Sample Two-rlimensional System

\begin{tabular}{|c|c|c|c|c|}
\hline $0.257243536,51)+03$ & $0.256 .739002 .11+03$ & $0 . ?=53447877 \mathrm{D}+03$ & $0.252856 .37971) \cdot 03$ & 0.249074135010103 \\
\hline $0.244402721010 \cdot 03$ & $(1.23197875831)+03$ & $0.236 .46 .33550 \mathrm{D}+0$, & $0.2339727080 \mathrm{D}+03$ & $0.232329466,3 \mathrm{D}+03$ \\
\hline $0.23132574870+03$ & $0.23(17 \times 344+51)+03$ & $0.2301626,7455 D+03$ & & \\
\hline
\end{tabular}

An attempt was made to correlaie the computer data in terms of dimensionless parameters as

$$
\theta=\frac{T-T_{\infty}}{T_{i}-T_{\infty}}, n=\frac{d}{D}, \quad \zeta=\frac{\theta}{180},
$$

where d denotes the depth of the cavity and $D$ the outside diameter of the transfer line. For the cases tested, six equations were correlated. The first three are valid for $\mathrm{h}=5.68 \times 10^{-5} \mathrm{~W} / \mathrm{mm}^{2} \cdot{ }^{\circ} \mathrm{C}\left(10 \mathrm{Btu} / \mathrm{h} \cdot \mathrm{ft}^{2} \cdot{ }^{\circ} \mathrm{F}\right)$ :

1. For cavity angular span of $120^{\circ}$,

$$
\begin{aligned}
\theta(\eta, \zeta) & =\left(0.102+1.101 \eta^{2}\right)+\left(-0.001-0.028 \eta+0.265 \eta^{2}\right) \zeta-(0.054 \\
& \left.-0.222 \eta+5.237 \eta^{2}\right) \sigma^{2}+\left(0.043-0.193 \eta+3.966 \eta^{2}\right) \zeta^{3} .
\end{aligned}
$$

2. For cavity angular span of $180^{\circ}$,

$$
\begin{aligned}
\theta(\eta, \zeta)= & \left(0.101+0.02 \eta+1.039 \eta^{2}\right)+\left(0.02-0.163 \eta+1.794 \eta^{2}\right) \zeta-(0.086 \\
& \left.-0.437 \eta+6.906 \eta^{2}\right) \zeta^{2}+\left(0.054-0.278 \eta+4.156 \eta^{2}\right) \zeta^{3} .
\end{aligned}
$$

3. For cavity angular span of $240^{\circ}$,

$$
\begin{aligned}
\theta(\eta, \zeta)= & \left(0.101+0.025 \eta+1.056 \eta^{2}\right)+\left(0.013-0.058 \eta+0.959 \eta^{2}\right) \zeta-(0.04 \\
& \left.-0.042 \eta+2.558 \eta^{2}\right) \zeta^{2}+\left(0.015+0.045 \eta+0.686 \eta^{2}\right) \zeta^{3}
\end{aligned}
$$

The second three are valid when the value of the convective coefficient is doubled: 
4. For cavity angular span of $120^{\circ}$,

$$
\begin{aligned}
\theta(\eta, \zeta)= & \left(0.056-0.027 \eta_{1}+0.751 \eta^{2}\right)+\left(-0.001-0.018 \eta+0.222 \eta^{2}\right) \zeta \\
& -\left(0.043-0.274 \eta+3.974 \eta^{2}\right) \zeta^{2}+\left(0.035-0.233 \eta+3.059 \eta^{2}\right) \zeta^{3} .
\end{aligned}
$$

5. For cavity angular span of $180^{\circ}$,

$$
\begin{aligned}
\theta(\eta, \zeta) & =\left(0.055-0.016 \eta+0.686 \eta^{2}\right)+\left(0.018-0.16 \eta+1.494 \eta^{2}\right) \zeta \\
& -\left(0.072-0.51 \eta+5.492 \eta^{2}\right) \zeta^{2}+\left(0.045-0.328 \eta+3.327 \eta^{2}\right) \zeta^{3} .
\end{aligned}
$$

6. For cavity angular span of $240^{\circ}$,

$$
\begin{aligned}
\theta(\Pi, \zeta)= & \left(0.055-0.018 \eta+0.705 \eta^{2}\right)+\left(0.011-0.068 \eta+0.753 \eta^{2}\right) \zeta \\
& -\left(0.032-0.123 \eta+1.859 \eta^{2}\right) \zeta^{2}+\left(0.011-0.006 \eta+0.405 \eta^{2}\right) \zeta^{3} .
\end{aligned}
$$

The correlated equations given above were also checked to see how well they fit the data. Equation 46 was chosen and plotted for a wide range of cavity depths, d, as shown in Fig. 16. The equation appears to correlate fairly well with the computed data for shallow cavities, but to disagree markedly at large angles; for example, a deviation of over $7^{\circ}$ is found for the deepest cavity, $d=44.4 \mathrm{~mm}$ ( $1.75 \mathrm{in}$.), at an angle of about $150^{\circ}$.

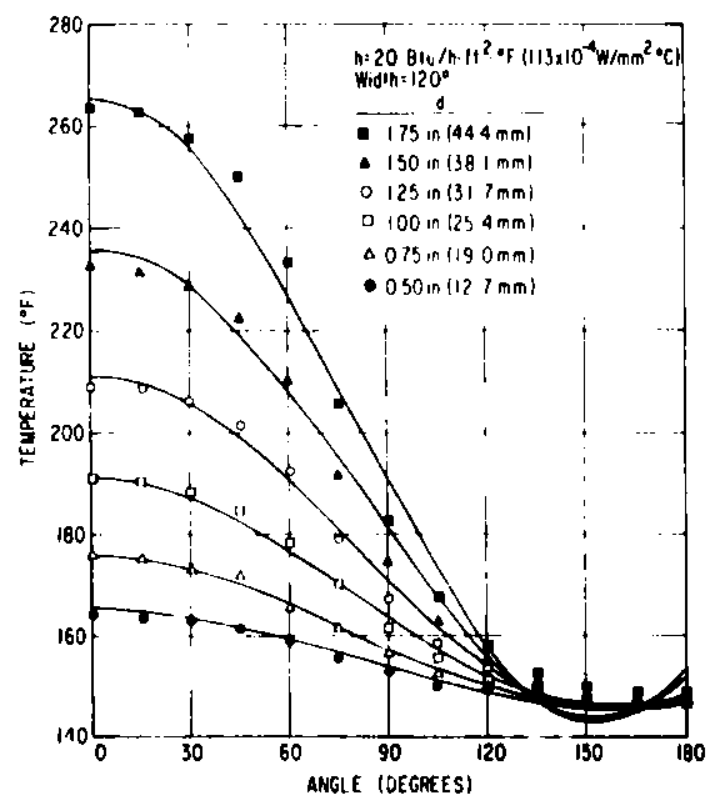

Fig. 16

Comparison between Correlated Eq. 46 and Test Data. ANL Neg. No. $306-80-145$.

A further attempt to incorporate the cavity width (angular span) in the correlation did not mect with success. From the experience of exact solutions, one might be tempted to expand $T(r, \theta)$ in a Fourier series. Indeed, a more successful correlation would probably have to use a Fourier series, as is suggested by the trend of the calculated data shown in Fig. 16. Two recent analytical studies ${ }^{25,26}$ also support this proposition. 
B. Prediction of Surface Temperatures for a Two-dimensional Model Fitted with a Telltale Rib

The two-dimensional model studied in the preceding section was modified by adding a "telltale rib" penetrating into the refractory lining as shown in Fig. 17. Appendix E provides a computer program for this system. The surface temperature for a two-dimensional system fitted with a telltale $r$ ib was calculated for a test case, as shown in Table $V$. The legend at the top of Table $V$ summarizes the test conditions used in the computation. The four groups of data correspond to four positions of the rib, indexed as NQJ in the output. To permit testing of a wide range of rib locations, the angular mesh size was reduced to $5^{\circ}$. The actual rib location can be found by using the equation

Rib Position $=($ NQJ -1$) \times 5$.

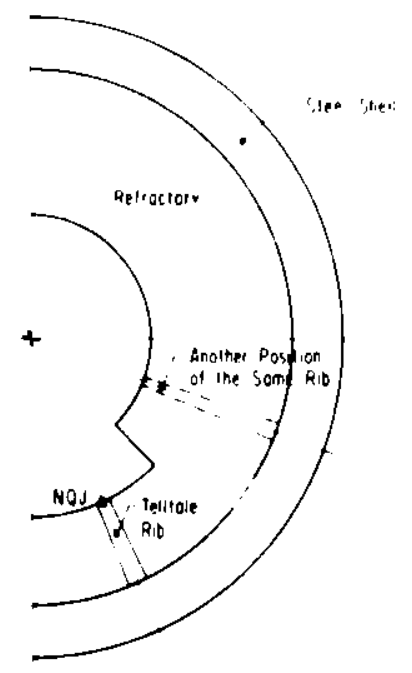

Fin. 17

A Two-dimensional system Modified by installation

of a Telltale Rib. ANL Neg. No. 306-80-147.

TABIE V. Curliputer Dala lor a Iwo-dunensional System filted wilh d lelltale Rib

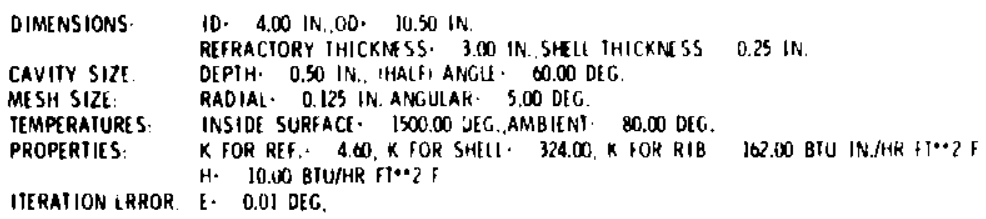

IIERAIION LRROR. E. O.OJ DEG.

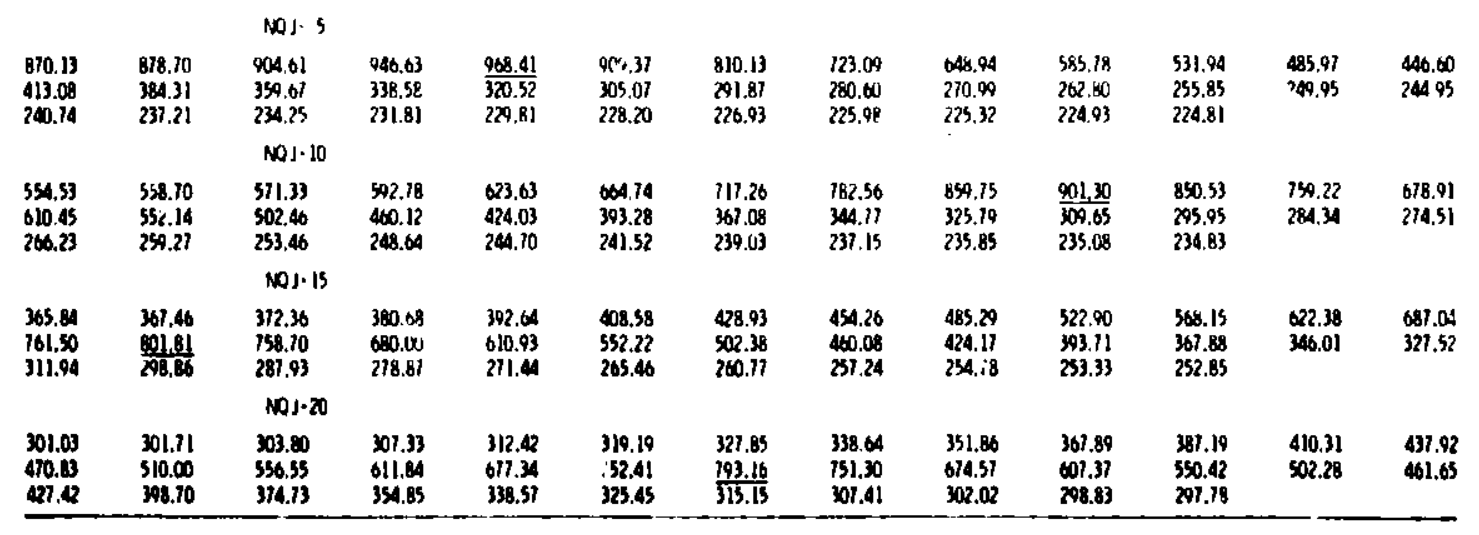


The first two sets of data in Table V (NQJ $=5,10)$ refer to ribs located inside the eroded region; the other sets (NQJ $=15,20$ ) refer to ribs located outside this region. Surface temperatures at the rib are underlined in the output to facilitate inspection.

Several conclusions can be drawn by examining Table $V$. In all cases, the hot-spot temperature is located where the rib is installed; this is not unexpected because of the high conductivity of the rib material. If the $\mathrm{rib}$ is inside the eroded region, this hot-spot temperature is a strong function of of rib location: Thus, a change in the angular position of the rib from $20^{\circ}$ (NQJ $=5)$ to $45^{\circ}(\mathrm{NQJ}=10)$ decreases the hot-spot temperature by about $37^{\circ} \mathrm{C}\left(67^{\circ} \mathrm{F}\right)$. However, such a trend is not found if the rib is located outside the eroded region. When the rib position is moved from $70^{\circ}$ (NQJ $\left.=15\right)$ to $95^{\circ}$ (NQJ $\left.=20\right)$, the hot-spot temperature drops only $4^{\circ} \mathrm{C}\left(8^{\circ} \mathrm{F}\right)$. Also, the hot spot is much cooler outside the eroded region. (Compare hot-spot temperatures for NQJ $=15$ and $N Q J=10$. ) From this preliminary study it appears that the telltale $\mathrm{rib}$ indeed has a high potential to predict the cavity position and location. A more detailed analysis is in order for further substantiation.

C. Prediction of Surface Temperatures for a Three-dimensional Model

Surface temperatures for a three-dimensional model have been calculated using the computer program given in Appendix B. A total of 108 cases were tested, encompassing 54 cavity sizes, with each size tested for two values of convective coefficient. These test conditions are summarized in Table VI. For illustrative purposes, only one set of data output is used; it is shown in Tables VII and VIII and Figs. 18-22.

TABLE VI. Test Conditions

for Studies of Three-

dimensional Modela

\begin{tabular}{|c|c|}
\hline \multicolumn{2}{|l|}{ System Dimensions } \\
\hline \multicolumn{2}{|c|}{ Height $=508 \mathrm{~mm}(20$ in. $)$} \\
\hline \multicolumn{2}{|c|}{ Cavity Sizes Tested } \\
\hline Cavity height & $=50.8 \mathrm{rnm}$ ( 2 in.) \\
\hline & $101.6 \mathrm{~mm}(4 \mathrm{in.})$ \\
\hline & $1 \mathrm{~b} 2.4 \mathrm{~mm}(\dot{\mathrm{c}}$ in.) \\
\hline
\end{tabular}

aConditions given in this table are in addition to those in Table III. 
TABLE. VII. Sample Output of Surface-temperature Distribution for Study of a Three-dimensional Modela

\begin{tabular}{|c|c|c|c|c|}
\hline DIMENSION: & \multicolumn{4}{|c|}{$\begin{array}{l}\text { ID }=4.00 \mathrm{IN} ., \mathrm{OD}=10.50 \mathrm{IN} .,(\mathrm{TOTAL}) \mathrm{HEIGHT}=20.00 \mathrm{IN} . \\
\text { REFRACTORY THICKNESS }=3.00 \mathrm{IN} . \text { SHELL THICKNESS }=0.25 \mathrm{IN} .\end{array}$} \\
\hline CAVITY SIZE: & \multicolumn{4}{|c|}{$\begin{array}{l}\text { DEPTH }=1.75 \mathrm{IN} . \text { (HALF) ANGLE }=60.00 \mathrm{DEG} \\
\text { (HALF) HEIGHT }=4.00 \mathrm{IN} .\end{array}$} \\
\hline $\begin{array}{l}\text { MESH SIZE: } \\
\text { TFMPERATURES: }\end{array}$ & \multicolumn{4}{|c|}{$\begin{array}{l}\text { KADIA ! }=4 . \angle 50 \text { IN.,ANGULAR }=15.00 \text { DEG.,AXIAL }=2.00 \mathrm{IN} . \\
\text { INSIDE SURFACE }=1500.00 \text { DEG.AMBIENT }=80.00 \mathrm{DEG} .\end{array}$} \\
\hline PROPERTIES: & \multicolumn{3}{|c|}{$\mathrm{H}=10.00 \mathrm{BTU} / \mathrm{HR} \mathrm{FT}^{* *} 2 \mathrm{~F}$} & $\mathrm{FT}^{* * 2 \mathrm{~F}}$ \\
\hline ITERATION ERR' & $E=0.10 \mathrm{DEG}$ & & & \\
\hline $0.3899547520 D+03$ & $0.38818713550+03$ & $0.3822654137 \mathrm{D}+03$ & $0.3701768897 \mathrm{D}+03$ & 0.34832 \\
\hline $0.3141240687 \mathrm{D}+03$ & $0.2848730100 D+03$ & $0.2643068513 \mathrm{D}+03$ & $0.2510403843 D+03$ & \\
\hline $0.2382365105 D+03$ & $0.2358361864 D+03$ & $0.2351013763 \mathrm{D}+03$ & & \\
\hline $0.3830147199 D+03$ & $0.3813386428 D+03$ & $0.3757178647 D+C 3$ & $0.3642019465 \mathrm{D}+03$ & $6 D+03$ \\
\hline $0.31020672290+03$ & $0.2821306552 D+03$ & $0.26252721200+03$ & $0.2499457392 D+03$ & $0.2422716051 D+03$ \\
\hline $0.2378422950 \mathrm{D}+03$ & $0.23557507100+03$ & $0.2348813648 \mathrm{D}+03$ & & \\
\hline $0.3573585806 \mathrm{D}+03$ & $0.3559657728 D+03$ & $0.3513070999 \mathrm{D}+03$ & $0.3417781416 D+03$ & $0.3243208024 \mathrm{D}+03$ \\
\hline $0.2963343464 D+03$ & $0.27 ? 6,110878 D+03$ & $0.2569373658 \mathrm{D}+0 ?$ & $0.2466614960 D+03$ & $0.24037951970+03$ \\
\hline $0.2367334533 \mathrm{D}+03$ & $0.2348571229 \mathrm{D}+03$ & $0.2342805940 \mathrm{D}+03$ & & \\
\hline $0.30051+7367 \mathrm{D}+03$ & $0.2995436071 D+03$ & $0.2964080132 \mathrm{D}+03$ & $02905209480 D+03$ & 0.28 \\
\hline $0.2686376391 D+03$ & $0.2570412304 \mathrm{D}+03$ & $0.2480911486 \mathrm{D}+03$ & $0.2418320329 D+03$ & $0.2377382648 \mathrm{D}+03$ \\
\hline $0.2352438086 \mathrm{D}+03$ & $0.2339173148 D+03$ & $0.2335033907 \mathrm{D}+03$ & & \\
\hline $0.2686575763 \mathrm{D}+03$ & $0.2680358136 \mathrm{D}+03$ & $0.2661168184 \mathrm{D}+03$ & $0.4278367810+03$ & 0.258 \\
\hline $0.2522710062 \mathrm{D}+03$ & $0.2466360086 D+03$ & $0.2418826581 D+03$ & $0.2382610833 D+03$ & $0.2357159216 \mathrm{D}+03$ \\
\hline $0.2340754086 \mathrm{D}+03$ & $0.2331693676 \mathrm{D}+03$ & $0.2328806388 D+03$ & & \\
\hline $0.2592284691 \mathrm{D}+03$ & $0.2587335427 D+03$ & $0.2572355214 D+03$ & $0.254724604] D+03$ & $0.2512992417 D+03$ \\
\hline $0.2472948110 D+03$ & $0.24330148751) \cdot 03$ & $0.2397979473 \mathrm{~L}+03$ & $0.2370173478 \mathrm{D}+03$ & $0.2349907110 D+03$ \\
\hline $0.233647851110+03$ & $0.2328910018 D+73$ & $0.2326478393 \mathrm{D}+03$ & & \\
\hline
\end{tabular}

${ }^{\text {a }}$ Temperatures in $\mathrm{F}$. Conversion factor: $\mathrm{C}=\left({ }^{\circ} \mathrm{F}-32\right): 1.8$.

TAB1.E VIII. Features Defined by Data in Table ViI

\begin{tabular}{|c|c|c|}
\hline \multicolumn{2}{|c|}{ TOTAI. VOI.UME UNDERNEATH THE SURFACE } & \multirow{3}{*}{$\begin{array}{c}0.74356 \mathrm{~F} .05 \\
\text { INTECIRATED } \\
\text { VOLUME }\end{array}$} \\
\hline ISOTHERM & AREA INSIDE & \\
\hline & 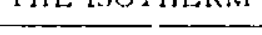 & \\
\hline 232.6 & $0.2750 \mathrm{E}+03$ & $0.1038 \mathrm{~F}+05$ \\
\hline 240.5 & $0.1810 \mathrm{E}+03$ & $0.8685 \mathrm{E}+04$ \\
\hline 248.4 & $0.1470 E+03$ & $0.7388 F+0.4$ \\
\hline 256.2 & $0.1290 \mathrm{E}+03$ & $0.6310 E+04$ \\
\hline 264,1 & $0.4900 E+02$ & $0.5447 \mathrm{E}+04$ \\
\hline 272.0 & $0.8300 \mathrm{E}+02$ & $0.4743 \mathrm{E}+04$ \\
\hline 279.8 & $0.7900 E+02$ & $0.4117 \mathrm{E}+04$ \\
\hline 287 & $0.6900 \mathrm{E}+02$ & $0.3550 \mathrm{~F}+0.4$ \\
\hline 295.6 & $0.6500 \mathrm{E}+02$ & $0.3027 \mathrm{E}+04$ \\
\hline 303.4 & $0.5100 \mathrm{E}+02$ & $0.2594 E+04$ \\
\hline 311.3 & $0.4700 \mathrm{E}+02$ & $0.2197 \mathrm{E}+04$ \\
\hline 319.2 & $0.4500 \mathrm{~F}+02$ & $0.1838 \mathrm{E}+04$ \\
\hline 3270 & $0.4100 \mathrm{E}+02$ & $0.1495 E+04$ \\
\hline 334.9 & $0.4100 E+02$ & $0.1172 \mathrm{E}+04$ \\
\hline 342.8 & $0.3700 E+02$ & $0.8535 E+03$ \\
\hline 350.6 & $0.3100 \mathrm{E}+02$ & $0.5966 E+03$ \\
\hline 358.5 & $0.2100 E+02$ & $0.3939 E+03$ \\
\hline 366.4 & $0.1700 \mathrm{E}+02$ & $0.2374 ;+03$ \\
\hline 374.2 & $0.1500 \mathrm{E}+02$ & $0.11] 6, E+03$ \\
\hline 382.1 & $0.7000 E+01$ & $0.2226 \mathrm{E}+02$ \\
\hline
\end{tabular}

- Temperatures are in ${ }^{\circ} \mathrm{F}$. Conversion factor: ${ }^{\circ} \mathrm{C}=\left({ }^{\circ} \mathrm{F}-32\right) / 1.8$. 


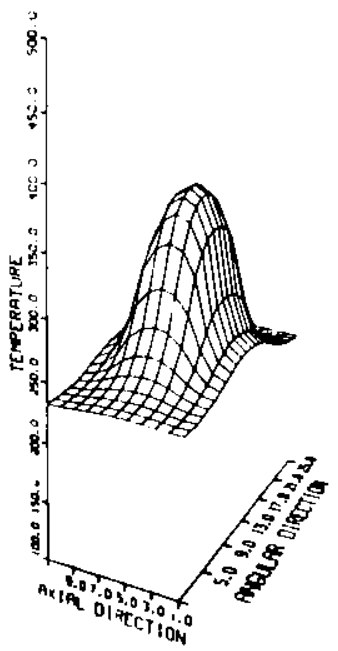

Fig. 18

A Three-dimensional Surfacetemperature Plot Using Data in Table VIl. Temperatures in ${ }^{\circ} \mathrm{F}$. Conversion factor. ${ }^{\circ} \mathrm{C}=\left({ }^{\circ} \mathrm{F}-32\right) / 1.8$. ANL Neg. No. 306-80-130.

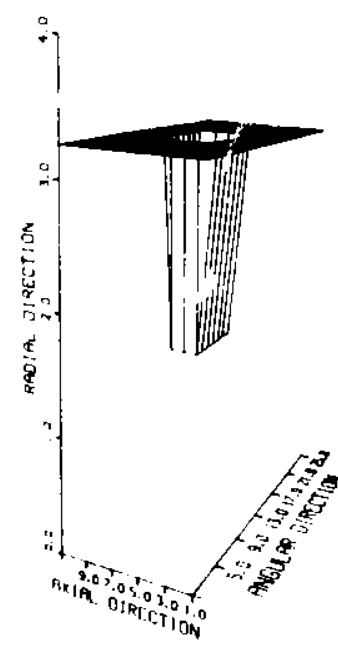

Fig. $: 9$

A Three-dimensional Plot of the Cavity Configuration Reconstructed from the Temperature Data in Fig. 18. ANL Neg. No. 306-80-134.

SURFACE ISOTHERM COHIOUNS:

LEGEND:

SYMBOL ISOTHERM PAFID HIOTII IOEG.FI

\begin{tabular}{|c|c|}
\hline $\begin{array}{l}A \\
B \\
C \\
D \\
E \\
F \\
G \\
H \\
I \\
J \\
K\end{array}$ & $\begin{array}{ll}200.0 & 10 \\
219.0 & 10 \\
233.1 & 10 \\
257.1 & 10 \\
276.2 & 10 \\
235.2 & 10 \\
314.3 & 10 \\
333.3 & 10 \\
352.4 & 10 \\
371.4 & 10 \\
390.5 & 10\end{array}$ \\
\hline
\end{tabular}

NOTE: ALTHOUGH ELEVEN SYHIOLS ARE USEO TO REFPESENT ISOTHEPM BAHOS IH THE LEGEHD, THE TEMPEPATUFE RAIGES FOR THESE SYHBOLLS HAVE EEEN SELECTED SUCH THAT THENTY ONE EANDS CAH BE PEAD OFF FROH THE ISOTHERM MAP. NOTE THAT THE TELIPERATUPE RAHGES IH THE LEGEHID A.RE DISCOHITINOUS, SIGHIFYIHG THAT A HiHITE BAHD EXISIS III BETHEEH THE NEIGHEORING LETTEPED BAHISS; THE TEHPERATURE RAIGE FOR THE HHITE BAHIO IS BRIDGEO IN BETHEEN THOSE OF THE NEIGHBORING BASIDS.

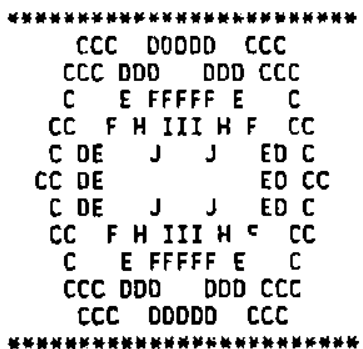

Fig. 20. A Surface Isotherm Map for Data in Table VII 


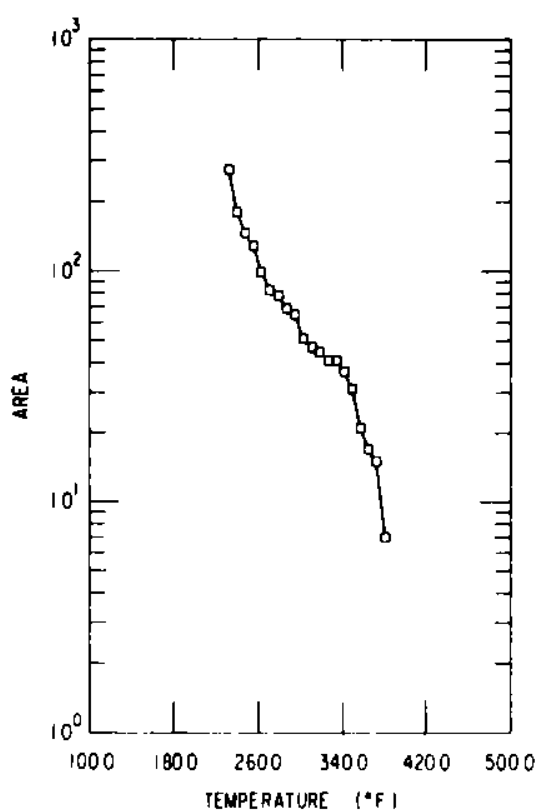

Fig. 21

Plot of Areas Enclosed inside Isotherm Loops (Table VIII) vs Temperature. Conversion factor: ${ }^{\circ} \mathrm{C}=\left({ }^{\circ} \mathrm{F}-32\right) / 1.8$. ANL Neg. No. 306-80-154.

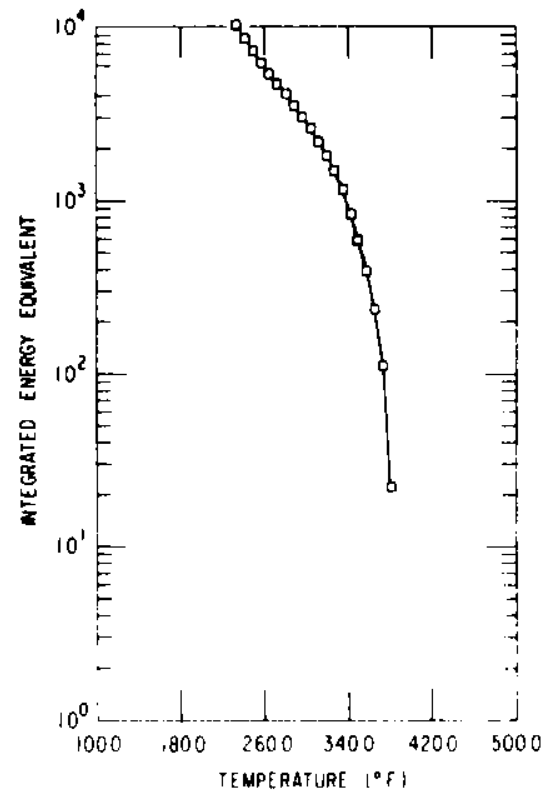

Fig. 22

Integrated Energy Equivalents from Table VIII vs Temperature. Conversion factor: " $\mathrm{C}=\left({ }^{\circ} \mathrm{F}-32\right) / 1.8$. ANL Neg. No. 306-80-151.

Table VII gives the surface temperatures (in ${ }^{\circ} \mathrm{F}$ ) for the test conditions given at the top of the table. The temperatures are listed according to the following computer instruction:

DO $29 \mathrm{~K}=1, \mathrm{NK}$

29 WRITE(6.30) (TNEW(NII, J,K), J = 1, NJ)

Hence, the first temperature in the data array represents the hotspot, the last the cold spot. This temperature array was also used to reconstruct the total temperature field and was plotted in three dimensions as shown in Fig. 18 . In the three-dimensional plot, the spatial coordinates are indexed with numerals. They can be converted to actual coordinates using the mesh size given in the legend of Table VII. A reconstruction of the cavity configuration was also attempted, as shown in Fig. 19. The top flat surface in the plot represents the inside refractory surface.

Figure 20 presents an isotherm map; the legend at the top of the figure lists the temperature ranges for the bands coded in the map. A short paragraph of explanation is also provided in the figure to clarify how the isotherm map can be used to read additional bands not coded in the map.

Features extracted from the temperature data in Table VII are listed in Table VIII. The integrated-volume (also called energy-equivalent) data refer to the volume lying underneath a temperature surface, but contained above a specified temperature level. The area and volume data in Table VIII are plotted in Figs. 21 and 22, respectively. The integrated energy-equivalent curve (Fig. 22) appears to be smoother than the area curve (Fig. 21). 
To study the effect of cavity-depth changes on surface temperatures, temperature data for three cavity configurations are presented in a composite diagram (Fig. 23). The figure shows clearly that a deepening of the cavity, while the cavity cross section remains constant, not only increases the volume lying underneath the temperature surface, but also raises the maximum and minimum temperature readings measured on the surface. In a like fashion, if the cavity cross section is increased while the cavity depth remains constant, both the volume and the temperature readings again increase (see Fig. 24). As a further attempt to quantify these observations, features were extracted from these temperature data and replotted in Figs. 25 and 26 . The legs of the integrated energy-equivalent curves in Fig. 25 shift rapidly toward the right when the cavity is deepened. However, only a slight shift of the curves is noted if the cavity cross section is enlarged (see Fig. 26).

The method given above is probably adequate to predict the cavity configuration if the temperature data can be used for detailed analysis. The method is still too complicated for practical purposes, and simplification is desirable. This was done by picking two features for comparison. Among those features that are easily extractable from the scanned data are (a) the total volume lying underneath the temperature surface, (b) the maximum temperature reading on the surface, and (c) the minimum temperature reading on the surface. A calculation of these three features for a wide range of cavity configurations is shown in $\mathrm{T}$ able IX. Of the three, total volume and maximum temperature (columns 5 and 6 , respectively) are the most sensitive to cavity configuration; minimum temperature (last column) shows a spread of only $9.5^{\circ} \mathrm{F}\left(5.3^{\circ} \mathrm{C}\right)$ for the wide range of cavities tested, illustrating well the insensitivity of this feature to the presence of flaws.

In Fig. 27, total volume is plotted against maximum surface temperature for each output line of Table IX. To facilitate interpretation of Fig. 27, solid curves have been fitted to all points that have icientical cavity cross sections; dashed curves have been fitted to all points sharing identical cavity depths. Obviously, fitting the solid curves by means of a linear function yields satisfactory results; however, data scattering is evident with respect to the dashed curves, particularly for large cavities.

A close examination of Fig. 27 reveals that the data points tend to converge if they share the same cavity cross section and if their cavity widths have similar aspect ratios. For example, points 48 and 50 with cross sections of $60^{\circ} \times 150 \mathrm{~mm}$ and $90^{\circ} \times 100 \mathrm{~mm}$, respectively, and therefore a common product of $9000^{\circ} \cdot \mathrm{mm}$, converge. This trend is also seen from pairs 3 and 5 , 12 and 14,21 and 23, 30 and 32, and 39 and 41. However, such a trend is not found if the cavity width is disproportionately expanded in one direction. For example, points 47 and 52 , with cross sections of $60^{\circ} \times 100 \mathrm{~mm}$ and $120^{\circ} \times 50 \mathrm{~mm}$, respectively, fall far apart in the chart, although they share a product of $6000^{\circ} \cdot \mathrm{mm}$. Other pairs of points showing the same behavior include 2 and 7,11 and 16,20 and 25,29 and 34 , and 38 and 43. In practice, the one nearest-neighbor rule in pattern-recognition theory ${ }^{27}$ can be used, together with the chart, to predict erosive wear. 

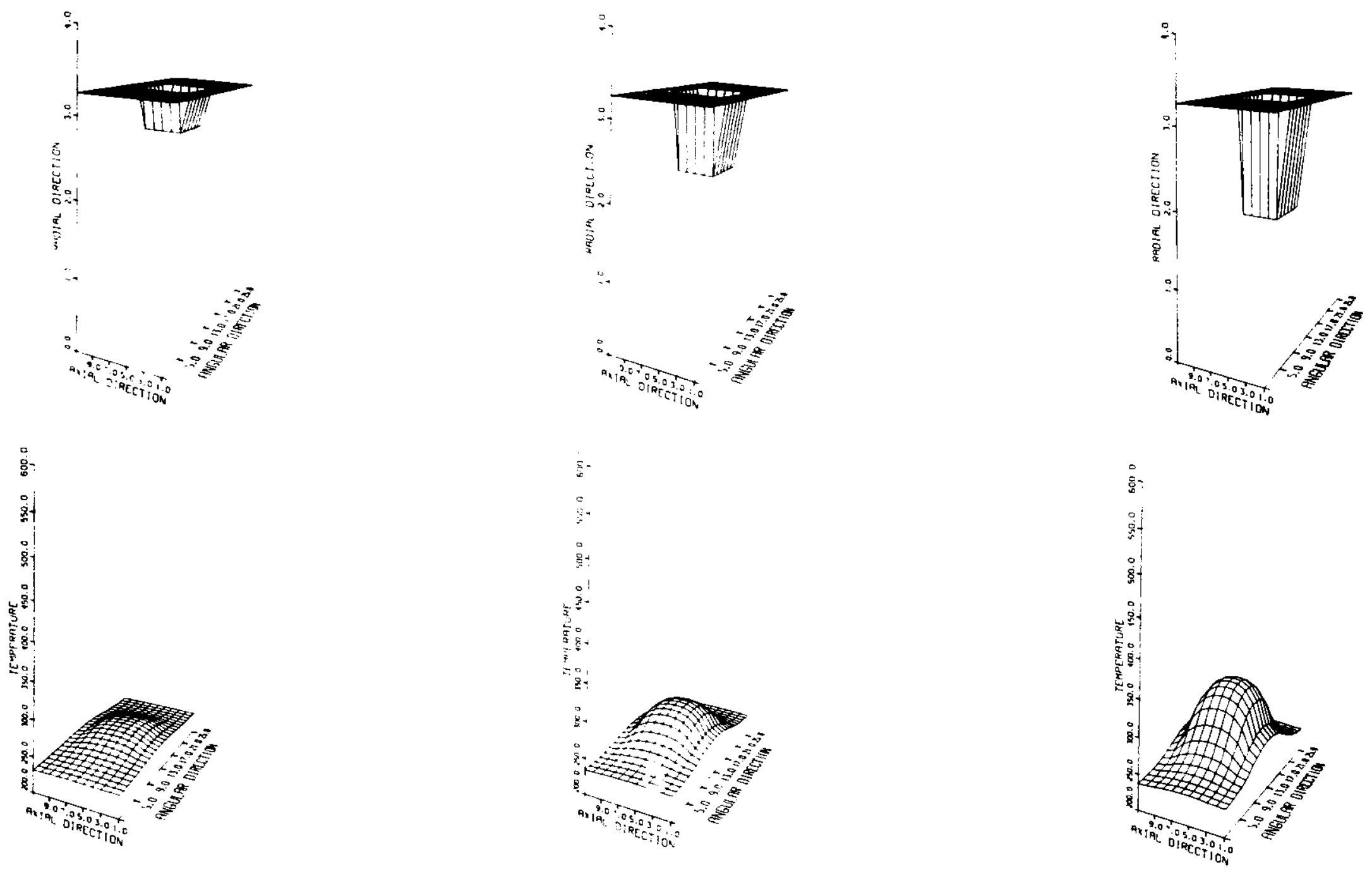

Cavity Size: $12.7 \mathrm{~mm} \times 120^{\circ} \times 304.8 \mathrm{~mm} ; 25.4 \mathrm{~mm} \times 120^{\circ} \times 304.8 \mathrm{~mm} ; 38.1 \mathrm{~mm} \times 120^{\circ} \times 304.8 \mathrm{~mm}$

Fig. 23. Effect of Cavity Depth on Temperature. Top row: reconstructions of three cavity configurations. Bottom row: three-dimensional surface-temperature plots. Temperatures in ${ }^{\circ} \mathrm{F}$. Conversion factor: ${ }^{\circ} \mathrm{C}=\left({ }^{\circ} \mathrm{F}-32\right) / 1.8$. ANL Neg. No. $306-77-398$. 

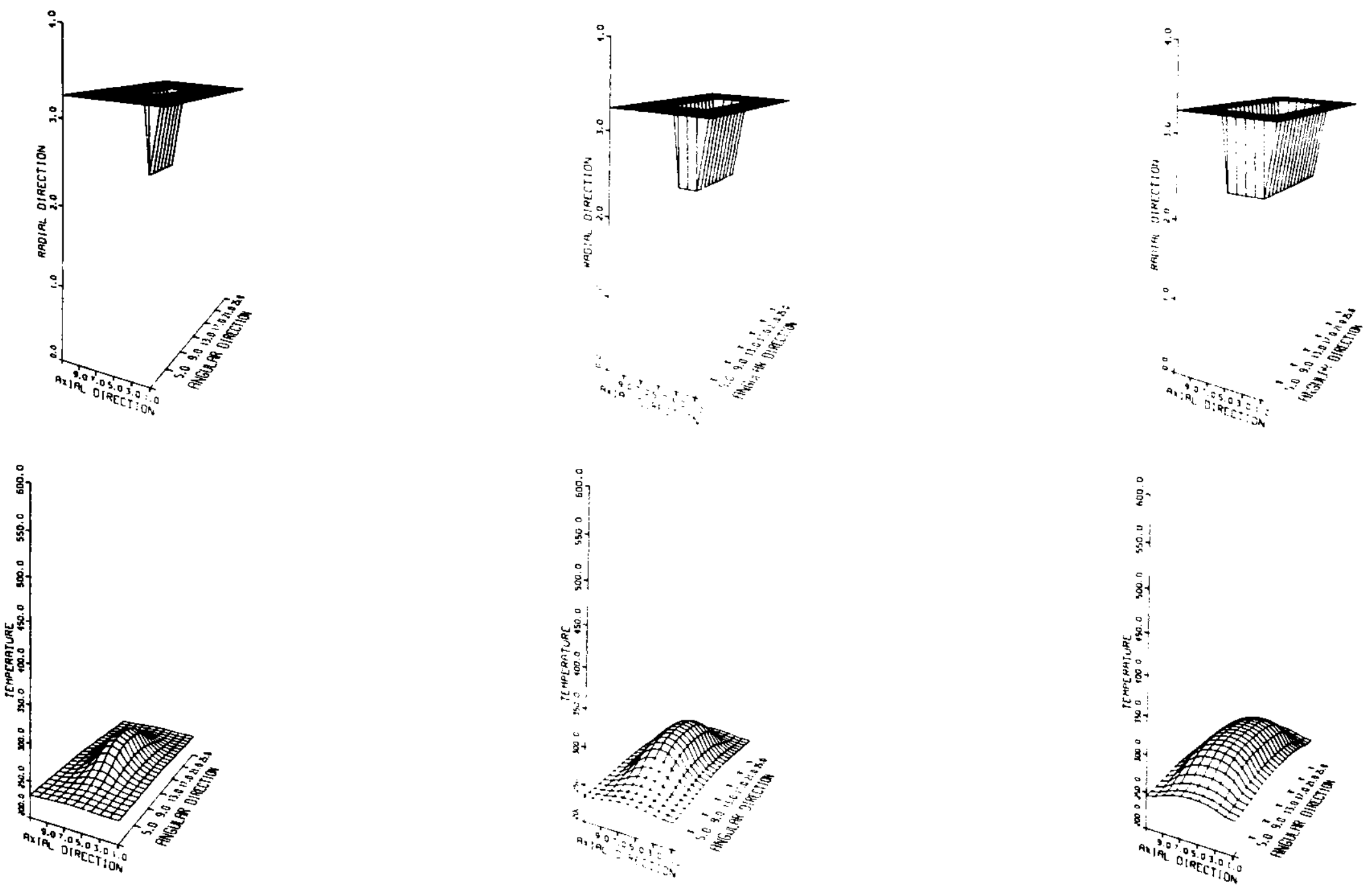

Cavity Size: $25.4 \mathrm{~mm} \times 120^{\circ} \times 101.6 \mathrm{~mm} ; 25.4 \mathrm{~mm} \times 180^{\circ} \times 203.2 \mathrm{~mm} ; 25.4 \mathrm{~mm} \times 240^{\circ} \times 304.8 \mathrm{~mm}$

Fig. 24. Effect of Cavity Width on Temperature. Top row: reconstructions of three cavity configurations. Bottom row: three-dimensional surface-temperature plots. Temperatures in ${ }^{\circ} \mathrm{F}$. Conversion factor: ${ }^{\circ} \mathrm{C}=\left({ }^{\circ} \mathrm{F}-32, / 1.8\right.$. ANL Neg. No. 306-77-399. 
ARER INCLOSEO INSIDE ISOTHERM I LURS

INTELGRTED TRERGY EOUIVALENT
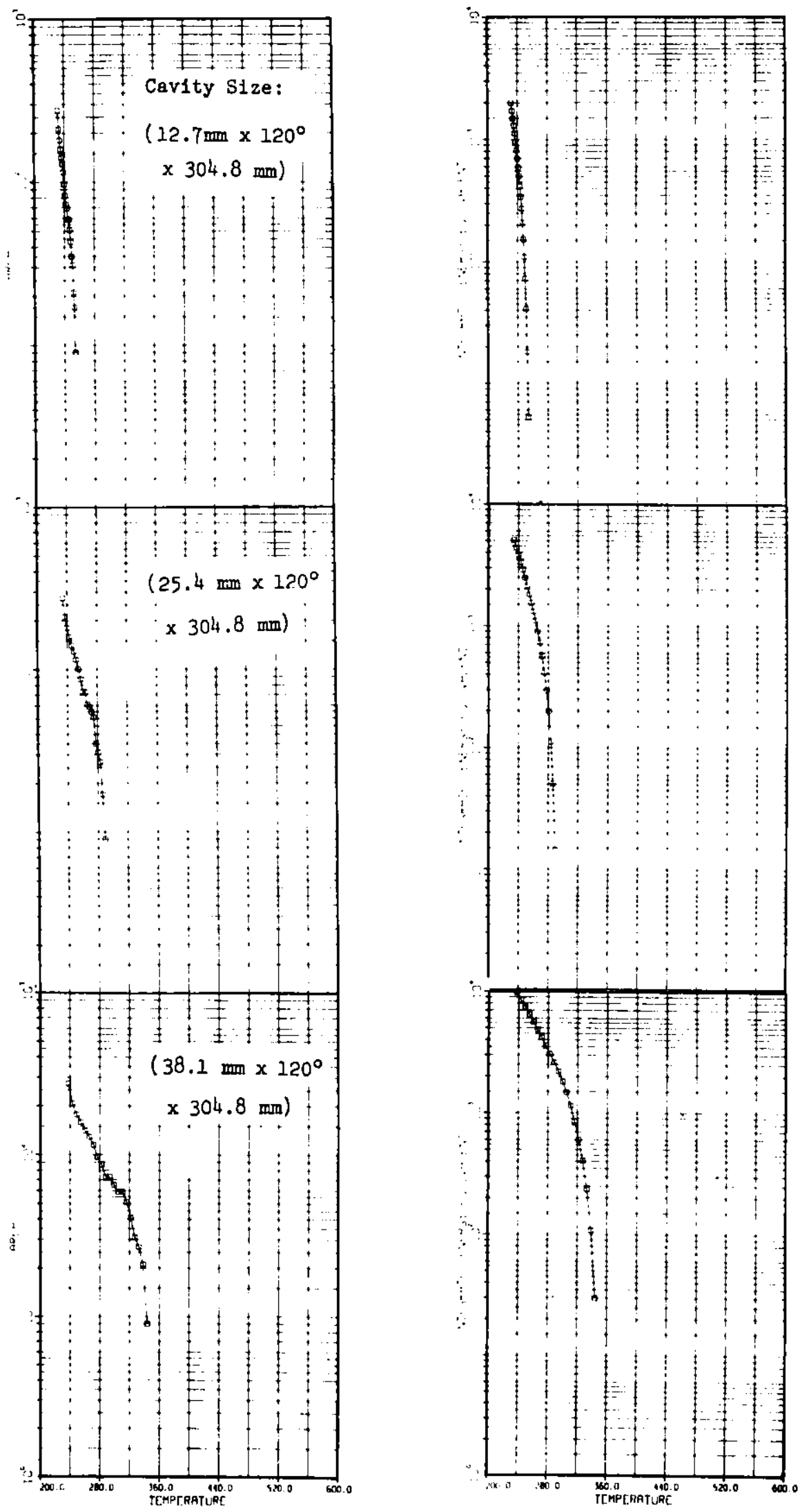

Eig. 25. Feature Curves for Cases in Fig. 23. Temperatures in ${ }^{\circ} \mathrm{F}$. Conversion factor: ${ }^{\circ} \mathrm{C}=\left({ }^{\circ} \mathrm{F}-32\right) / 1.8$. ANL Neg. No. 306-77-397. 


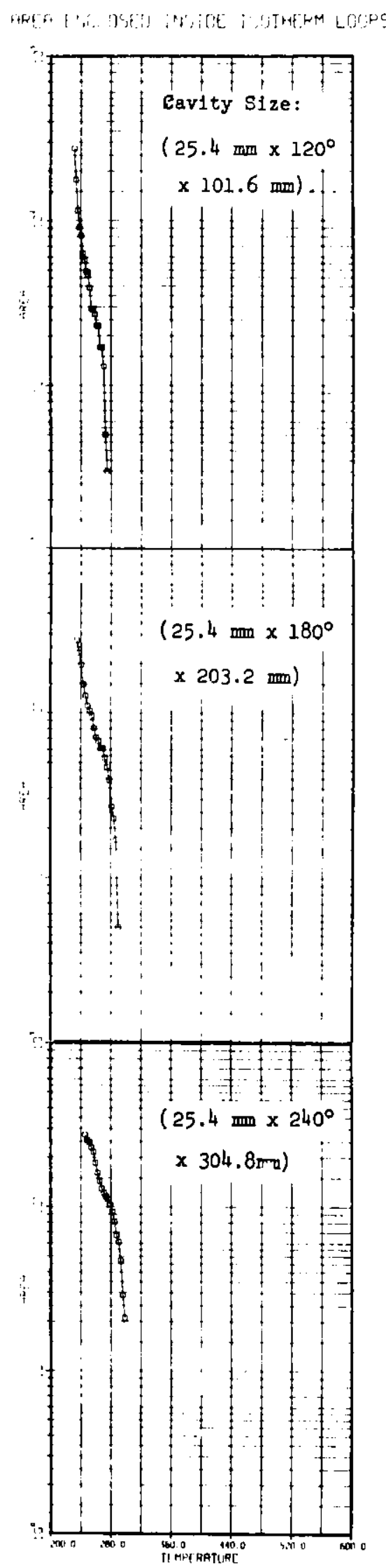

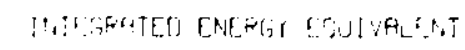

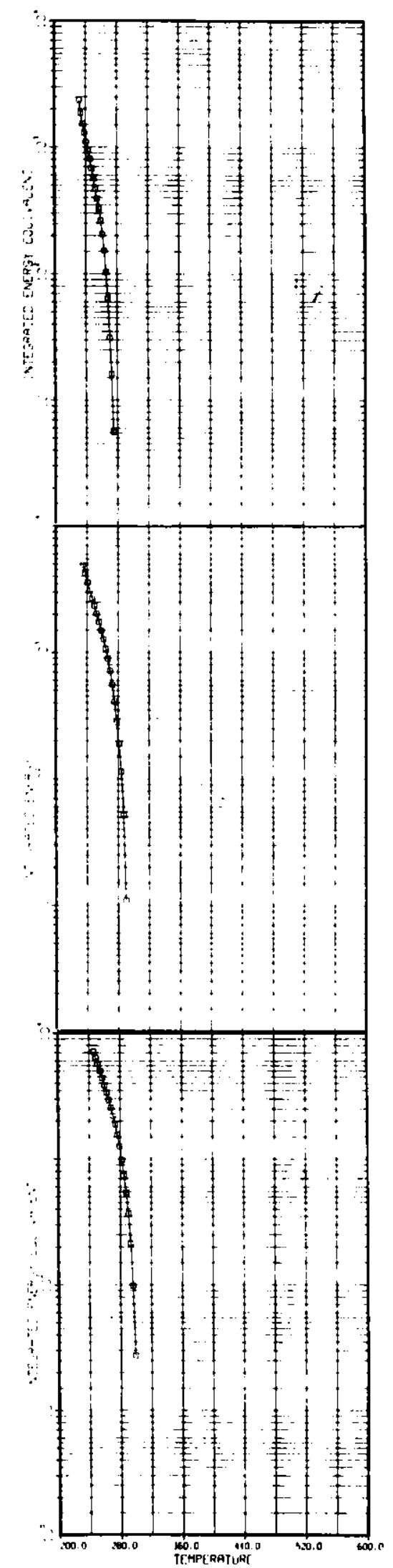

Fig. 26. Feature Curves for Cases in Fig. 24. Temperatures in ${ }^{\circ} \mathrm{F}$. Conversion factor: ${ }^{\circ} \mathrm{C}=\left({ }^{\circ} \mathrm{F}-32\right) / 1.8$. ANL Neg. No. 306-77-400. 
IABLE IX. Computer Dała Used for Prediclion ol Cavity Conflguration

\begin{tabular}{|c|c|c|c|c|c|c|}
\hline NO & DEPTH & WIDTh & HE IGHTd & $\begin{array}{c}\text { IOIAL V } \\
\text { IENEKGY EOUIVALENTS }\end{array}$ & $\operatorname{Max} \mathrm{T}^{\mathrm{C}}$ & MIN $K$ \\
\hline 1 & 0.50 & 600 & 20 & 44039.3 & 171 1 & 158.1 \\
\hline 2 & 0.50 & 600 & 4.0 & $\$ 4406.4$ & 173.0 & 158.1 \\
\hline 3 & 0.50 & 60.0 & 60 & 447920 & 1745 & 158.2 \\
\hline 4 & 050 & 90.0 & 2.0 & 44273.1 & 171.6 & 158.2 \\
\hline 5 & 050 & 40.0 & 40 & 44790.3 & 174.3 & 158.3 \\
\hline 6 & 0.50 & $\$ 0.0$ & 60 & $45360 ?$ & 1753 & 158.7 \\
\hline 1 & 0.50 & 1200 & 20 & 44512.8 & 1717 & 158.3 \\
\hline 3 & 0.50 & 1200 & 40 & 45209.8 & 1745 & 158.8 \\
\hline 9 & 0.50 & 1200 & 60 & 458012 & 1750 & 159.7 \\
\hline 10 & 0.75 & 60.0 & 2.0 & 4444.8 & 1802 & 158.1 \\
\hline 11 & 0.75 & $\infty 00$ & 40 & 450624 & 1841 & 1582 \\
\hline 12 & $\therefore 75$ & 0,00 & 00 & $45712 ?$ & $185 \mathrm{~s}$ & 1583 \\
\hline 13 & 0.75 & $\$ 00$ & 2.0 & 448384 & 1800 & 1582 \\
\hline 14 & 0.15 & 90.0 & 40 & $45724 ?$ & 1851 & 158.5 \\
\hline 15 & 075 & 90 & 00 & $45634 !$ & 1800 & 1590 \\
\hline 16 & $0 \mathrm{H}$ & 1200 & 2.0 & 452680 & $181 ?$ & 158.6 \\
\hline 11 & 075 & $|x| 0$ & 40 & $4841 ? !$ & 1854 & 1593 \\
\hline 18 & 0.75 & 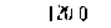 & 0.0 & 476347 & 3871 & 160.9 \\
\hline 19 & 1.00 & 600 & 2.0 & 448510 & 1917 & 1582 \\
\hline 20 & 1.00 & a) 0 & 40 & 458750 & $197 !$ & 1582 \\
\hline 21 & 100 & not & 40 & $408 / 46$ & $194:$ & 1585 \\
\hline$n$ & I 05 & 100 & 20 & 455434 & $19: 0$ & 158.3 \\
\hline 3 & 1.60 & $x \neq 0$ & 40 & 40860 . & 1984 & 158.7 \\
\hline 24 & 10 & (x) & Ai) & 482430 & 2000 & 1594 \\
\hline 25 & 100 & $1,4,0$ & 20 & $40170 ?$ & 1924 & 158.8 \\
\hline $2 h$ & 1.00 & $1 \times 0$ & 40 & 47892 : & 198.4 & 159.9 \\
\hline$n$ & 1.00 & 1200 & (0) & 49717.8 & $201 ?$ & 162.2 \\
\hline 28 & $1 x^{x}$ & तN 0 & 20 & 455850 & 2003 & 158.2 \\
\hline .99 & 1.3 & 60,0 & 40 & 468925 & 2130 & 1583 \\
\hline 30 & 1.85 & 00.0 & 00 & $48291 ?$ & 210.3 & 158.6 \\
\hline $3 i$ & 13 & 900 & $\therefore 0$ & 46454.6 & rat & 158.5 \\
\hline 32 & 1.75 & $x 0$ & 4.0 & 48300.3 & : & 159.0 \\
\hline 33 & 1.25 & 400 & 0.0 & 50389 & $? \mid 8\}$ & 160.0 \\
\hline 34 & $1 / 5$ & 1000 & 2.0 & a/3a:? ? & 20174 & 159.1 \\
\hline 35 & 1.25 & 1200 & 40 & $49734 ?$ & א א & 100.5 \\
\hline 36 & 1.25 & 100 & ou & 523014 & II B B & 163.7 \\
\hline $3 i$ & 1.50 & 00.0 & 20 & $46344 \mathrm{R}$ & $\because x$ & 1582 \\
\hline 38 & $1.56 \mathrm{i}$ & 600 & 4.0 & $4821 z \zeta$ & $25 ; 1$ & $15 B S$ \\
\hline 30 & ניני & 60.0 & 60 & s00\% : & 1384 & $15 B .8$ \\
\hline 40 & 1.50 & $\$ 0$ & 2.0 & 475851 & $2 a b+$ & 158.6 \\
\hline d) & 150 & 40 & 40 & $50104 ;$ & 3111 & $15 ?$ \\
\hline 42 & 130 & $\$ 00$ & 0.) & 528035 & ' $411 \mathrm{x}$ & 100.6 \\
\hline 43 & iso & 1200 & 20 & 488420 & 2213 & 159.3 \\
\hline 4 & 150 & 1200 & 40 & S2llys & 311 & $16] 4$ \\
\hline 45 & 1.50 & 180 & 0.0 & 556110 & 2415 & 165.5 \\
\hline 40 & 115 & 6). 0 & 2.0 & $47450 \mathrm{I}$ & (s) 3 & 1582 \\
\hline 47 & 1.15 & to 0 & 40 & $4991 / 4$ & 2034 & 158.5 \\
\hline 48 & .15 & 1,00 & bo & $52444 \%$ & $20 \times 3$ & $1>90$ \\
\hline 49 & 113 & 贵) 0 & 20 & 490801 & S3: & 1587 \\
\hline 50 & $1 / 5$ & (4) 0 & 40 & 52524.1 & $26 \tan 4$ & 1590 \\
\hline 51 & 1.75 & 400 & 61) & 561527 & $2 n 1$ & 1012 \\
\hline 32 & 175 & $\mid 2010$ & 20 & 507580 & 831 & 1541 \\
\hline 53 & 175 & 1200 & 40 & 55228.11 & $i t 7.1$ & $\ln 2.3$ \\
\hline 34 & 1.75 & $1 \times 0$ & 0.0 & 509055 & $: 7 ? 1$ & 1076 \\
\hline
\end{tabular}

an inclies. Conversion factor I in , $284 \mathrm{~mm}$

Hall the arqular span of the cavil, lin dergiters

in of Conversinn factor o. $19-32 \mathrm{ml} B$

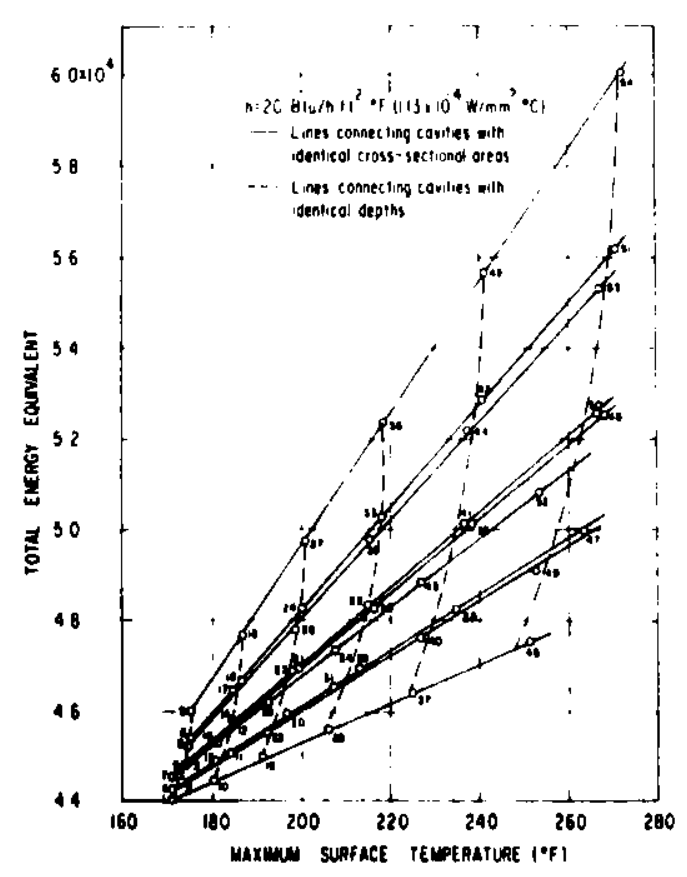

Fig. 27

Chart for Predicting Cavity Configurations.

Conversion factor: ${ }^{\circ} \mathrm{C}=\left({ }^{\circ} \mathrm{F}-32\right) / 1.8$.

ANL Neg. No. 306-80-156. 
D. Prediction of Surface Temperatures for a Three-dimensional Model with a Dual-component Wall Lining

Surface temperatures were also calculated using the three-dimensional heat-transfer model with a dual-layered refractory lining. The materials used in the analysis are those of the $\mathrm{CO}_{2}$ Acceptor Plant test section, shown schematically in Fig. 28. The computer program developed for this case is included as Appendix F. Again, for illustrative purposes, results for only two conditions will be presented. Table X and Fig. 29 provide outputs for a 12.7-mm (0.5-in.)-deep cavity. The case of a 38.1-mm (1.5-in.)-deep cavity was also calculated, and the results are shown in Table XI ard Fig. 30. Input

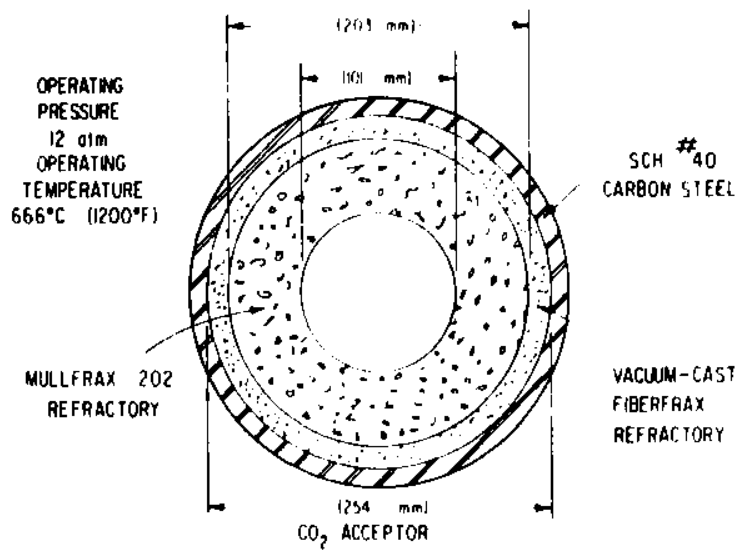

Fig. 28

Schematic Diagram Showing Construction of a Transfer Line with Double-layered Refractory Lining. ANL Neg. No. 306-80-143.

IABLF $X$ Surfarelemperature Data for System Shown in Fig. 28 with a $0.5-$ in. $(12.7-\mathrm{mm})$-deep Cavity

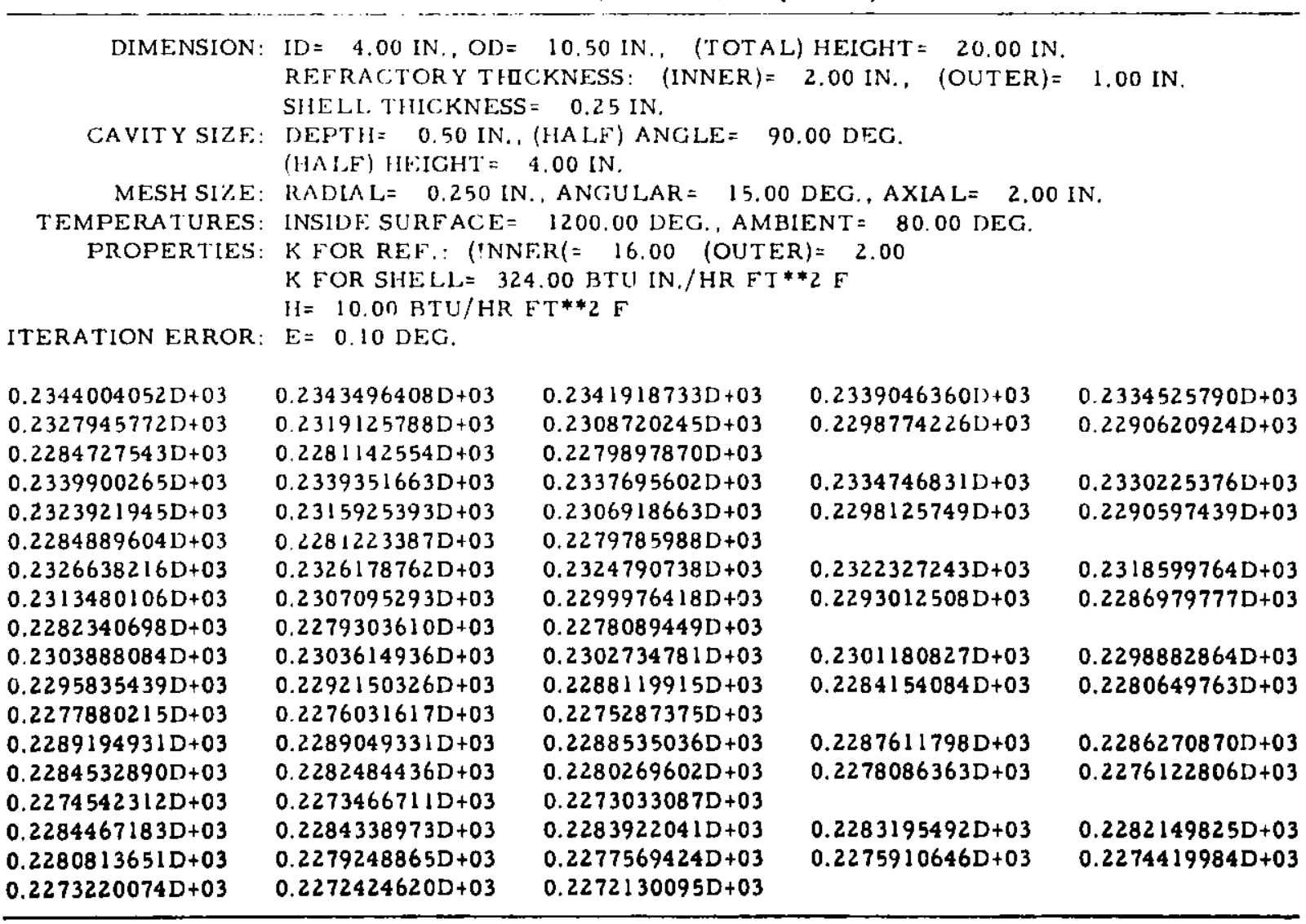


THREE-DIMENSIONAL SURTACE TEMPERATURE PLOT

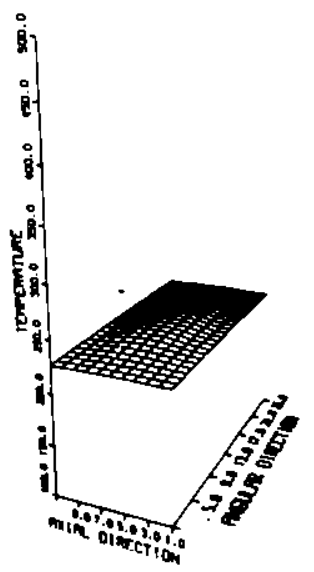

AREA ENCLOSED INSIOE ISOTHERM LOOPS

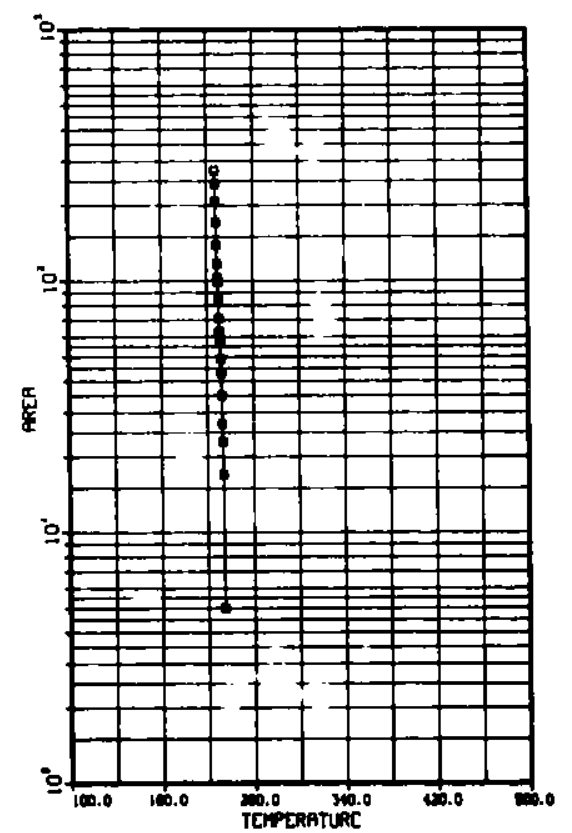

RELONSTRUCTION OF CAVITY CONFIGURATION

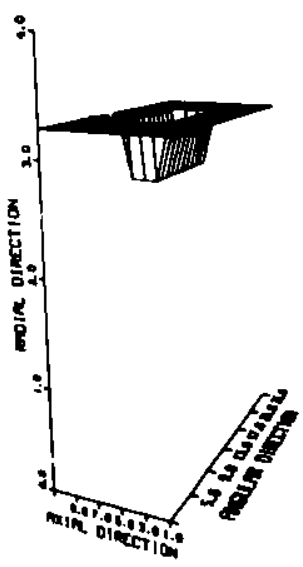

INTEGRATED ENERGY EOUI VRLENT

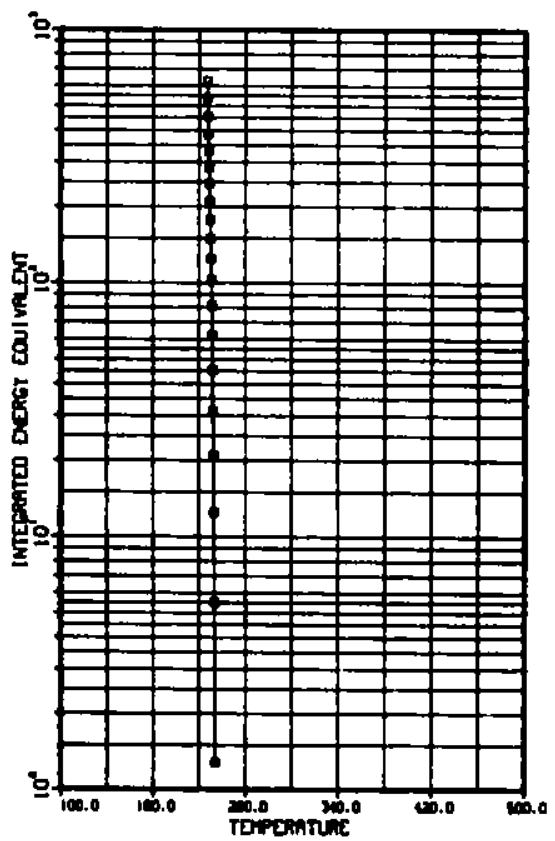

Fig. 29. Feature Data for Case in Table $X$. Temperatures in ${ }^{\circ} \mathrm{F}$. Conversion factor: ${ }^{\circ}\left(\quad{ }^{\circ} \mathrm{F}-32\right) / 1.8$. ANL Neg. No. 306-80-139. 
RECONSTRUCTION OF CAVITY CONFIGURATION

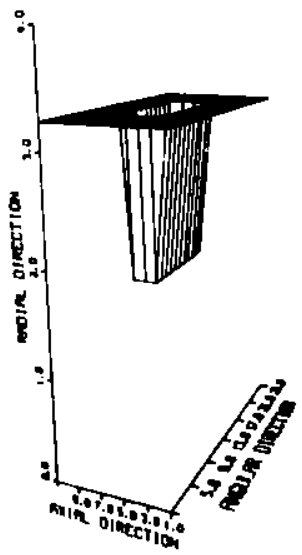

THREE-DIMENSIONAL SURFACE TEMPERATURE PLOT

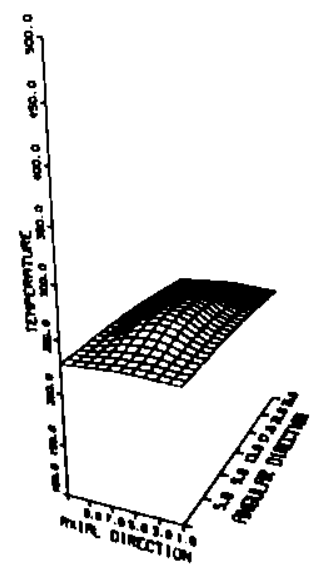

RREA ENCLOSEO INSIOE ISOTHERM LOOPS

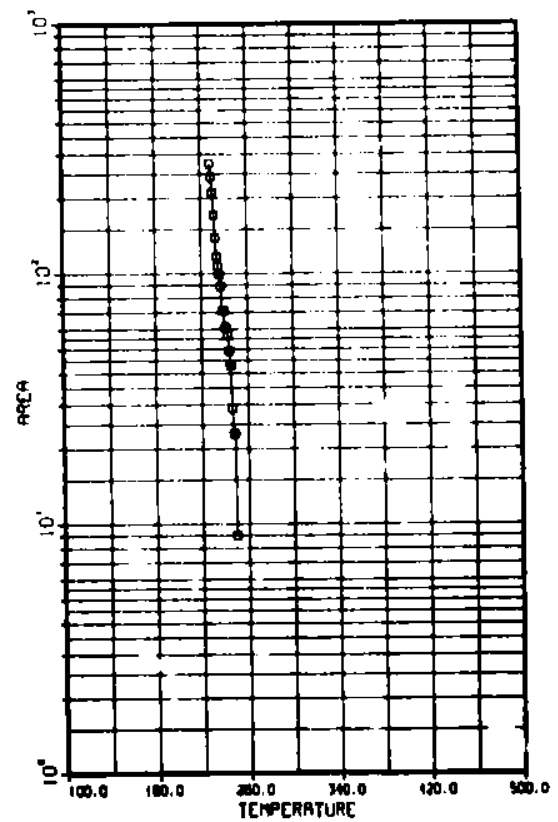

INTEGRATED ENERGY EOUIVALENT

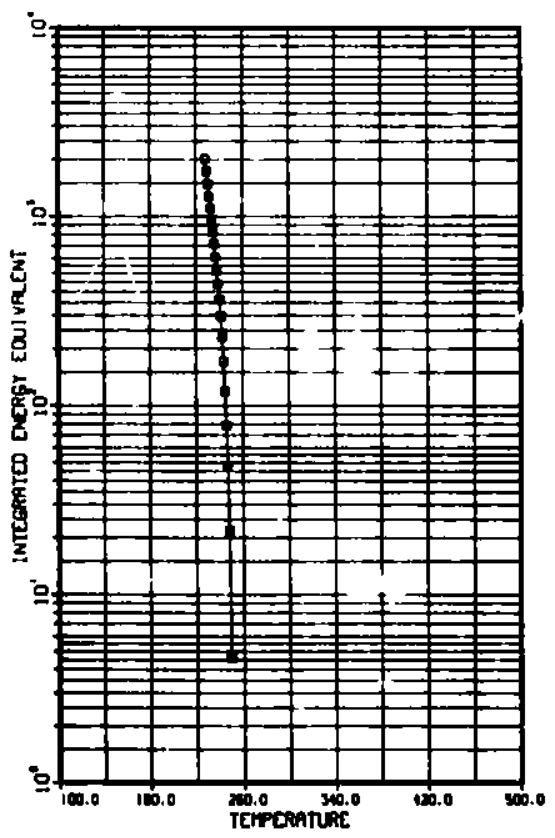

Fig. 30. Feature Data for Case in Table XI. ANL Neg. No. 306-80-136. 
TABLE XI. Surface-temperature Data for System Shown in

Fig. 28 with a $1.5-i n .(38.1-\mathrm{mm})$-deep Cavity

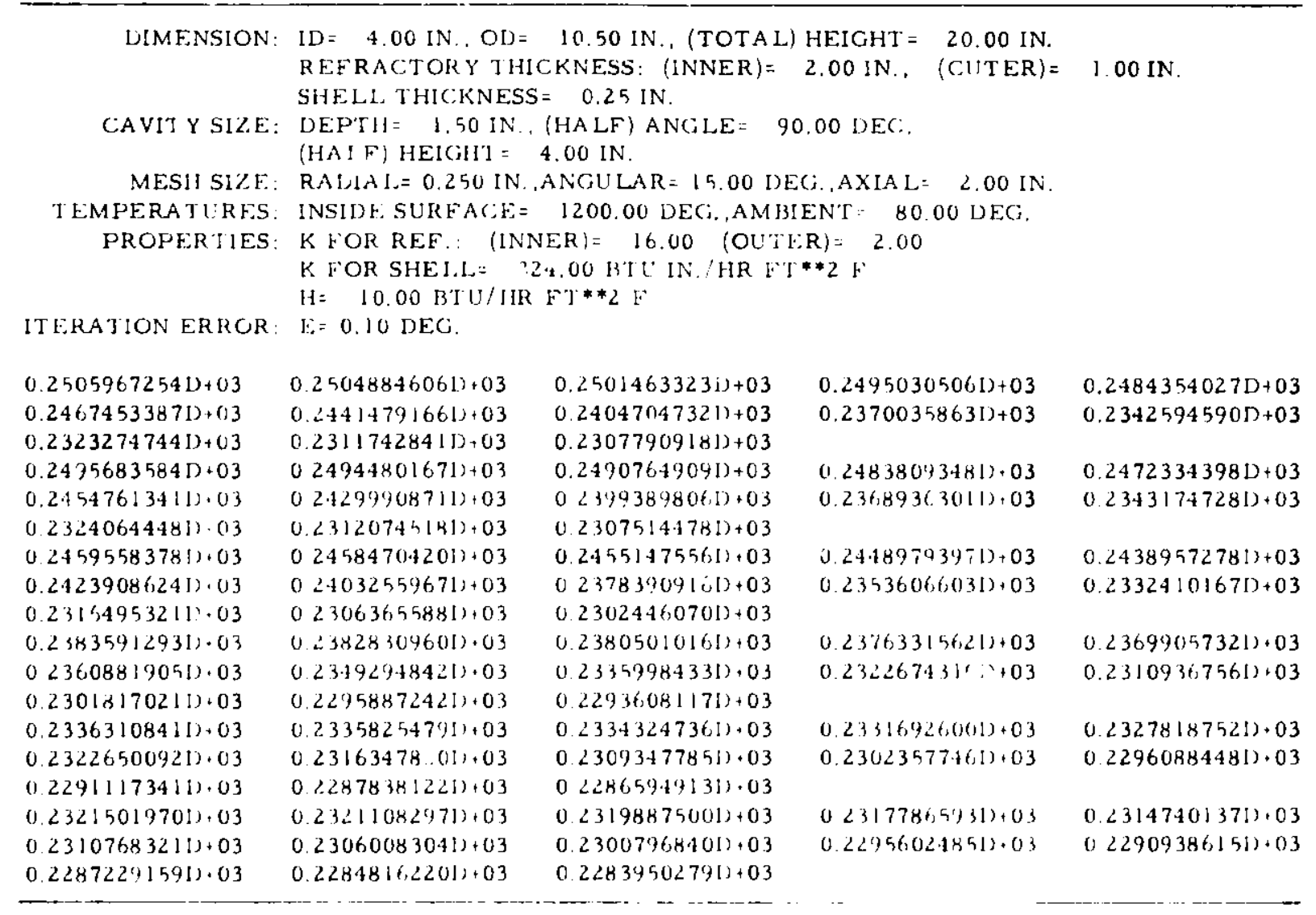

data for the runs are listed at the tops of the tables. In each table, the first and last temperature in the output array represent the hot spot and cold spot, respectively.

For a cavity depth of $12.7 \mathrm{~mm}$ ( $0.5 \mathrm{in}$.), because of the presence of an insulation layer between the inner refractory and the steel shell, the hot-spot temperature at the steel surface is only $4^{\circ} \mathrm{C}\left(7^{\circ} \mathrm{F}\right)$ higher than the cold-spot temperature (see Table $\mathrm{X}$ ). This temperature difference is raised to $12^{\circ} \mathrm{C}\left(22^{\circ} \mathrm{F}\right)$ if the cavity is deepened to $38.1 \mathrm{~mm}(1.5 \mathrm{in}$.) (see Table XI). A thin layer of insulation is thus seen to markedly diminish the temperature gradient on the surface. The shift of curves in the feature plots is also drastically reduced (compare Figs. 29 and 30). Both of these findings point to the fact that in dual-layered systems, the insulation layer might render infrared scanning useless for erosion detection.

\section{E. Prediction of Surface Temperatures for a Three-dimensional Model with Contact Resistances}

In the previous calculations, no consideration was given to contact resistance between the steel shell and the refractory lining. This resistance will be considered here, and the computer programs given in Appendix $G$ will be used to examine the effect of contact resistance on surface-temperature distributions. 
For a uniform contact resistance between the refractory lining and the steel shell, the resistance plays the role of the second insulation layer studied previously. Figure 31 is a composite diagram comparing the effects of various

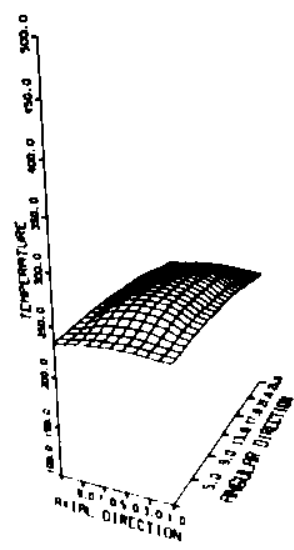

(a) 0

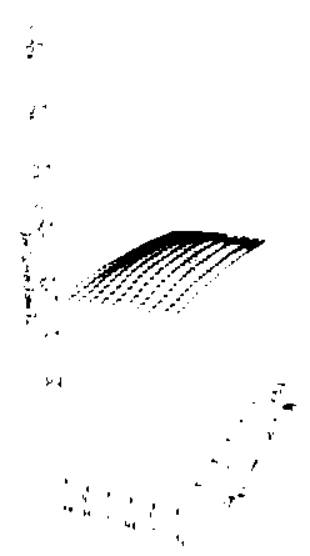

(c) 0.04076

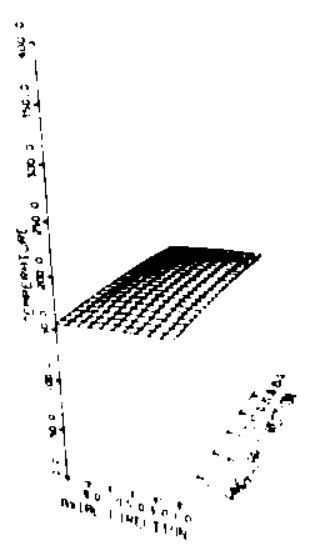

(e) 0.09510

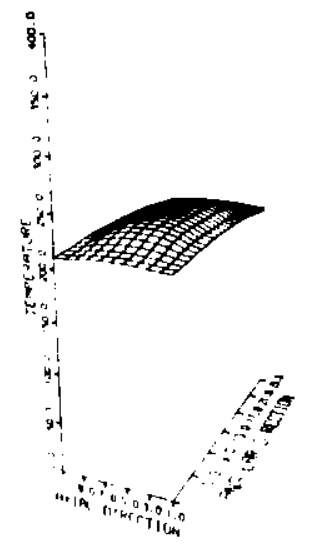

(b) 0.01358

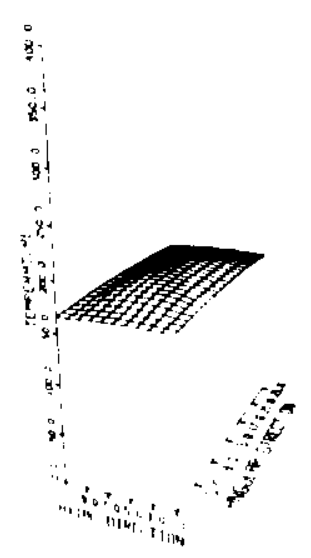

(d) 0.06793

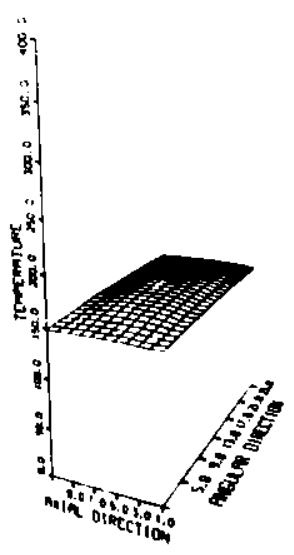

(f) 0.12228

Fig. 31. Comparison of Three-dimensional Surface-temperature Plots Obtained with Indicated Values (in h.deg/Btu) of Uniform Interfacial Contact Resistance. Note the different ordinate scale in (a), the no-resistance case. Temperatures in ${ }^{\circ} \mathrm{F}$. Conversion factor: $\left.{ }^{\circ} \mathrm{C}={ }^{\circ} \mathrm{F}-32\right) / 1.8$. ANL Neg. No, 306-80-137. 
uniform contact resistances. The test conditions are summarized in Table XII. From Figs. $3 \mathrm{lb}-3 \mathrm{lf}$, the resistance increases ninefold; the difference between the calculated peak and minimum temperatures in Fig. $3 \mathrm{lb}$ is $11^{\circ} \mathrm{C}\left(20^{\circ} \mathrm{F}\right)$, in contrast to only $4^{\circ} \mathrm{C}\left(8^{\circ} \mathrm{F}\right)$ in Fig. $31 \mathrm{f}$. Figure 31 a is a no-resistance case included for comparison.

TABLE XII. Test Conditions for Data Presented in Fig. 31

\begin{tabular}{|c|c|}
\hline DIMENSION: & $\begin{array}{l}\text { ID }=4.00 \mathrm{IN},, \mathrm{OD}=10.50 \mathrm{IN} .,(\text { TOTAL) HEIGHT }=20.00 \mathrm{IN} . \\
\text { REFRACTORY THICKNESS }=3.00 \mathrm{IN} . \text {. } \mathrm{HELL} \text { THICKNESS }=0.25 \mathrm{IN} .\end{array}$ \\
\hline CAVITY SIZE: & $\begin{array}{l}\text { DEPTH }=0.50 \mathrm{IN}, \text { (HALF) ANC:LE }=120.00 \mathrm{DEG} . \\
\text { (HALF) HEIGHT }=6.00 \mathrm{IN} .\end{array}$ \\
\hline MESH SIZE: & RADIAL $=0.250$ IN.,ANGULAR $=15.00$ DEG., AXIAL $=$ \\
\hline TEMPERATURES: & INSIDE SURFACE $=1500.00$ DEG.,AMBIENT $=80.00$ DEG. \\
\hline PROPERTIES: & 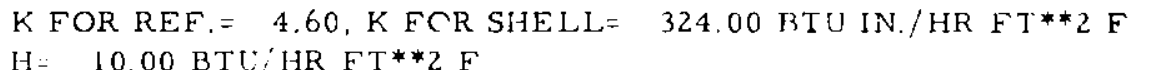 \\
\hline ITERATION FRROR: & $0.10 \mathrm{DEG}$. \\
\hline
\end{tabular}

In a similar manner, the effe't of a nonuniform contact resistance at the interface is examined as shown in Fig. 32. Test conditions are summarized in Table XIII. The contact-resistance function used in the modeling has been given as Eq. 32. The test conditions given here represent a deep-cavity case, which, in the ru-resistance condition, has the temperature distribution shown in Fig. 32a. Because of the resistance, the temperature distribution becomes distorted. In the last plot (Fig. 32f), the temperature distribution is so distortad that one might suspect that the pipe has a ringlike cavity because of the dip of the center temperature. As a means of checking what resistance values have been used for tests at the interface, a plot of contact resistance is also shown in Fig. 33.

F. Study of Distortions of Infrared Images

in this section, the sample output for the three-dimensional model study (Table VII) will be used to illustrate image distortions. With reference to Fig. 8, it is assumed that the transfer line $\left[r_{0}=0.1333 \mathrm{n}\right.$ ( $(5.25 \mathrm{in}$.) $]$ is located at a distance $D=1.524 \mathrm{~m}$ (60 in.) from the camera. For this test setup, Fig. 9 can be used to study the spatial distortions of the image, and Figs. 14 and 15 to study thermal distortions.

For convenience, only the is otherm contour in the first quadrant is presented in Fig. 34. Curve a refers to the isotherm contour for $T=$ $157.2^{\circ} \mathrm{C}\left(315^{\circ} \mathrm{F}\right)$ as predicted by the model. The coordinates used for this plot are $z$ versus polar angle. Because of the spatial distortion, the actual infrared image observed on the oscilloscope screen will not be what curve a predicts: The actual image observed is curve b. This is otherm contour is viewed in a $z$-versus-view-angle coordinate system and is obtained using Fig. 9 for correction. Here a displacement of the contour is clearly noted in the angular direction. 


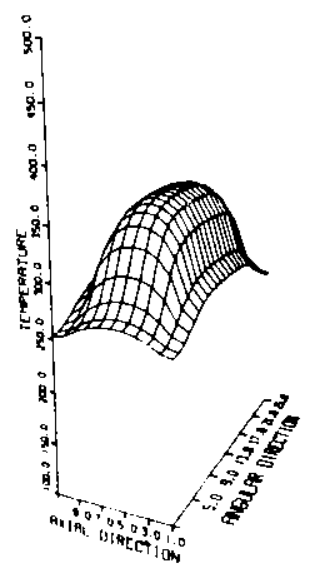

(a) 0

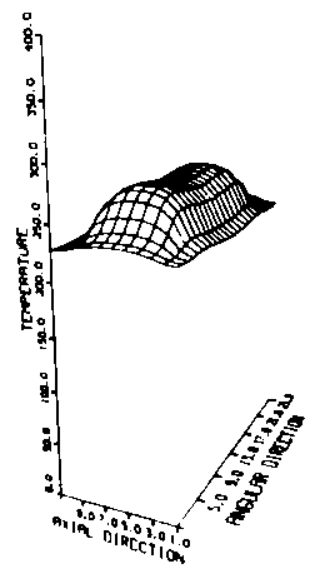

(c) 1.75

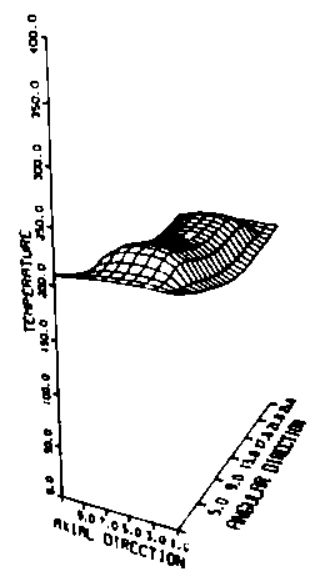

(e) 2.75

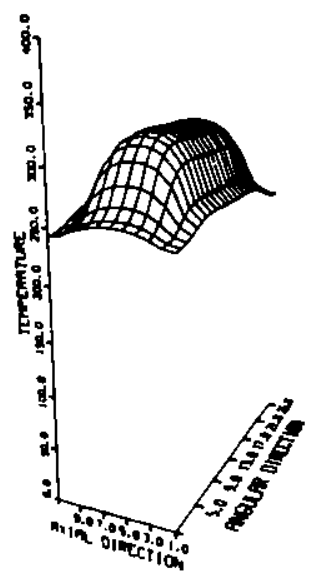

(b) 1.25

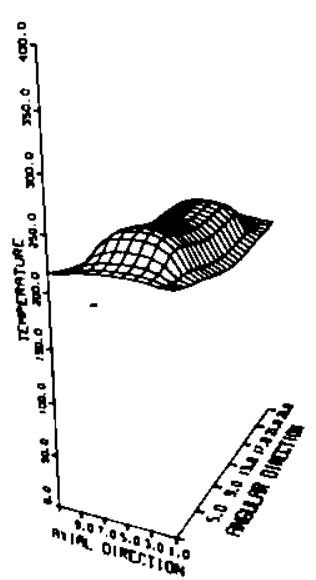

(d) 2.25

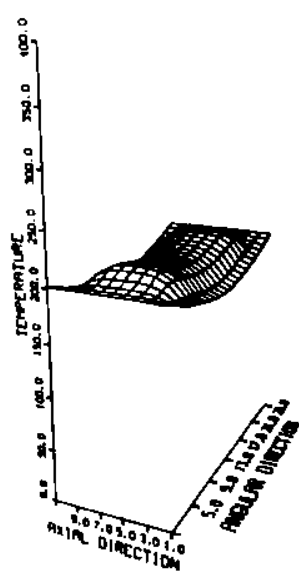

(f) 3.25

Fig. 32. Comparison of Three-dimensional Surface-temperature Plots Obtained with Various Nonuniform Interfacial Contact Resistances. The peak resistance parameter $f$ for each plot is indicated. Note the different ordinate scale in (a), the $\mathrm{nc}$-resistance case. Temperatures in ${ }^{\circ} \mathrm{F}$. Conversion factor: ${ }^{\circ} \mathrm{C}=\left({ }^{\circ} \mathrm{F}-32\right) / 1.8$. ANL Neg. No, 306-80-138. 


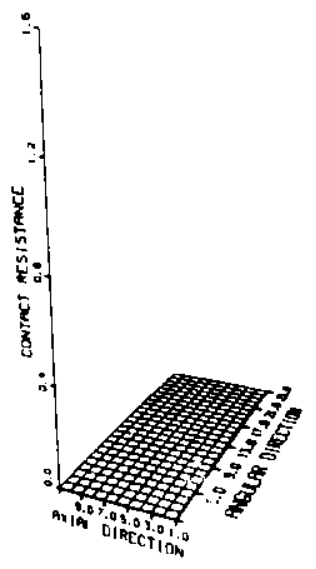

(a)

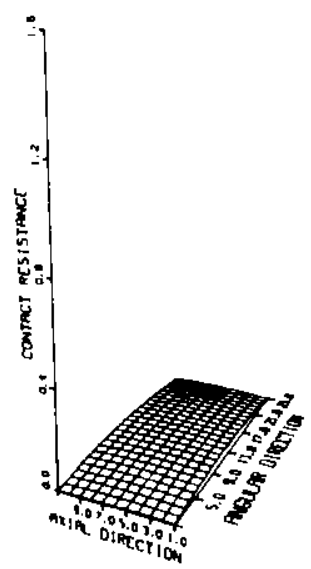

(b)

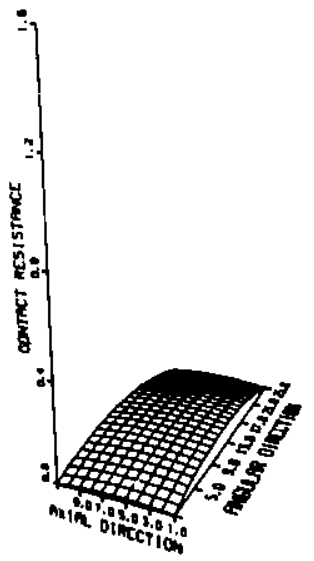

(d)

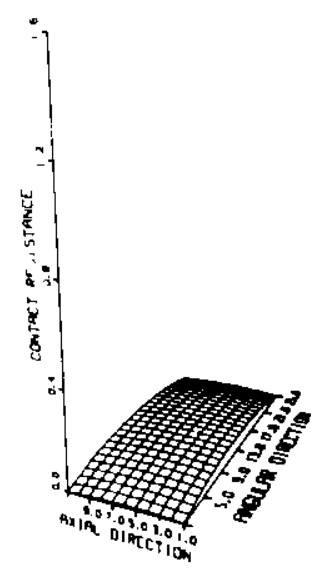

(c)

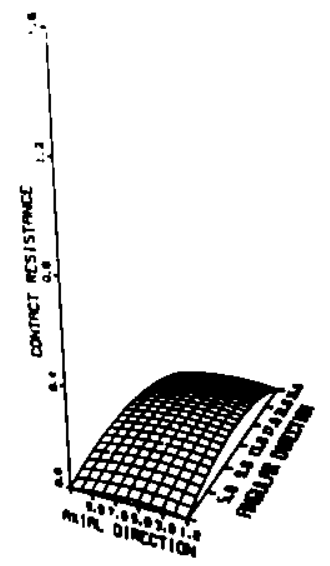

(e)

Fig. 33. Three-dimensional Plots of Variable Interfacial Resistances Used to Generate Temperature Plots Presented in Fig. 32. ANL Neg. No. 306-80-135. 
TABLE XIL. Test Conditions for Data Presented in Fig. 32

\begin{tabular}{|c|c|}
\hline DIMENSION: & $\begin{array}{l}\text { ID }=4.00 \mathrm{IN} ., \mathrm{OD}=10.50 \mathrm{IN} .,(\mathrm{TOTAL}) \mathrm{HEIGHT}=20.00 \mathrm{IN}, \\
\text { REFRACTORY THICKNESS }=3.00 \mathrm{IN} \text {. SHELL THICKNESS }=0.25 \mathrm{IN} \text {. }\end{array}$ \\
\hline CA VITY SIZE: & $\begin{array}{l}\text { DEPTH }=1.50 \mathrm{IN} ., \text { (HA LF) ANGLE }=120.00 \mathrm{DEG} . \\
\text { (HALF) HEIGHT } 6.00 \mathrm{IN} .\end{array}$ \\
\hline MESH SIZE: & RADIAL $=0.250$ IN. $\triangle N G U L A R=15.00$ DEG,,$A X I A L=$ \\
\hline TEMPERATURES: & INSIDE SURFACE $=1500.00$ DEG.,AMBIENT $=80.00$ DEG. \\
\hline PROPERTIES: & K FOR REF $=4.60, \mathrm{~K}$ FOR SHELL $=$ \\
\hline & $\mathrm{H}=10.00 \mathrm{BTU} / \mathrm{HR} \mathrm{FT**2 \textrm {F }}$ \\
\hline ITERATION ERROR: & $E=0.10 \mathrm{DEG}$. \\
\hline
\end{tabular}

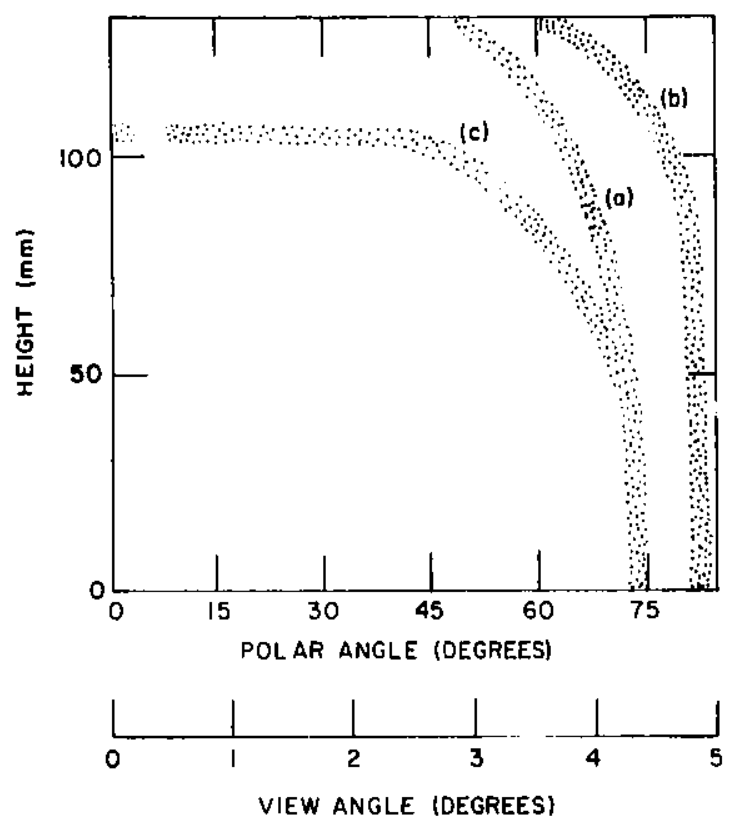

Fig. 34

Distortion of Infrared Images. ANL Neg. No. 306-78-525.

Depending on the surface material, one could anticipate another distortion resulting from surface-emissivity effects. If the surface has optical constants given as $\mathrm{n}=4, \mathrm{k}=0$, then Fig. 15 can be used for correction, yielding curve $c$ of Fig. 34. In this correction, the data predicted in Table VII were multiplied by $\epsilon^{1 / 4}$, which is a function of the view angle. Of course, this method can also be applied to correct for emissivity effects if the surface is made of metal with, say, $\mathrm{n}=4, \mathrm{k}=10$. For the latter case, Fig. 14 would have been used. As it turns out, the small emissivities of metals make the corrected temperatures so low that even the hot-spot temperature [predicted value $\left.198.86^{\circ}\left(389.95^{\circ} \mathrm{F}\right)\right]$ in Table VII drops to $119^{\circ} \mathrm{C}\left(234^{\circ} \mathrm{F}\right)$. Toward the edge of the pipe, where the emissivity increases (peak value $\approx 0.24$ ), a multiplication correction factor of about 0.7 is necessary, but the temperature there has also declined to such a level that the resulting temperature is too luw to be presented in the image without readjusting the infrared camera settings.

If the 1 sotherm on the camera is selected to be initially located near the center of the view field, the spatial correction will be very small because of the linearity between polar and view angles. However, the temperature distortion will still be present, unless the body is painted black. 


\section{CONCLUSIONS AND RECOMMENDATIONS}

This analytical study has shown that a quantitative erosive-wear determination through the use of infrared scanning cameras, which are sensitive only to surface-temperature distributions, is extremely difficult. Although three-dimensional heat-transfer models can be established, variables that are unknown to the individual conducting the test can lead to erroneous conclusions in a quantitative sense. One such variable is the thermal-contact resistance. However, if the investigator can be assured that thermal-contact resistance is minimal or at least uniform, then refractory linings up to $200 \mathrm{~mm}$ thick on steel piping up to $12 \mathrm{~mm}$ thick can be examined. Thicker steel boundaries conduct the heat so rapidly that up to $50 \%$ of the thickness of the refractory wall must be eroded before temperature gradients can be sensed.

This study has shown that similar surface-temperature profiles are obtained for cavities (eroded sections) that are reasonably shallow with a large cross section, and cavities that are reasonably deep with small cross sections. These can be discriminated only if the images are analyzed further to determine, for example, the area inside isotherms and the integrated energy (volume) equivalent. Additionally, scanning of round objects produces thermalimage distortion uwing to surface-emissivity direction effects.

It is the refore the conclusion of this analysis that erosive wear cannot be determıned quantitatively and the cavity geometry cannot be defined without the risk of large errors. 


\section{APPENDIX A \\ Computer Program for a Two-dimensional System}

A computer program for evaluating the surface temperature in a twodimensional system has been developed and is shown in Fig. A.l. Input variables used in the program are defined in Table A.l. The algorithm for the program is given as follows:

1. Lines 6-8 convert SPACEI and SPACEJ to integer constants that are used later to generate a wide range of cavity sizes for tests in the program.

2. Lines 9-14,17-21, and 30-33 calculate the nodal locations that are used later in various DC loops as index parameters. (See Fig. A.2 for the se nodal locations.)

3. Lines 15 and 16 calculate the index parameters for the largest cavity size tested in the program. MIL and MJL represent maximum values that $L$ and $M$ may assume in the DO statements appearing on lines 28 and 29.

4. Lines 22-27 define and compute additional parameters that are later used in the temperature equation. The se parameters are defined as follows:

$\begin{array}{ll}\text { Line 22 } & \text { DLIS }=(\Delta r)^{2} \\ \text { Line 23 } & \text { DLJV }=1 /(\pi \Delta \theta / 180)^{2} \\ \text { Line 24 } & \text { DLIH }=\Delta r / 2 \\ \text { Line 25 } & \text { CONIR }=k_{1} /(\Delta r)^{2} \\ \text { Line 26 } & \text { CON2R }=k_{2} /(\Delta r)^{2} \\ \text { Line 27 } & \text { CON12 }=k_{1}+k_{2}\end{array}$

5. Lines 34-36 initialize all nodal temperatures to $\left(T_{i}+T_{\infty}\right) / 2$.

6. Lines 37-43 set the temperatures at the refractory surface and inside the cavity as $T_{i}$, which is unchanged in the course of iteration. This assignment is made by using two DO loops in the program.

7. Starting on line 44 and ending on line 95, the program calculates temperatures (TNEW) at each point in the system. Before the calculation is made, a series of cards placed before the TNEW statements computes the parameters that are later used in the TNEW equation. (For example, lines 4750 calculate parameters $\mathrm{C} 1, \mathrm{C} 2, \mathrm{C} 3$, and $\mathrm{C} 4$, which appear in the TNEW equation on line 51.) In all instances, the se parameters are radially dependent. 


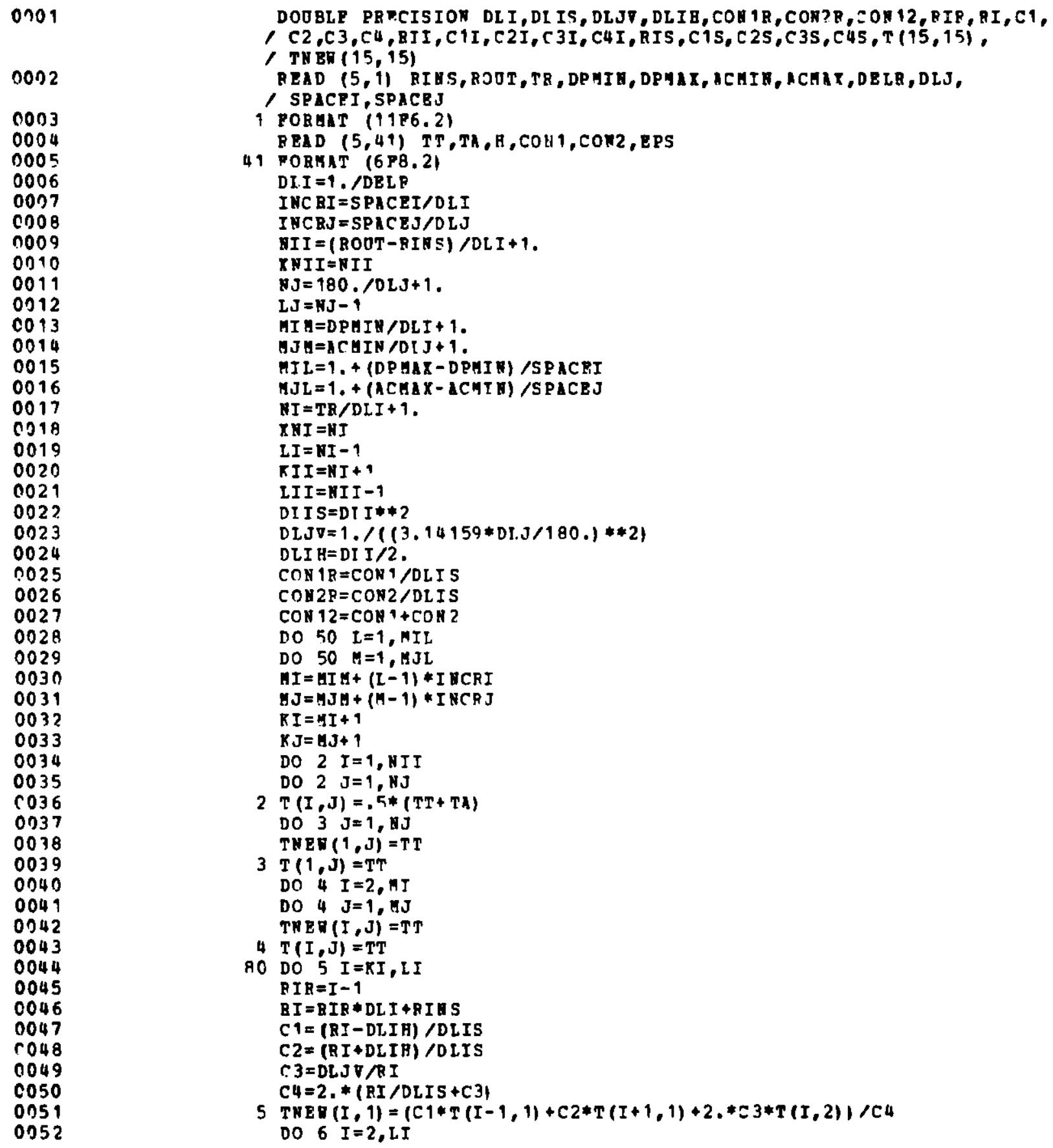

Fig. A.1. Computer Program for Evaluating Surface Temperature in a Two-dimensional System 
RI $R=I-1$

$B I=R I R * D L I+R I$ N

$C 1=(R I-D L I B) / D L T S$

$C 2=(R I+D L I B) / D L I S$

$C 3=\Gamma L J V / B I$

$C 4=2, *(R I / O L I S+C 3)$

6 TNE $(I, B J)=(C 1 * T(I-1, B J)+C 2 * T(I+1, H J)+2, * C 3 * I(I, C J)) / C 4$

DO $7 \mathrm{I}=2, \mathrm{BI}$

DO $7 \mathrm{~J}=\mathrm{KJ}, \mathrm{IJ}$

BI $R=I-1$

$R I=R I R * D L I+R I N S$

$C 1=(R I-D I I B) / D L I S$

$C 2=(R I+D L I H) / D L I S$

$\mathrm{C} 3=\mathrm{DLJ} \nabla / \mathrm{RI}$

$C 4=2$ * $*(R I / D L I S+C 3)$

$7 T N E R(I, J)=(C 1 * T(I-1, J)+C 2 * T(I+1, J)+C 3 *(T(I, J-1)+T(I, J+1)) 1 / C 4$ DO $8 \mathrm{I}=\mathrm{KI}, \mathrm{II}$

DO 8 J $\mathrm{z}, \mathrm{z}, \mathrm{IJ}$

EIR $=I-1$

$R I=R I R * D L I+R I \& S$

$C I=(R I-D I I H) / D L I S$

$C 2=(B I+D I I H) / D L I S$

$\mathrm{C} 3=\mathrm{DLJV} / \mathrm{PI}$

$\mathrm{C} 4=2, *(\mathrm{RI} / \mathrm{DLIS}+\mathrm{C} 3)$

8 TNER $(I, J)=(C 1 * T(I-1, J)+C 2 * T(I+1, J)+C 3 *(T(I, J-1)+r(I, J+1))) / C 4$ $R I I=(X Y I-1) * D L I+.P I N S$

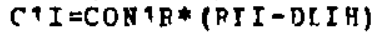

$C 2 I=C O N 2 R *(R I I+D I I H)$

C3I $=.5 * C O N 12 * D L J \nabla / R I I$

$C 4 I=C 1 I+C 2 T+2$. * $3 I$

THEN $(N I, 1)=(C 1 I * T(N I-1,1)+C 2 I * T(N I+1,1)+2 . * C 3 I * T(H J, 2)) / C 4 T$ TNER $(N I, N J)=(C 1 I * T(N I-1, N J)+C 2 I * I(N J+1, N, J)+2 . * C 3 I * T(N I, N J-1)) / 24 I$ DO $9 \mathrm{~J}=2, \mathrm{IJ}$

- TNEN $(N I, J)=(C 1 I * T(N I-1, J)+C 2 T * T(N I+1, J)+C 3 I *(T(R I, J-1)+$

T $(N I, J+1)) 1 / C 4 I$

RI $S=(X N I I-1) * D T . I+.R I N S$

$C 1 S=C O N 2 R *$ (RTS - DLIR)

C $2 S=H *$ RIS /DLI

C $3 S=.5 * C O N 2 * D L J V / R I S$

$C 4 S=C 15+C 2 S+2$. $* 3 S$

TNEN $(N I I, 1)=(C 1 S * T$ (NII $-1,1)+C 2 S * T A+2 * C 3 S * T(N I T, 2)) / C 4 S$

$T N P,(N I I, N J)=(C 1 S * T(N I I-1, N J)+C 25 * T A+2, * C 3 S * I(N I I, N J-1)) / C 4 S$ DO $10 \mathrm{~J}=2, \mathrm{LJ}$

10 TNEN $(N I I, J)=(C 1 S * T(N I I-1, J)+C 2 S * I A+C 35 *(T(N I I, J-1)+T(N I I, J+1)))$ I C4S

DO $85 \mathrm{I}=2, \mathrm{MI}$

DC. $85 \mathrm{~J}=\mathrm{KJ}, \mathrm{NJ}$

IF (DABS(T (I,J)-TNEN (J,J))-EPS) $95,85,40$

85 CONTINUE

DO $27 I=K I, N T I$

$0027 \mathrm{~J}=1, \mathrm{NJ}$

IP (DABSIT $(I, J)-T N B$ (I, J)) -EPS) $27,27,40$

27 CONTINUE

GO TO 9 n

4O DO $31 \quad I=2$, HI

Fig. A.1 (Contd.) 
0176

0.907

0108

rino

a11

0111

C 112

ก113

$+114$

$\because 115$

ก.116
DC $31 \mathrm{~J}=\mathrm{KJ}, \mathrm{NJ}$

उ $T(I, J)=T N P Q(I, J)$

DO $32 I=R T, N I I$

DO $32 \mathrm{~J}=1, \mathrm{~N} J$

3) $T(T, M)=T N R(I, J)$

Gก TO 90

or NRITE $(6,3 \cap)$ (THEN (NII, J) , J=1, NJ)

JA FCRMAT (5n22.1)

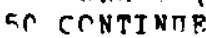

STOP

FND

Fig. A.1 (Contd.) 
TABLE A.1. Definitions of Input Variables for Program in Fig. A.1

\begin{tabular}{|c|c|c|}
\hline $\begin{array}{l}\text { Variable } \\
\text { Name }\end{array}$ & Definition & Unit \\
\hline ACMAX & $\begin{array}{l}\text { Maximum (half) angular span of the cavity } \\
\text { lo be tested in the program }\end{array}$ & Degree \\
\hline ACMIN & $\begin{array}{l}\text { Minimum (half) angular span of the cavity } \\
\text { to be tested in the program }\end{array}$ & Degree \\
\hline CON1 & Therma! conductivity of refractory & $\mathrm{Btu} / \mathrm{h} \cdot \mathrm{ft}^{2} \cdot{ }^{\circ} \mathrm{F} / \mathrm{in}$. \\
\hline CON2 & Thermal conductivity of steel shell & $\mathrm{Btu} / \mathrm{h} \cdot \mathrm{ft}^{2} \cdot{ }^{\circ} \mathrm{F} / \mathrm{in}$ \\
\hline DELL & $\begin{array}{l}\text { Number of divisions per inch in the radial } \\
\text { direction--a parameter to determine mesh } \\
\text { size, } 1 / \mathrm{Cr}\end{array}$ & l/in. \\
\hline DLJ & Mesh gize in the angular direction, $\Delta E$ & D.griee \\
\hline DPMAX & $\begin{array}{l}\text { Maximum depth of the cavity te be tosted } \\
\text { in the program }\end{array}$ & in. \\
\hline I)PMIN & $\begin{array}{l}\text { Minimum drepth of the cavity to be testerl } \\
\text { in the program }\end{array}$ & in. \\
\hline EPS & Fipsilon--convergence criterion & $\mathrm{F}$ \\
\hline$H$ & Convective he at -transfer coefficient & $\mathrm{Itu} / \mathrm{h} \cdot \mathrm{Ct}^{2} \cdot \mathrm{F}$ \\
\hline KINS & Insider raclius of the transfer line & in. \\
\hline ROUT & (Mutside radius of thr transfir r linc. & in. \\
\hline SPAC:F:I & $\begin{array}{l}\text { Ine rement of the cavity depth usidl in a } \\
\text { sreries of trosts of cavity sizes }\end{array}$ & in. \\
\hline SPACF.J & $\begin{array}{l}\text { Increment of the cavity (angular) span } \\
\text { used in a series of tests of cavity sizess }\end{array}$ & Degre.. \\
\hline TA & Ambient trmperature. $T_{\infty}$ & $\mathrm{F}$ \\
\hline $\mathrm{TR}$ & Ihickness of the refractory & in. \\
\hline T'T & Retractory (inner) surface temperature, $\mathrm{T}_{\mathrm{i}}$ & $r$ \\
\hline
\end{tabular}

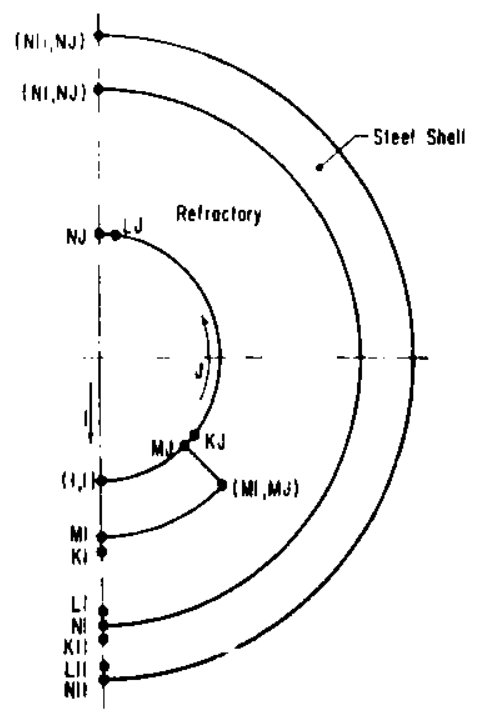

Fig. A.2

Schematic Diagram Showing Nodal Locations in a Two-dimensional System. ANL Neg. No. 306-80-147. 
Hence, they must be recalculated every time the I index is varied. This makes them reappear in nearly all DO loops in this part of the program. Of course, if desired, the set of statements between lines 45 and 50 could be written as a subprogram. But this would be done at the expense of the simplicity of other parts of the program.

8. Starting on line 96 and ending on line 103, two DO loops are used to check the convergence of the temperature data. If the convergence is not met, the program branches to statement 40 to as sign the new temperature (TNEW) data to $\mathrm{T}$, again using two DO loops. The GO TO statement on line 111 causes the computer to transfer control to statement 80 (line 44) to reinitiate iteration. This process is repeated until the convergence is realized. Then a normal exit from the DO loop (line 103) advances the computer control to line 104, where another GO TO statement instructs the computer to write the surface-temperature data according to the desired format.

To improve accuracy, all computations are carried out in double precision. 


\section{APPENDLX B \\ Computer Prugram for a Three-dimensional System}

A computer program for evaluating the surface temperature in a threedimensional system is shown in Fig. B.l. The method for indexing the nodal points in a three-dimensional system follows that of the two-dimensional system (Fig. A.2), except that a third coordinate is added along the axial direction (see Fig. B.2). Additional variables required for computer inputs are defined in Table B.1. Since the three-dimensional system represents a general case, the computer program was written with sufficient generality to perform the following functions:

1. Evaluate and tabulate the surface temperature on the steel shell.

2. Plot the surface temperature in three dimensions.

3. Plot the configuration of the cavity in three dimensions.

4. Construct an isotherm map for the surface-temperature distribution, with alphabets in the map to label various isotherm bands.

5. Calculate the total volume lying under the three-dimensicnal temperature surface that was previously plotted in item 2 above.

6. Tabulate the areas enclosed inside isotherm loops and the volumes lying under the temperature surface, with both evaluated as functions of temperature.

7. Use punched cards to record output data that include the depth, angular span and height of the tested cavity, the data for item 5 above, and the highest and lowest teinperature readings observed on the surface of the steel shell.

8. Plot the data given in item 6 above for graphical presentation.

In the development of the computer program, provisions were made to use the computer to scan the output data so that all axes in the plots were drawn with proper lengths and scales. The figures were plotted by means of Argonne's DISSPLA routines. A combination of these features, built into the program, enables the user to run a wide range of test conditions without modification of the program. This capability can be seen from the algorithm as delineated below:

1. Lines 10-16 in the program (Fig. B.1) convert SPACEI, SPACEJ, and SPACEK to integer constants that are used later to generate a wide range of cavity sizes for tests in the program.

2. Lines 17-20,27 and 28, and 43-50 calculate the index parameters for nodal locations shown in Figs. A. 2 and B.2. 


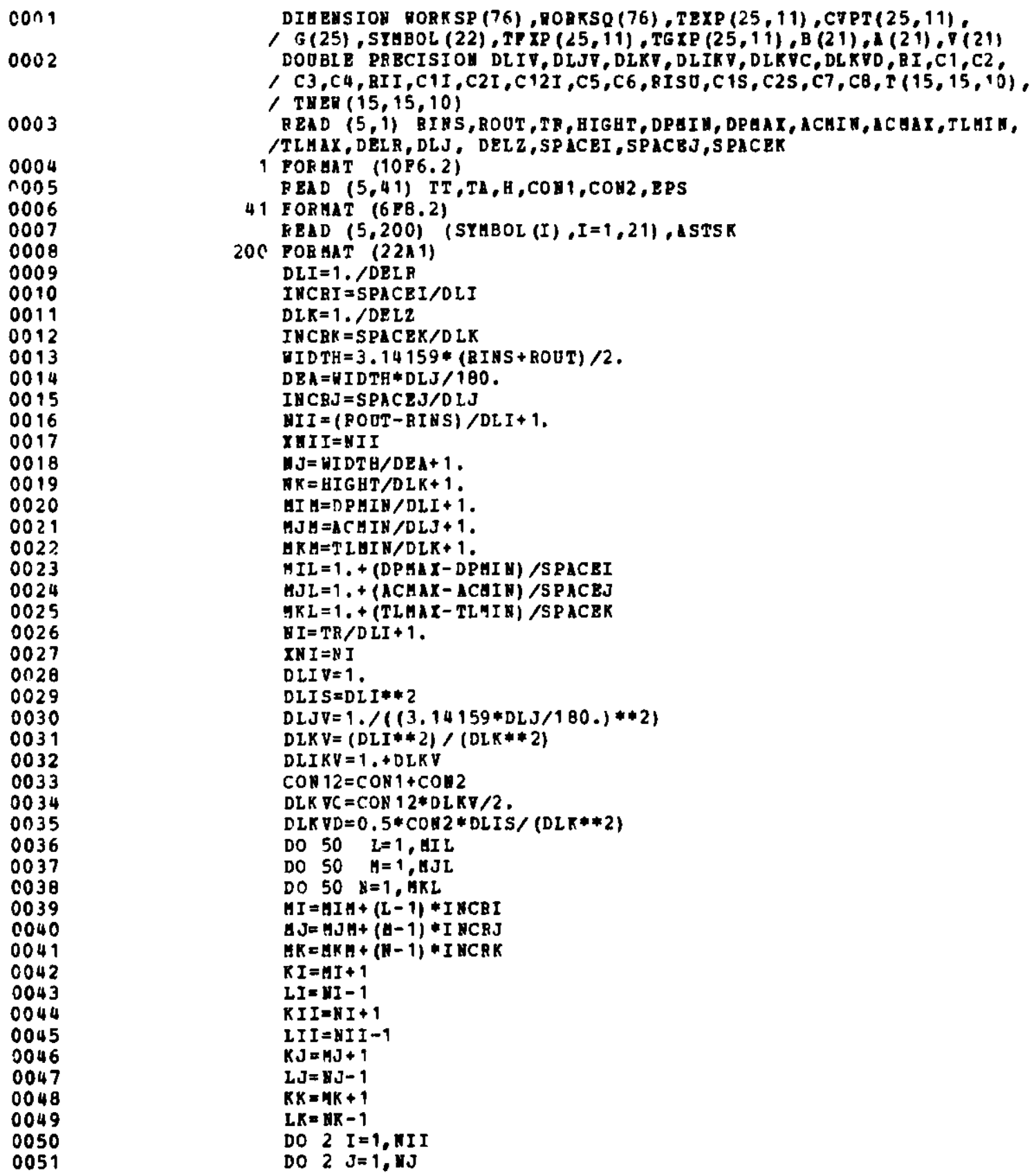

Fig. .1. Computer Program for Evaluating Surface Temperature in a Three-dimensional System 


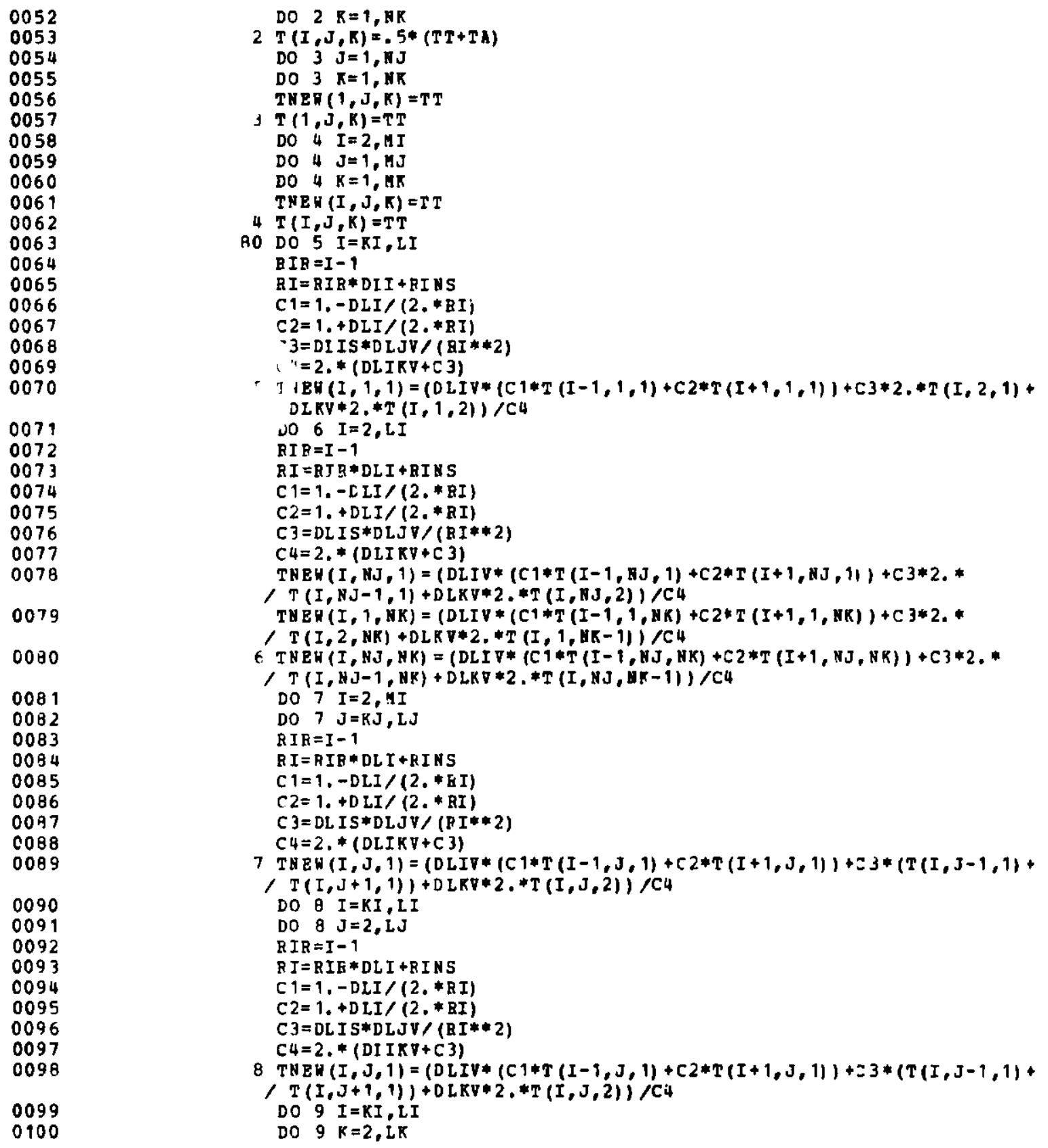

Fig. B.1 (Contd.) 


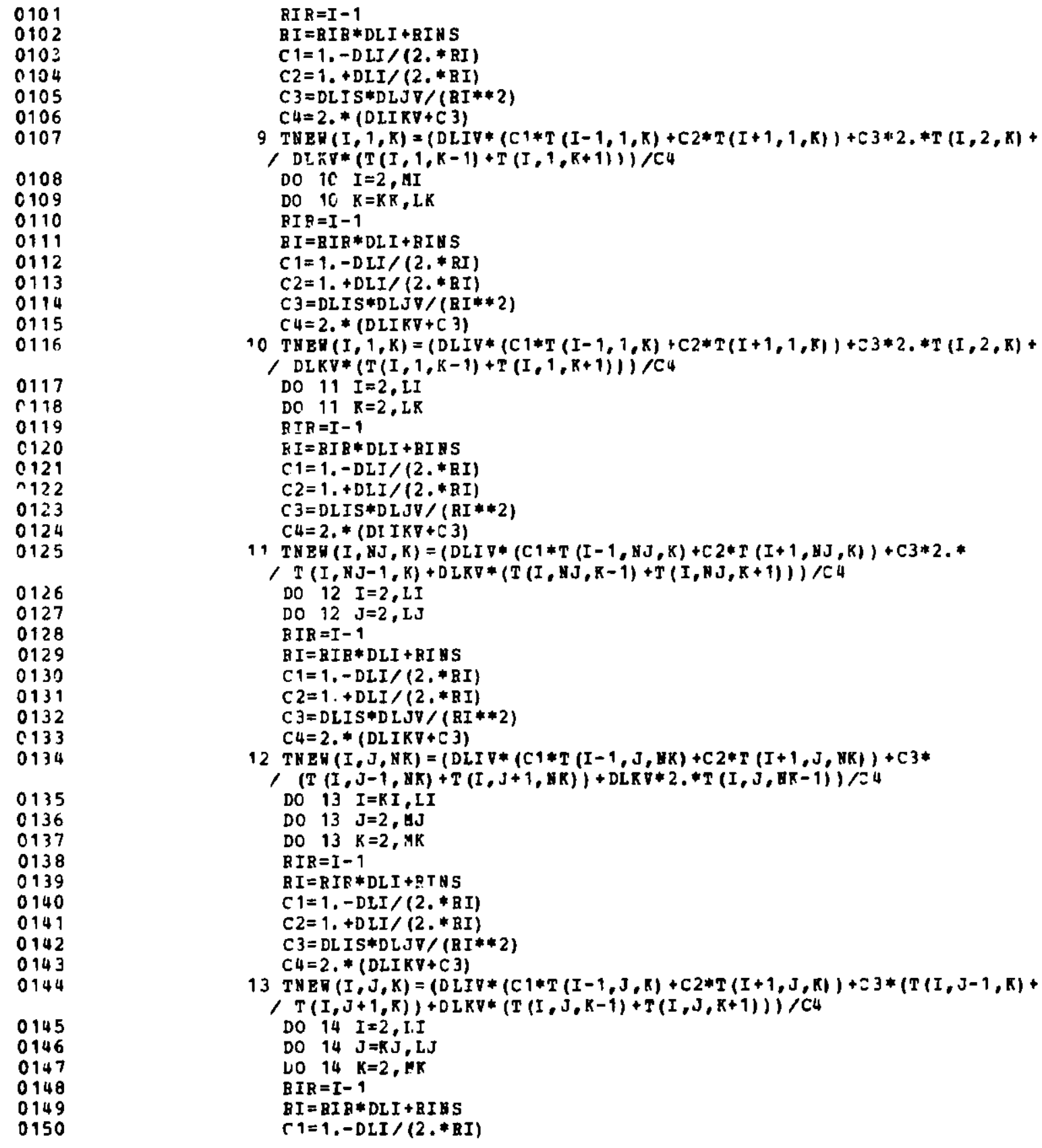

Fig. B.1 (Contd.) 
Fig. B.1 (contd.) 


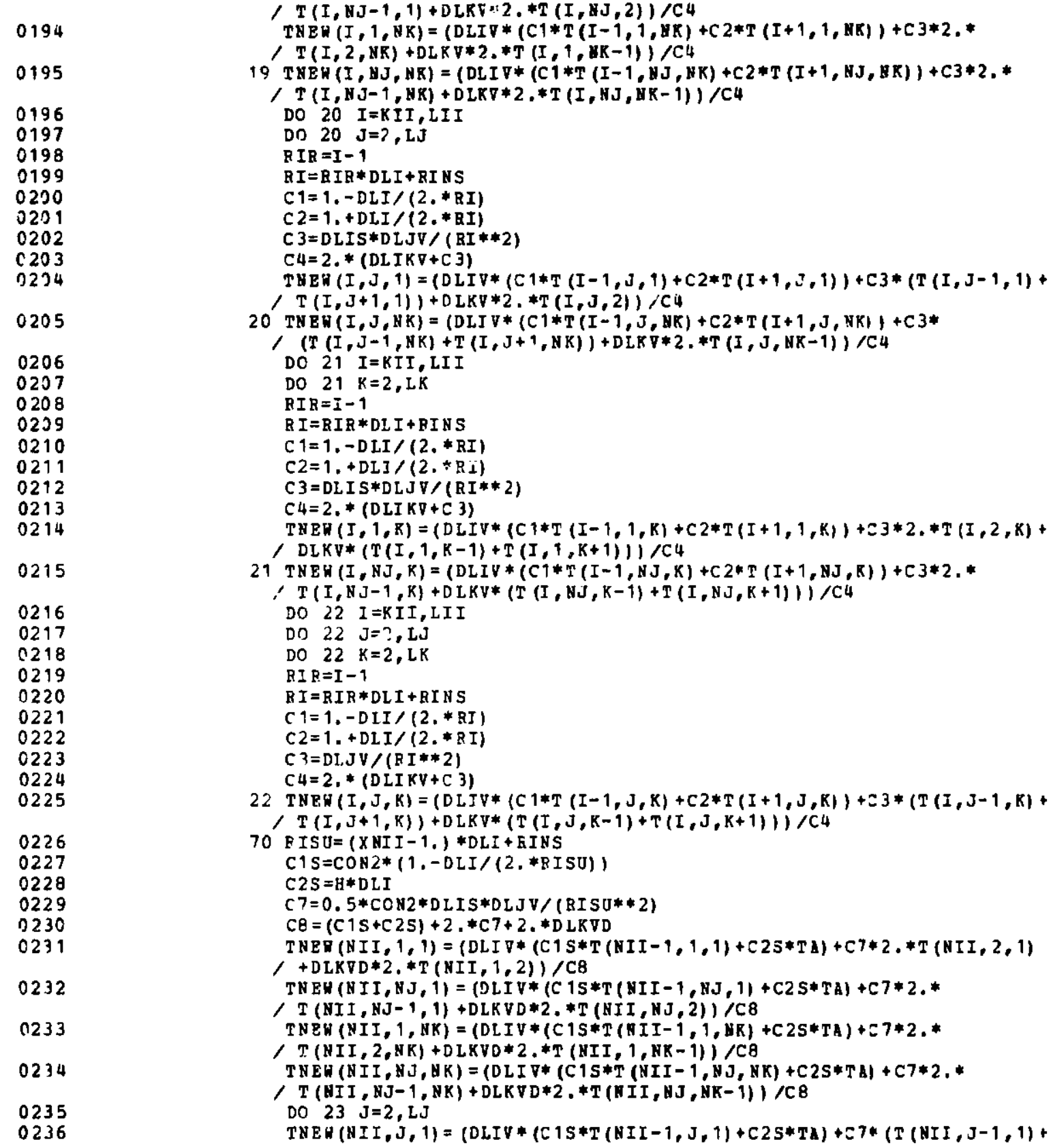

Fig. B.1 (Contd.) 
/ T(BII, J+1, 1)) +DLKVD*2, *T(NII, J,2) /CR

$23 T N E H(N I I, J, H R)=(D L I V *(C 1 S * T(N I I-1, J, N K)+C 2 S * T A)+C 7 *$ $/(T(A I I, J-1, H K)+T(M I I, J+1, M K))+D L K V D * 2, * T(N I I, J, G K-1)) / C \theta$ DO $24 K=2, L K$

TNEH (NII, $1, K)=(D L I V *(C 1 S * T(H I I-1,1, K)+C 2 S * T A)+C 7 * 2$. * T (NII, ?,K) + / DLKVD: (T (NII, $1, K-1)+T(H I I, 1, K+1))\} / C 8$

$24 T K E H(N I I, N J, K)=(D L I V *(C 1 S * T(N I I-1, N J, K)+C 2 S * I A)+C 7 * 2$. *

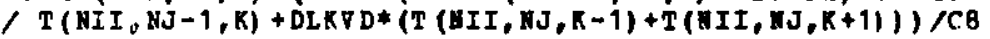
DO $25 \mathrm{~J}=2, \mathrm{LJ}$

DO $25 \mathrm{~K}=2, \mathrm{LK}$

$25 \operatorname{TNE}(N I I, J, K)=(D L I V *(C 1 S * T(R I I-1, J, K)+C 2 S * T A)+C 7 *(T(R I I, J-1, K)+$

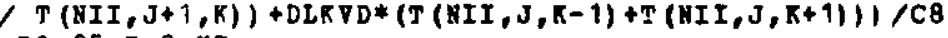

DO $85 \mathrm{I}=2, \mathrm{MI}$

DO $85 \mathrm{~J}=\mathrm{K}, \mathrm{L}, \mathrm{NJ}$

DO $85 \mathrm{~K}=1, \mathrm{MR}$

IF (DABS (T $(I, J, K)-T N E R(I, J, K))-$ EPS) $85,85,40$

85 CONTINUE

DO $27 \quad I=2$, $M I$

DO $27 \mathrm{~J}=1, \mathrm{NJ}$

DO $27 K=K K_{0}, \mathrm{BK}$

IF (DABS TT $(I, J, K)-T N E R(I, J, K))-$ BPS) $27,27,40$

27 CONTINUE

DO $26 \mathrm{I}=\mathrm{KI}, \mathrm{NII}$

DO $26 \mathrm{~J}=1, \mathrm{NJ}$

DO $26 K=1, N K$

IF (DABS( $T(I, J, K)-T N E N(I, J, K))-$ EPS) $26,26,40$

26 CONTINUE

60 TO 90

40 DC $31 \mathrm{I}=2$, $\mathrm{HI}$

DO $31 \mathrm{~J}=\mathrm{KJ}, \mathrm{NJ}$

DO $31 K=1$, $M K$

$31 T(I, J, K)=T$ NEN $(I, J, K)$

DO $32 I=K I, B I I$

DO $32 \mathrm{~J}=1, \mathrm{NJ}$

DO $32 \mathrm{~K}=1$, $M K$

$32 T(I, J, K)=T$ EBN $(I, J, K)$

DO $33 \mathrm{I}=2$, NII

DO $33 \mathrm{~J}=1, \mathrm{NJ}$

DO $33 K=K K$, NK

$33 T(I, J, K)=T$ NBN $(I, J, K)$

GO TO 80

$90 \times M I=M I$

$Y \mathrm{MJ}=\mathrm{MJ}$

$\mathrm{ZHK}=\mathrm{HK}$

DEPTH $=D L I *(X H I-1$.

ACROS $=$ DLJ* (YHJ -1.)

HICAV $=D L Y *(Z H K-1$.

DINS $=2$. *AINS

DOUT $=2, *$ ROOT

HIGHO $=2$, * HIG T T

$S H T K=R O U T-R I N S-T R$

HRITE $(6,28)$ DIYS, DOUT, RIGHO, TR, SBTK, DBPTH, ACROS, H ICAV, DLI, OLJ, / DLR,TT, TA, COH 1, COH2, B, EPS

28 FORAAT (1H 1,20 \&DIHBHSIOA:

, $21 \mathrm{HIN}$.. (TOTAL) BBIGBT=8B.2,

$I D=78,2,8$ B IH, ,OD=P8.2,

Fig. B.1 (Contd.) 
/ 4H IH. /18X, 21 HBEPBACTORY THICKHESS=P6.2,

/ 21H IN.,SHELL THICKNESS=P6,2,4H IH./13H CAVITY SIZR:,5X,

/ 6 HDEPTH=P6.2, 19H IH., (HALP) AB3IE=F7.2,5H DEG.

, 17X,15H (BALP) HEIGET $=P 7.2,4 \mathrm{H} I \mathrm{~N} . /$

/ 11H MESB SIZE : ,7X, 7HPADIAT,=P6.3,13H IM, , ABGULAR=P6.2,

, $12 \mathrm{H} \mathrm{DEG.} \mathrm{,} \mathrm{AXIAL=F6.2,} \mathrm{4H} \mathrm{IN.}$

/ $14 \mathrm{H}$ TEHPERATORES: , $4 \mathrm{X}, 15 \mathrm{HI}$ HSIDE SURFACE=

/ F10.2, 148 DEG .,ALBIENT = P8.2,5H JEG./12B PROPERTIES:,6X,

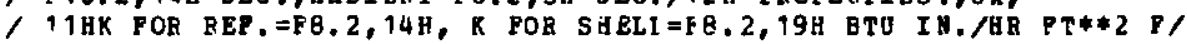

/ $18 \times, 2$ 甘H=P8.2, 15H BTO/HR TT*2 F/2OH ITERATION ERROR: E=

/ F5.2, SH OEG.///

DO $29 \quad K=1, N K$

$2 c$ URITE $(6,30)$ (TKEH (NII, J, K), J =,$N J$ )

$3 C$ FORHAT $(5020.10)$

$\mathrm{NJCT}=2 * \mathrm{NJ}-1$

NKCT $=2 * N K-1$

$\mathrm{NJDT}=\mathrm{NJ}+1$

$N K D T=N K+1$

HJET $=\mathrm{NJ}-1$

NKET $=\mathrm{HK}-1$

A N CT $=\mathrm{NJCT}$

A NKCT $=$ NKCT

BN JCT $=-(2 . * A$ HJCT $)$

BNKCT $=-(2, * A N R C T)$

CNJCT $=1.5 *$ RHJCT

MTTT=T IEN $(N I I, 1,1) / 100,+1$.

$V T T=M T T T * 100$

$\triangle T T B=T N P W(N I I, U J, N K) / 100$.

$V T B=\| T T B * 100$

$M T T R=$ ROUT $-R I N S+1$.

$\mathrm{BTT}=\mathrm{MTTR}$

DO $101 \mathrm{~J}=1$, $\mathrm{HK}$

DO $101 \mathrm{I}=1$, HJCT

IF (I-NJ) $102,102,103$

$102 \operatorname{TEXP}(I, J)=T N E W(N I I$, Y JDT $-I, J)$ GO TO 101

$103 \operatorname{TEXP}(I, J)=T N E N(N I I, I-N J E T, J)$

101 CONTINUE

DO $104 \mathrm{I}=1, \mathrm{NJCT}$

DO $104 \mathrm{~J}=1$, NRC T

IF $(\mathrm{J}-\mathrm{NK}) \quad 105,105,106$

$105 \operatorname{TFXP}(I, J)=T E X P(I, X K D T-J)$

GO TO 104

$126 \operatorname{TFXP}(I, J)=T E X P(I, J-N K E T)$

104 CONTINUE

2 HI $=$ ROOT-RINS

ZCI $=$ ROUT - RI NS - $(X M I-1) * D L$,

$\mathrm{NJFT}=\mathrm{NJ}-\mathrm{MJ}+1$

$N K P T=N K-M K+1$

NJGT $=\mathbb{N} \mathrm{J}+\mathrm{HJ}-1$

$M K G T=N K+B K-1$

NJ HT $=$ N J FT +1

NKH $T=M X P T+1$

NJI $T=N J G T-1$

NRI $T=N K G T-1$

Fig. B.1 (Contd.) 


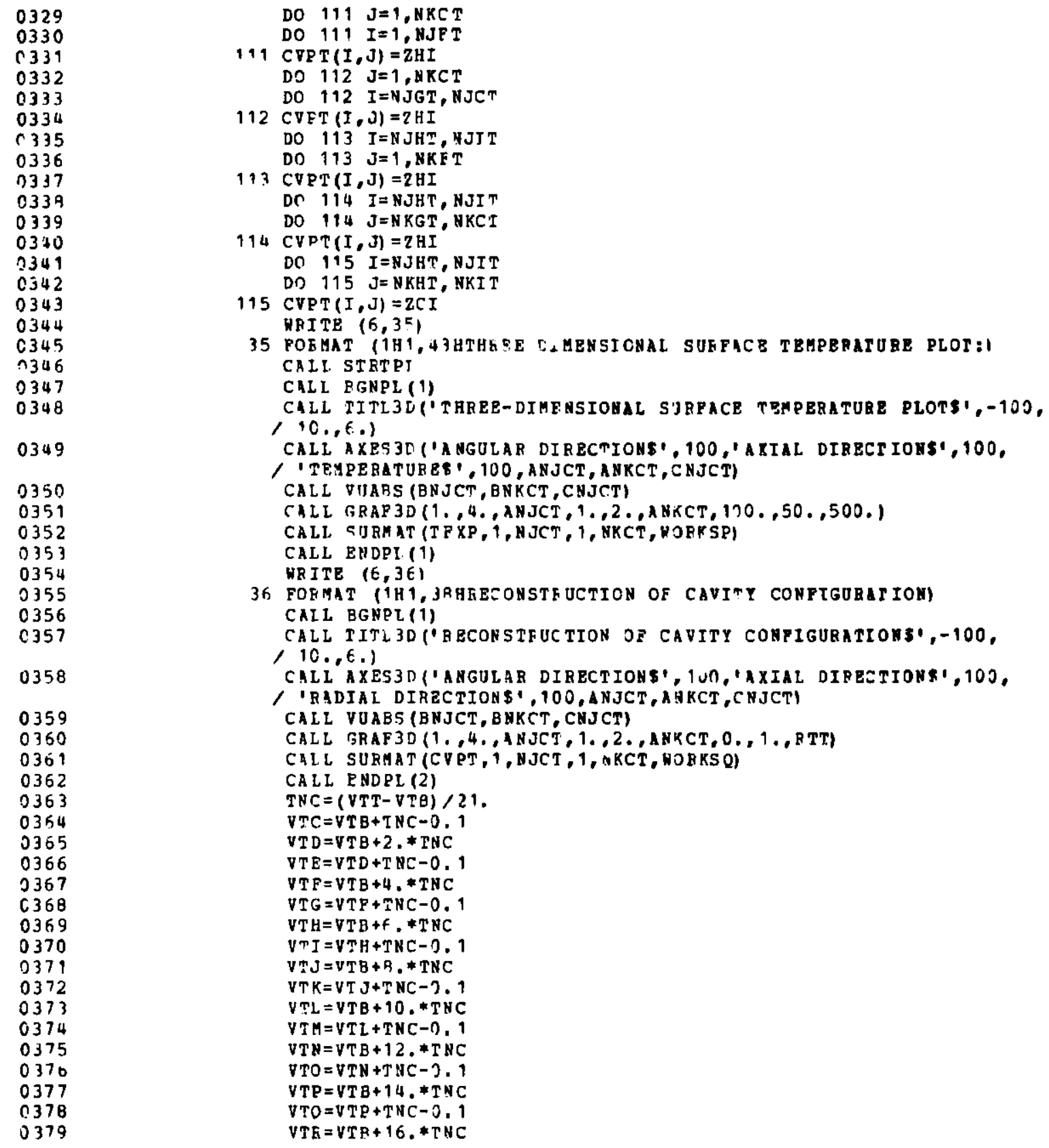

Fig. B.1 (Contd.) 


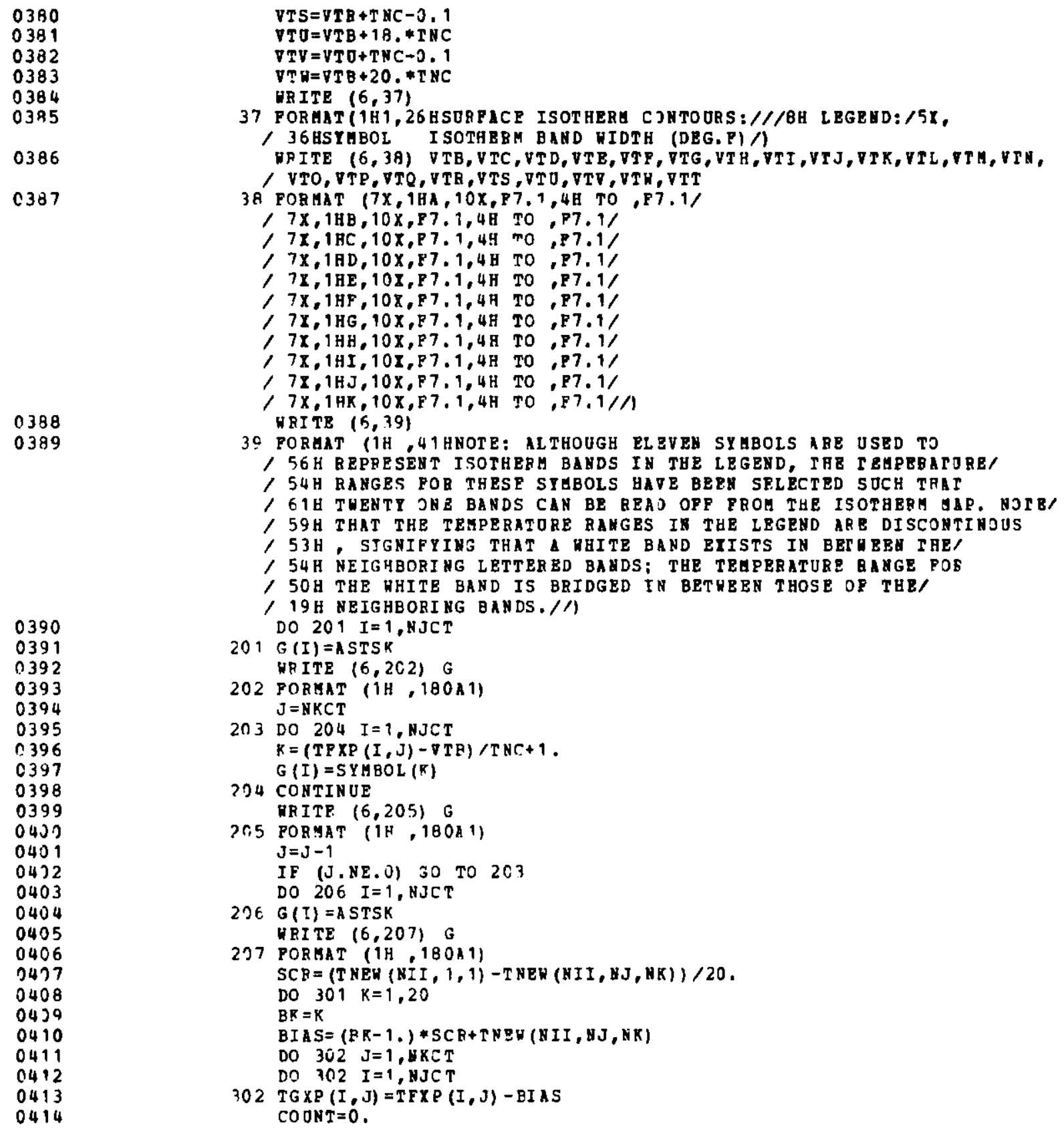

Fig. B.1 (Contd.) 


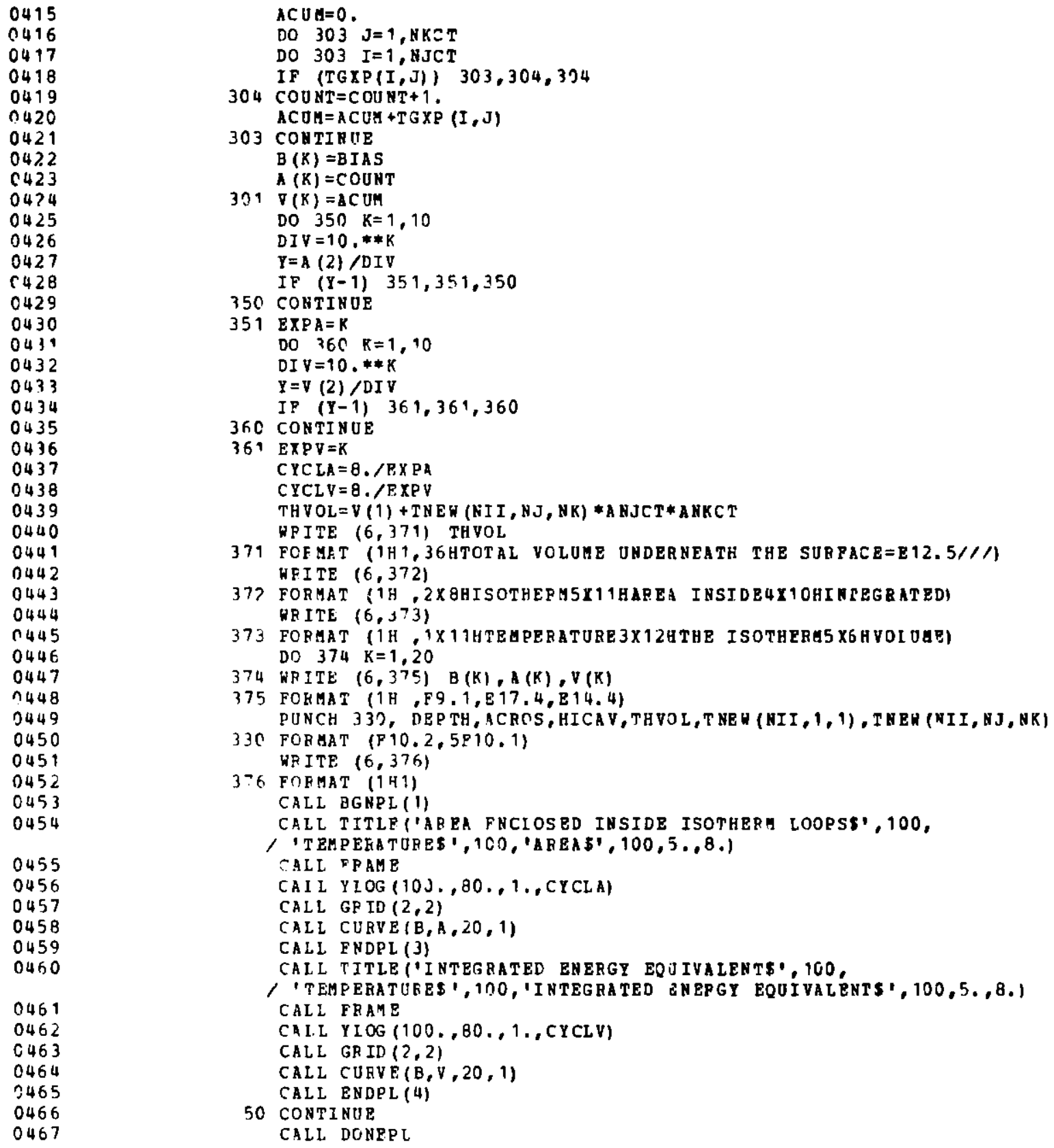

Fig. B.1 (contd.) 
PCRTAAN IV G1 EFIEACF 2.0

0468

STOP

3469

END

Fig. B.1 (Contd.) 


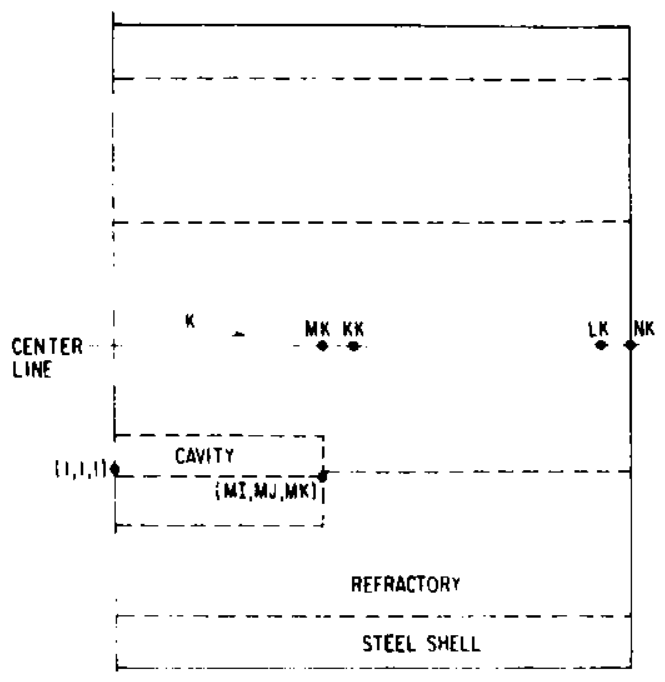

Fig. B.2

Schematic Diagram Showing Nodal Locations in the Axial Direction in a Three-dimensional System

TABLE B.1. Definitions of Additional Input Variables for Program in Fig. B. ${ }^{a}$

\begin{tabular}{ll}
\hline Variable Name & \multicolumn{1}{c}{ Definition } \\
\hline DELZ & $\begin{array}{l}\text { Number of divisions per inch in the } \\
\text { axial direction--a parameter to } \\
\text { determine mesh size, } 1 / \Delta z\end{array}$ \\
HIGHT & $\begin{array}{l}\text { Half-height (length) of the transfer } \\
\text { line }\end{array}$ \\
SPACEK & $\begin{array}{l}\text { Increment of the cavity height usted } \\
\text { in a series of tests of cavity sizes }\end{array}$ \\
TLMAX & $\begin{array}{l}\text { Maximum (half) height of the cavity } \\
\text { to be tested in the program } \\
\text { TLMIN }\end{array}$ \\
& $\begin{array}{l}\text { Minimum (half) height of the cavity } \\
\text { to be tested in the program }\end{array}$ \\
\hline
\end{tabular}

a This table is to be used together with Table A. I for definitions of all input variables.

3. Lines 21-29 calculate the minimum and maximum indexes for the cavity sizes in three coordinates. MIL, MJL, and MKL are subsequently used as index parameters for DO loop 50 (lines 37-39); MIM, MJM, and MKM are used to specify the cavity boundary on lines $40-42$.

4. Lines 30-36 define and compute parameters that are later used in the temperature equations. These parameters are related to physical quantities as follows: 


$\begin{array}{ll}\text { Line } 30 & \text { DLUS }=(\Delta r)^{2} \\ \text { Line } 31 & \text { DLJV }=1 /(\pi \Delta \theta / 180)^{2} \\ \text { Line } 32 & \text { DLKV }=(\Delta r / \Delta \mathbf{z})^{2} \\ \text { Line } 33 & \text { DLIKV }=1+(\Delta r / \Delta z)^{2} \\ \text { Line 34 } & \text { CONl2 }=k_{1}+k_{2} \\ \text { Line 35 } & \text { DLKVC }=\left(k_{1}+k_{2}\right)(\Delta r / \Delta z)^{2} / 2 \\ \text { Line 36 } & \text { DLKVD }=k_{2}(\Delta r / \Delta z)^{2} / 2\end{array}$

5. Lines 51-54 initialize all nodal temperatures using $\left(T_{i}+T_{\infty}\right) / 2$.

6. Lines 55-63 set the temperatures at the refractory surface and inside the cavity as $\mathrm{T}_{i}$, which is unchanged in the course of iteration.

7. Lines 64-244 calculate nodal temperatures. Again, preceding each temperature-calculation step, a series of computations is made of parameters that appear in the TNEW equation. Right after the computation of temperatures at the refractory/steel interface, a transfer of control is built into the program (line 185). This is done to account for the fact that the program takes the thickness of steel shell as one of the inputs. In some instances, the selected mesh sizes are large while the steel shell is so thin that mesh points are no longe $r$ present inside the steel shell. Under these circumstances, $\mathrm{KII}=\mathrm{NII}, \mathrm{NI}=\mathrm{LII}$, and LII < KII. The built-in logic (line 185) enables the computer to bypass lines 186-226 and proceed directly to compute TNEW at the steel surface once the interfacial nodal temperatures have been found.

8. Lines 245-259 check the convergence of the calculated temperature. If the convergence is not realized, the program redirects the control to statement 40 (line 261), where three DO loops (lines 261-271) are used to reassign TNEW values to $T$ at each nodal point. The GO TO statement on line 273 causes the computer to return to statement 80 (line 64) and to repeat iteration.

Eventually, the convergence criterion is met, and a series of normal exits from DO loops 85,27 , and 26 is sequentially effected to advance the computer control to line 274 via the GO TO statement on line 260 .

9. Lines 274-285 compute and write those quantities that are later used in the legend in the temperature tabulations. This tabulation is made possible by lines $286-288$.

10. Lines 289-363 are used to plot the surface temperature and the cavity configuration, both in three dimensions. Before Argonne's DISSPLA graphic routines are called, some preparations are made in the program. 
Because only one quadrant of the total system was used in the analysis, the calculated temperature data only cover one-fourth of the total surface. Arrangements must therefore be made to extend the temperature data to the other three-quarters using planes of symmetry. The reconstruction of the temperature field is carried out in the computer program as follows. First, lines 289-294 are used to calculate the indexing parameters for DO loops, as well as other indexes to extend the temperature array. This is followed by lines 295-299 to calculate parameters that are later used in the computer graphics. Since the temperature axis must be properly labeled to show temperature scales in the succeeding three-dimensional plot, the end-point temperature readings on the axis must be determined from the minimum and the maximum temperature data. Physically, these temperatures are, respectively, TNEW(NII, NJ, NK) and TNEW(NII, 1, 1). Hence, the end-point temperatures can be determined by using lines 300-303. In a similar manner, the end points of the radial axis in the cavity configuration plot (discussed later) are also estimated using lines 304 and 305. Finally, two DO loops (lines 306-319) are used to reconstruct the total temperature field.

The next set of statements (lines $320-344$ ) is used to identify the cavity contours. The thickness ( $\mathrm{ZHI}$ ) of the transfer line is computed via line 320 , and the position of the cavity bottom $(Z C I)$ is determined via line 321. Again, eight statements (lines 322-329) are used to compute indexing parameters that appear in the succeeding DO loops (lines 330-344) and thus to reconstruct the cavity configuration in three dimensions.

The preparation for three-dimensional plots is now complete. The surface temperature is plotted using lines 345-354; the cavity configuration is plotted using lines 355-363. The computer graphics used in these plots are based on Argonne's DISSPLA routines. Procedures used to develop this part of the program are given in Ref. 28.

11. Lines 364-408 are used to make an isotherm map. The legend of the map is dealt with first. The prograrn divides the temperature span (VTB to $\mathrm{VTT}$ ) into 21 bands (line 364). Then the temperature ranges represented by these bands are calculated using lines 365-384. Starting from line 385, the program prepares the legend of the map. Alphabets A-K are used to denote bands in the legend. To explain why 11 alphabets can be used to represent 21 bands, a short statement is injected and written (lines 389 and 390) as part of the output.

Lines 391-408 spell out how the isotherm map is constructed. The map is marked with asterisks for upper and lower boundaries (lines 391-394 and 405-408). Then the temperature data are examined point by point, coded with proper alphabets, and printed sequentially on the map (lines 395-403).

12. Lines 409-426 are used to calculate the areas enclosed inside isotherm loops and the volumes contained under the temperature surface, but lying above a given temperature level. Both of these data are calculated as a function of temperature. 
The algorithm for this part of the program starts with the division of the total temperature range [TNEW(NII, NJ, NK) to $\mathrm{TNEW}(\mathrm{NI}, 1,1)]$ into 20 equal intervals (line 409). Then a bias temperature is calculated (line 412) inside a DO loop (DO 301). By calculating TGXP (line 415) and using the IF statement on line 420 , we can compute the area enclosed inside an isotherm (i.e., COUNT) and the volume contained below the temperature surface (i.e., ACUM). These calculated data are stored together with the BIAS value into $A, V$ and $B$ arrays.

13. The $A$ and $V$ data calculated above may span several orders of magnitude for the range of the bias temperature tested. To plot these $A$ and $\mathrm{V}$ curves requires the use of semilog coordinates with the log scale used for $A$ and $V$ axes. The values of $A$ and $V$ at two ends of the log axis must be predetermined before plotting. This is accomplished by inclusion of lines 427440 in the program.

A typical computation to evaluate the number of cycles required to plot the A data is given in lines 427-432. The exponent thus determined is stored as EXPA or line 432. A similar procedure is followed in lines 433438 to determine the number of cycles for $V$. Then, lines 439 and 440 are used to convert EXPA and EXPV to parameters CYCLA and CYCLV, which are later used in the graphics routines.

14. The program is also designed to calculate the "total" volume lying under the temperature surface (see line 441). This piece of data is written together with the calculated $A$ and $V$ data as a part of data output (lines 442 450). To facilitate use of these data for analysis, the program also reproduces outputs on punched cards (line 451). Here the data punched are: cavity depth, cavity angular span, cavity height, the total volume lying under the temperature surface, and the highest and lowest temperature readings observed in the surface-temperature array.

15. Lines 453-467 are used to plot the area enclosed inside isotherm loops and the integrated energy-equivalent curves, using $\mathrm{A}$ and $\mathrm{V}$ data. For simplicity, the title "integrated energy equivalent" is used. Again, the portion of the program developed for computer graphics is based on Argonne's DISSPLA routine s. $^{29}$ 


\section{APDENDIX C \\ Computer Program for Evaluating Emissivity Effects}

A computer program for correction of surface emissivity effects is presented in this appendix (Fig. C.1). The program takes the following as inputs:

D Distance from camera to the center of the transfer line.

ROUT Outside radius of the transfer line.

$\mathrm{CN}$ Optical constant $\mathrm{n}$ in the complex index of refraction ( $\mathrm{n}-\mathrm{ik}$ ).

$\mathrm{CK}$ Optical constant $\mathrm{k}$ in the complex index of refraction.

The computer program is able to produce the following as outputs:

1. Tabulations of polar angle $(\theta)$, view angle $(\beta)$, and emission angle $(\alpha)$.

2. Tabulation of emissirity.

3. Plot of polar-to view-angle conversion curve.

4. Plot of polar - to emission-angle conversion curve.

5. Plot of directional emissivity curve.

A DO loop (line 2) was invoked in the program to make runs for four test conditions. This loop may be removed if desired. 


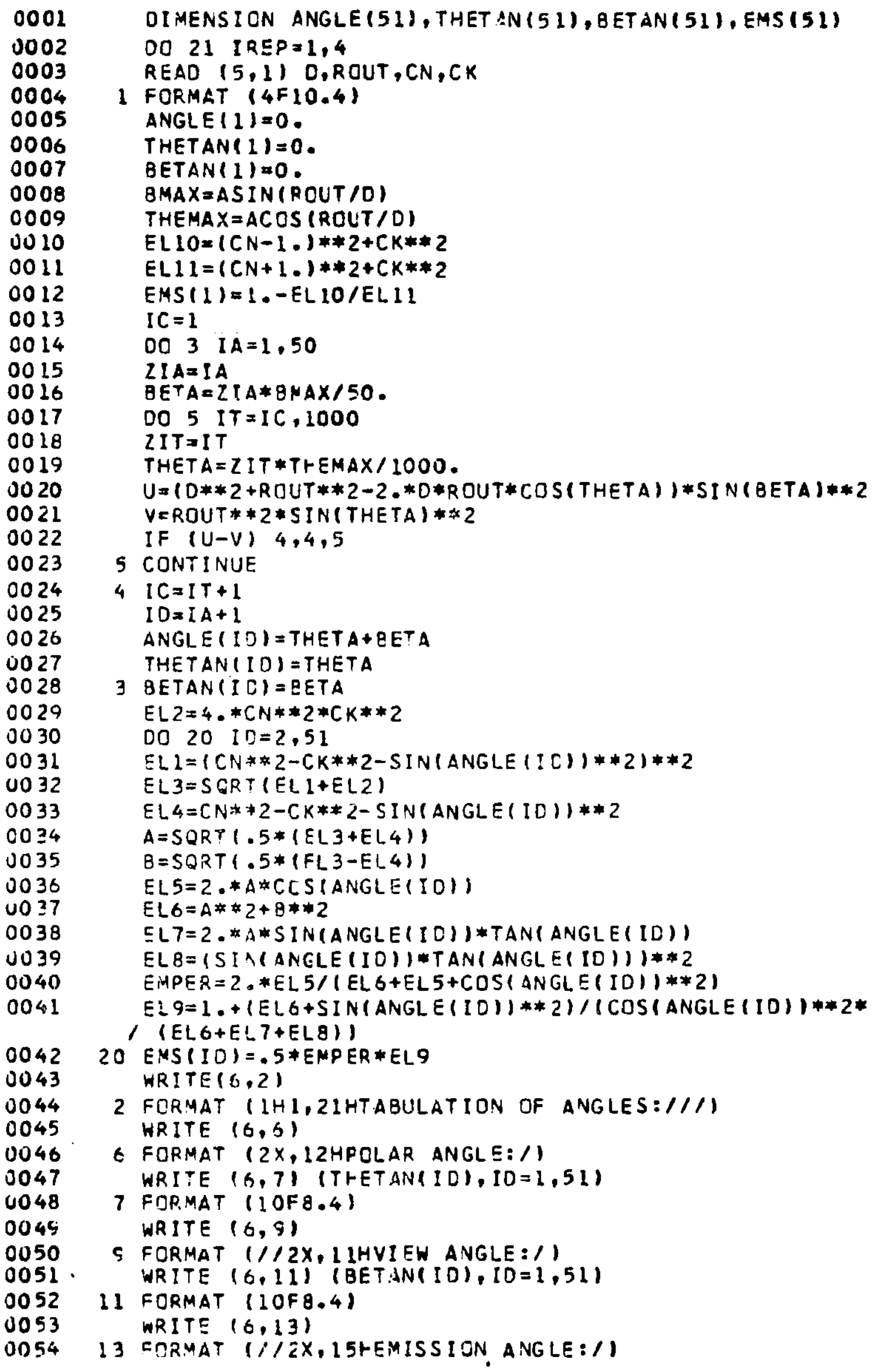

Fig. C.1. Computer Program for Correction of Emissivity Effects 


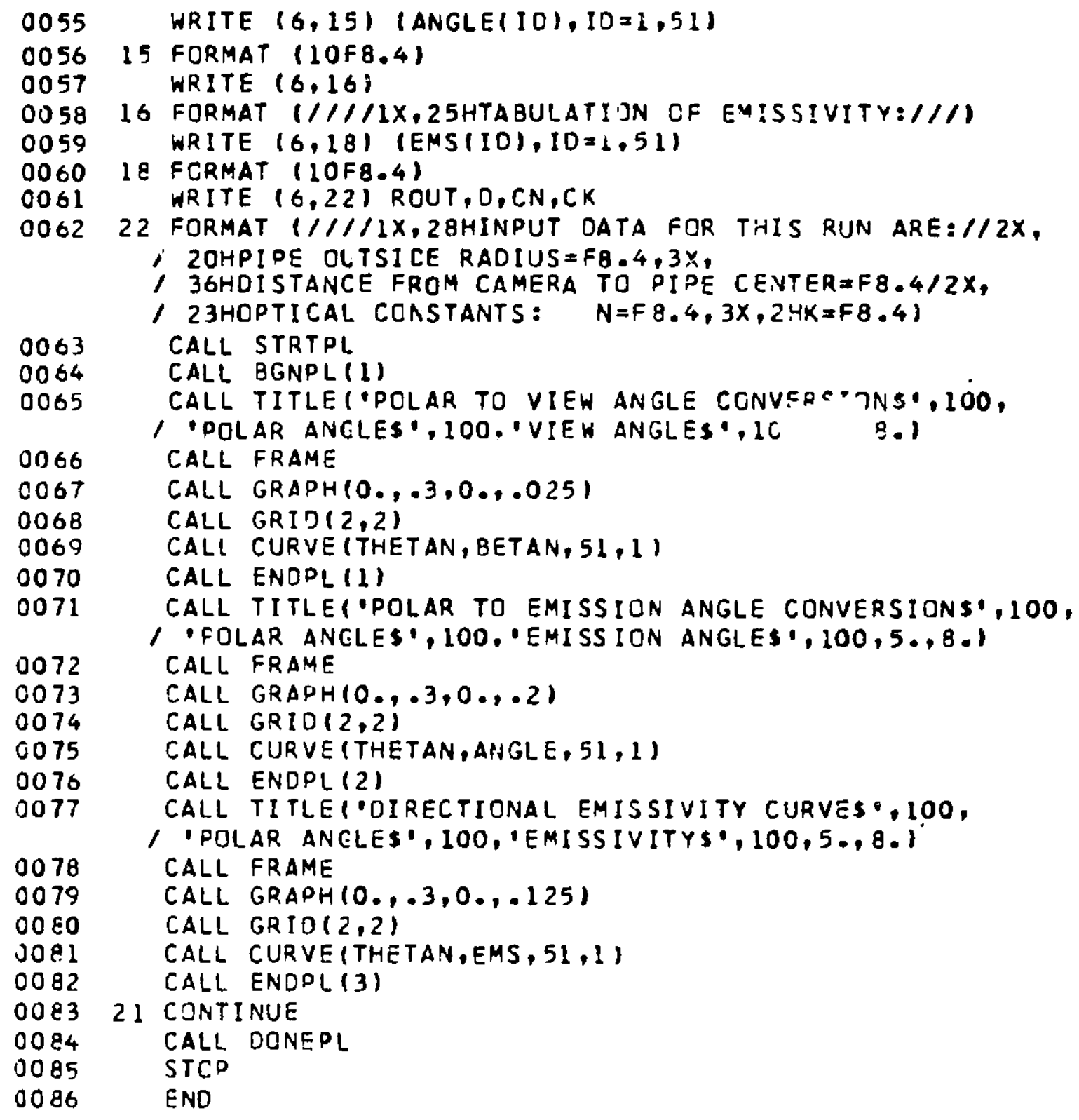




\section{APPENDIX D}

\section{Derivation of Equations for Estimating Limiting Temperatures}

The simplified problem that will be used to check the numerical solution consists of a cylindrical pipe with a two-layer wall, made of materials with conductivities $k_{1}$ and $k_{2}$. There is no contact resistance at the interface between these two materials. Only radial heat flow is considered, and the problem is analyzed under steady-state conditions. The problem can be formulated as follows:

In the inner wall, the governing equation for heat conduction is

$$
\frac{\partial}{\partial r}\left(r \frac{\partial T}{\partial r}\right)=0
$$

with the boundary condition given as

$$
\mathrm{T}_{\mathbf{r}}\left(\mathrm{r}_{\mathrm{i}}\right)=\mathrm{T}_{\mathrm{i}} \text {. }
$$

In che outer wall, the governing equation is

$$
\frac{\partial}{\partial r}\left(r \frac{\partial T_{s}}{\partial r}\right)=0
$$

with the boundary condition given as

$$
-k_{s} \frac{\partial T_{s}\left(r_{0}\right)}{\partial r}=h\left[T_{s}\left(r_{0}\right)-T_{\infty}\right]
$$

At the interface, the following; two conditions hold:

$$
\begin{aligned}
& \mathrm{T}_{\mathbf{r}}\left(\mathrm{r}_{\mathrm{m}}\right)=\mathrm{T}_{\mathrm{s}}\left(\mathrm{r}_{\mathrm{m}}\right) ; \\
& \mathrm{k}_{\mathrm{r}} \frac{\partial \mathrm{T}_{\mathbf{r}}\left(\mathrm{r}_{\mathrm{m}}\right)}{\partial \mathrm{r}}=\mathrm{k}_{\mathrm{s}} \frac{\partial \mathrm{T}_{\mathrm{s}}\left(\mathrm{r}_{\mathrm{m}}\right)}{\partial \mathrm{r}} .
\end{aligned}
$$

The exact solution for the above problem is

$$
T_{s}-T_{\infty}=\frac{T_{i}-T_{\infty}}{\frac{k_{s}}{k_{r}} \ln \frac{r_{i}}{r_{m}}+\ln \frac{r_{m}}{r_{0}}-\frac{k_{s}}{h r_{0}}} \ln \frac{r}{r_{0}}-\frac{T_{i}-T_{\infty}}{\frac{k_{s}}{k_{r}} \ln \frac{r_{i}}{r_{m}}+\ln \frac{r_{m}}{r_{0}}-\frac{k_{s}}{h r_{0}}} \frac{k_{s}}{h r_{0}} .
$$

Hence, the surface temperature can be expressed as

$$
T_{s}\left(r_{0}\right)=T_{\infty}-\frac{T_{i}-T_{\infty}}{\frac{k_{s}}{k_{r}} \ln \frac{r_{i}}{r_{m}}+\ln \frac{r_{m}}{r_{0}}-\frac{k_{s}}{h r_{0}}} \frac{k_{s}}{h r_{0}} .
$$




\section{APPENDIX E \\ Computer Program for a Two-dimensional System Fitted with a Telltale Rib}

The two-dimensional system described in Appendix A was modified by adding a rib to the outer steel shell. The rib, which penetrates into the refractory lining, can presumably help detect the condition of the refractory lining, and therefore represents an improvement in the design of the transfer line. A computer program for studying temperature distribution in this modified system is presented in Fig. E.l.

Obviously, the presence of the telltale rib lengthens the computer program considerably. The program was developed on the assumption that the rib was made of a material of conductivity CON3 (see lines 6 and 7 in the program). There is no contact resistance between the rib and the refractory lining. For convenience of formulation, the rib has a tapered profile (see Fig. 17 of the text). The center of the rib is located at index NQJ; the thickness of the rib is $2(\Delta \theta)$ (lines 29-31 in the program). To test the effect of rib location on the temperature distribution a DO loop (line 28) was written into the program to relocate the rib as desired. 


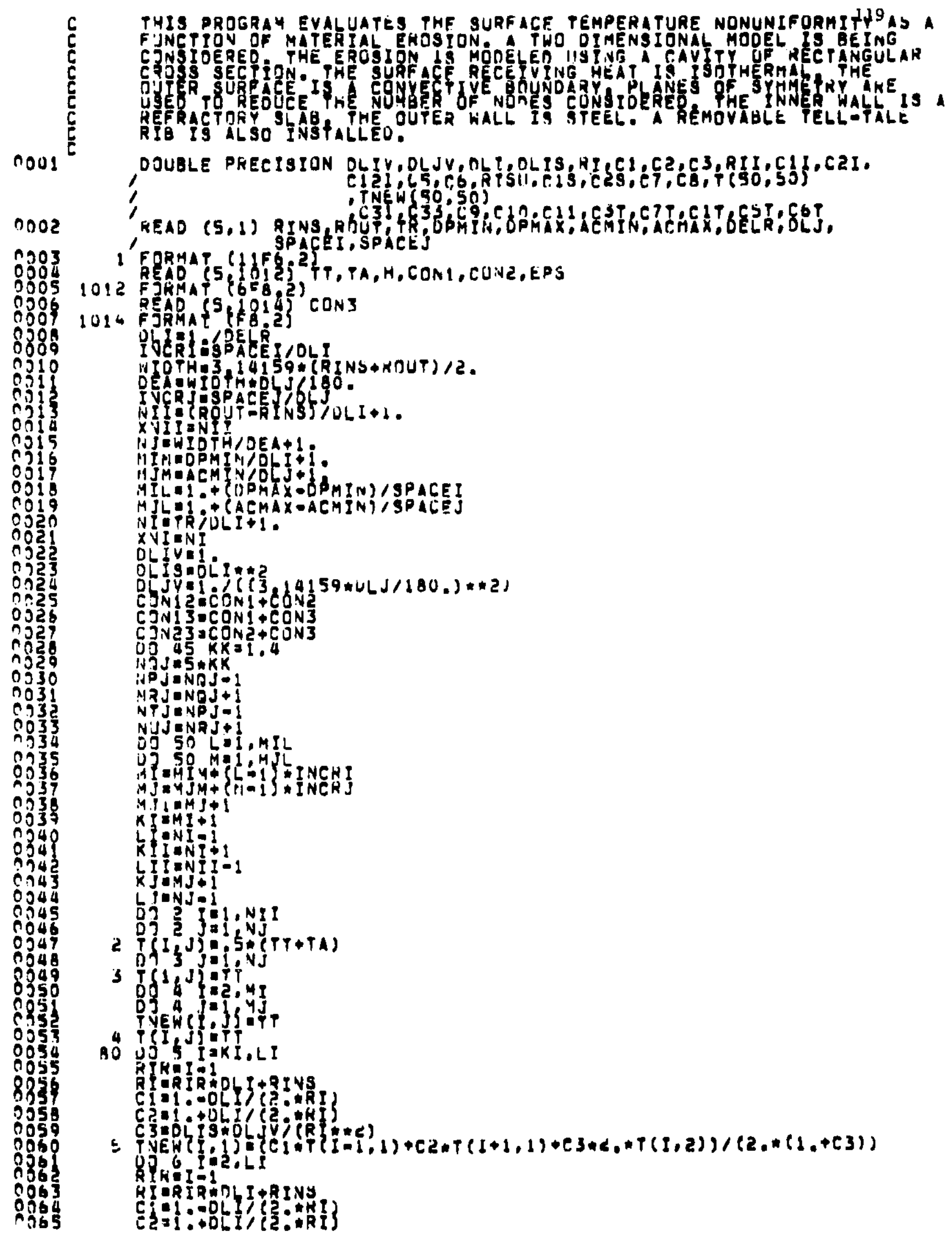

Fig. E.1. Computer Program for Evaluating Surface Temperature in a Modified Two-dimensional svstem Containing a "Telltale Rib" 


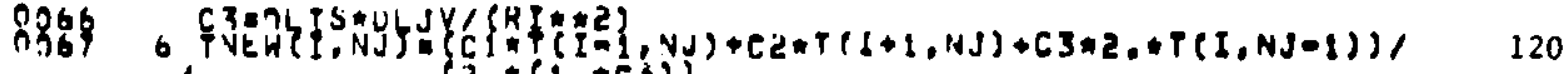

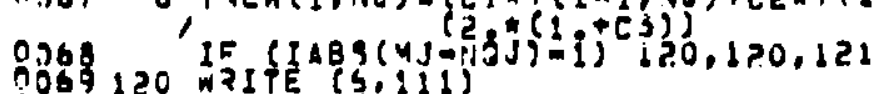

Oด70 III FJRMAT (IHI)

0071

80730100 T5 45

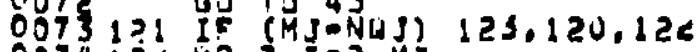

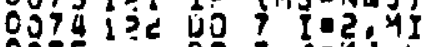

กิ75 D

$0076 \quad K I R=1-1$

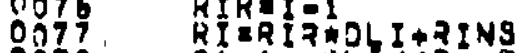

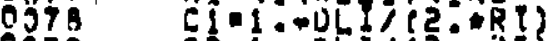

6079

0389, C 300 i IS

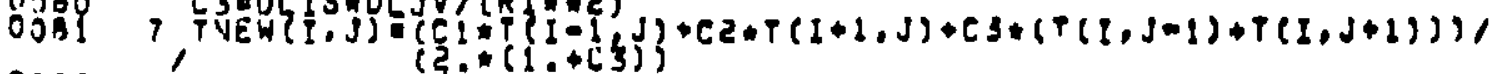

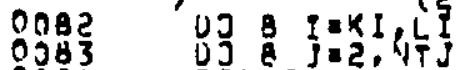

0383 प

กOB 5

0586

0037

กิว 383

REPIR०DLI+RINY

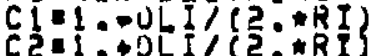

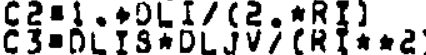

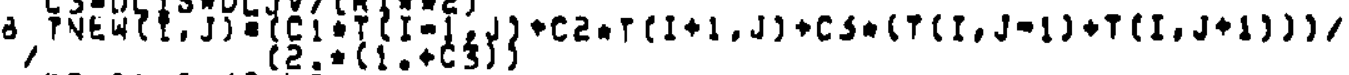

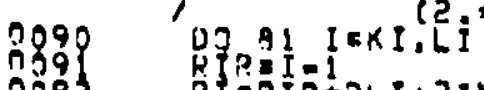

RIORIRHOLI+RINS

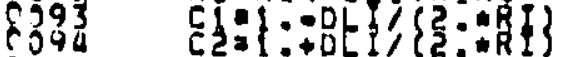

0095 C30JiIg HULJVi(RIA\#2)

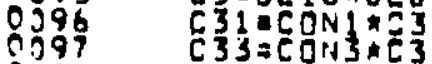

0998

ก.9

ด100

C $33=0$ Ons

COAC

C10.CDN $3 * C 2 \%$ ?

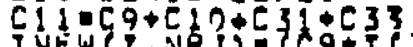

$0: 02$

$0 ! 03$

ât 04

n.

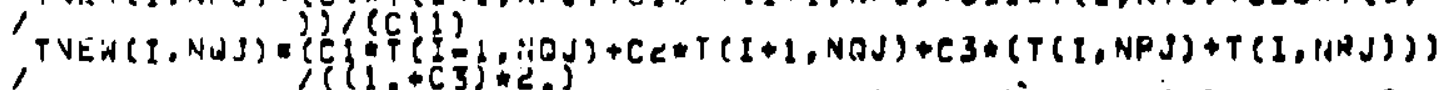

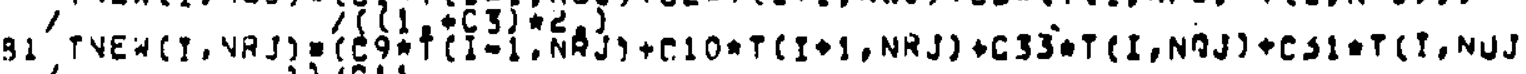

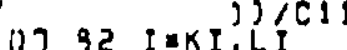

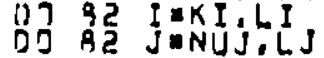

RIRIIUI

alog

ก109

กิ1

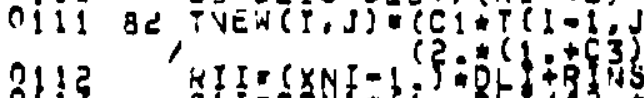

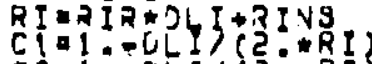

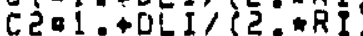

C3-DLYS*DLJVi(RI*\#Z)

n)

A I1

กิt

กิt?

ก! 18

0

ดाड1

กीट

तों

cीटाट⿺

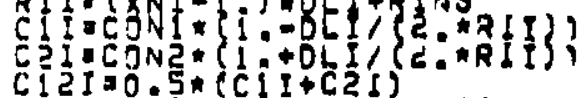

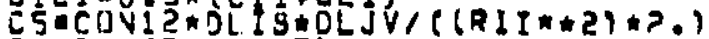

C6*5 $*(015 i+C 5)$

TNEW $\{1, I\}=(C I I * T(N I-1,1)+C ? I * T(N I+1,1)+2, n C S * T(N\}, 5)) / C O$

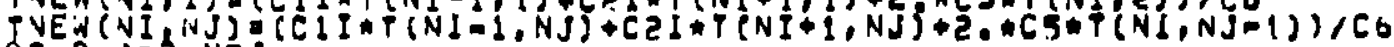

$9=2, N T$

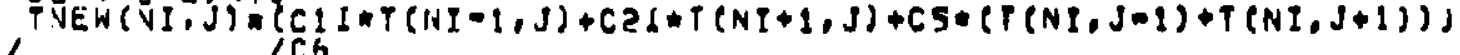
'

C 3IDOLIS*OLJYG/ (RII**2)

CI:I-JL

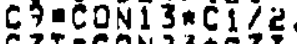

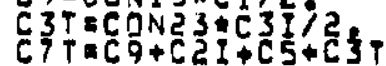

TVEH $(N I, N P J)=(C Q R T(L I, N P J)+C 2 T * T(K I I, N P J)+C S * T(N I, N T J)+C S T *$ '

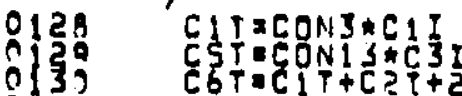

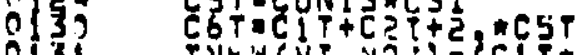

ก13i TVENCNI,NJj)

ก132

'T

$+T\{N, N K J\} J) C 6 T$ TVEN(VI, NRJ) - C C C

Fig. E.1 (Contd.) 
O! $\begin{aligned} & 133 \\ & 0\end{aligned}$ O

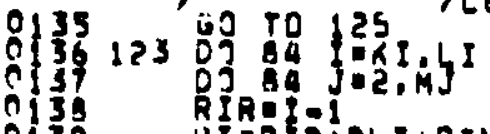

ก) 30

of if

0143

$09 \begin{aligned} & 49 \\ & 45\end{aligned}$

0.45

0147

0148

19:

o 150

0153
0153
0154
h. 55
0156
0159
0159
0150
0160
0161
01625
0163

HIARFDOLI+RINS

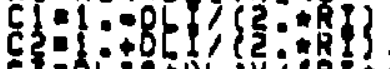

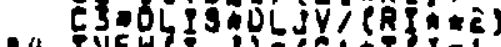

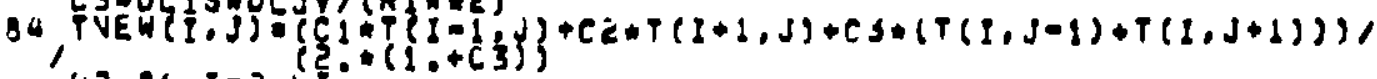

DJ 86 J

RIRดI-

AYARIP:OLI+RINS

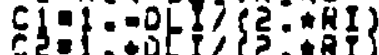

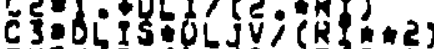

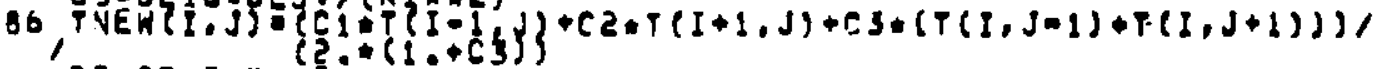

$0) 87$ I. $2, L I$

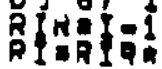

R.ATQRDLI+RINS

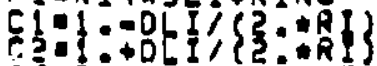

$C T=D L I S \cap O L j V I(R I \oplus * 2)$

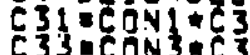

Eaconi onl

CIOGCONISCLYi.

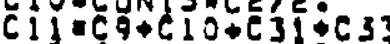

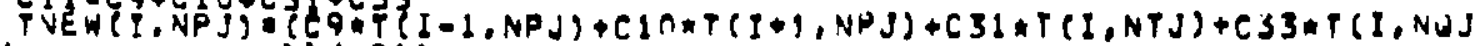

0164

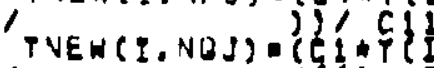

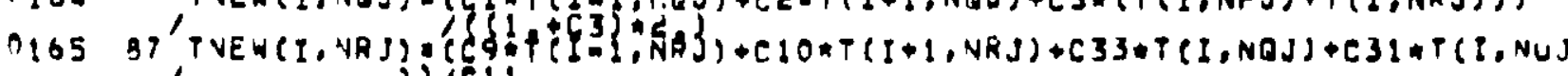

Ofo6

ôt

nif

0170

0171

ใิ? 173

0179

0176

c17?

n? 798

nis

ดโs

0183

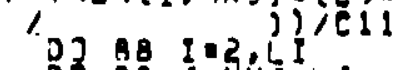

D. 88 jenUj,LJ

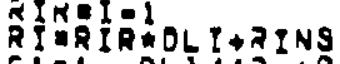

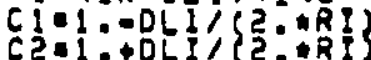

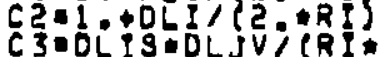

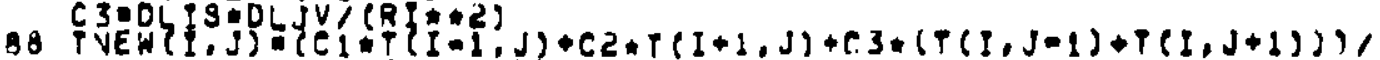

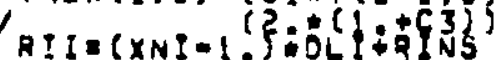

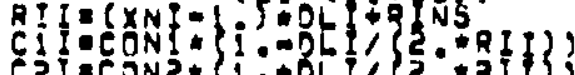

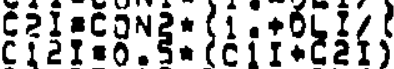

$C\left\{\sum I=0.5 *(C) I+C 2 I\right)$ (

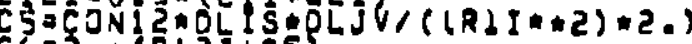

Ch०

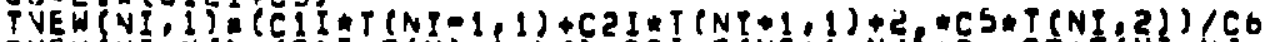

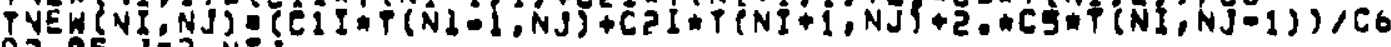

95

$0305, j \in Z, N T$

PUEW?nI, J) Q

$I+T(N I-1, J)+C ? I+T(N I+1, J)+C S *(T(N I, J-1)+T(N I, J+1)))$

G1B4 C

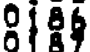

กิ8

0190 CSTECONZECI

CᄏCQNi

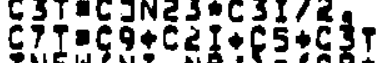

PVENG

ही?

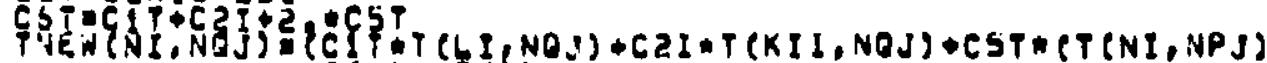

0194

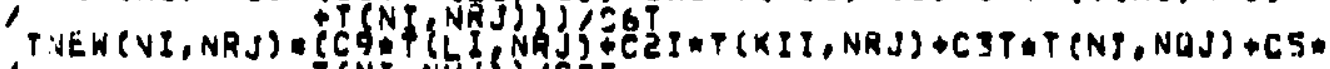

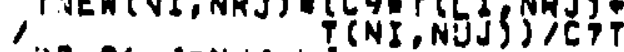

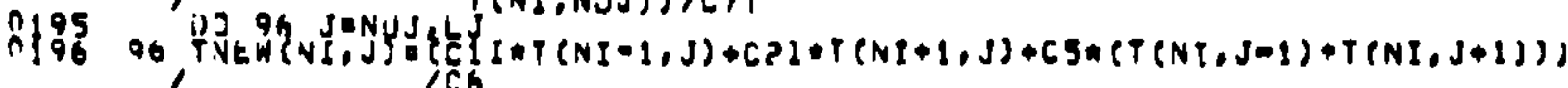

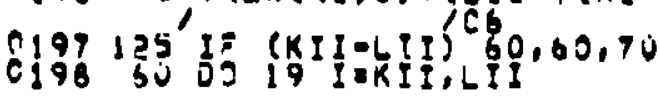

Fig. E.1 (Contd.) 


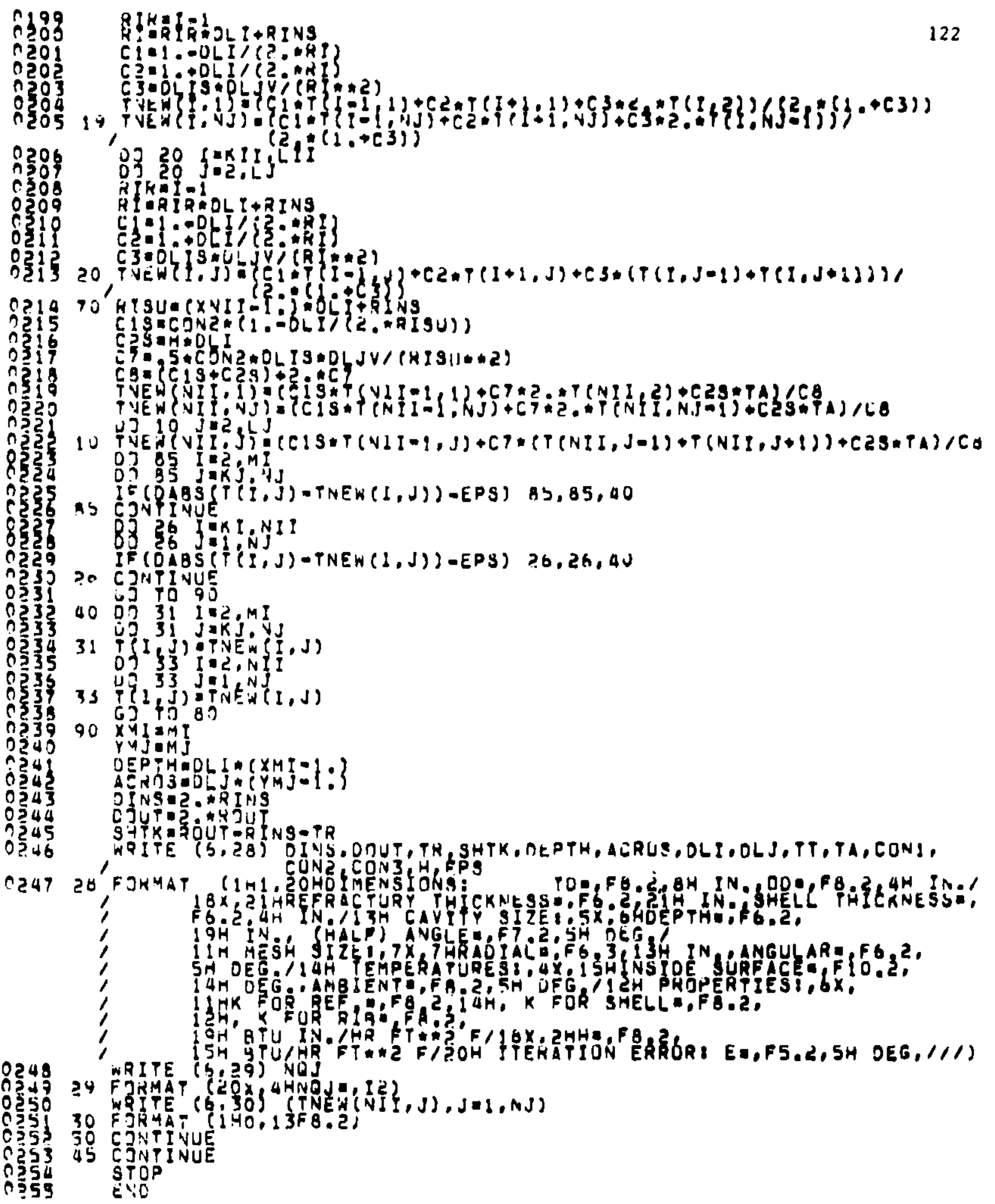




\section{APPENDIX F \\ Computer Program for a Three-dimensional System with \\ a Double-layered Refractory Lining}

The program given in Fig. B.l was modified to account for the situation when the transfer line has a double-layered refractory lining. For this case, additional input variables are needed to describe the system. CONI and CON2 in Table A.l are to be redefined as follows:

CON1 - Thermal conductivity of the inner refractory.

CON2 - Thermal conductivity of the outer refractory (or insulation) that is sandwiched between the inner refractory and the steel shell.

In addition, the following three new variables are introduced:

CON3 - The rmal conductivity of the steel shell.

TR1 - Thickness of the inner refractory layer.

TRL - Thickness of the outer refractory (or insulation) layer.

The computer program for the modified system is presented in Fig. F.1. In the program, the added refractory layer is handled separately. The index parameters used to identify this added layer in the radial direction are shown in Fig. F.2. The presence of a second refractory layer only complicates the solution in the radial directign. Hence, the index parameters in the angular and axial directions remain unchanged from before (refer to Figs. A.2 and B.2). 
REQUESTED OR NOTERM,OPT=2

DPTICNS IN B NAME(MAN) OPTIMIZE(2) LINECOUNT(60) SIZE(MAX) AUTODBL (NCNE) SOURCE EBCDIC NOLIST NODECK OBJECT MAP NOFORMAT GOSTMT NOXREF NOAL

ISN 0002

I SN 0003

ISN 0004

I SN 0005

ISN 0006

I SN 0007

I SN 0008

ISN 0009

ISN 0010

ISN 0011

ISN 0012

ISN 0013

ISN 0014

ISN 0015

ISN 0016

I SN 0017

ISN 0018

ISN 0019

I SN 0020

ISN 0021

ISN 0022

ISN 0023

ISN 0024

I SN 0025

I SN 0026

I SN 0027

I SN 0028

I SN 0029

I SN 0030

ISN 003 I

ISN 0032

I SN 0033

I SN 0034

ISN 0035

ISN 0036

ISN 0037

I SN 0038

ISN 0039

ISN 0040

ISN 0041

ISN 0042

I SN 0043

ISN 0044

- ISN 0045

I SN 0046

IS IN 0047

I SN 0048

ISN 0049

I SN 0050
OI MENS ION HORK SP $(76)$, TEXP $(25,11)$, CVPT $(25,11)$,

/ G(25),SYHBOL(22), TFXP (25,11),TGXP(25,11),B(21),A(2), V(21)

DOUBLE PRECISION DLIV.DLJV,DLKV,DLIKV, OLKVC,DLKVO,R?, CI,C2,

IC3,C4,RII,C1I,C2I,C12I,C5,C6,RISU,CIS,C2S,C7,C8, T125,15,101,

1 TNEW(25,15,10),DLXHC, OLKWO,OLIS

READ (5,1) RINS,ROUT, TRI, HIGHT, OPHIN, OPMAX, ACMIN, ACHAX, TLMIN, /TLMAX. DELR,DLJ, DELZ, SPACEI, SPACEJ, SPACEK, TRZ

1 FORMAT (LOFG.2)

REAO $(5,41) T T, T A, H, C O N 2, C O N 2, C O N 3, E P S$

41 FORMAT (7F8.2)

REAO $(5,200)$ (SYMBOL $(1), I=1,21)$, ASTSK

200 FORMAT $122 \mathrm{AL}:$

DLI $=1$. IDELR

INCR I = SPACEI /DLI

OLK=1. IDEL Z

INCRK $=$ SPACEK/DLK

WIOTH=3.14159*(RINS+ROUT) $/ 2$.

OEA $=H I D T H * D L \mathrm{~J} / 180$.

INCR J $=$ SPACEJ/OLJ

$N I I=(R O U T-R I N S) / D L I+I$.

XNII INII

$N J=W I O T H / O E A+1$.

NK $x H I G H T / O L X+1$.

HI $N=D P M I N / D L I+1$.

$M J H=A C M I N / D L J+1$.

$M K M=T L M I N / D L K+1$.

$M I L=1++(D P M A X-D P M I N) /$ SPACE I

$M J L=1++(A C M A X-A C M I N) /$ SPACEJ

$M K L=1 .+(T L M A X-T L M I N) / S P A C E K$

$N I=T R I / D L I+1$.

$X N I=N I$

$N 2=I T R 1+T R 2 I / O L I+1$.

$X N 2=N 2$

$L I \approx N I-1$

$K I I=N I+I$

MI I $=\mathrm{NZ}-\mathrm{I}$

$K I 2=N 2+1$

LII $I N I I-I$

OLI $V=1$.

DLIS=DLI $\$ 2$

$O L J V=1 . /(13.14159 * O L J / 180) * 2$,

$D L K V=(O L I * 2) /(O L K * 2)$

OLIKV $=1 .+D L K V$

CON1 $2=C O N 1+C$ ON2

DLKVC $=$ CON $12 * 0 L K V / 2$.

DL $X V D=0.5 * C O N 2 * D L$ I $S /(D L K * 2)$

$\operatorname{CON} 23=\operatorname{CON} 2+\mathrm{CON} 3$

DL $K: C=C O N 23 * D L K V / 2$.

$\mathrm{DLKWD}=0.5 * C O N 3 * O L I S /(D L K * 2)$

DO $50 \quad L=I, M I L$

DO $50 \quad M=1, M J L$

DO $50 \mathrm{~N}=1, M K L$

$M I=M[M+(L-1) * I N C R I$

Fig. F.1. Computer Program for Evaluating Surface Temperature in a Three-dimensional system Constructed with a Double-layered Refractory Lining 


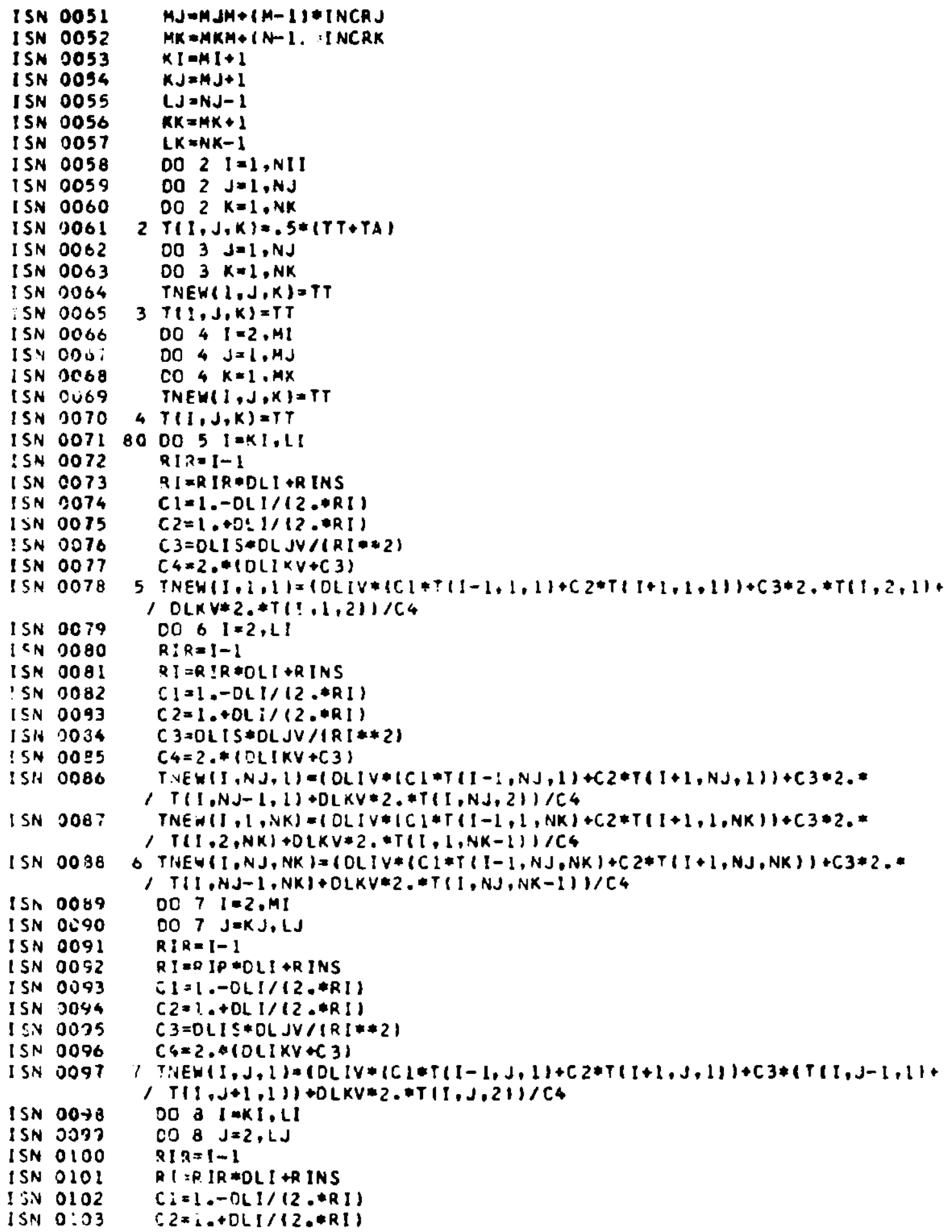

Fig. F.1 (Contd.) 


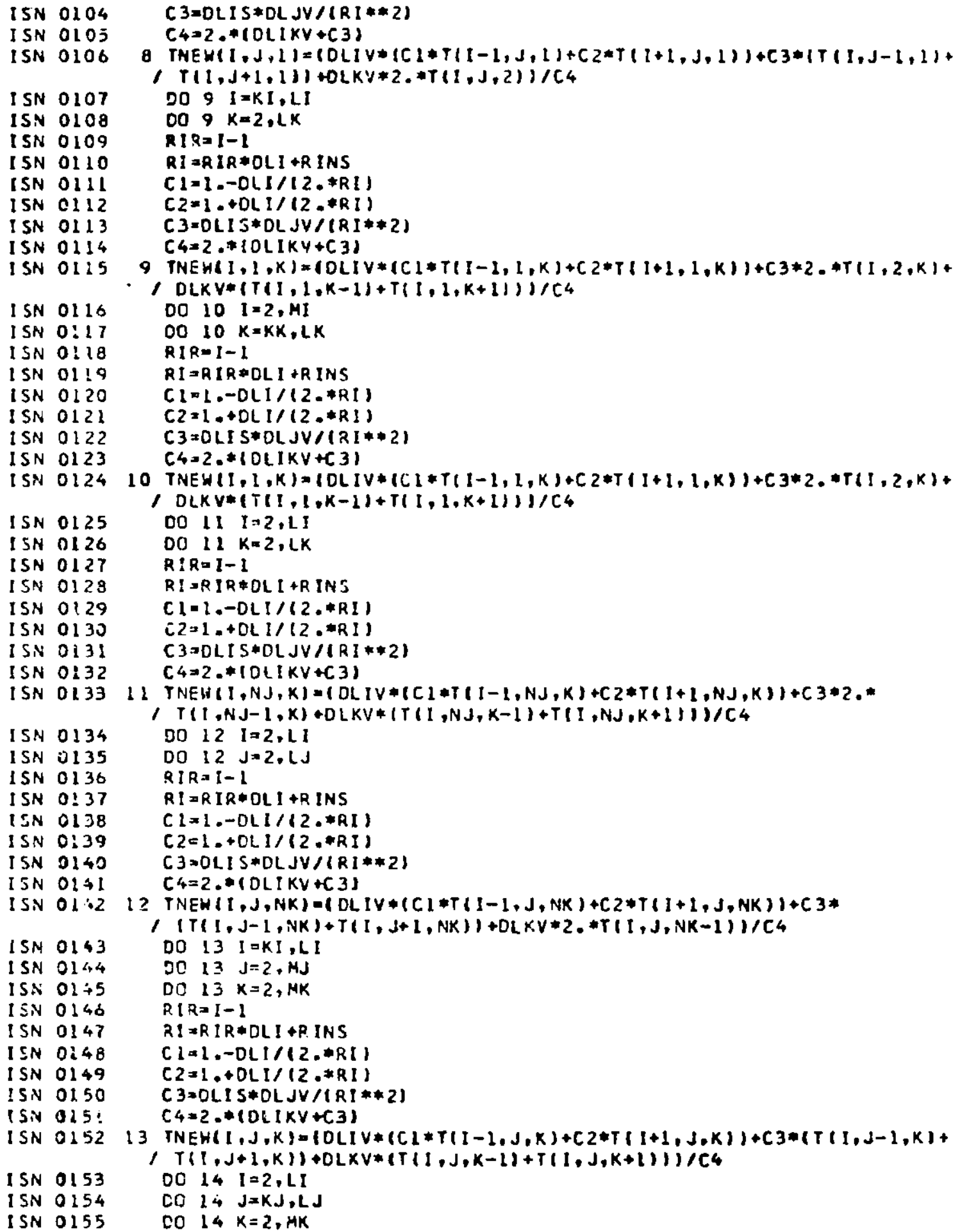

Fig. F.1 (Contd.) 


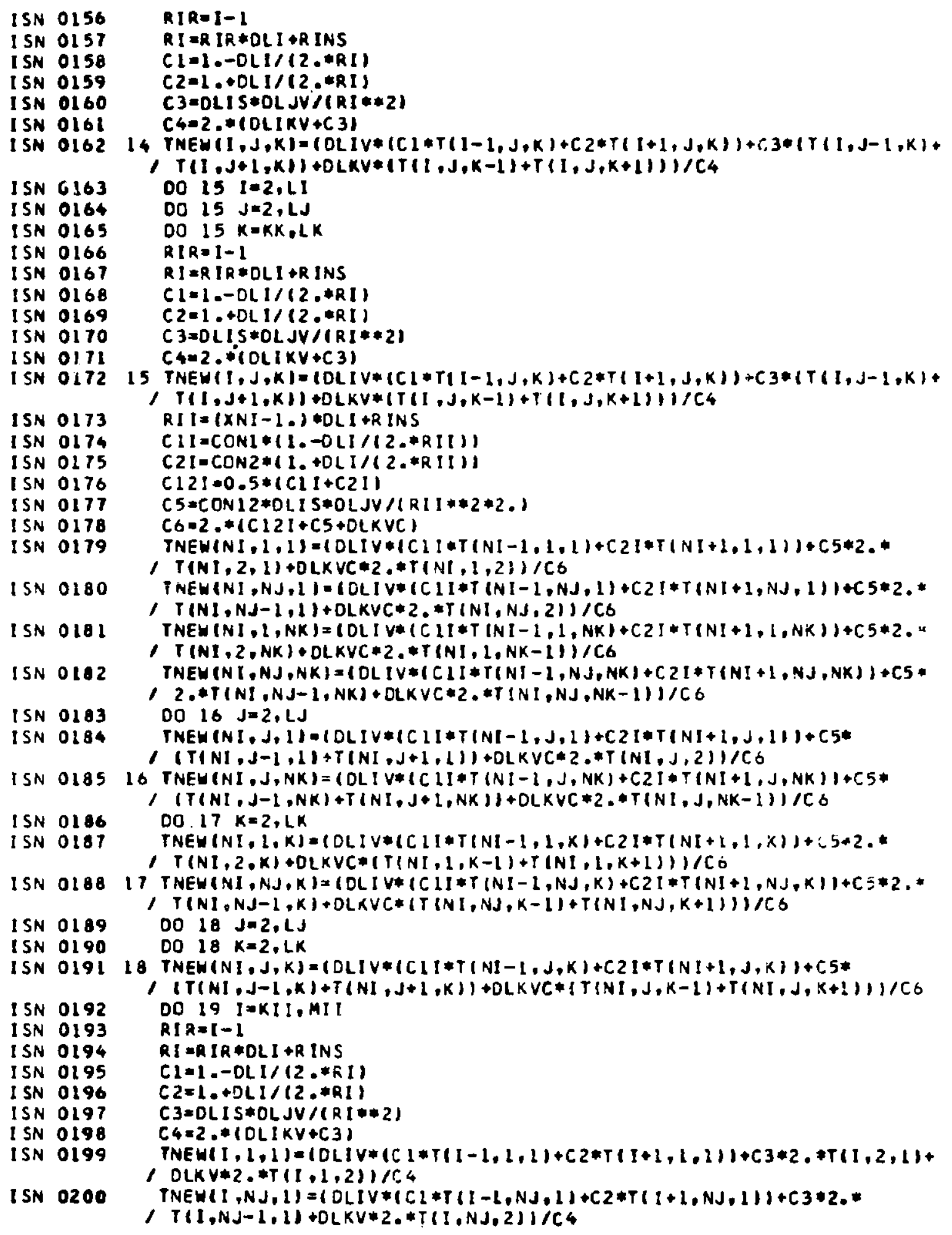

Fig. F.1 (Contd.) 


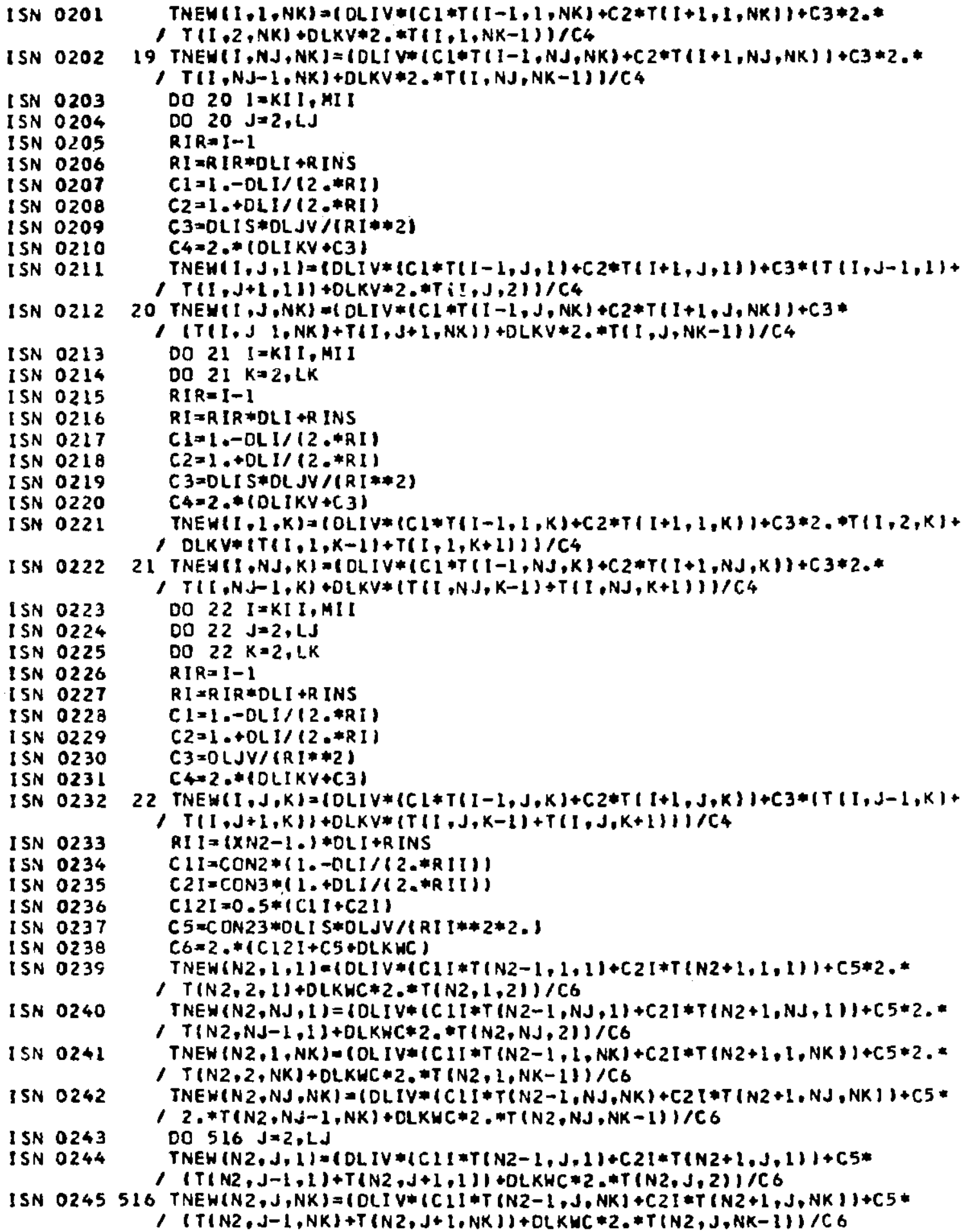

Fig. F.1 (Contd.) 


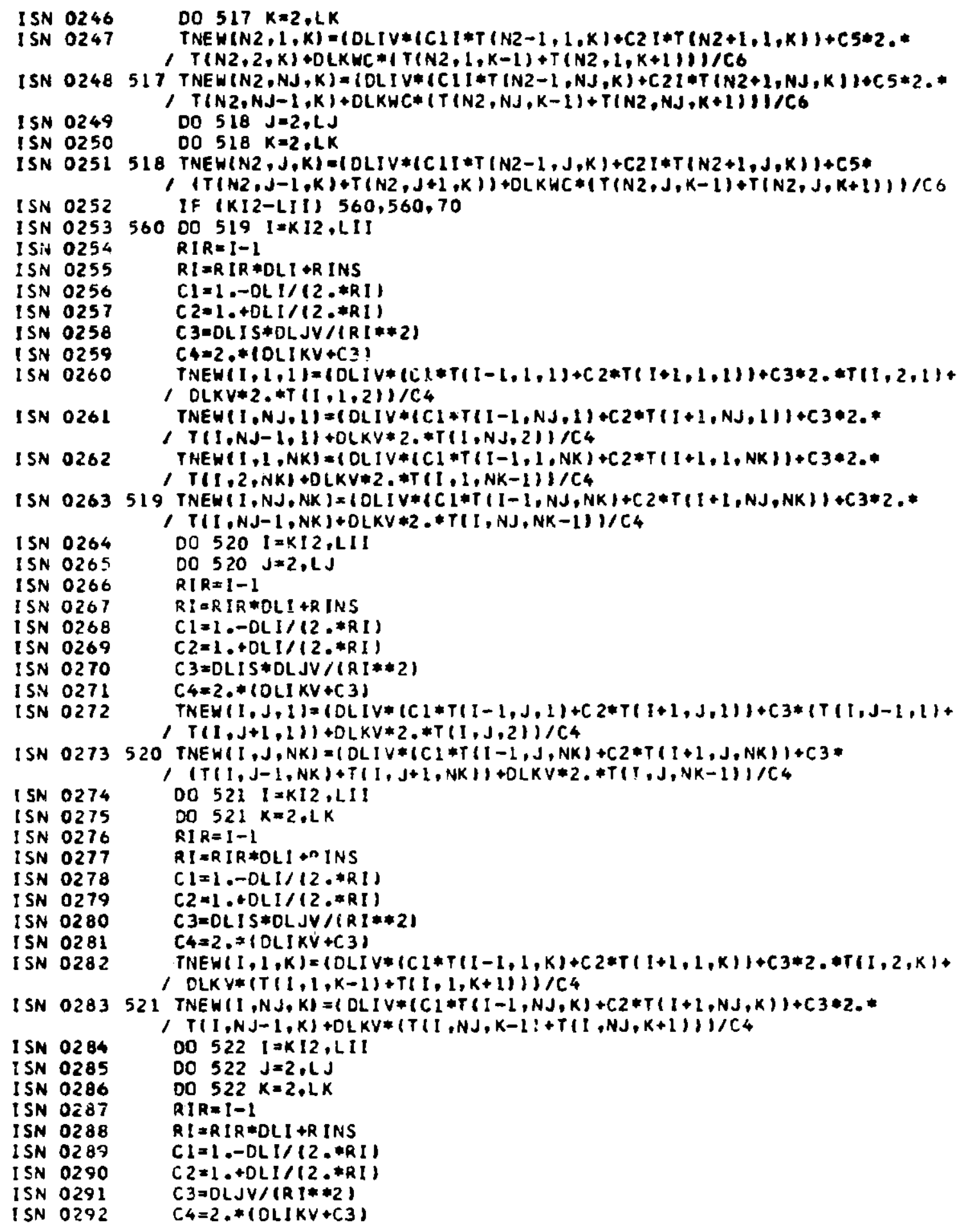

Fig. F.1 (Contd.) 


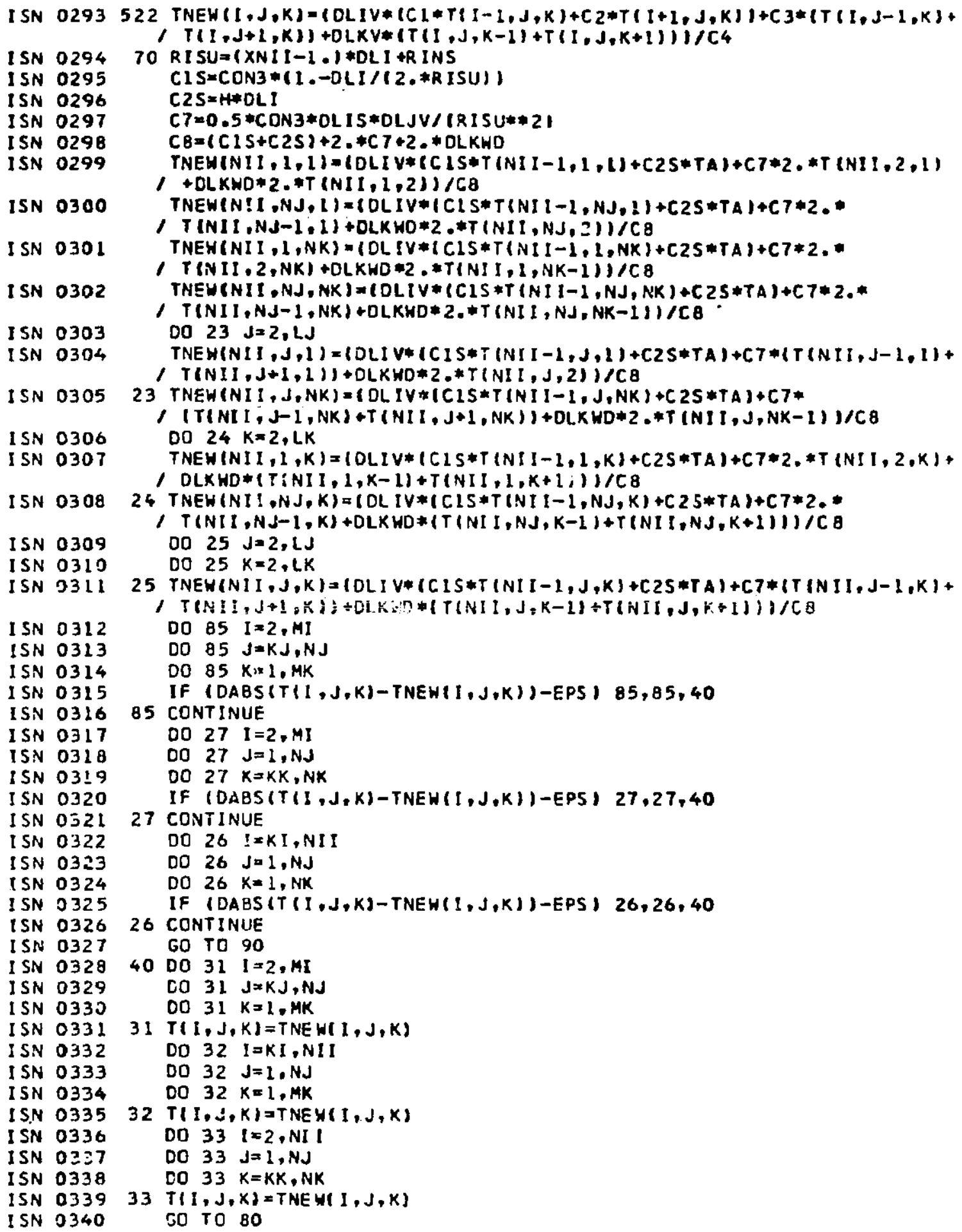

Fig. F.1 (Contd.) 


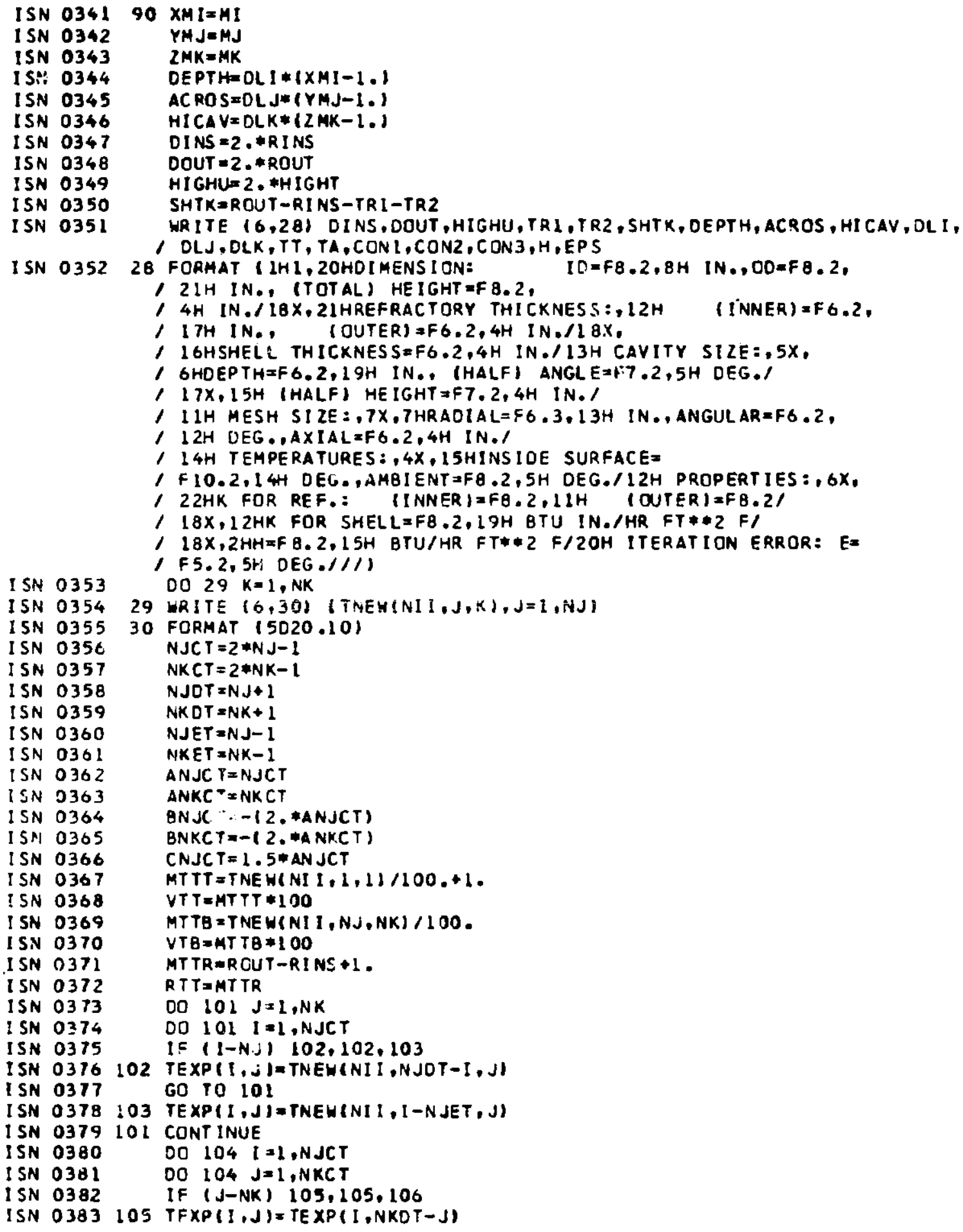

Fig. F.1 (Contd.) 


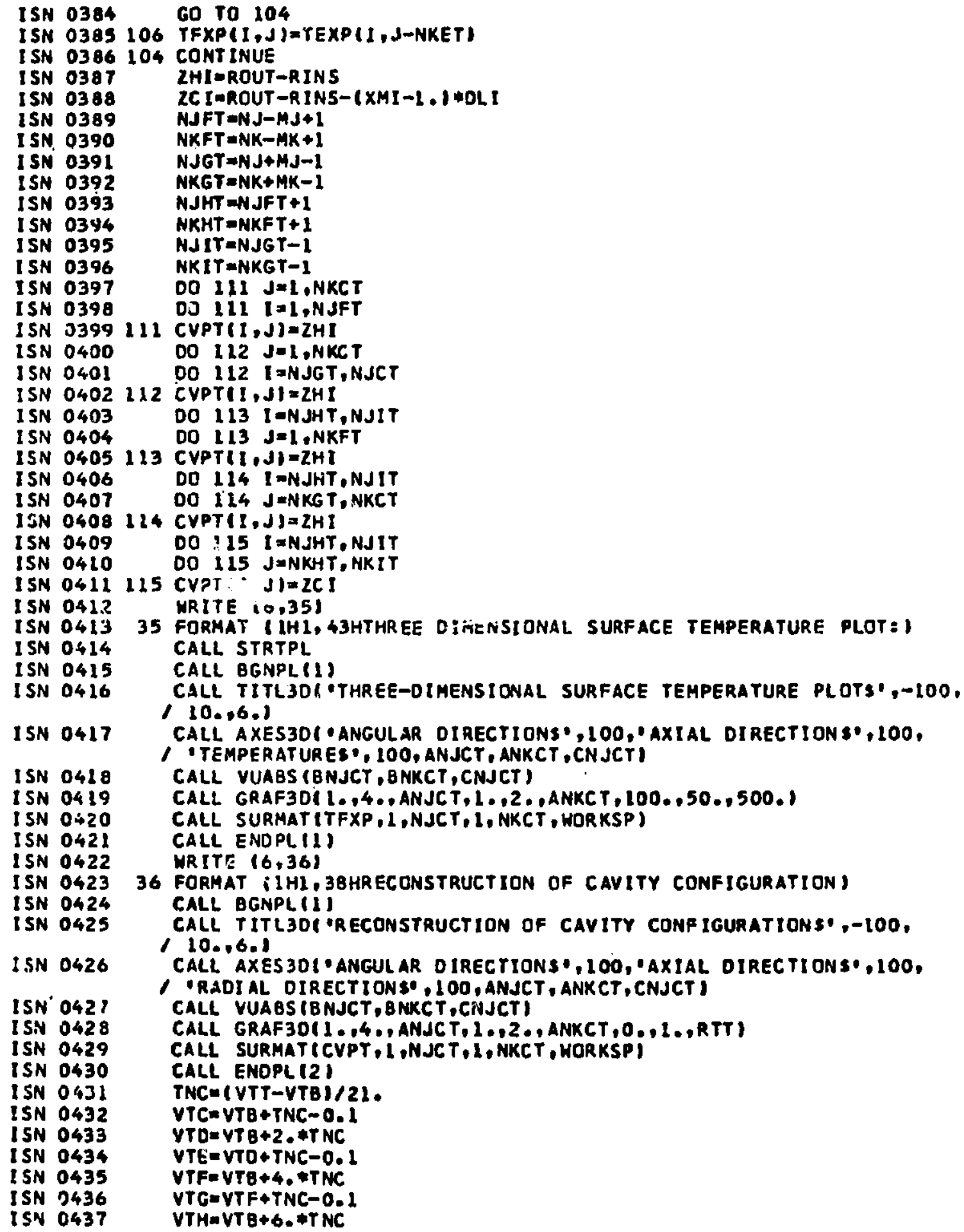

Fig. F.1 (Contd.) 


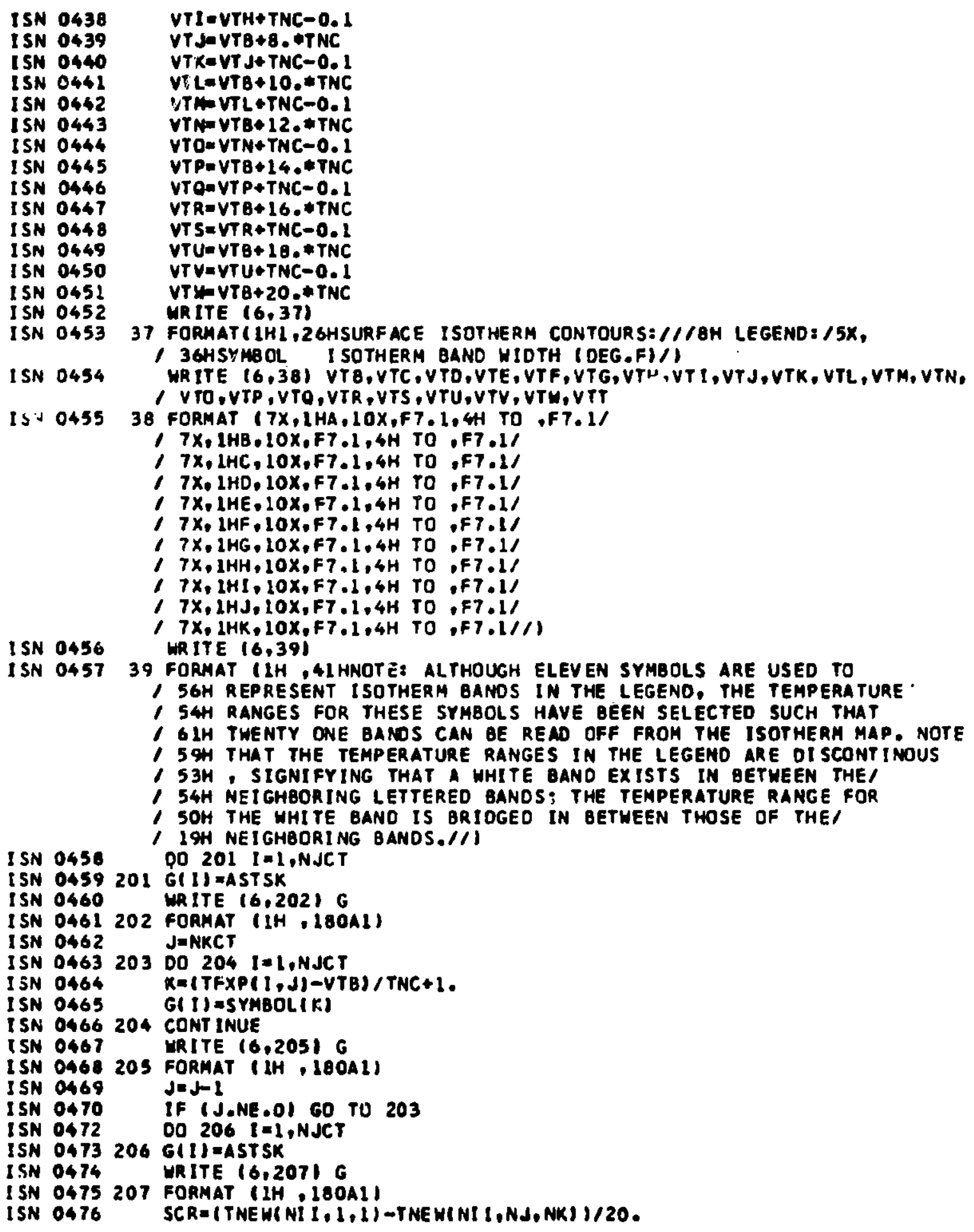

Fig. F.1 (Contd.) 


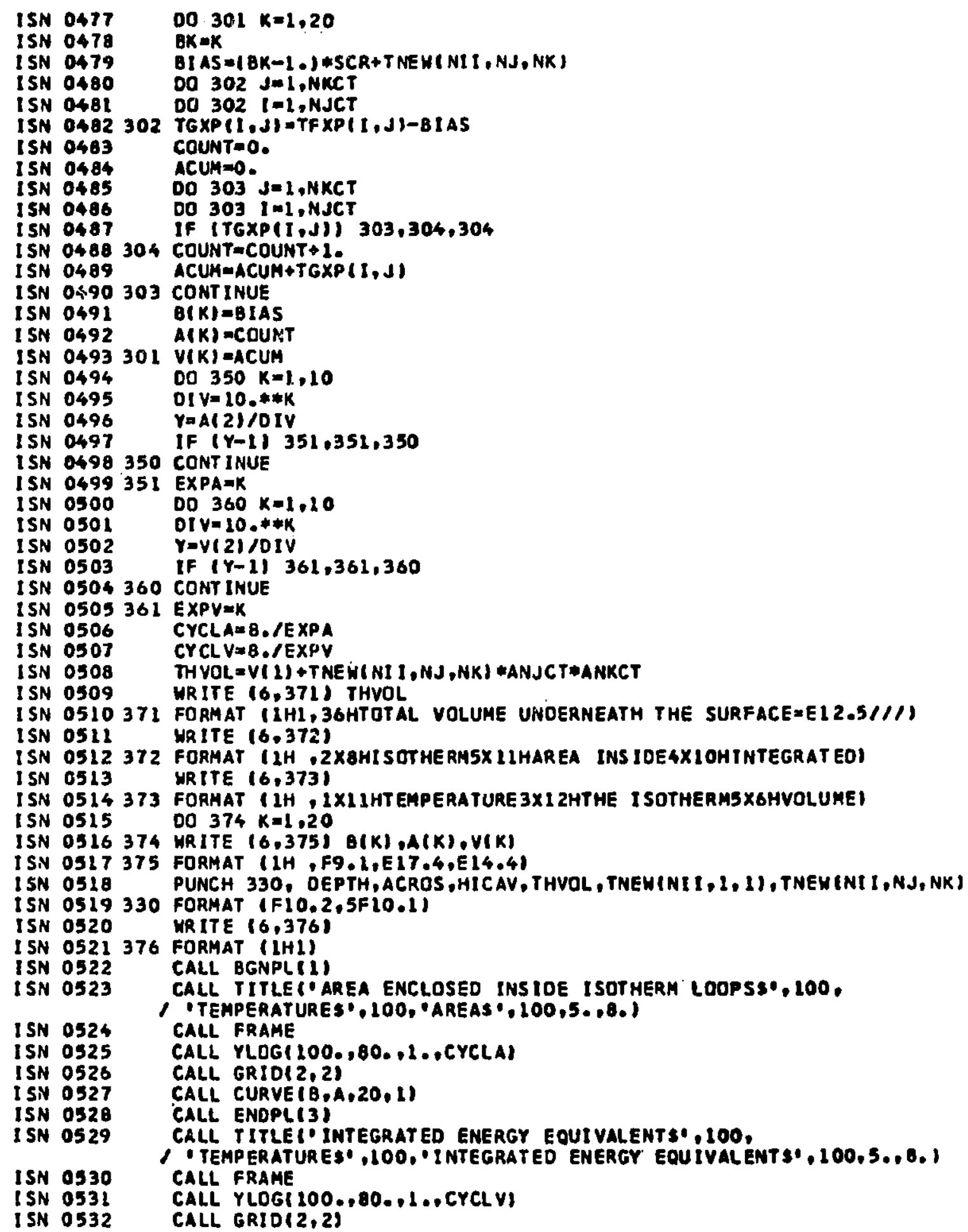

Fig. F.1 (Contd.) 
I SN 0533

ISN 0534

ISN 0535

ISN 0536

ISN 0537

ISN O538
CALL CURVE $(8, V, 20,1)$

CALL ENOPL (4)

So CONTINUE

CALL DONEPL

STOP

ENO

Fig. F.1 (Contd.)

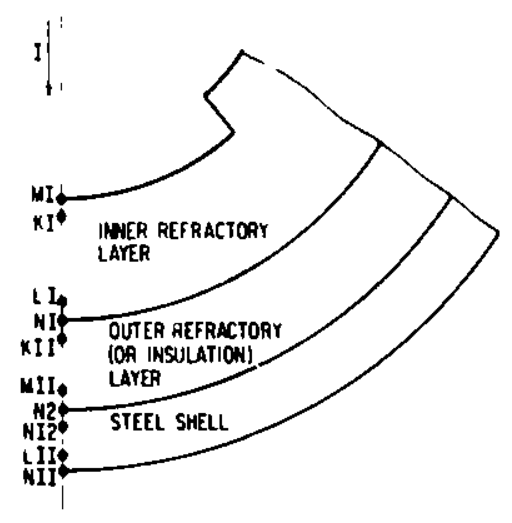

Fig. F.2

Schematic Diagram Showing Nodal Locations in Radial Direction in a Modified Three-dimensional System 


\section{APPENDIX G \\ Computer Program for a Three-dimensional System with Interfacial Contact Resistance}

Figure G.l shows a computer program for a three-dimensional system with constant contact resistance occurring at the refractory/steel interface. Another program for a similar system, but with variable contact resistance, iz presented in Fig. G.2. In both programs, the system under study has only one refractory layer. To generate a wide range of resistance values for tests, additional DO loops have been inserted in each program. Slight modifications have also been made in the resistance expressions used in the interfacial nodal equations. These modifications are rather straightforward in the case of constant contact resistance. For a variable contact resistance, a subprogram is introduced to calculate the resistance parameter at each mesh point on the interface. In addition, since the contact-resistance value, not the resistance parameter, is of practical interest, the program is also designed to calculate these resistance values and tabulate them as additional outputs. 


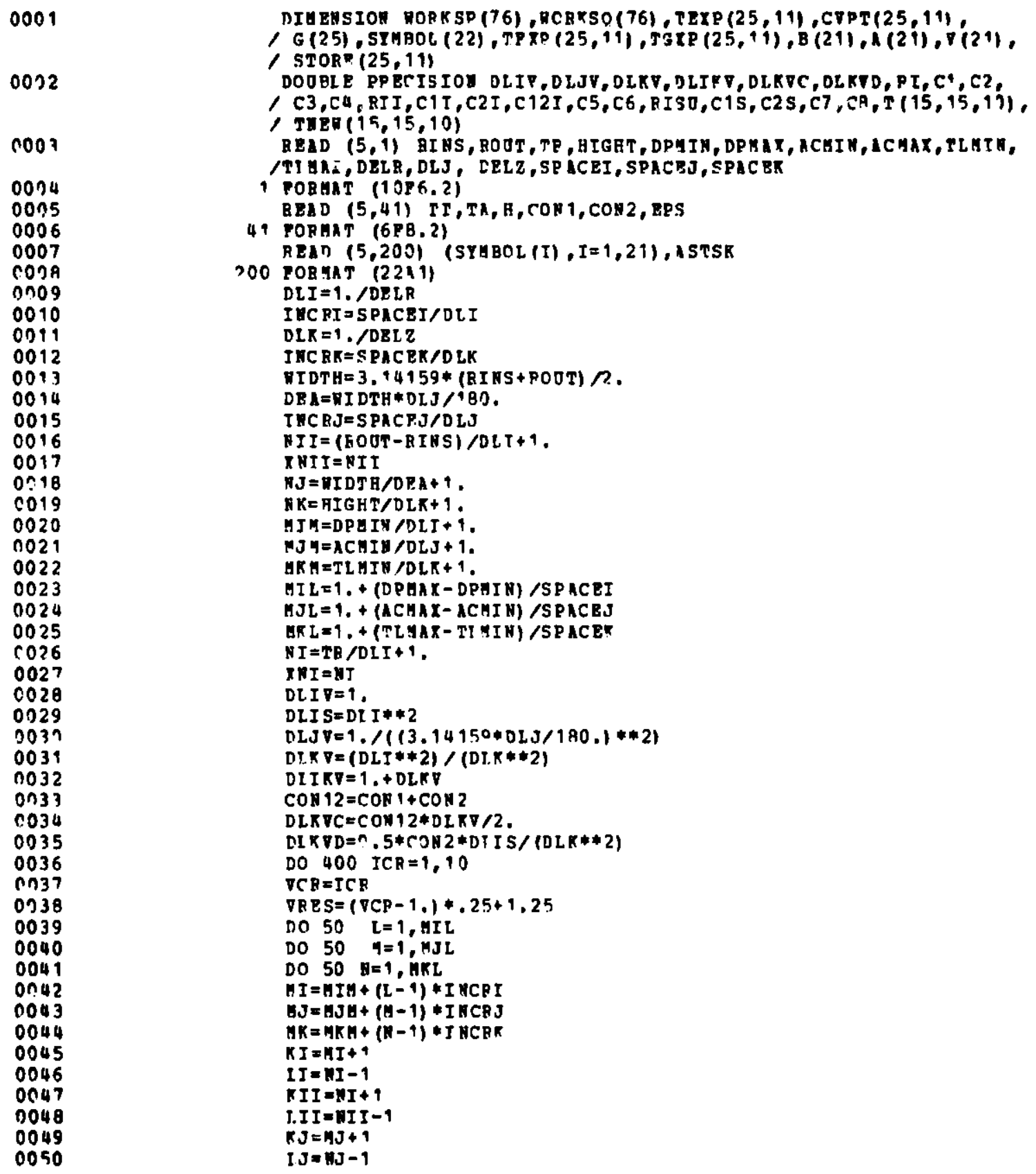

Fig. G.1. Computer Program for Evaluating Surface Temperature in a Three-dimensional System with Constant Contact Resistance 


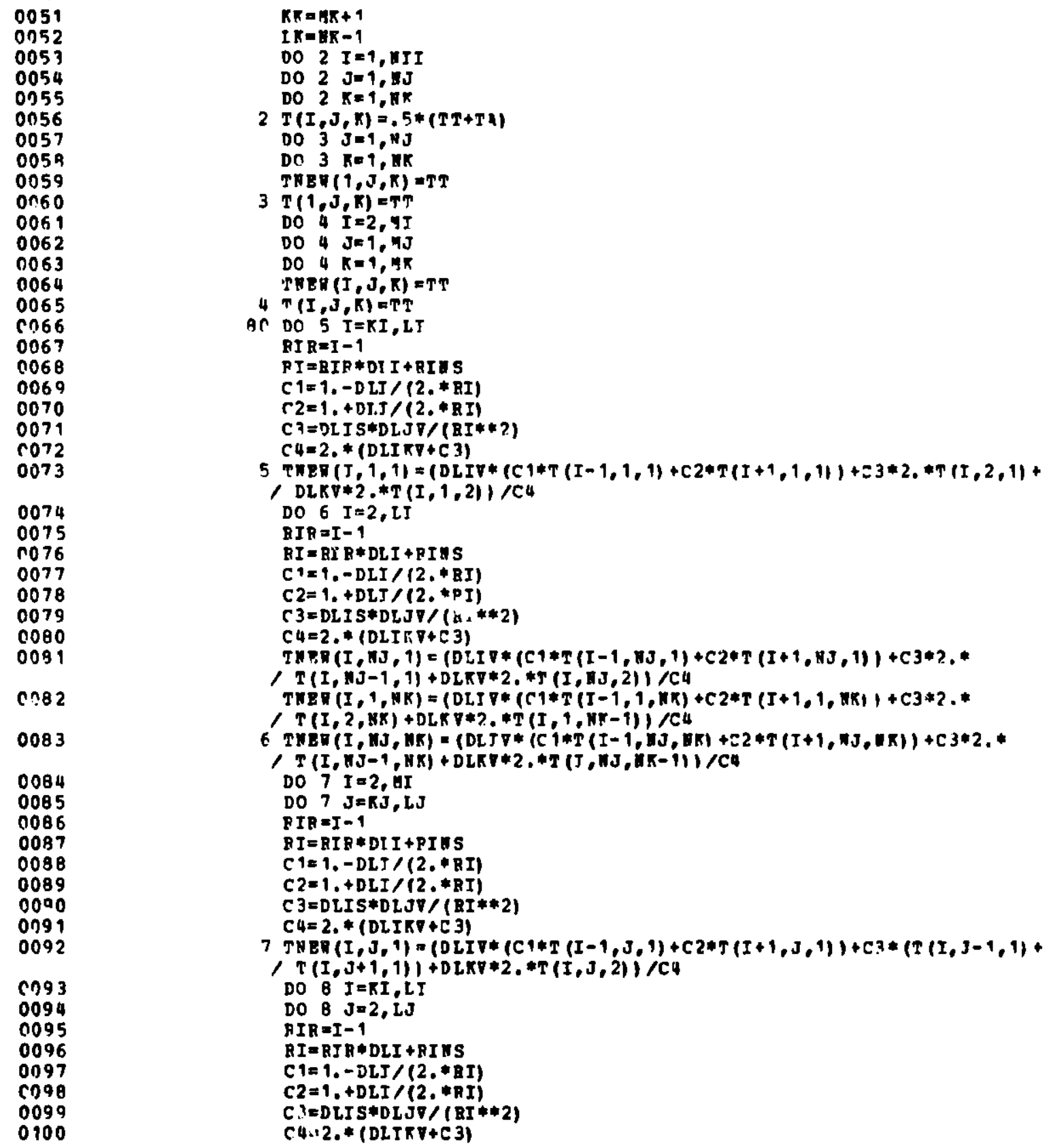

Fig, G.1 (Contd.) 


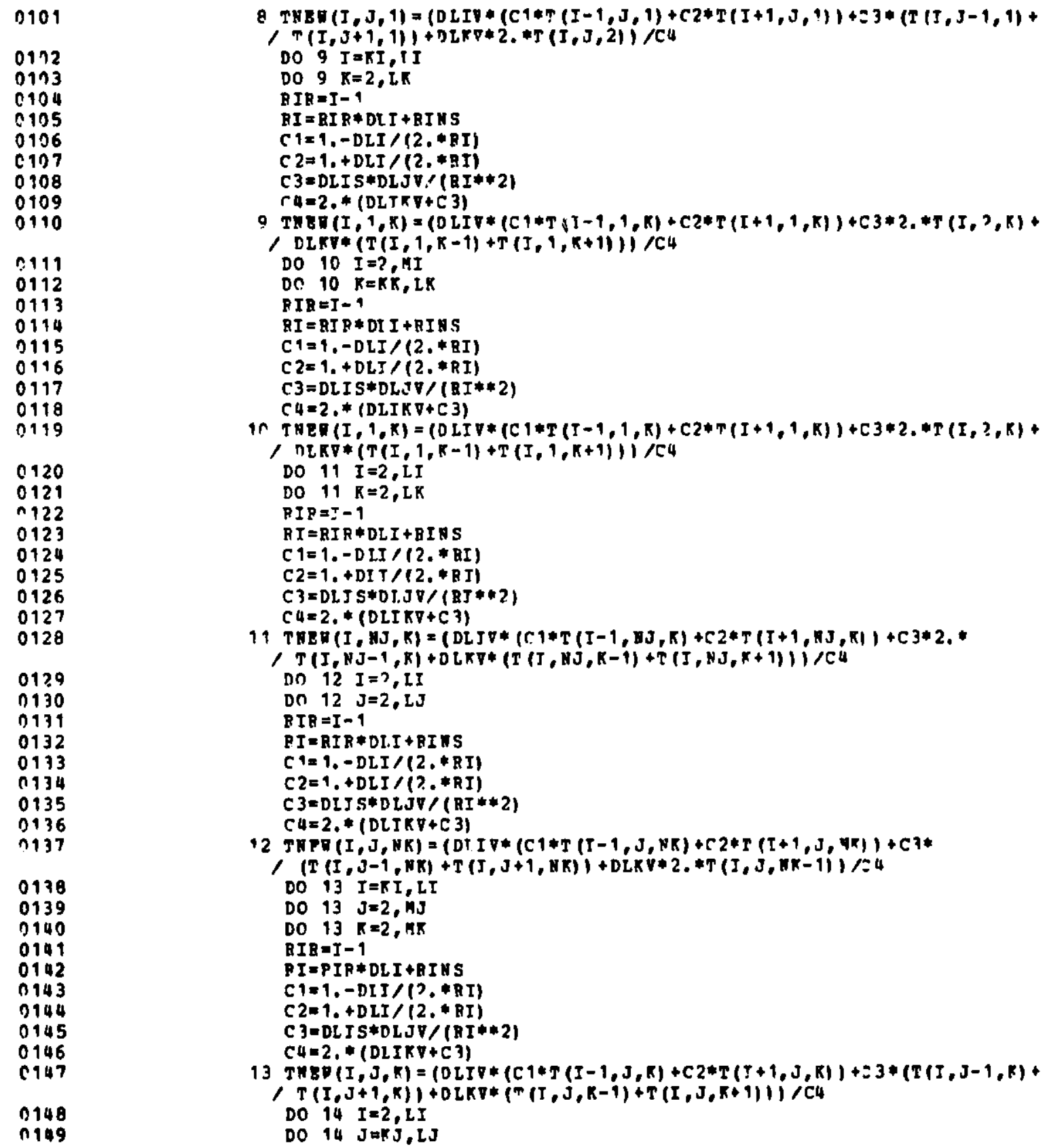

Fig. (i.1 (Contd.) 


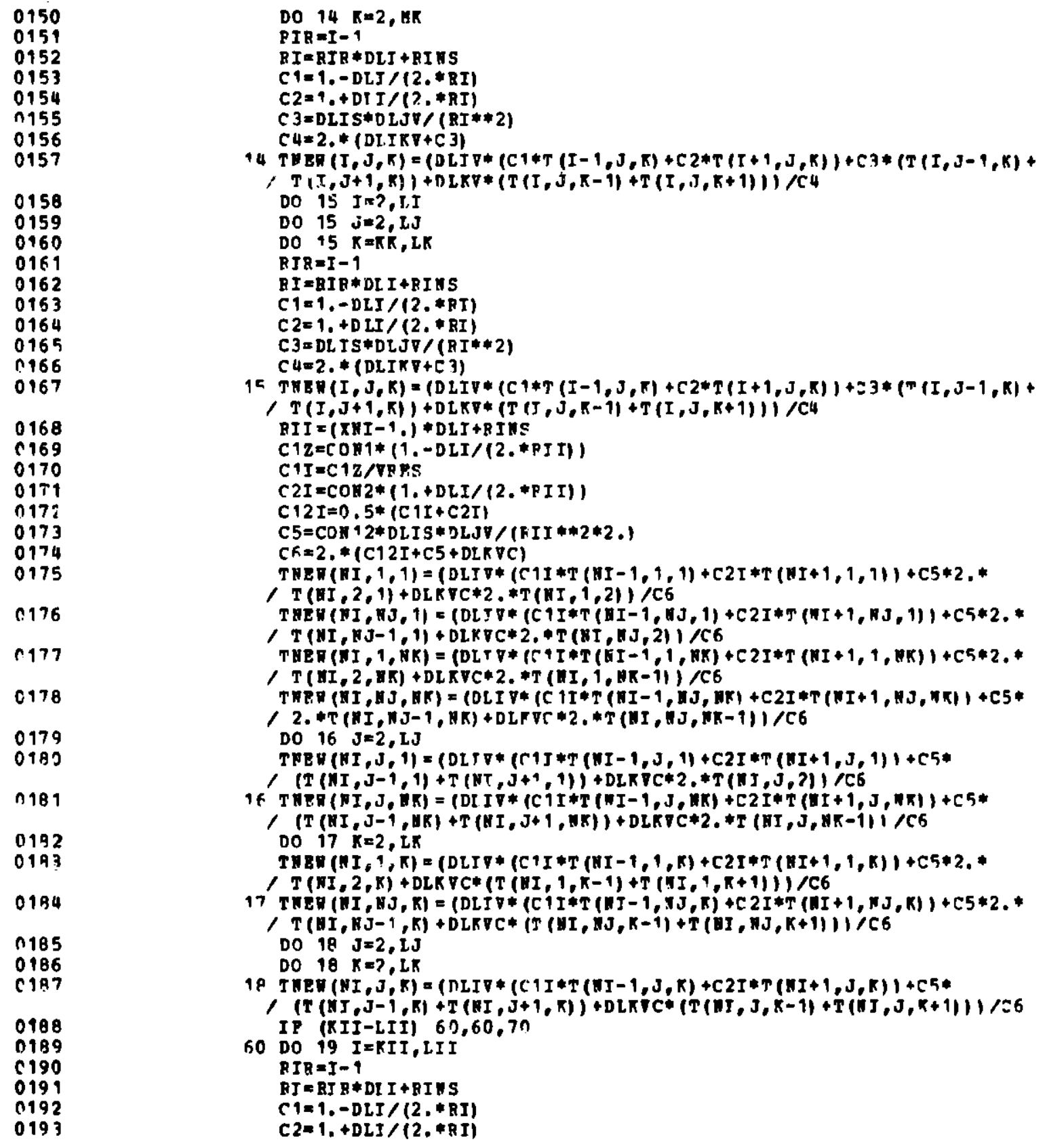

Fig. G.1 (Contd.) 


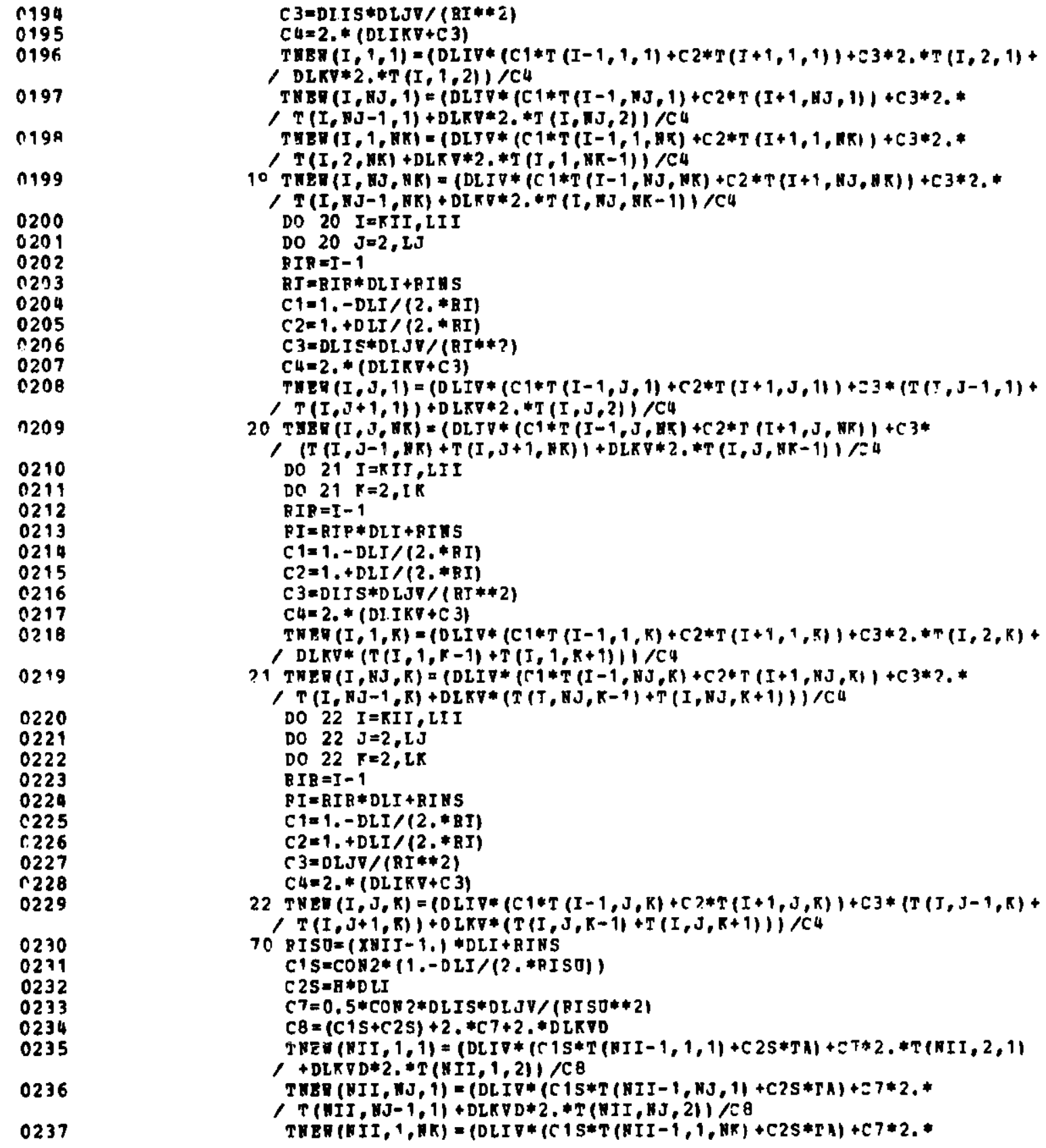

Fig. G.1 (Contd.) 


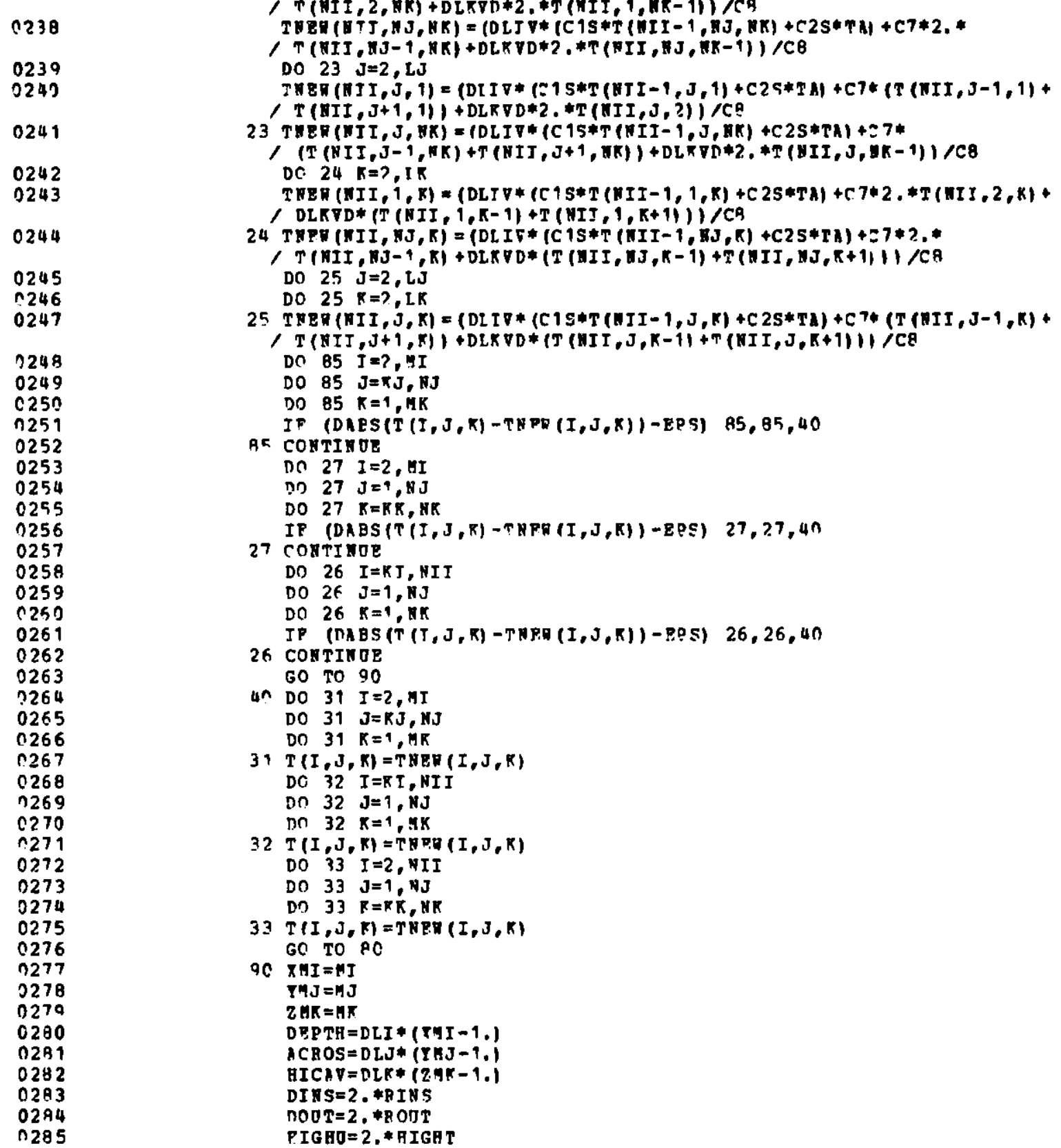

Fig. G.1 (Contd.) 

0302

0303

0304

0305

0306

0307

ก308

0309

0310

0311

0312

0313

0314

0315

0316

0317

0318

0319

0320

032

0322

0323

0324
SATKE ROUT-RIBS -TP

DRITE $(6,28)$ DIMS, DOTT, GIGAO, TR, SHTR DEPTH, ACBOS, HICIV, DLI, DC J, / DIK, TT, TA, CON 1, COH $2, \mathrm{~B}, \mathrm{BPS}$

28 POBAT (181,20HDTMENSTOR:

, 218 IU.. (TOTAL) HETGHT=P8.2,

I $D=P 8,2, B \mathrm{~B}$ IR.,OD=FB, ?,

4日 IR. 198,21 HPEPBACTORY THICKHESSEP6,2,

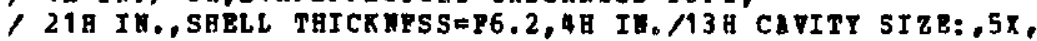

/ GBDEPTB=P6.2, 19日 IB., (HILP) $A B G L B=77,2,5 B$ DEG.

17I, 15日 (HALE) HBIGHT=7,2,4 $\mathrm{H}$ IH./

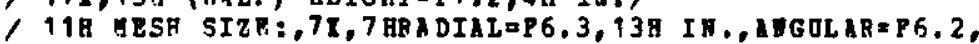

12 DEG. AXIAL=F6.2,4日 IH,

/ 148 TEHPERATORBS:, 4X, 15HINSIDE SURFACB=

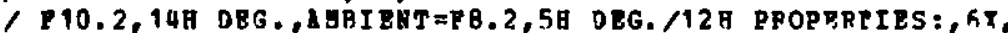

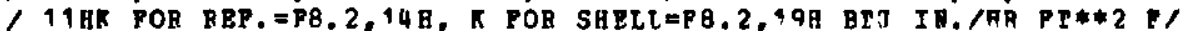

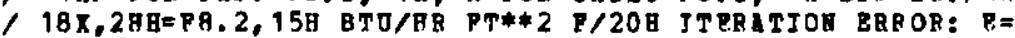

/ F5.2,5H DPG.//n

DO $29 R=1, N K$

29 ARTTK $(6,30)$ (THER (NII, J,K),J=1, HJ)

3) POREAT (5020.10)

TPITE $(6,401)$

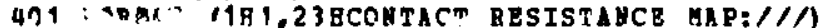

's $2: i: 1,11$

$13: 6: 1,25$

$402: \mathrm{rGE}, 1, \mathrm{Y}=(\mathrm{PBBS}-1,1) \mathrm{DLI} / \mathrm{CON}$

D. 3 i 1,19

$4 \cap 3$ प्रPITE $(6,406) \quad$ (STORE $(J, K), J=1,25)$

406 PORMAT (7E14.5)

DRITE $(6,4 n 4)$ VRRS

404 POBAAT ///458 NOTE: ONIT POB COHTACT DESISTANCB-BR DEG/BIO/

/ 54 COHTACT RESISTANCP VALOES RBRE GRNBRATED TSING: VQES=P5. $2 /$

01) IGI013I STATAX

NJCT $=2 *$ NJ -1

BKCTE2*NK-1

MJDT=MJ+1

RKDT $T=N K+1$

MJET $=\mathrm{BJ}-1$

HRET $=M R-1$

AnJCT = HJCT

$\triangle A R C T=R R C T$

BNJCT $=-\{2 . * A B J C T)$

BNRCT $=-(2, * 1 N K C T)$

CX JCT $=1.5 * A B J C T$

ETT $=T R E(N I I, 1,1) / 900,+1$.

VTT=BTTT*103

HTT B=THER (BI I, BJ, NK) $/ 100$.

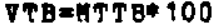

GTT $B=$ BOOT-RIHS+1.

RTT= ATTR

DO $1 C 1 \mathrm{~J}=1, \mathrm{H}$

DO $101 \mathrm{I}=1, \mathrm{BJCT}$

IP $(I-\mathrm{YJJ}) 102,102,103$

$102 \operatorname{TEXP}(I, J)=\operatorname{TNEQ}($ NII, NJDT $-I, J)$

GO TO 104

$103 \operatorname{TETP}(I, J)=\operatorname{TNE}(\mathrm{RII}, I-M, J E T, J)$

Fig. G.1 (Contd.) 


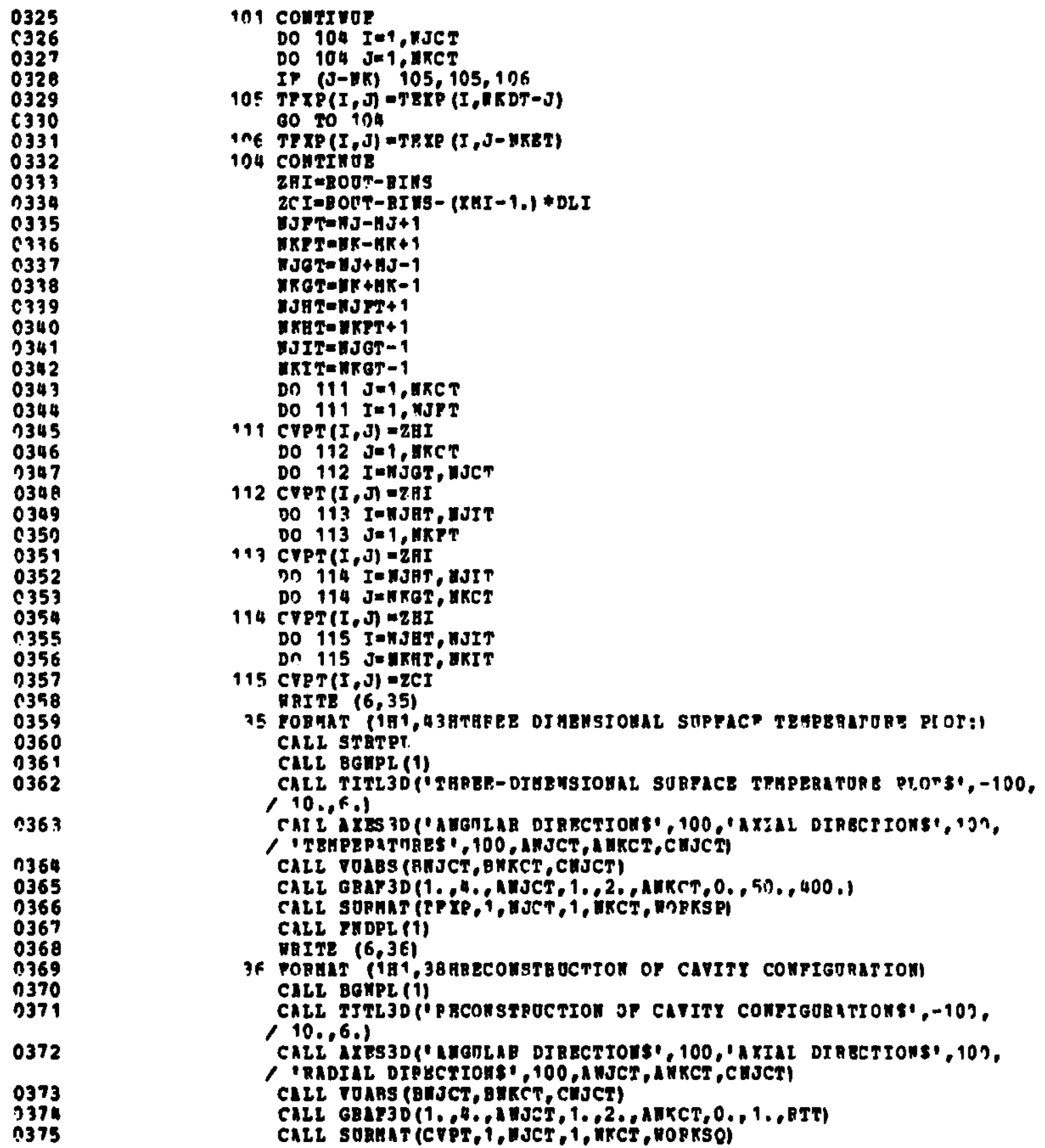

Fig. G.1 (Contd.) 


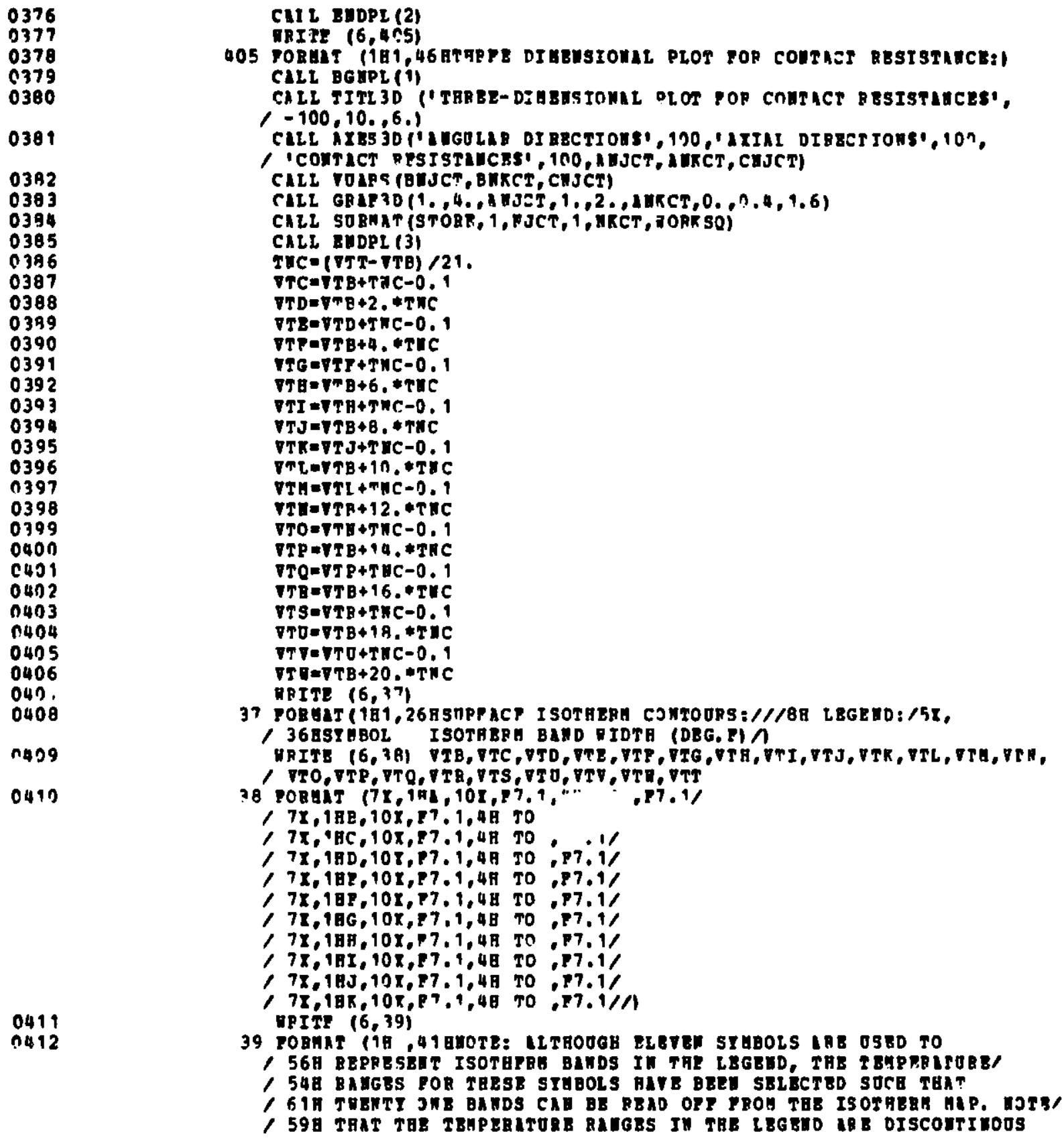

CAI I BADPL (2)

TRIT2 $(6,455)$

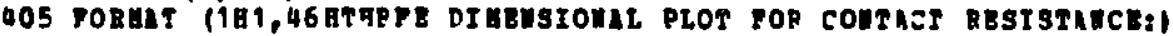
CILL BGIPL (1)

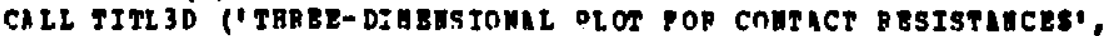
$1-100,10 ., 6.1$

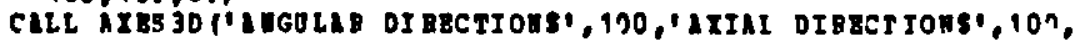
/ 'COATICT PESISTINCES', 100, ABJCT, AUKCT, CAJCT)

CALL TOAPS (BHJC?, BHKCT, CHSCT)

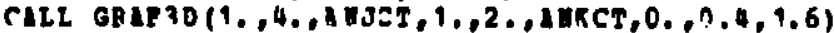

CALL SOBNAT (STORR, 1, FJCT, 1, ARCT, RORR SO)

CALL EUDPL (3)

TMC $=(\nabla T T-\nabla T B) / 21$

จTC=TTB+TतC-0,1

VTD $=\nabla T B+2$. *THC

TTR-VTD+TNC-0.1

VTP-TTB+4. *THC

$T T G=\nabla T T+T N C-0,1$

$\nabla T B=V^{m} B+6$. * THC

$\nabla T I=\nabla T H+T N C-0,1$

$\nabla T J=T B+8$ * *TAC

$\nabla T K=V T J+T M C-0,1$

VTL

$V T H=T T L+T N C-D .9$

TTE-VTR+12. *THC

$\nabla T O=7 T B+T N C-0.9$

TTP $=\mathrm{TR} B+14$. * TRC

VTO=VT $P+T$ B $B C-0.1$

TTB $=\nabla T B+16$. $T M C$

$\nabla T S=\nabla T B+T N C-0.9$

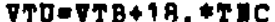

$\nabla T \nabla=\nabla T O+T H C-0,1$

$\nabla T D=\nabla T B+20$. $T N C$

MAITE $(6,37)$

37 POBGAT 1月1,26R / 368STHBOL ISOTABR BAND RIDTA (DBG. FI)

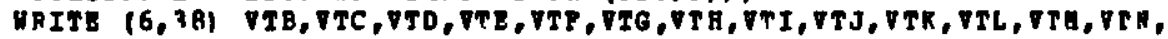
/ TTO,VTP, VTQ, VTR, VTS, VIO, VTV, VTR, VTT

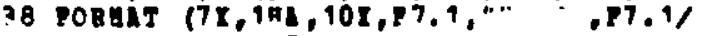

$17 x, 1 \mathrm{BE}, 10 \mathrm{x}, \mathrm{T7}, 1,4 \mathrm{H}$ TO

$/ 7 x, 4 \mathrm{BC}, 10 x, 87,1,4 \mathrm{H}$ TO, $1 /$

/ 7X,18D,108, P7, 1,48 TO, $77,1 /$

/ 7X,187,10x,P7.1,48 TO ,.77,1/

/7x,18P,10x, $77,9.48$ TO , $77,1 /$

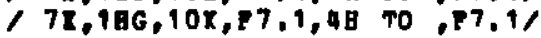

7x, 18日, 10x, $7,1,4$ स TO, $77,1 /$

/ 7x, 18I, 10x, $77.9,48$ TO $, 77,1 /$

$17 x, 18 \mathrm{1}, 10 x, 77,1,4$, TO, $77.1 /$

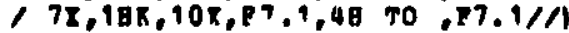
APITY $(6,39)$

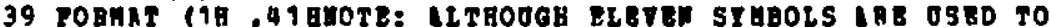

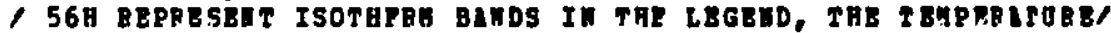

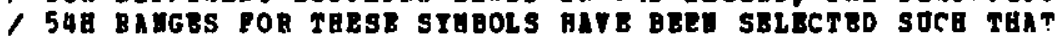

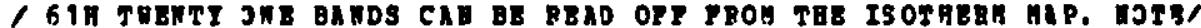

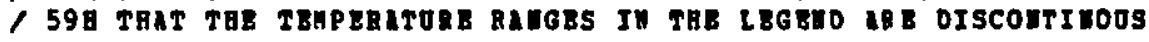

Fig. G.1 (Contd.) 
112
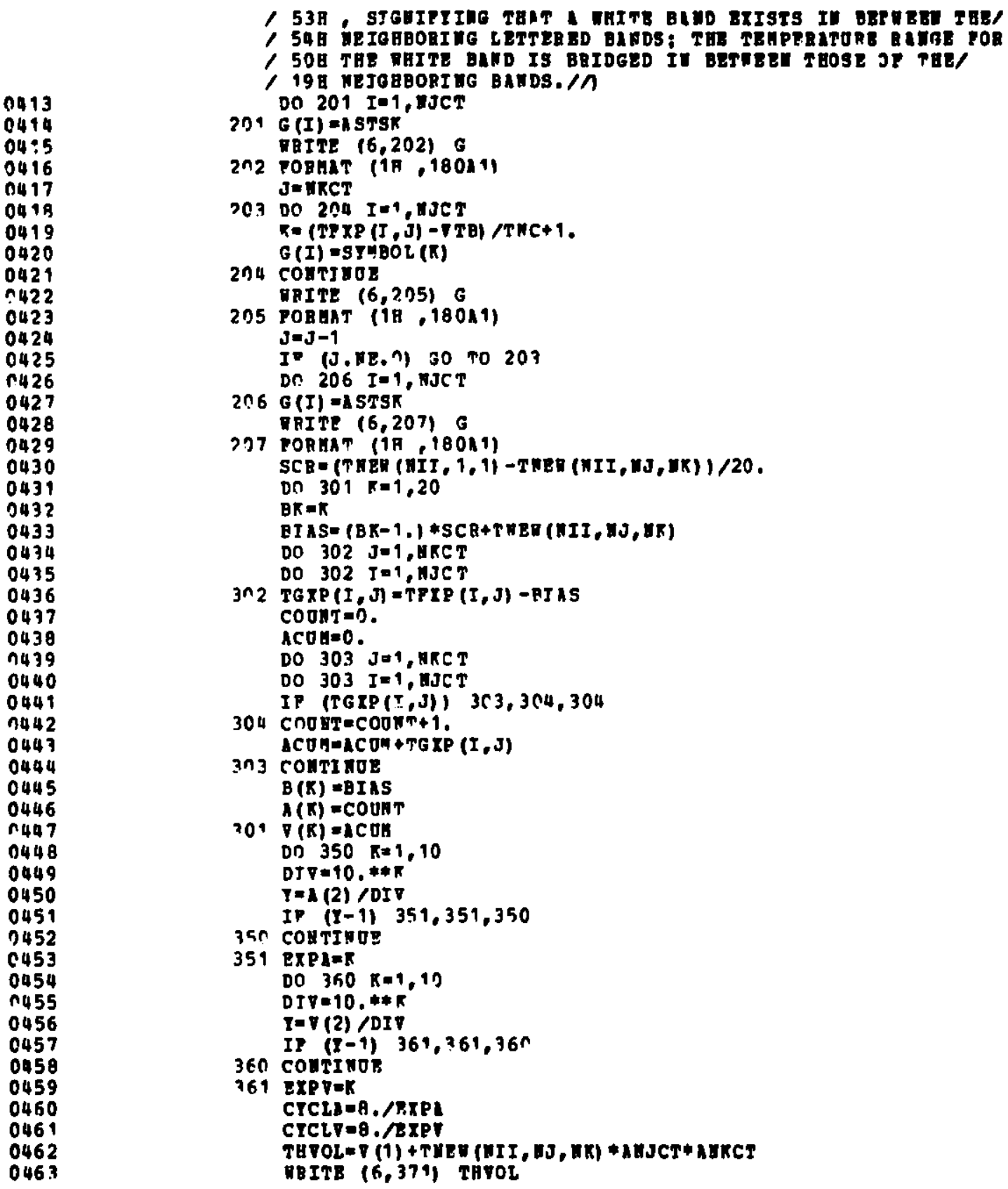

Fig. G.1 (Contd.) 


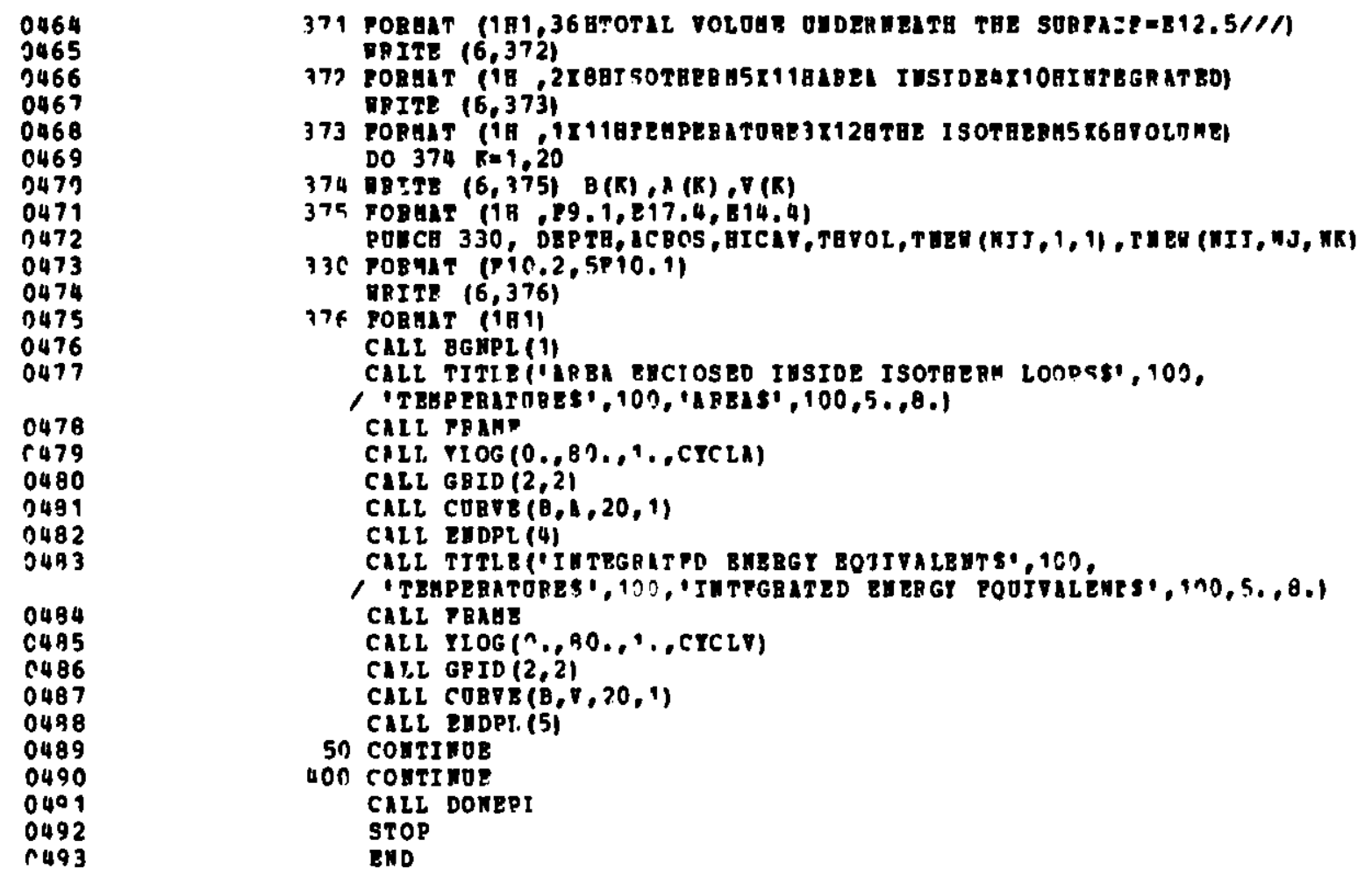

Fig. G.1 (Contd.) 


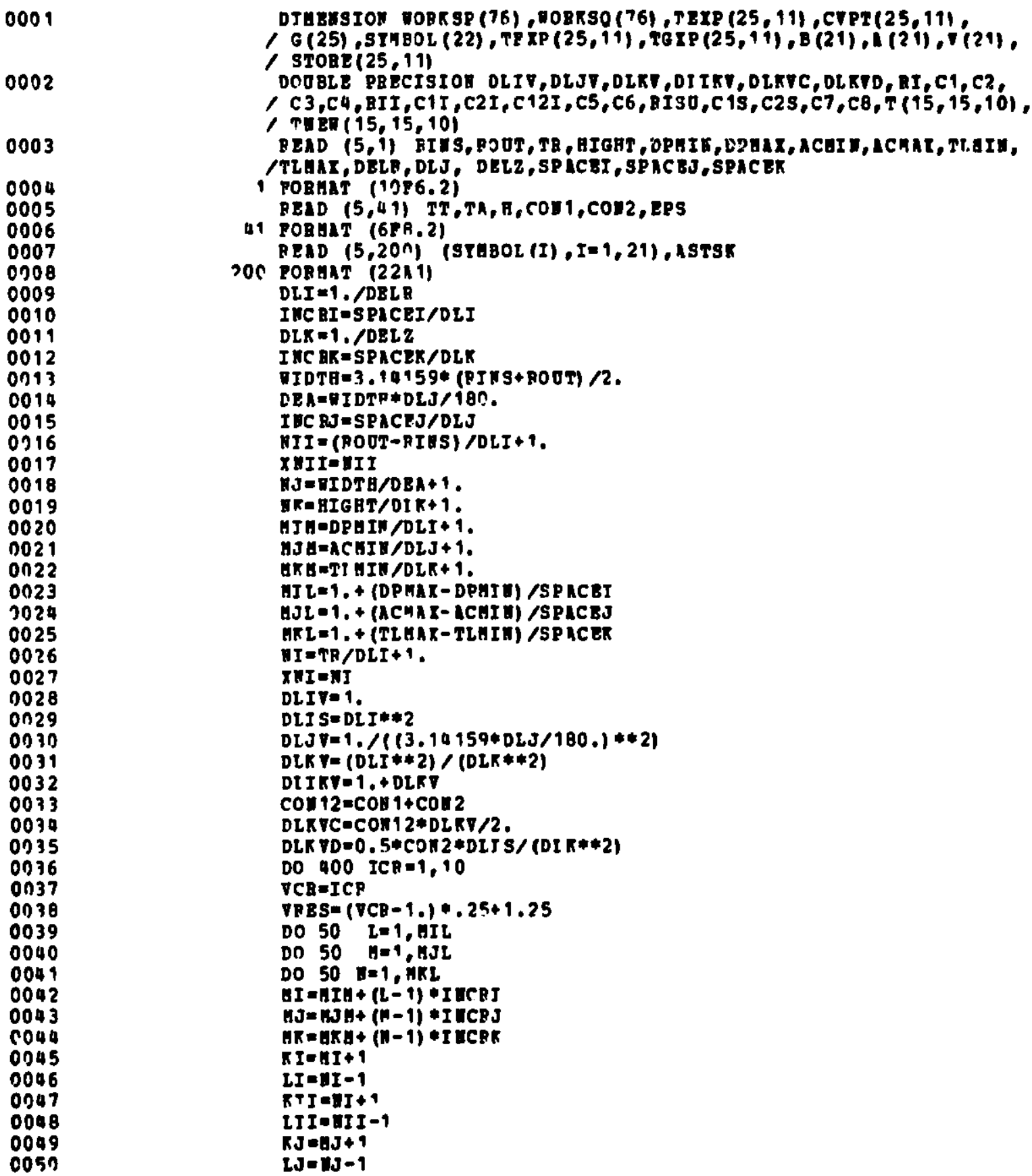

0008

0009

0010

0011

0012

0013

0014

0015

0316

0017

0018

0019

0020

0021

0022

0023

3024

0025

0026

0027

0028

Oก29

0) 35

0031

0032

0033

0034

0335

0036

0ก37

0038

0039

0040

0049

0042

0043

CO44

0045

0046

0047

0048

0049

005 1

1 PORHAT (19F6.2)

BEDD $(5,41) T T, T A, B, \operatorname{CON} 1$, CON2, EPS

L1 PORART (6FR.2)

BEAD $(5,20 \mathrm{n})$ (STGBOL (I), I=1,21), Astsk

206 PORMAT (22K1)

DLI $=1$. /DELR

IMC BI-SPICEI/DLI

DLX=1./DEL Z

I IC $\mathrm{BR}=\mathrm{SPACEK} / \mathrm{OLK}$

DIDTH $=3.14159 *($ BINS+ROOT) $/ 2$.

DEA $=$ IDTP $\# D E J / 18$ ?

$I B C R J=S P A C E J / D L J$

$M I I=($ ROOT - RIBS $) / D L I+1$.

$X$ XII $=I I I$

$M J=n I D T B / O B A+1$.

BRABIGBT/OIR+1.

HJHODPHIM/DLI+ 1 .

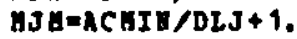

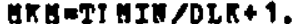

UI $L=1 .+$ (DPMAX - DPAI D) /SP RCET

GJL-1.+ (ACMRI-ICHI $)$ /SPLCBJ

GRL $=1 .+(T L A A X-T L A I H) / S P A C E R$

$H I=T R / D L I+1$

THI $=$ NI

DLIV=1.

DLIS $=D L I * * 2$

DLJV=1. $/(13.14$ 159*DLJ $/ 180) *$.

DLK V $=(D L I * * 2) /(D L R * * 2)$

DT IKV=1 + DLRV

Con $12=\cos 1+\cos 2$

DLXVC-COM12*DLRV $/ 2$.

DLK VD $=0.5 * C O H 2 * D I J S /(D I R * 2)$

DO 400 ICA $=1,10$

$\nabla C B=I C P$

VRBSE $($ VCB -1.$) * .25+1.25$

DO $50 \quad L=1$, $\operatorname{trL}$

DO $50 \quad \mathrm{H}=1, \mathrm{HI}$

DO $50 \quad B=1$, $\mathrm{ARL}$

$B I=M I H+(L-1)+I$ ECRJ

$H J=H J+(H-1) \neq I I C B J$

$H R=u k a+(N-1) * I$ ICBR

$K I=\mathrm{HI}+1$

$I I=M I-1$

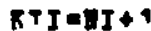

III-日II -1

$R J=B J+1$

LJ-II -1

Fig. G.2. Computer Program for Evaluating Surface Temperature in a Three-dimensional System with Variable Contact Resistance 


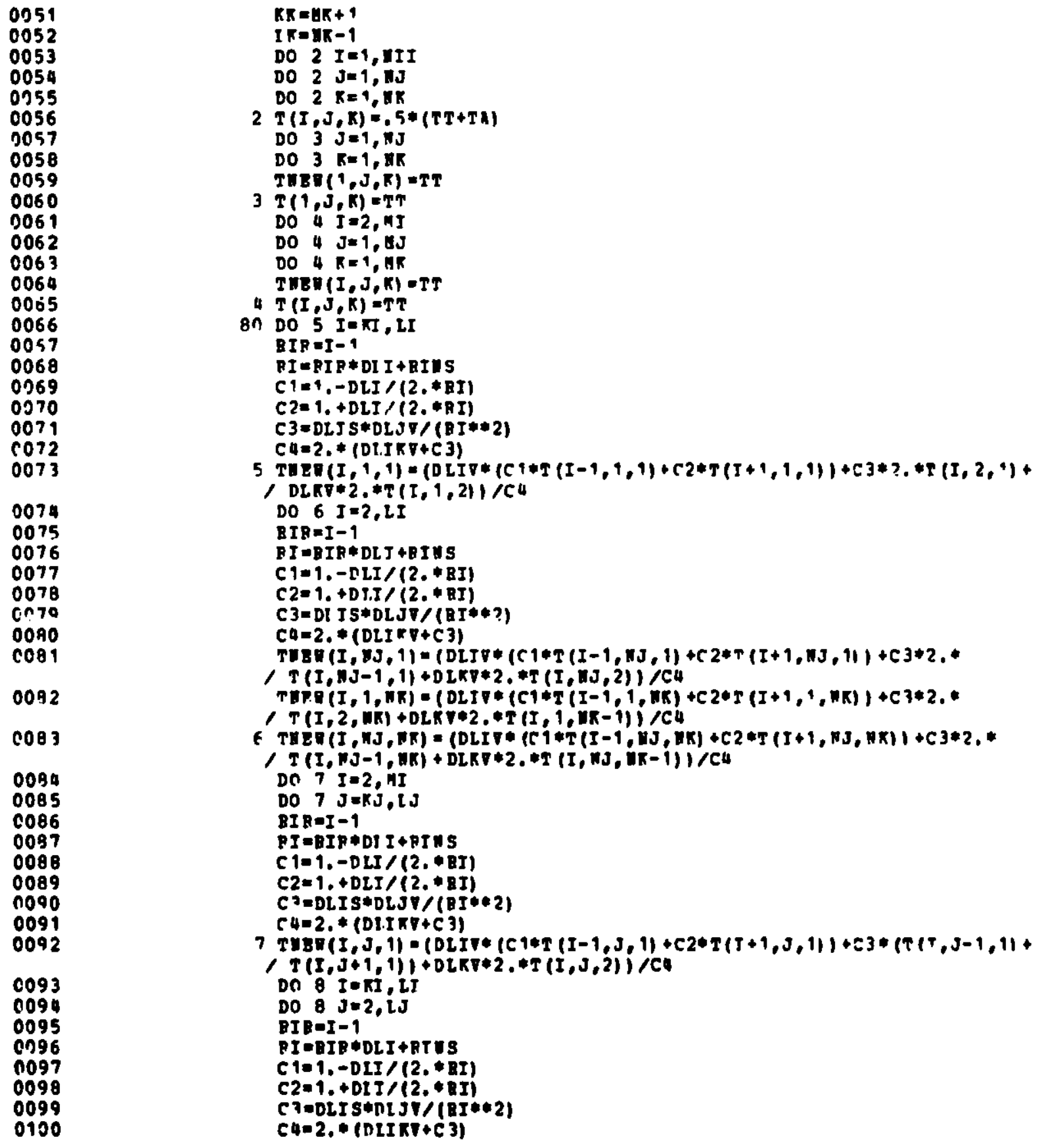

Fig. G.2 (Contd.) 
116

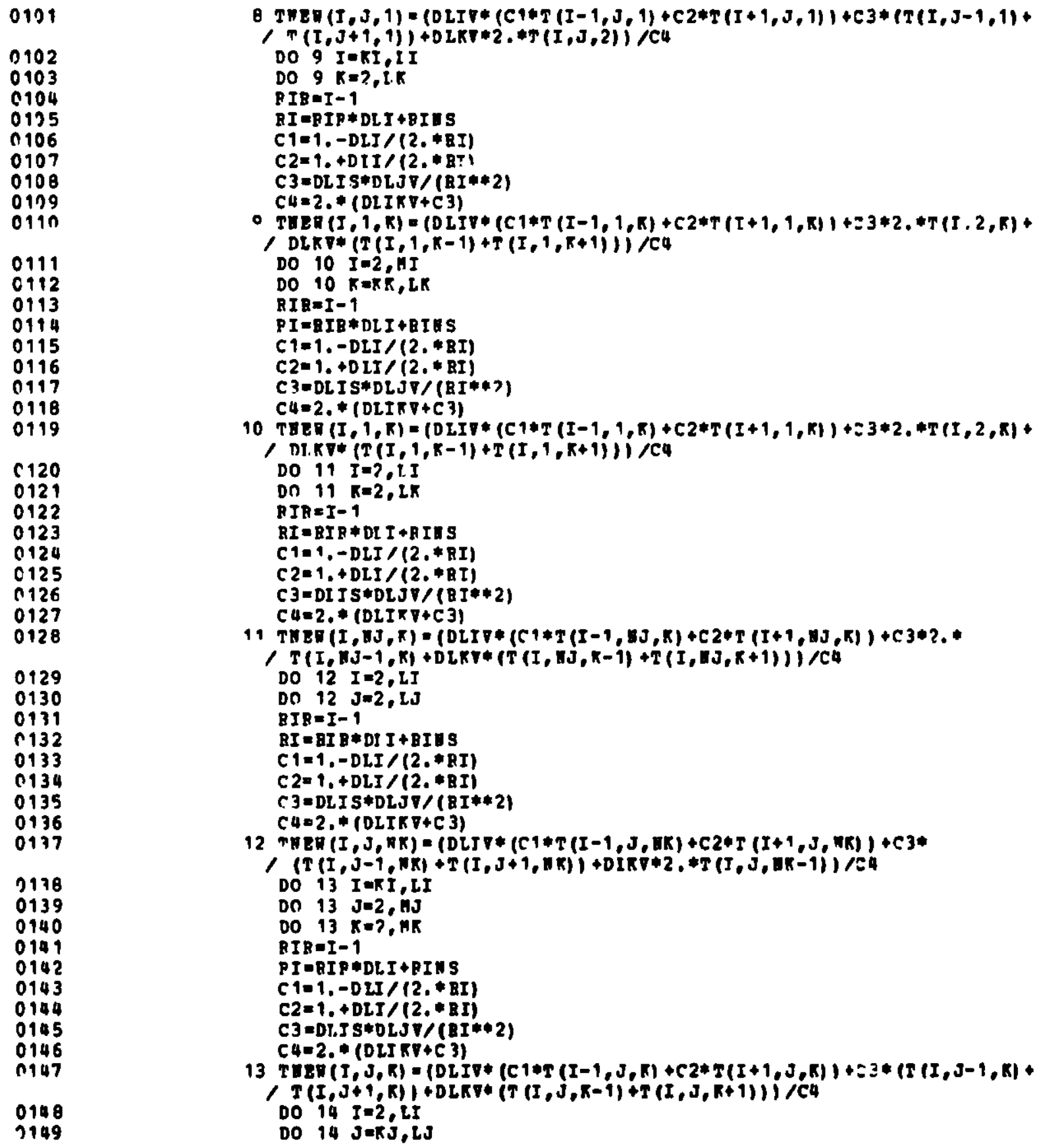

Fig. G.2 (Contd.) 


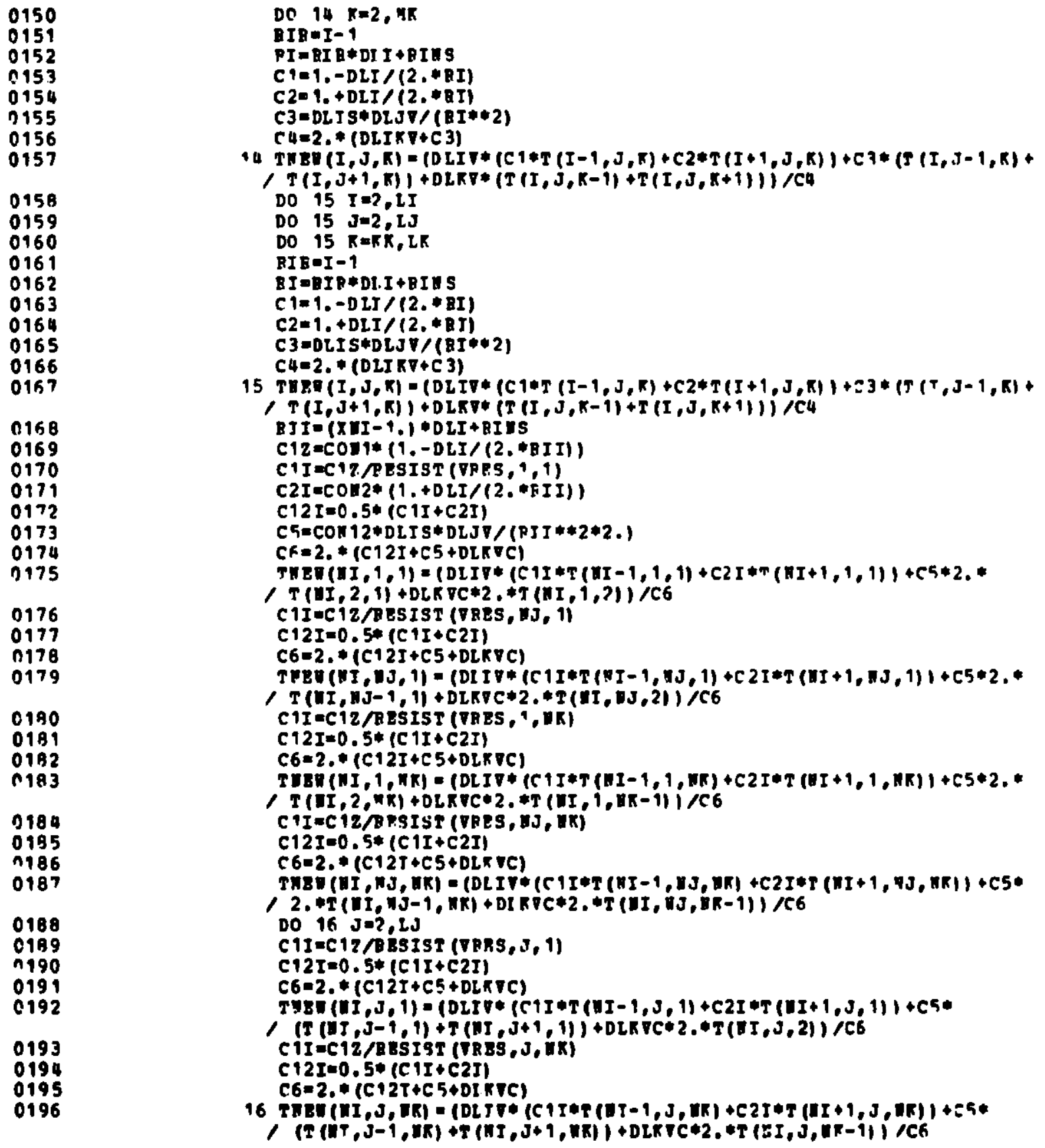

Fig. G.2 (Contd.) 


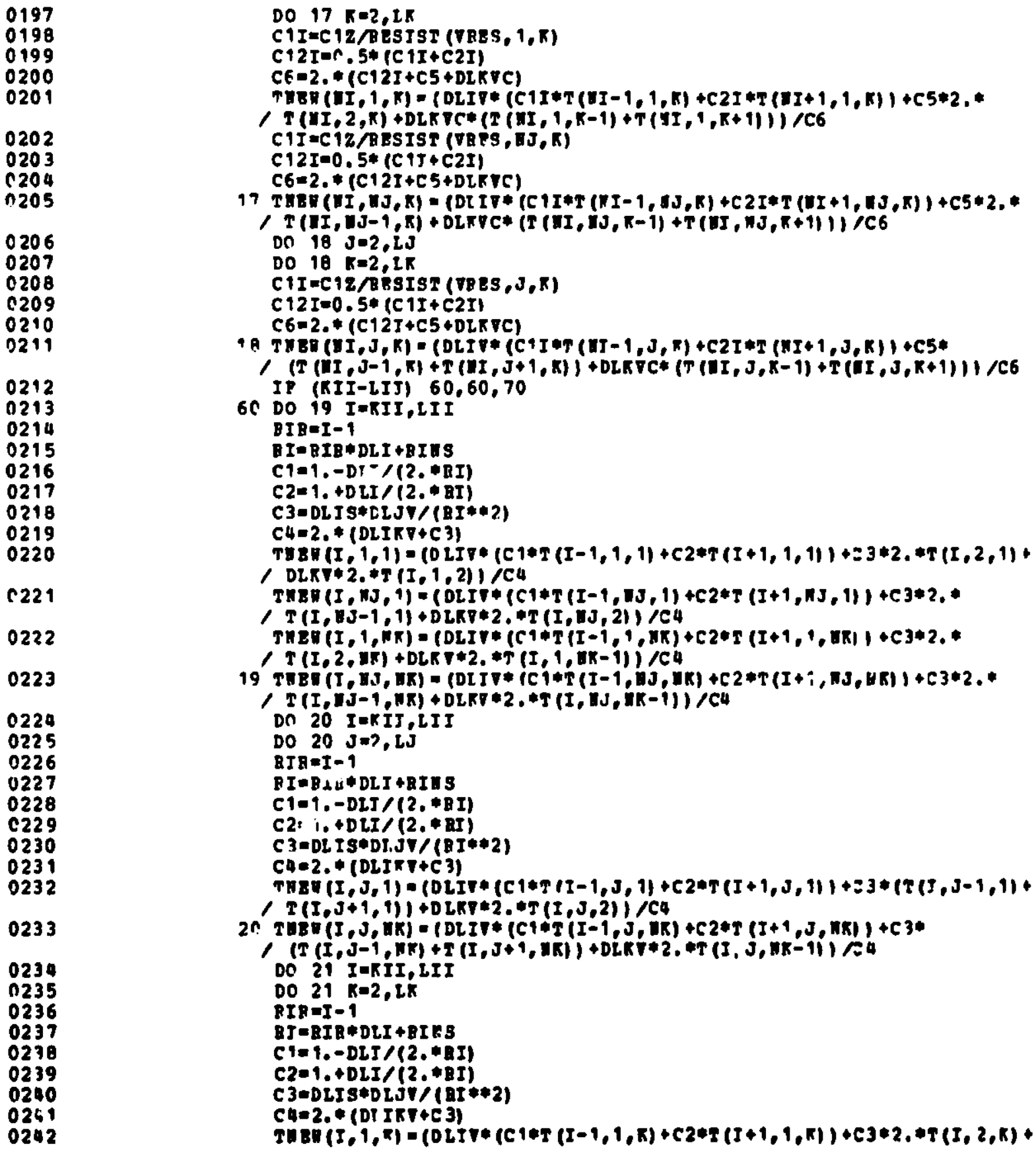

Fig. G.2 (Contd.) 
0257

025 A

0259

0260

0261

$\$ 262$

0263

0264

0265

0266

0267

0268

0269

0270

0271

0272

0273

0274

0275

0276

0277

0278

C279

0280

0281

0282

0283

0284

02 ค 5

(DLKV* T T I $1, R-1)+T(I, 1, R+1))) / C 4$

21 THBP $(I, \forall J, K)=(D L I \nabla *(C I * T(I-1, B J, K)+C 2 * T(I+9, B J, R) 1+C 3 * 2$. * $T(I, B J-1, R)+D L K V *(T(I, D J, R-1)+T(I, M J, K+I))) / C 4$

DO 2 ? I=KII,LII

DO $22 \mathrm{~J}=2,1 \mathrm{~J}$

DO $22 \mathrm{~K}=2, \mathrm{LK}$

$P I R=I-1$

$B I=B I B * D I I+B I * S$

$C 1=1,-D L I /(2, * B I)$

$C 2=1 .+D L^{\top} /(2 . * B I)$

$C 3=D L J V /(R J * 2)$

$C 4=2$. $*(D L I K T+C 3)$

$22 \operatorname{IRET}(I, J, K)=(0 L I \nabla *(C I * T(I-1, J, K)+C 2 * T(I+1, J, K))+C 3 *(T(I, J-1, R)+$

, $T(I, J+1, R))+D L K V *(T(I, J, R-I)+T(I, J, R+1))) / C 4$

70 BISO= (XHII-1.) *DI.I + BJHS

Cथ $S=\operatorname{Cos} 2 *(1,-D L I /(2, * R I S O))$

C25 $=$ H*neI

$r 7 \approx 0.5 * \operatorname{CON} 2 * D L I S * D L J \nabla /(B I S O * * 2)$

$C B=(C 1 S+C 2 S)+2 . * C 7+2$, *DLKVD

$T H R *(H I I, 1,1)=(D L I V *(C 1 S * T(N I I-1,1,1)+C 2 S * T A)+C 7 * 2$ *T $(T I I, 2,1)$

$/$ QDLRTD*2.*T(III, 1,2))/CB

THEV (NII, HJ, 1) $=(0 L I V *(C 1 S * T(H I I-1, H J, 1)+C 2 S * I A)+C 7 * 2, *$

, $T(M I I, N J-1,1)+D I R \nabla D * 2$ * *T(UII, $1 J, 2)) / C B$

$T H E R(B I I, 1, H R)=(D L I V *(C 1 S * T(B I I-1,1, R K)+C 2 S * T A)+C 7 * 2$. *

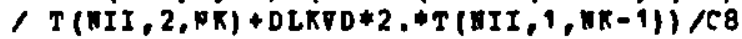

TMEQ (BII, BJ, HK) $=(D L I V *(C 1 S * T(M I I-1, B J, R R)+C 2 S * T A)+C 7 * 2$ *

$/ T(N I I, B J-1, H K)+D L K V D * 2 . * T(B I I, B J, H R-1) \mid / C A$

DO $23 \mathrm{~J}=2, \mathrm{IJ}$

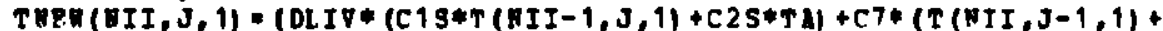

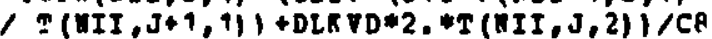

23 TRED (HII,J,KR) $=(D L I \nabla *(C 15 * T(B I I-1, J, B K)+C 2 S * T A)+C 7 *$

$/(T(k I I, J-1, R R)+T(R I I, J+1, B K))+D L K V D * 2 . T(B I I, J, H R-1)) / C \theta$

DO $24 k=2, I R$

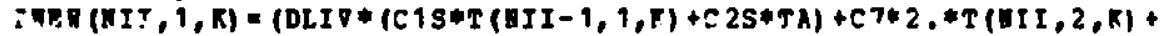

/ DLRVD* (T (III, $1, r-1)+T(K I I, 1, K+1) 1 / C 8$

24 TNED (BII, NJ, K) $=(0 I, I \nabla *(C 1 S * T(R I I-1, N J, K)+C 2 S * I A)+C 7 * 2$, *

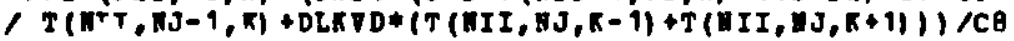

DO $25 \mathrm{~J}=2, \mathrm{LJ}$

DO $25 \quad R=2, L R$

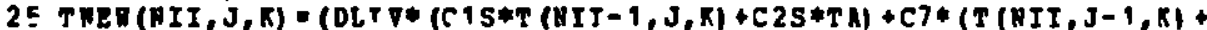

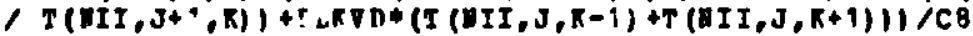

DO 85 I $=2, \mathrm{HI}$

Do $85 \mathrm{~J}=\mathrm{KJ}, \mathrm{MJ}$

Dn $85 \quad K=1$, in

IP (DLBS(T (I,J,K)-TKPD $(I, J, K))-E P S) \quad 85,85,40$

Q5 COHTINOE

DO 27 I $=2, \mathrm{HI}$

DO $27 \mathrm{~J}=1, \mathrm{MJ}$

DO $27 \mathrm{R} M \mathrm{RK}, \mathrm{BR}$

IY (DLBS(T $(I, J, K)-T R B R(I, J, K))-8 P S) \quad 27,27,40$

27 CONTIVOB

DO 26 I $=$ RI, II I

DO $26 \mathrm{~J}=1, \mathrm{HJ}$

DO $26 \quad k=1, \pi K$

If $\operatorname{CABS}(I(I, J, K)-T D R M(I, J, K))-8 P S) 26,26,40$

Fig. G.2 (Contd.) 
0293

0294

0295

0296

0297

0298

0299

0300

0301

0302

0303

0304

0305

0306

0307

0308

C 309

0310

C 311

0312

0313

0314

0315

0316

0317

0318

0319

ก 320

0321

0322

0323

0324

0325

26 COHTIROB

GO TO 90

40 DO $31 \quad I=2$, $\mathrm{HI}$

DO $31 \mathrm{~J}=\mathrm{KJ}, \mathrm{BJ}$

DO $31 k=1$,,$k$

$34 T(I, J, K)=\operatorname{TAEN}(I, J, K)$

DO 32 I = RI, HI I

DO $32 \mathrm{~J}=1, \mathrm{~J}$

DO $32 K=1, H K$

$32 \operatorname{T}(I, J, K)=\operatorname{TAE}(I, J, ")$

Do $33 I=2$, $\mathrm{nI} I$

DO $33 \mathrm{~J}=1, \mathrm{BJ}$

DO $33 R=R \pi$, BR

$33 T(I, J, K)=T \operatorname{Tg}(I, J, K)$

GO TO 80

on $x$ तก $=$ -

$T M J=4 J$

ZEK $=8 \mathrm{~K}$

DEPTB $=D L I *(Y H I-1$.

ACBOS=DLJ*(IAJ-1.)

EICA $=$ DLK * (ZMK-1.)

DIBS $=2$, *PINS

DOOT=2.*BOOT

BIGHO $=2$, * BIGH I

$S B T R=B O O T-B I N S-T B$

RAITE $(6,28)$ DINS, DOUT, HIGRU, TR, SBTK, DEPTR, ACBOS, AICAV, DLI, DC J,

/ DLR,TT,TA, CON 1, CON2,B, BPS

28 FORALT (1R 1,20日DIGEASIOH:

/ 21月 IH. (TOTAI) HEIGET=28.2,

/ 4甘 IH. $/ 18 \times, 21$ BQFPRACTORY THICKHBSS=76.2,

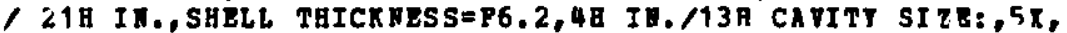

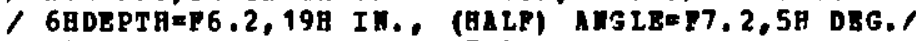

, 17X, 15B (HALP) HPIGHT=7.2,4日 IM./

/ 11B HESH SIZE:,7X,7 HAA DIAL=P6.3,13H IH., AMGOLAR=86.2,

/ 12B DEG.,AXIAL=F6.2, 48 IB.,

/ 14月 TEHPBRATORFS: 4X, 15HIRSIDF SURFACB=

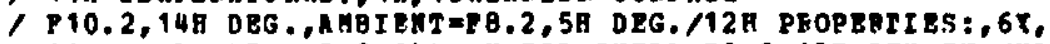

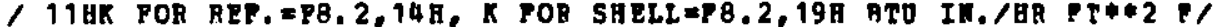

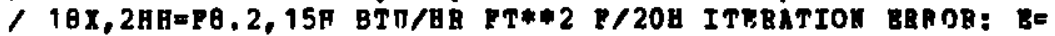

/ P5.2, 5H DEG.1/N

DO $29 x=1,8 K$

29 RPITE $(6,30)$ (THEQ (KII, J,K), J=1, NJ)

3C FORGAT (5020.10)

DRITE $(6,401)$

409 PORHAT (1月1,23 ВCONTICT RESISTAECE MAP:///)

DO $402 R=1,11$

DO $402 \mathrm{~J}=1,25$

$4 \cap 2 \operatorname{STORE}(J, K)=$ RESISL (VRPS, DLI, COM1, J, R) DO $403 \quad K=1,11$

40.3 RBITE $(6,406)$ (STORE $(J, K), J=1,25)$

406 RORMIT (7814,5)

VR ITE $(6,404)$ VRES

404 POBAAT ///45B MOTE: ONIT POR COATACS RESISTAMCB-FR DEG/BIO/

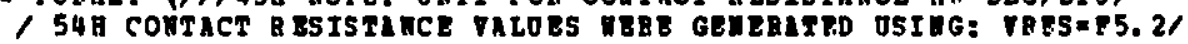

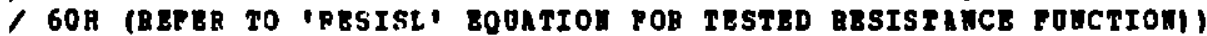

Fig. G.2 (Contd.) 


\begin{tabular}{|c|c|c|}
\hline $\begin{array}{l}0326 \\
0327 \\
0328 \\
0329 \\
0330 \\
0331 \\
0332 \\
0333 \\
0334 \\
0335 \\
0336 \\
0337 \\
0338 \\
0339 \\
0349 \\
0341 \\
0342 \\
0343 \\
0344 \\
0345 \\
0346 \\
0347 \\
0348 \\
0349 \\
0350 \\
0351 \\
0352 \\
0353 \\
0354 \\
0355 \\
0356 \\
0357 \\
0358 \\
0359 \\
0360 \\
0361 \\
0362 \\
0363 \\
0364 \\
0365 \\
0366 \\
0367 \\
0368 \\
0369 \\
0370 \\
0371 \\
0372 \\
0373 \\
0374 \\
0375 \\
0376 \\
0377 \\
0378 \\
0379 \\
0380\end{array}$ & $\begin{array}{l} \\
1 n 2 \\
113 \\
101 \\
195 \\
106 \\
194\end{array}$ & 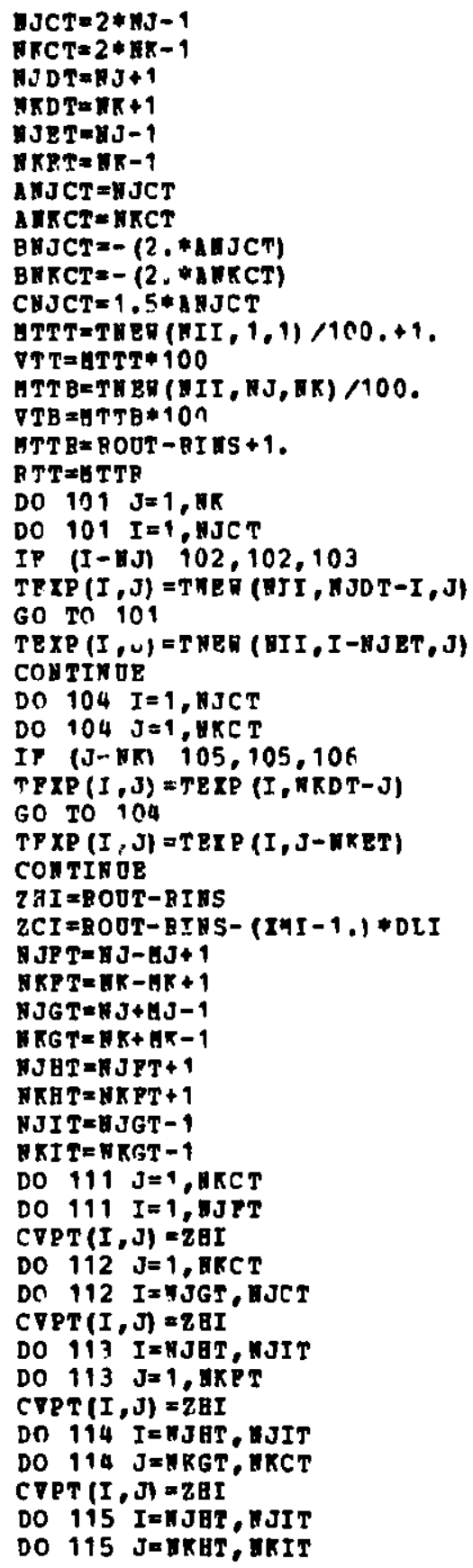 \\
\hline
\end{tabular}

Fig. G.2 (Contd.) 


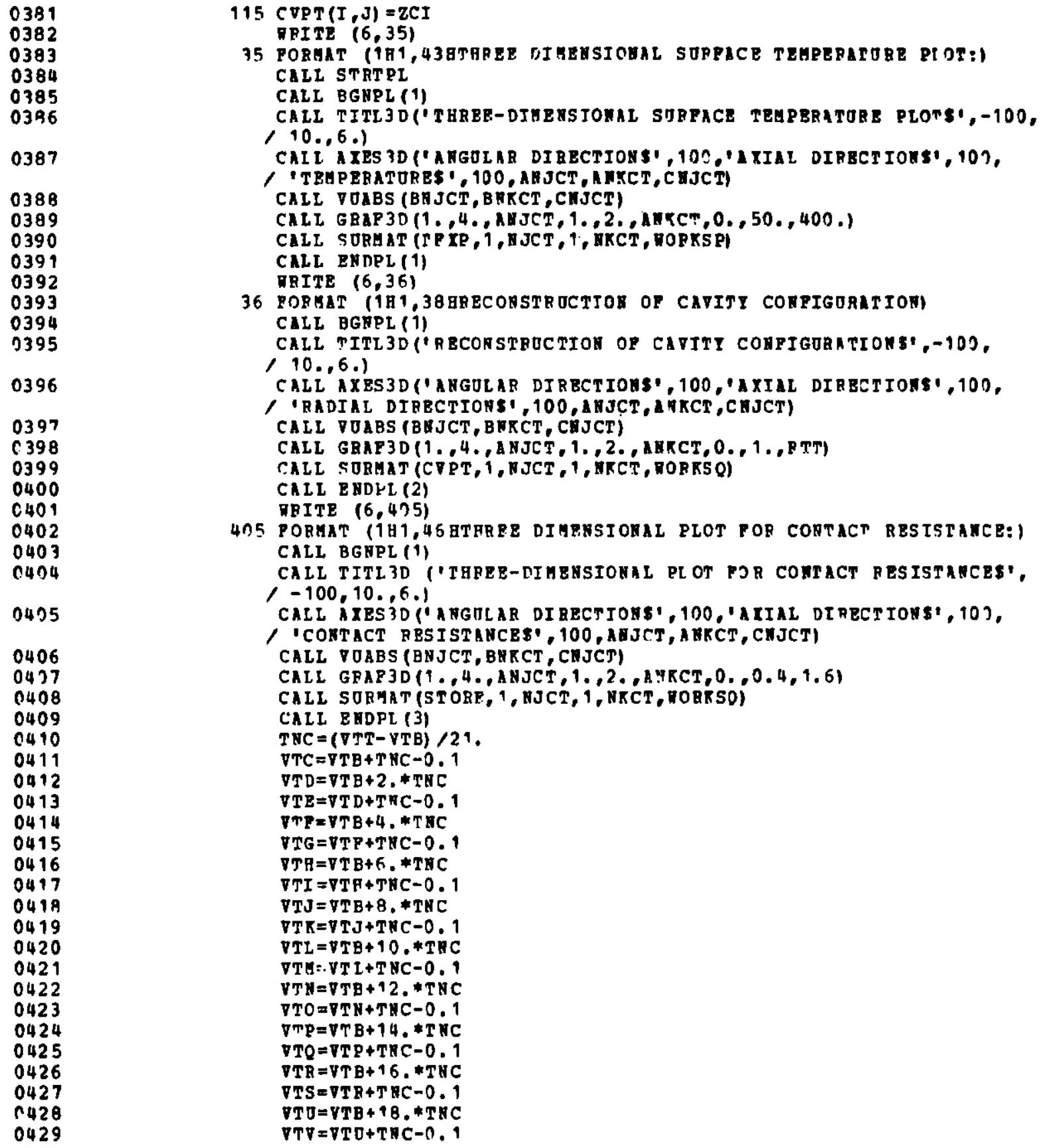

Fig. G.2 (Contd.) 


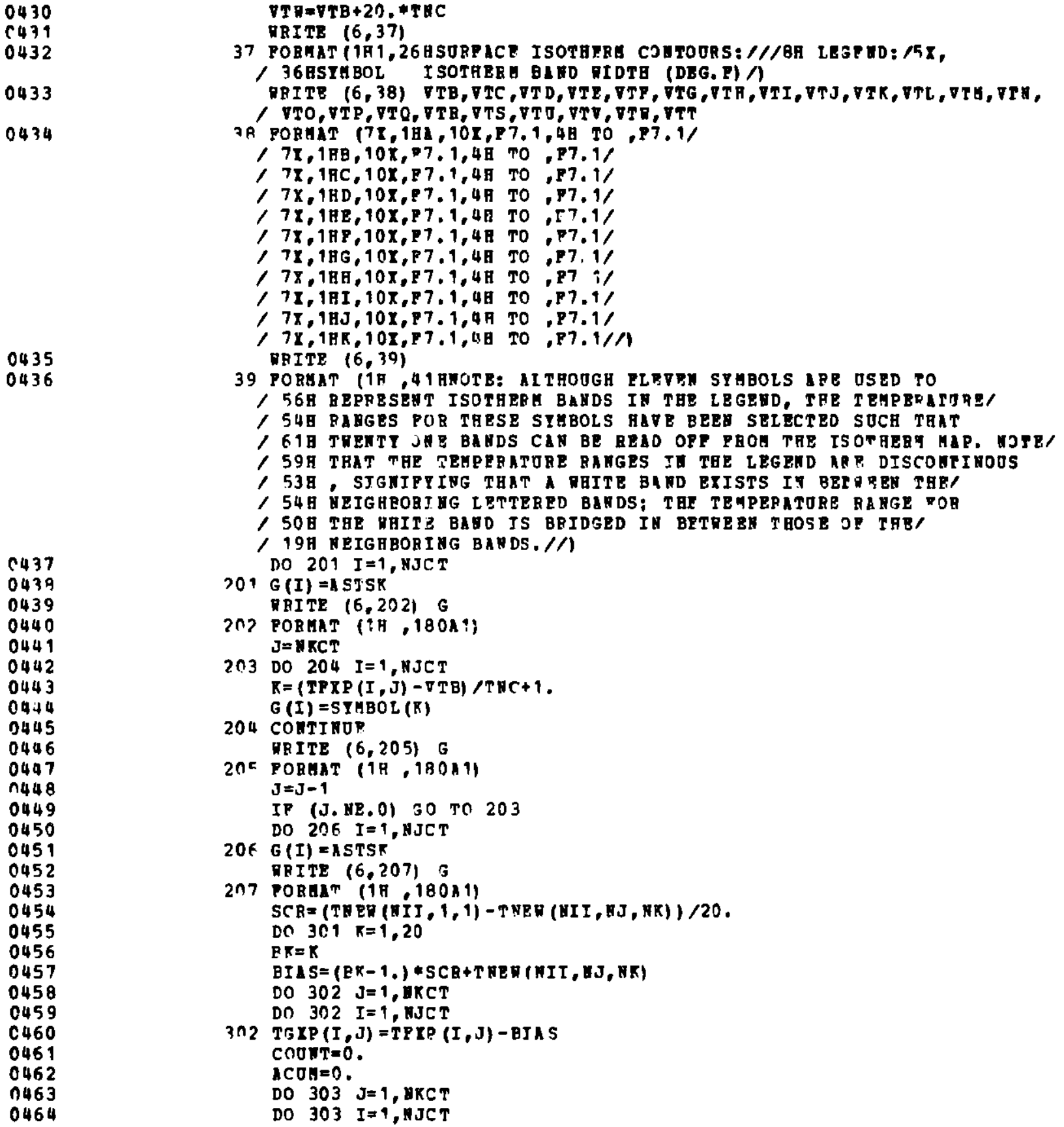

Fig. G.2 (Contd.) 


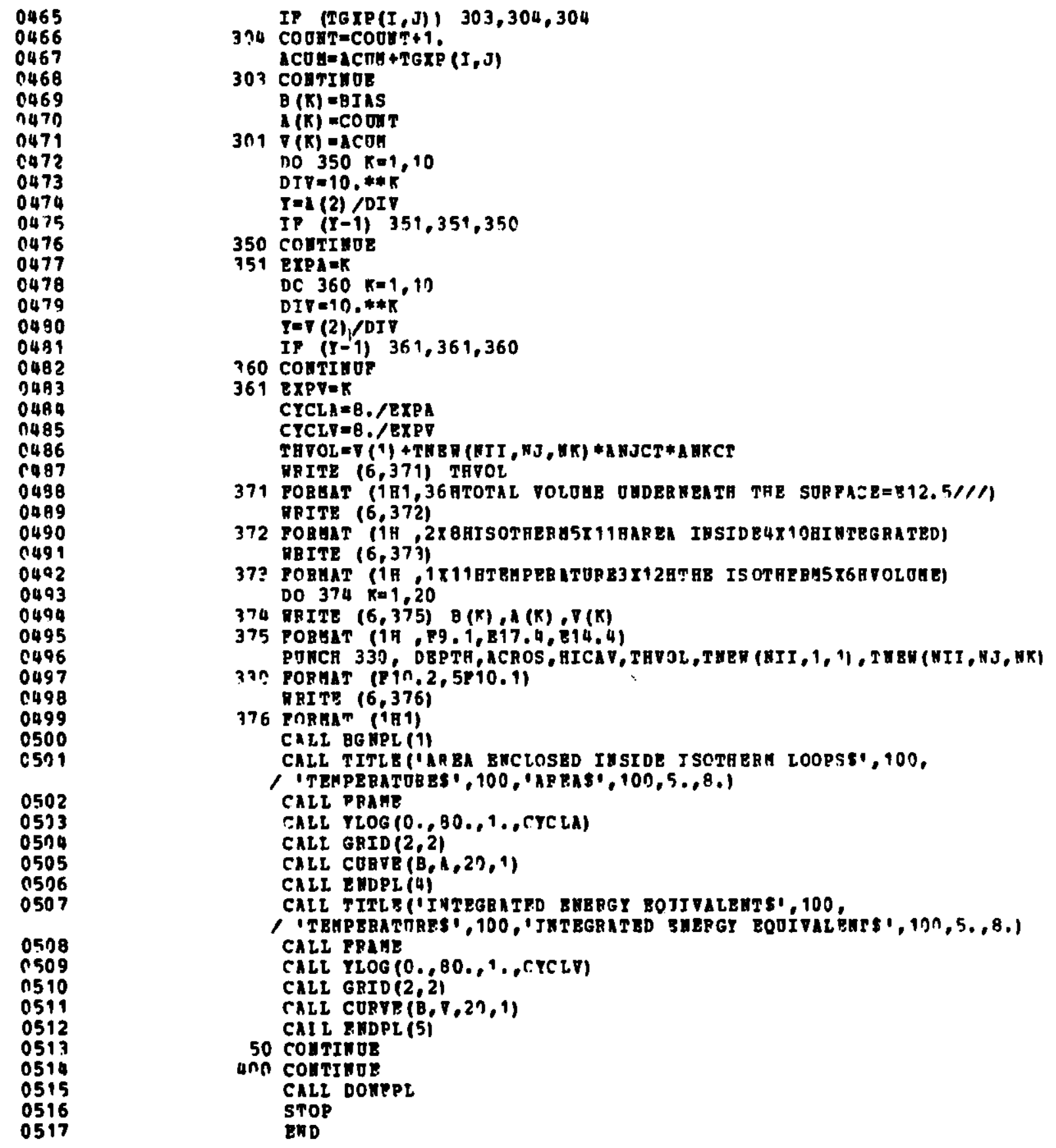

Fig. G.2 (Contd.) 


\section{REFERENCES}

1. C. A. Youngdah1 and W. A. Ellingson, "Development of Ultrasonic Techniques for Remote Monitoring of Erosive Wear in Coal Conversion Systems," 1978 Ultrasonics Symposium Proceedings, IEEE Cat \#78-CH1344-1SU, pp. 305-310 (1978).

2. C, A. Youngdahl and W, A. Ellingson, "Long Term Erosion Monttoring of Metallic Conduits by Ultrasonic Pulse-echo Techniques," Proc. 12th Int. Symposium on Nondestructive Evaluation, San Antonio, TX, pp. 282-291 (1979).

3. N. P. Lapinski, Gamma Radiography of Refractory-lined Vessels and Components, ANL-78-43 (Aug 1978).

4. Materials Science Division Coal Technology Ninth Quarterly Report, OctoberDecember 1976, ANL-77-5 (May 1977).

5. S. H. Birchard and L. M. Rogers, Industrial Thermography--How Representative of Plant Condition is the Thermal Image Produced by an Infrared Camera, Brit. J. Nondestr. Test., July 1976, 111-113 (1976).

6. S. H. Birchard and L. M. Rogers, A Review of Industrial Applications of Thermography, Brit. J. Nondestr. Test., Jan 1976, 2-11 (1976).

7. E. Sundstrom, wide-angle Infrared Comera for Industry and Medicine, Appl. Opt. 7(9), 1763-1768 (1968).

8. S. Borg, Thermal Imaging with Real Time Picture Presentation, Appl. Opt. $7(9), 1697-1704$ (1968).

9. R. W. Astheimer and F. Schwarz, Thermal Imaging Using Pyroelectric Detectors, Appl. Opt. 7(9), 1687-1696 (1968).

10. C. W. Hurley and K. G. Kreider, Applications of Thermography for Energy Conservation in Industry, NBS Technical Note 923 (1976).

11. E. A. Farber, C. K. Hsleh, anl N. C. K. Yang, Space Shuttle Thermal Protection System Condition Assessment by Thermal Radiation Analysis Techniques, Report TRL-74-B1, Thermal Radiation Laboratory, Mechanical Engineering Department, University of Florida (1974).

12. A. M. Clausing, "Numerical Methods in Heat Transfer," in Advanced Heat Transfer, B. T. Chao, Ed., University of Illinols Press, Urbana (1969).

13. C. K. Hsieh and F. E. Davis, Bibliography on Thermal Contact Conductance, Air Force Materials Laboratory Report AFML-TR-69-24 (1969).

14. C. K. Hsieh, on the Nature of Thermal Contact Conductance, M.S. thesis, Purdue University (1964).

15. C. K. Hsieh and Y. S. Toulouktan, "Correlation and Prediction of Thermal Contact Conductance for Nominally Flat Surfaces," Thermal Conductivity, Proc. Eighth Conference, Plenum Press, New York, pp. 477-494 (1969).

16. C. K. Hsieh, K. M. Yeddanapud1, and Y. S. Touloukian, "An Analytical Study of Thermal Contact Conductance for Two Rough and Wavy Surfaces Under a Pressure Contact," 9th Conf. on Thermal Conductivity, Howard R. Shanks, Ed., CONF-691002, pp. 554-570 (1970).

17. R. K. Francis and J. R. Tinklepaugh, Thermal Conductivity in Ceramic-Metal Laminates, J. Am. Ceram. Soc. 43(1), 560-563 (1960). 
18. R. C. Daniel and I. Cohen, In-Pile Effective Thermal Conductivity of Oxide Fuel Elements to High Fission Depletions, WAPP-246, Bett1s Atomic Power Laboratory (1964).

19. M. Born and E. Wolf, Principles of Optics, Pergamon Press (1970).

20. E. M. Sparrow and R. D. Cess, Radiation Heat Transfer, Brooks/Cole (1966).

21. R. Siegel and J. R. Howel1, Thermal Radiation Heat Transfer, Volune 1, "The Blackbody, Electromagnetic Theory, and Material Properties," NASA SP-164 (1968).

22. M. N. Ozisik, Radiative Transfer and Interactions with Conduction and Convection, Wiley-Interscience (1973).

23. H. C. Hottel and A. F. Sarafim, Radiative Transfer, McGraw-Hil1 (1967).

24. C. K. Hsieh and W. A. Ellingson, A Quantitative Determination of Surface Temperatures Using an Infrared Camera, J. Soc. Photo-0pt. Instrum. Eng. 124, 228-235 (1977).

25. W. A. Scheffler, Heat Conduction in Bodies with Small Boundary Perturbations, J. Heat Transfer $96 C(2), 248-249$ (1974).

26. C. K. Hsieh and K. C. Su, "A Perturbation Solution of Heat Conduction In a Cavitated Region Subjected to a Convective Boundary Condition," presented at 16th Int. Thermal Conductivity Conf., Ch1cago (Nov 1979).

27. J. T. Tou and R. C. Gonzalez, Pattern Recognition Principles, AddisonWesley (1974).

28. DISSPLA Advanced Manual, Volume II, Integrated Software Systems Corp. (1970).

29. DISSPLA Beginners and Intermediate Manual, Volume I, Integrated Sof tware Systems Corp. (1970). 
Distribution of ANL-78-82

\section{Internal:}
W. E. Massey
E. G. Pewitt
B. R. T. Frost
J. J. Roberts
R. W. Weeks (6)
N. M. O'Fallon
D. Diercks

\author{
E. M. Stefanski (3) \\ W. A. Ellingson (6) \\ K. J. Reimann \\ C. A. Youngdahl \\ A. A. Jonke \\ C. R. Kennedy
}

\author{
E. L. Hartig \\ R. B. Poeppel \\ W. J. Shack \\ A. B. Krisciunas \\ ANL Contract File \\ ANL Libraries (5) \\ TIS Files (6)
}

\section{External:}

DOE-TIC, for distribution per UIC-90c, $-90 \mathrm{e},-90 \mathrm{~h} \mathrm{(463)}$

Manager, Chicago Operations and Regional Office, USDOE

Chief, Office of Patent Counsel, DOE-CORO

President, Argonne Universities Association

Materials Science Division Review Committee:

E. A. Aitken, General Electric Co., Sunnyvale

G. S. Ansell, Rensselaer Polytechnic Inst.

R. W. Balluffi, Massachusetts Inst. Technology

R. J. Birgeneau, Massachusetts Inst. Technology

S. L. Cooper, U. Wisconsin, Madison

C. Laird, U. Pennsyt vania

M. T. Simnad, General Atomic

C. T. Tomizuka, U. Arizona

A. R. C. Westwood, Martin Marietta Laboratories

E. M. Anderson, The Babcock and Wilcox Company, Lynchburg

W. G. Bair, Inst. Gas Technology, Chicago

G. Baker, Grand Forks Energy Technology Center

R. A. Bradley, Cak Ridge National Lab.

C. F. Brandenburg, Laramie Energy Technology Center

G. B. Brenneman, Maxon Corp., Muncie, Ind.

J. A. Brooks, Amoco Oil Co., Naperville, Ill.

M. Crowley, Standard Oil of Indiana, Naperville, Ill.

S. Danyluk, U. Illinois, Chicago Circle

S. J. Dapkunas, Div. Plans and Technology Assessment, USDOE

N. F. Fiore, U. Notre Dame

E. Fox, Stearns-Roger Corp., Homer City, Pa.

S. M. Gaitonde, Commonwealth Edison Co., Maywood, Ill.

J. Gardner, Morgantown Energy Technology Center

D. Glaser, Stearns-Roger Corp., Denver

W. M. Heher, Grand Forks Energy Technology Center

H. Heysteck, Tuscaloosa Metallurgy Research Centrr, University, Ala.

V. Hill, IIT Research Inst.

L. C. Ianniello, Div. Materials Sciences, USDOE

R. I. Jaffee, Electric Power Research Institute

D. L. Keairns, Westinghouse Research Labs., Pittsburgh

H. Leavenworth, Albany Metallurgy Research Cericer

G. R. Leverant, Southwest Research Inst.

A. V. Levey, Lawrence Berkeley Laboraiory

W. J. Lochman, The Ralph M. Parsons Co., Pasadena 
G. Long, Northern Illinois Gas Co., Aurora

R. M. Lundberg, Commonwealth Edison Co., Chicago

M. M. Mamoun, Inst. Gas Technology, Chicago

J. M. O'Donnell, The Lummus Co., Bloomfield, N.J.

K. Pater, Morgantown Energy Technology Center

F. A. Prange, Phillips Petroleum Corp., Bartlesville

S. J. Schneider, National Bureau of Standards (2)

R. Searles, Ashland Synthetic Fuels, Inc., Ashland, Ky.

A. G. Sharkey, Jr., Pittsburgh Energy Technology Center

G. Sorell, Exxon Research and Engineering Co., Florham Park

J. Stevenson, Rolla Metallurgy Research Center

J. Sudbury, Consolidated Coal Co., Library, Pa.

C. Whitten, Peabody Coal Co., Columbia, Tenn. 